\title{
Materializing Memory in Art and Popular Culture
}

Edited by

László Munteán, Liedeke Plate, and Anneke Smelik

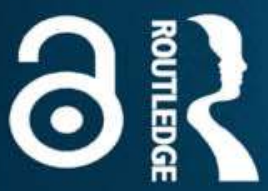




\section{Materializing Memory in Art and Popular Culture}

This book arises from authors doing rigorous interdisciplinary work and demonstrates just the kind of Swiss army knife of intellectual tools needed to tackle the problems and puzzles of memory and materiality.

-Lindsey A. Freeman, State University of New York-Buffalo State, USA

Memory matters. It matters because memory brings the past into the present and opens it up to the future. But it also matters literally because memory is mediated materially. Materiality is the stuff of memory. Meaningful objects that we love (or hate) function not only as aide-mémoire but are integral to memory. Drawing on previous scholarship on the interrelation of memory and materiality, this book applies recent theories of new materialism to explore the material dimension of memory in art and popular culture. The book's underlying premise is twofold: on the one hand, memory is performed, mediated, and stored through the material world that surrounds us; on the other hand, inanimate objects and things also have agency on their own, which affects practices of memory, as well as forgetting. By accounting for the material world as a medium through which acts of remembering and forgetting take place, the chapters of this book offer new insights on such topics as the study of ruins, the exchange and circulation of souvenirs, digitization and the Internet of Things, fashion and technology, as well as the material dimensions of corporeality and traumatic reenactment.

László Munteán is Assistant Professor of Cultural Studies and American Studies at Radboud University Nijmegen, the Netherlands. His publications have focused on cultural memory in literature and the visual arts, culture, heritage, and photography. He is leader of the research group 'Memory, Materiality, and Meaning in the Age of Transnationalism'. 
Liedeke Plate is Associate Professor of Gender Studies and Literary and Cultural Studies at Radboud University Nijmegen, the Netherlands. Her research focuses on literature, gender, and cultural memory. She is the author of Transforming Memories in Contemporary Women's Rewriting (2011) and co-editor of Technologies of Memory in the Arts (2009), Performing Memory in Art and Popular Culture (Routledge, 2013), and other works.

Anneke Smelik is Katrien van Munster Professor of Visual Culture at Radboud University Nijmegen, the Netherlands. She has published widely in the field of fashion, cinema, popular culture, and cultural memory. Her latest books are Thinking Through Fashion: A Guide to Key Theorists (2016) and Delft Blue to Denim Blue: Contemporary Dutch Fashion (2017). 
This page intentionally left blank 


\section{Routledge Research in Cultural and Media Studies}

For a full list of titles in this series, please visit www.routledge.com

94 The Creative Underground

Arts, Politics and Everyday Life

Paul Clements

95 Subjectivity across Media

Interdisciplinary and Transmedial Perspectives

Edited by Maike Sarah Reinerth and Jan-Noël Thon

96 The Rise of Transtexts

Challenges and Opportunities

Edited by Benjamin W.L. Derhy Kurtz and Mélanie Bourdaa

97 Explorations in Critical Studies of Advertising

Edited by James F. Hamilton, Robert Bodle, and Ezequiel Korin

98 Popular Culture and the Austerity Myth

Hard Times Today

Edited by Pete Bennett and Julian McDougall

99 Historicising Transmedia Storytelling

Early Twentieth-Century Transmedia Story Worlds

Matthew Freeman

100 LGBTQs, Media and Culture in Europe

Edited by Alexander Dhoest, Lukasz Szulc and Bart Eeckhout

101 Matrix Activism

Global Practices of Resistance

Michela Ardizzoni

102 Materializing Memory in Art and Popular Culture

Edited by László Munteán, Liedeke Plate, and Anneke Smelik 


\section{Materializing Memory in Art and Popular Culture}

Edited by László Munteán,

Liedeke Plate, and Anneke Smelik 
First published 2017

by Routledge

711 Third Avenue, New York, NY 10017

and by Routledge

2 Park Square, Milton Park, Abingdon, Oxon OX14 4RN

Routledge is an imprint of the Taylor \& Francis Group, an informa business

(C) 2017 Taylor \& Francis

The right of the editors to be identified as the authors of the editorial material, and of the authors for their individual chapters, has been asserted in accordance with sections 77 and 78 of the Copyright, Designs and Patents Act 1988.

With the exception of Chapters 1, 4 and 5 no part of this book may be reprinted or reproduced or utilised in any form or by any electronic, mechanical, or other means, now known or hereafter invented, including photocopying and recording, or in any information storage or retrieval system, without permission in writing from the publishers.

Chapters 1, 4 and 5 of this book is available for free in PDF format as Open Access at www.tandfebooks.com. It has been made available under a Creative Commons Attribution-Non Commercial-No Derivatives 3.0 license.

Trademark notice: Product or corporate names may be trademarks or registered trademarks, and are used only for identification and explanation without intent to infringe.

Library of Congress Cataloging-in-Publication Data

CIP data has been applied for.

ISBN: 978-1-138-20323-5 (hbk)

ISBN: 978-1-315-47217-1 (ebk)

Typeset in Sabon

by codeMantra 


\section{Contents}

List of Figures ix

Acknowledgments xiii

Prelude: The Memory Cabinet of Mrs. K. $1960 \quad$ xv

A POEM BY SUSAN STEWART

1 Things to Remember: Introduction to Materializing Memory in Art and Popular Culture

LÁSZLÓ MUNTEÁN, LIEDEKE PLATE, AND ANNEKE SMELIK

PART I

Material Remains: Ruins and Souvenirs

2 El Helicoide: Modern Ruins and the Urban Imaginary 29 CELESTE OLALQUIAGA

3 Souvenirs and Memory Manipulation in the Roman Empire: The Glass Flasks of Ancient Pozzuoli

MAGGIE L. POPKIN

PART II

Entangled Memories

4 How Memory Comes to Matter: From Social Media to the Internet of Things

ELISA GIACCARDI AND LIEDEKE PLATE

5 Memory and Materiality in Hussein Chalayan's

Techno-Fashion

LIANNE TOUSSAINT AND ANNEKE SMELIK 
viii Contents

6 Size Matters: Karl Ove Knausgård's Min Kamp and Roberto Bolaño's 2666 as (Anti-) Monumental Novels INGE VAN DE VEN

PART III

Reenactment, Affect, and Remembrance

7 Archives of Affect: Performance, Reenactment, and the Becoming of Memory LOUIS VAN DEN HENGEL

8 Crystal Tears and Golden Crowns: Materializing Memories of the Suffering Mother WILLY JANSEN

9 Matters of Memory in Los rubios by Albertina Carri 158 ANNA FORNÉ

PART IV

Corporeality and Objects of Trauma

10 Chilling Burlesque: The Act of Killing ALEID FOKKEMA

11 Modeling the Memories of Others: David Levinthal's I.E.D.: War in Afghanistan and Iraq LÁSZLÓ MUNTEÁN 


\section{List of Figures}

2.1 Partial view of El Helicoide. Photograph by Julio César Mesa, 2016.

2.2 Architect Dirk Bornhorst's wedding cake in the shape of El Helicoide, Caracas, 1957. Courtesy of PROYECTO HELICOIDE/Archivo Bornhorst.

2.3 One of the models of the original 1956 project. Courtesy of PROYECTO HELICOIDE/Archivo Bornhorst.

2.4 El Helicoide surrounded by barrios. Photograph by Julio César Mesa.

3.1 Prague Vase in the Collection of the National Museum, Prague, Czech Republic, inventory number 137. Photograph: National Museum, Prague, reproduced with permission.

3.2 Drawing of the scene of Puteoli engraved on the Prague Vase in the Collection of the National Museum, Prague, Czech Republic, inventory number 137. Drawing: National Museum, Prague, reproduced with permission.

3.3 Drawing of the scene of Puteoli engraved on the Pilkington Vase in the Pilkington Glass Collection, the World of Glass, St. Helens, United Kingdom, inventory number SAHGM.1974.002. Drawing by Maggie L. Popkin.

3.4 Reconstruction drawing of the Mérida Vase following the parameters known from other surviving vases, Consorcio Ciudad Monumental de Mérida, Spain. Drawing by Ana María Bejarano Osorio, 2005, reproduced with permission.

4.1 Moving People. Photograph placed on Facebook by Wing-Ka Chung, 16 September 2015 (https://www. facebook.com/powerofarthouse). 
4.2 RememberMe at FutureEverything 2010: tag attached to jewellery in Oxfam shop, Manchester. Photo $\mathbb{C}$ Jane Macdonald.

4.3 Ghostly vessel of a dancing shoe with accrued social memories in the Tales of a Changing Nation exhibition, National Museum of Scotland, Edinburgh, 2011. Photograph by Jane Macdonald, 2010.

4.4 The Earthquake Shelf. Courtesy of Mark Shelby. 76

4.5 Chiocciola. Courtesy of Mirsaeid Mousavi. 77

4.6 Carolan Guitar. Courtesy of Steve Benford. 78

4.7 Geist. Courtesy of Connected Everyday Lab and The Incredible Machine.

4.8 me.mento. Courtesy of Felix Marschner. 81

4.9 Photobox. Courtesy of Mark Selby. 82

4.10 Photobox. Courtesy of Mark Selby. 82

5.1 Hussein Chalayan, Ready-to-Wear Women, One

Hundred and Eleven Collection, Spring/Summer 2007. Courtesy of FirstVIEW.

5.2 Hussein Chalayan, Ready-to-Wear Women, One

Hundred and Eleven Collection, Spring/Summer 2007. Courtesy of FirstVIEW.

6.1 Listing the girls in his class (Knausgård, 2012, p. 40). Photograph by Inge van de Ven.

6.2 Example of an entry in a list of police reports (Bolaño, 2008, p. 546). Photograph by Inge van de Ven.

7.1 VALIE EXPORT, Aktionshose: Genitalpanik (Action Pants: Genital Panic, 1969), photo serial, self-staging. Photograph by Peter Hassmann. Courtesy of VALIE EXPORT and Bildrecht, Vienna, 2016.

7.2 Marina Abramović performing VALIE EXPORT's Action Pants: Genital Panic (1969), Seven Easy

Pieces, Solomon R. Guggenheim Museum, New York, 2005. Photograph by Attilio Maranzano. Courtesy of Marina Abramović Archives.

7.3 Mary Coble, 'Untitled 1' (from Note to Self, 2005).

Photograph by Brian Twilley. Courtesy of Mary Coble.

7.4 Mary Coble, 'Untitled 3' (from Blood Script Portfolio, 2008). Photograph by Kenny George. Courtesy of Mary Coble.

8.1 The float with the Virgin leaves the church, Antequera, 2013. Photograph by W. Jansen.

8.2 Malaga, 2012. Photograph by W. Jansen.

9.1 Analía Couceyro as Albertina in Los rubios.

9.2 Analía Couceyro as Albertina in the process of scrapping and remapping. 
List of Figures xi

9.3 Analía Couceyro as Albertina and Albertina Carri as Carri in Los rubios.

11.1 A photograph from I.E.D.: War in Afghanistan and Iraq. Courtesy of David Levinthal Studio.

11.2 A photograph from I.E.D.: War in Afghanistan and Iraq. Courtesy of David Levinthal Studio. 
This page intentionally left blank 


\section{Acknowledgments}

The editors and publishers wish to thank the following rights holders for permission to reproduce copyright material.

- Julio César Mesa for two photographs of El Helicoide.

- PROYECTO HELICOIDE/Archivo, for photographs of one of the models of the original 1956 project and Dirk Bornhorst's wedding cake in the shape of El Helicoide, 1957.

- The National Museum in Prague, Czech Republic, for a photograph of a Prague Vase and for a drawing of the scene of Puteoli engraved on the vase.

- Ana María Bejarano Osorio for a reconstruction drawing of the Mérida Vase following the parameters known from other surviving vases, 2005.

- Jane Macdonald for photographs of Tales of Things, 2010, and Tales of a Changing Nation, 2011.

- Mirsaeid Mousavi for a photograph of Chiocciola.

- Steve Benford for a photograph of the Carolan Guitar.

- Connected Everyday Lab and The Incredible Machine for a photograph of Geist.

- Felix Marschner for a photograph of me.mento.

- Mark Selby for photographs of Photobox and The Earthquake Shelf.

- FirstVIEW for photographs of Hussein Chalayan's Ready-to-Wear Women, One Hundred and Eleven Collection, Spring/Summer 2007.

- VALIE EXPORT for a photograph from Aktionshose: Genitalpanik.

- Marina Abramović for a photograph of her performance of VALIE EXPORT, Action Pants: Genital Panic.

- Mary Cobble for photographs from Note to Self and Blood Script Portfolio.

- David Levinthal Studio for two photographs from I.E.D.: War in Afghanistan and Iraq.

Every effort has been made to trace rights holders, but if any have been inadvertently overlooked, the publishers would be pleased to make the 
xiv Acknowledgments

necessary arrangements at the first opportunity. We are grateful to the anonymous peer reviewers for their constructive criticism of the manuscript, which has been invaluable to making this book what it now is. Marieke Folkers receives our special thanks for her dedicated support in preparing the manuscript. 


\title{
Prelude
}

\section{The Memory Cabinet of Mrs. K. 1960}

\author{
A Poem by Susan Stewart
}

\section{Top Right Drawer}

Aspirin and pumice stone; emery board and peach stone; hourglass without sand; postcard from Watkins Glen; piece of quartz; sequined belt; red barrette; vermilion disc; a diary, January 8 saw L skating, branch, ice, glove ... breaking, line; white shoe buckle; half-knit mitten.

\section{Top Left Drawer}

Packet of pins with gold foil backing; six grosgrain ribbons-red, yellow, blue, pink, chartreuse, candy-striped; reel of hem tape; finishing nail; envelope with negative (girl on a tire swing); plug on a brass-beaded chain for a sink; five keys shaped like spades, diamonds, clubs.

\section{Middle Drawer}

Hammer and picture wire; rose-print pajamas; cross-stitched dresser scarf; kimono without belt; velveteen sandals, MADE IN PANAMA, huts and palm trees carved into the heels; squirt gun; detachable collar with lip-print; post-card from the Poconos; playing cards in a pack with Florentine borders; a trivet made of popsicle sticks.

\section{Bottom Drawer}

Ammonite; souvenir pillow, Watkins Glen; presser foot; zipper foot; flywheel belt; ink bottle with loose rubber stopper; extension cord; box of bobbins; belt for a blue kimono; certificate of perfect attendance. 
This page intentionally left blank 


\title{
1 Things to Remember Introduction to Materializing Memory in Art and Popular Culture
}

\author{
László Munteán, Liedeke Plate, \\ and Anneke Smelik
}

But when from a long-distant past nothing subsists, after the people are dead, after the things are broken and scattered, still, alone, more fragile, but with more vitality, more unsubstantial, more persistent, more faithful, the smell and taste of things remain poised a long time, like souls, ready to remind us, waiting and hoping for their moment, amid the ruins of all the rest; and bear unfaltering, in the tiny and almost impalpable drop of their essence, the vast structure of recollection.

-Marcel Proust (1956, pp. 57-58)

Stuff matters.

\section{Dipping a 'Petite Madeleine' in a Cup of Linden Tea}

From Pierre Nora's lieux de mémoire and its many successor projects across the European and American continents to Raphael Samuel's (2012) 'theaters of memory', the literature on memory intimates that remembering is entangled with things. This entanglement of memory with materiality can be illustrated by the souvenir that people buy as a memento on their travels; objects we keep so that they will remind us of a particular time, place, or situation we wish to remember. Built so as to make people remember, monuments and memorials further exemplify the interrelation of memory and materiality. Plaques commemorating writers and artists, statues of kings and politicians are a case in point. Perhaps the most famous literary example of this entanglement is the episode in Marcel Proust's À la recherche $d u$ temps perdu, when, dipping a 'little madeleine' cake in a cup of linden tea, Marcel unexpectedly remembers similar crumbs of the little madeleine which his aunt Léonie used to give him on Sunday mornings at Combray. 'The sight of the little madeleine had recalled nothing to my mind before I tasted it', Marcel observes (Proust, 1956, p. 57). But once he has recognized the taste of the madeleine soaked in linden tea, the memory of the old gray house in which his aunt used to live emerged before him, and with the house the town, indeed the 


\section{László Munteán, Liedeke Plate, and Anneke Smelik}

whole of Combray and its surroundings, 'like the scenery of a theatre' (58), inaugurating the narrative of his 'remembrance of things past', as Proust's novel is called in English. 'The past is hidden somewhere outside the realm, beyond the reach of intellect, in some material object (in the sensation which that material object will give us) which we do not suspect' (p. 54).

Proust's insight into the importance of things, and especially the sensation thereof, proves that the material, sensual, and sensory dimensions of memory in culture have long been known. As he makes clear, it is the feel, smell, and touch of things that trigger memory; it is the encounter between the embodied human being and the inanimate thing that occasions the act of remembrance, not some 'exercise of the will' (Proust, 1956, p. 53). Or, as Freeman, Nienass, and Daniell put it: 'we rarely remember through ideas only, but rather through our encounters with things' (2016, p. 3).

Like Proust's madeleine, the mundane things we accidentally find while clearing out drawers easily lend themselves as vehicles of time travel. They make us relive, in a fraction of a second, memories of places and events, of feelings, and of people we have met but long forgotten. Susan Stewart's poem 'The Memory Cabinet of Mrs. K. 1960', published as a prelude to this book, offers a poignant articulation of the mnemonic potential of things. Structured by the drawers' location within the cabinet, the poem constitutes an inventory of things that Mrs. K. accumulated. Unlike the madeleine that pries open the recesses of Marcel's memory in Proust's novel, Stewart's poem does not disclose Mrs. K.'s memories related to the objects in her cabinet. Instead, they are situated in the poem according to their location within the cabinet. The year 1960 serves as a temporal reference point, while the 'memory cabinet' suggests that these objects have been willfully retained. In Stewart's inventory, none of them emerges as more or less important than any other. Rather, they form a metonymic chain of contiguity, held together by commas and semicolons. The fact that they are stored in the drawers of a memory cabinet, however, invests them with a mnemonic aura. Beyond the functions they serve as cosmetics, souvenirs, cloths, and knickknacks, they emerge in the poem as metonyms of past journeys, events, and relationships. Like the letter K., which marks and at once conceals the name that it stands for, the things in Mrs. K.'s cabinet are material markers of memories undisclosed to the reader. But even if they are silent about memories, these objects also mark Mrs. K. as a person. They bespeak her social standing, her taste, her sense of self, and above all, her will to remember.

Yet if the entanglement of memory and materiality has long been known and can be traced throughout the massive amount of texts that make up the field of cultural memory studies, so far this material dimension has remained relatively undertheorized in memory studies. 
Materializing Memory in Art and Popular Culture seeks to remedy this situation. In this collection of essays, we examine practices of memory centered on the concept of materiality, by which we mean the concrete, material, and physical dimensions of acts of remembrance. As we shall demonstrate, this means that we regard materiality as the relations between people and things. As Ian Woodward asserts, 'materiality ... refers to the relations between people and objects, especially the way in which social life is inherently structured by everyday dealings with objects, such as technology or objects of memory' (2007, p. 55, emphasis in original). Important in this definition is the emphasis on the inherent relationality of materiality. Indeed, scholars tend to stress that matter is always embedded in its social relations. John Law, for example, defines materiality as 'a way of thinking about the material in which this is treated as a continuously enacted relational effect' $(2004$, p. 161). In The Oxford Handbook of Material Culture Studies, he writes that in Science and Technology Studies (STS), 'materiality is usually understood as relational effect' (2010, p. 173). Similarly, in their edited volume Material Powers, Tony Bennett and Patrick Joyce refer to the 'intrinsic sociality of matter' (2010, p. 15), while Giuliana Bruno argues that 'materiality involves a refashioning of our sense of space and contact with the environment, as well as a rethreading of our experience of temporality, interiority, and subjectivity' $(2014$, p. 8$)$.

In this book, we focus on the interrelation of memory and materiality in art and popular culture to explore material culture as an integral aspect of memory practices. As such, we seek to account for the material world as a medium through which acts of remembering and forgetting take place. On the one hand, we investigate the ways in which objects and things are endowed with meaning and affect through the various memory practices that are centered on them. On the other hand, we are especially interested in the 'agency' of objects as a key element in practices of memory and forgetting. The theoretical and methodological apparatus of the book stems from the paradigm known as the 'material turn', which has gained substantial recognition in social and cultural research over the past decades but has received significantly less attention in the field of memory studies. According to Bennett and Joyce (2010), the material turn was instigated by the need to rethink anti-ontologizing dualisms, such as those between the natural and the social, the human and the nonhuman, the material and the immaterial. The material turn encompasses the so-called new materialism (Barrett and Bolt, 2013; Dolphijn and van der Tuin, 2012) or new materialisms (Boscagli, 2014; Coole and Frost, 2010; St. Pierre, Jackson, and Mazzei, 2016), which looks at how material powers affect our daily lives and discusses the agency of nonhumans. Diana Coole and Samantha Frost emphasize that 'We live our everyday lives surrounded by, immersed in, matter' (2010, p. 1), while Estelle Barrett and Barbara Bolt draw attention to the performative 


\section{László Munteán, Liedeke Plate, and Anneke Smelik}

power of materiality without, however, throwing out the discursive dimension of reality $(2013$, pp. 6, 7). Fully to acknowledge the role of materiality in our daily lives 'entails recognising distinctive forms of agency and effectivity on the part of material forces', as Bennett and Joyce maintain (2010, p. 3).

A new materialist approach to comprehending practices of memory offers fresh perspectives on the study of memory in culture. The present book seeks to open new horizons in memory studies by focusing on materiality as an integral aspect of memory practices in a wide temporal and topographical range, from ancient Rome to contemporary Latin America and Indonesia. Its scope entails fields as diverse as modern ruins, the exchange and circulation of souvenirs, digitization and the Internet of Things, the materiality of the body and traumatic reenactment, as well as the material aspects of memory in creative performances, literature, film, and fashion design. As a whole, Materializing Memory in Art and Popular Culture addresses four underlying questions: What is the role of materiality in the mediation of memory at the individual, social, and cultural level? What is the role of memory and forgetting in the social and cultural life of objects? How do art and popular culture use materiality to bring the past into the present in the service of the future? And finally, in what ways are memory objects inscribed with meaning, affect, and agency? The answers that this volume provides are predicated on two premises: first, memory is performed, mediated, and stored through the material world that surrounds us. Second, inanimate objects and things also have a certain agency of their own, which affects practices of remembering as well as of forgetting.

\section{Performance and Materiality}

If memory is a performance of the past in the present, it is essential to account for the material world as a medium through which performances of memory take place. Whereas the focus of our previous book, Performing Memory in Art and Popular Culture, was 'on the "act" of memory, not its "theatre" or "palace", as we wrote in its introduction, 'inquiring into the processes of making, constructing, enacting, transforming, expressing, transmitting cultural memory through art and popular culture' (Plate and Smelik, 2013, p. 3), this time we direct our attention precisely to such theatres and palaces and look at ruins, souvenirs, interconnected objects, and other things to remember. Celeste Olalquiaga, for example, argues in her chapter that modern ruins induce a new form of memory-one that focuses on the brittleness of material reality. It is a material reality, moreover, that has become infused with an aura of 'realness' where perception is no longer a question of 'seeing is believing', but rather 'touching is believing'. This shift in focus, from the performance of memory to its materiality, follows from the insight 
that there is a material dimension to the performance of memory and that this material dimension has not been given sufficient attention in memory studies. This is not to say that material culture has been underrepresented in cultural memory studies. On the contrary, objects have been central to the study of cultural memory, for instance, in the case of memorials, photographs, souvenirs, and books (Young, 1993; Hirsch, 1997; Sturken, 2007; Rigney, 2012). It is rather a matter of developing the 'means by which to activate the implicit thing knowledge we already possess, as well as means to become more sensitive to the inherent qualities of things themselves', as Bjørnar Olsen writes in In Defense of Things (2013, p. 18). In Death, Memory and Material Culture (2001), Elizabeth Hallan and Jenny Hockey discuss the role of the body and its material environment in the making of memory, focusing on how objects and the rituals around these objects shape the memory of past generations, dead friends, and lovers. In The Memory of Clothes (2015), Robyn Gibson has collected stories of the ways in which memories and traces of the past are, as it were, woven or stitched into the fabrics of our clothes. Such narratives follow in the tracks of Peter Stallybrass's (1993) groundbreaking article on the pivotal role that clothes play in individual remembrance, as Lianne Toussaint and Anneke Smelik point out in their chapter on techno-fashion. On a different note, in his chapter Louis van den Hengel explores the potential of performance and re-performance to act as material processes of historical, cultural, and aesthetic memory-a multiple folding of time that carries the past into the present and affirms the presence of the present as the living force of memory. In contrast to the debates within performance theory that center on the ephemeral or fleeting nature of live art, he focuses on how memory is mediated through the distinct materiality of performance. Van den Hengel locates this materiality in the affective operations of performance as a timebased, yet profoundly untimely, art form. In this view, it is the expressive event of performance that creates an enduring archive in which the forces of matter and memory meet in a co-shaping dynamic.

Three works have been particularly influential in our project. The collection of essays edited by Marius Kwint, Christopher Breward, and Jeremy Aynsley entitled Material Memories: Design and Evocation (1999) anticipated and laid the groundwork for the present book by assigning crucial importance to the forms and materials of objects, their social, economic, and historic reasons for being, and the ways in which we remember by interacting with them through our senses, as did Bjørnar Olsen's In Defense of Things: Archaeology and the Ontology of Objects (2013). In the realm of the arts, Lisa Saltzman's (2006) discussion of material techniques of remembrance in her Making Memory Matter: Strategies of Remembrance in Contemporary Art has also been a source of inspiration for our project. It is this continued attention to the materiality of objects, and to the role of this materiality 
in the process of cultural remembering, that we want to pursue in this volume. For example, in her chapter, Inge van de Ven argues that digitalization has enabled new possibilities for scale, which in turn has reinforced a widespread cultural drive to capture and preserve 'everything'. She explores the effect of databases on literary representations in two 'big' novels-Knausgård's Min Kamp and Bolaño's 2666-that embody the monumental in a double meaning of the term: commemoration and material magnitude. She analyzes how the material dimensions of these works and their expansive scope relate to their workings as vehicles of cultural memory. The notion of scale plays a similarly central role in László Munteán's contribution to this volume, albeit in the essentially different context of the miniature. Munteán uses the photographer David Levinthal's 2008 project entitled I.E.D.: War in Afghanistan and Iraq as a case study that combines American soldiers' blogs of their war experience with photographs of miniature dioramas depicting scenes of America's War on Terror. Levinthal's photographs, as Munteán demonstrates, monumentalize these miniature objects and render them uncannily realistic, activating 'memories' of a war experienced through mediatized representations.

In Materializing Memory in Art and Popular Culture, we refer to an increasing body of research gathered under the rubric of 'new materialisms' as a terminological and theoretical apparatus fitting not only to discuss hitherto overlooked aspects of remembering but also to demonstrate the methodological value of studying materiality for a humanities and social sciences perspective on 'memory'. Similar to other adherents of the material turn in the humanities and social sciences (e.g., Hicks and Beaudry, 2010; Boscagli, 2014), we draw on insights from a variety of sources and disciplines. These range from archaeological, anthropological, and vernacular theories about things to literary studies, material culture studies, science and technology studies, philosophy, political theory, and quantum physics, all of which regard things not as inert but as 'vibrant' matter (Bennett, 2010) and perceive things, people, and society as co-producing one another. In this latter respect, Arjun Appadurai's edited volume The Social Life of Things has been a seminal text that pleads to 'follow the things themselves, for their meanings are inscribed in their forms, their uses, their trajectories' $(1986$, p. 5). The idea that a thing, a gift, or a commodity may have a social life is indeed illuminating, particularly in light of the distinction between what Appadurai describes as the social history of things, pertaining to longer-term shifts and larger-scale dynamics, and what Igor Kopytoff in the same volume calls the 'cultural biography' of things (1986, p. 34). In her contribution to the present book, Maggie Popkin follows Appadurai's and Kopytoff's example to show the evolving biographies and shifting functions and meanings over the course of the 'lives' of glass vases from ancient Pozzuoli. These vases were purchased as commodities but 
were then transformed into souvenirs with greater sentimental value and, ultimately, into grave goods in some cases. The complexities of their biographies, however, do not change the fact that they spent parts of their 'lives' as souvenirs. Willy Jansen, too, traces the 'social life of things' in her chapter on religious objects used in rituals, such as a crystal tear expressing the Virgin Mary's suffering. She claims that groups create and sustain a symbolic focal point for their identity construction by exhibiting, describing, and photographing the biography of their most precious things. Through their care for things, groups develop internal cohesion and distinguish themselves from others. On a personal level, objects serve to symbolize the intimate suffering of mothers in everyday life and the emotional work involved in caring for one's loved ones and keeping the memory of deceased or departed family members alive. Objects thus help to shape a variety of identities-individual and familial, social, spatial, political, and religious.

In everyday parlance, the terms 'object' and 'thing' are used interchangeably. Although this is often the case in scholarly literature as well, a theoretical tradition dating back to Heidegger's work (2001) does distinguish between the two categories. Drawing on the conceptualization of objects as things that we think of as 'relatively stable in form' (Hodder, 2012, p. 7), Bill Brown's seminal essay, 'Thing Theory' (2001), introduced literary scholars and cultural critics to a 'sense of things', which would become the title of his 2003 book. In 'Thing Theory' he writes: 'We begin to confront the thingness of objects when they stop working for us.... The story of objects asserting themselves as things, then, is the story of a changed relationship to the human subject and thus the story of how the thing really names less an object than a particular subject-object relation' (2001, p. 4). In her chapter on the Argentinian film Los rubios by Albertina Carri, Anna Forné draws on Brown's thing theory in relation to the exposition of different kinds of memory objects that is carried out in a filmic display of cutting, reorganizing, and staging, not only of the objects of memory but also of the modus operandi by which those objects are remembered. The importance of materiality in collective as well as individual labors of memory is thus highlighted. Expanding on Brown's thing theory, Forné argues that the object is revealed as a thing when the relationship between the human subject and the object is altered. She shows that the inevitable intertwinement of personal and public narratives of memory in Los rubios, and the way in which the objects of memory are staged, emphasize the changed relationship between the subject and the object contemplated. The film thus changes the objects into things.

In his latest book entitled Other Things, Brown (2015) expands on the object/thing distinction through the works of Heidegger and Lacan, examining the force of material culture through a range of writers and visual artists. Tracing the etymological root of the word 'thing' 


\section{László Munteán, Liedeke Plate, and Anneke Smelik}

in Old-High-German, Heidegger foregrounds 'gathering' as an inherent quality of thingness (2001, p. 172), thus foreshadowing that things are always already connected (Hodder, 2012) and entangled (Barad, Juelskjaer, and Schwennesen, 2012; Ingold, 2010). In their critical account of pioneering heritage work in the space of social media and the Internet of Things, for instance, Elisa Giaccardi and Liedeke Plate argue that 'doing' and 'saying' around connected objects creates new spaces of remembrance. Rather than using things to communicate with other people, people will communicate with things and things with peopleand with other things. Within this landscape, the ontological distinction between human and nonhuman, animate and inanimate becomes blurred. This new relationship with 'things' is something that people increasingly have to negotiate, and it may well be the next step in digital heritage. In this sense, the distinction between people and things also becomes more blurred. People are things too, as new materialists like to emphasize (Frow, 2001, p. 285; Ingold, 2012, p. 438); we are 'walking, talking minerals' (Margulis and Sagan, 2000, p. 49, qtd. in Bennett, 2010, p. 11), 'bundles of biochemical processes, flows of blood and nerves and cells temporarily coalesced into an entity that is thoroughly dependent on and connected to air, water, food and so on' (Hodder, 2012, p. 9).

This entanglement of things both human and nonhuman is crucial for our understanding of memory, not as a pure neurological event, but as the 'intra-action' of people and things. We borrow the term 'intra-action' from Karen Barad, who introduces it to signal how people and things are not separate entities that interact, but constitute each other in the process. As Barad maintains, 'Intra-actions are causally constraining nondeterministic enactments through which matter-in-the-process-of-becoming is sedimented out and enfolded in further materializations' (Barad, 2003 , p. 823). Barad's nondeterministic and nonrepresentational understanding of materiality provides a useful platform to rethink the role of things in the memory process. There is increasing recognition that we would not be who we are without things; that 'things are us' (Webmoor and Witmore, 2008, qtd. in Ingold 2012, p. 438). We are living in a society not only of consumption (Baudrillard, 1990, 2005) but of hyperconsumption (Lipovetsky, 2005), with more things than we know what to do with. In his historical and encyclopedic overview entitled Empire of Things, Frank Trentmann (2016) analyzes how consumers become more and more overwhelmed by possessions. Consequently, the question of how this surplus of things affects our ability to remember-individually as well as collectively-poses itself with increasing urgency. Surrounded by stuff, with more images in our computers than we can look at in a lifetime and more artifacts in depots and documents in archives than we can process, the question begs the answer as to how and what do we recollect? How, indeed, does 'peak stuff' (a term used by Steve Howard, head of Ikea's sustainability unit) relate to (cultural) memory? 
We do not need to refer to complex philosophical arguments to understand the basic truth of the insight that human life is entangled with things. Just think of how, physiologically, the things we ingest literally make us; or how the things we learn, memorize, and think about shape our brain. ${ }^{1}$ Without the insights of the (neuro)sciences, Deutscher Werkbund, the German industrial design association founded by artists and industrialists in 1907, maintained in its 1955 catalogue Deutsche Warenkunde that 'we not only shape things, but things shape us'-a belief that led to the Werkbund controversially attempting to influence people's lifestyles through design - through the aesthetics of things, such as a 'beautifully set table', with which they interacted and surrounded themselves. ${ }^{2}$ More recently, Marie Kondo's popular best-selling book, The Life-Changing Magic of Tidying Up: The Japanese Art of Decluttering and Organizing (2014), not only articulates readers' concerns about being overwhelmed by the things they have accumulated, but does so in terms distinctly similar to those of the new materialists, by speaking of 'belongings as if they were alive' and demanding that we acknowledge the support we receive from the things that surround us (pp. 169, 181). For Kondo, whose mission in life is to declutter homes, it is clear that memory-or, more specifically, the will to remember that attends the fear of forgetting - plays an important role in the accumulation of things in our lives and why we hold on to them. 'Starting with mementos spells certain failure', she heads one of the sections in the book, explaining that 'more often than not, it's one of your favorite comic books, an album, or some other item that brings back fond memories' that holds people back from making a clean sweep of their homes (pp. 44-45). As she writes, 'The thought of disposing of them sparks the fear that we'll lose those precious memories along with them' (p. 114).

Fittingly titled The Comfort of Things (2008), Daniel Miller's anthropological study of networks of relationships woven around simple household objects in a London street attests to the entanglement of people and things, things and memories, and of people's dependence on things (for memory) (see also Miller and Parrot, 2009). In an earlier book, Miller (2005) admits that he cannot give a definition of what a 'thing' is beyond 'a commonsense rather than academic presupposition of what we mean by the word thing. Is an ephemeral image, a moment in a streaming video, a thing? Or if the image is frozen as a still, is it now a thing? Is a dream, a city, a sensation, a derivative, an ideology, a landscape, a decay, a kiss? I haven't the least idea' (Miller, 2005, p. 7). Similarly, a few years later he exclaims to please not ask for a definition of 'stuff' (Miller, 2010, p. 1). This aversion to clear definitions does not prevent him from claiming that 'things make people as [much] as the other way around' (p. 42), and that 'things ... make us the people we are' (p. 53). In her chapter on the documentary The Act of Killing, which features perpetrators of mass killings that happened nearly five 


\section{0}

decades ago in a post-coup purge in Indonesia, Aleid Fokkema discusses how the film engages with 'objects that matter', a phrase she borrows from Miller (2005). Everyday objects, Miller argues, matter in a personal way and 'at the scene of action' (2005, p. 13). The Act of Killing can be taken to illustrate this with excessive performances where props and buildings come to figure significantly as the scene unfolds. The houses, offices, town squares, or patios that form the casual backdrop to the scene and the objects used for 'dressing up' performances appear to be mundane and generic but become uncannily meaningful because of the way they come to matter to the people who interact with them. In The Act of Killing, place, the lieu de mémoire, is intrusively present in collective space, with former locations of torture and killing simply extant as ordinary buildings and offices that in the film become suffused with their somber history through reenacted memories. The film visualizes how place has a way of invading the body in the act of retrieving and re-living memory. Such bodily affect is momentary and transient, as is the transformative power of things that matter. The film shows that memory retrieval does not provide closure and does not appear to have any lasting effect, but is restricted to the scene of action; to performance as it happens, as it is witnessed.

And indeed, what is the lieu de mémoire, if not the recognition that we need things to remember? According to Pierre Nora, the interest in lieux de mémoire occurs at a specific historical juncture, 'a particular historical moment, where consciousness of a break with the past is bound up with the sense that memory has been torn-but torn in such a way as to pose the problem of the embodiment of memory in certain sites where a sense of historical continuity persists' (1989, p. 7). Recognizing the material and embodied nature of memory, Nora acknowledges the way in which mind, body, and world work together to produce memory: 'We speak so much of memory because there is so little of it left,' he aphoristically writes. 'There are lieux de mémoire, sites of memory, because there are no longer milieux de mémoire, real environments of memory' (p. 7, emphases in original).

Although many people in the Western world still adhere to the (modernist) idea that mind, body, and world are separate and distinct, there is also an increasing recognition that this metaphysics can no longer be maintained and that it has reached the limits of its explanatory powers. To be sure, there are those who, like the Nestor of Cultural Memory Studies, Jan Assmann, continue to hold on to the ontological differentiation between mind, body, and world, asserting that 'Things do not "have" a memory of their own, but they may remind us, may trigger our memory, because they carry memories which we have invested into them' (2008, p. 111). Yet, there has been increasing dissatisfaction with such a view among scholars of memory and material culture. Katrina Schlunke introduces the readers of the dedicated journal Memory Studies to the 
idea that 'memory and materiality are better understood as intertwined producers of memory effects' because, as she argues, it 'provides us with a more telling idea of why memory constantly exceeds any easy division between individual and collective and between the unconscious and conscious' (2013, pp. 253-254). Seeking to understand the relationship between human memory and material culture in a more complex and satisfying way, archaeologist Andrew Jones draws on philosopher Andy Clark's (1997) theory of the extended mind to argue that memory is produced through the encounter between people and the material word. As he explains, 'The mind is best understood as emergent in its interactions with the world' (2007, p. 10). ${ }^{3}$ This theory implies that knowledge 'is dependent upon contingent interactions amongst brain, body, and world' and that remembrance can best be understood as a 'dialogue', 'a process distributed between people and objects' (2007, pp. 10, 26). As Marius Kwint writes elsewhere, such a view 'opens up the proposition that human memory has undergone a mutual evolution with the objects that inform it; that, in other words, the relationship between them is dialectical. Not only does the material environment influence the structure and contents of the mind, but the environment must also have been shaped along the lines of what persists in the mind's eye' (1999, p. 4).

In other words, to take the materiality of things seriously means to be able to 'have finally and fully transcended the dualism of subjects and objects', in the words of Daniel Miller (2005, p. 43). An early problematization of this dualism can be found in Michel Serres's The Parasite (1982) where, through the example of the ball used for playing games, he comes to the realization that 'The ball isn't there for the body; the contrary is true: the body is the object of the ball; the subject moves around this sun. ... Playing is nothing else but making oneself the attribute of the ball as a substance' (p. 226). The ball, in Serres's sense, operates as a 'quasi-object' and 'quasi-subject,' an entity constitutive of the subject that engages with it in the game. Drawing on this subversion of the conventional subject/object divide, Bruno Latour (1993) furthers the concept of quasi-objects and quasi-subjects by recognizing their role as catalysts of exchange within larger networks: 'They are real, quite real, and we humans have not made them. But they are collective because they attach us to one another, because they circulate in our hands and define our social bond by their very circulation' (p. 89). This formulation later became one of the conceptual pillars of his actor-network theory (2005), which grants equal agency to objects within intricate human-nonhuman networks, providing a widely applied model to overcome the subject/object dualism in social science research. Reverberations of this thinking can be felt in a renewed interest in ontology and the ontology of things in particular, as evidenced by the proponents of Speculative Realism and Object-Oriented Ontology (Harman, 2002, 2010; Bryant, 2011; Bogost, 2012). 


\section{László Munteán, Liedeke Plate, and Anneke Smelik}

Coming from a wide range of disciplines, the theories we have discussed here highlight two aspects of the interrelation of performance and materiality. First, performance is no longer conceived of in terms of human agency in relation to the object world. It is reconceptualized as an attribute intrinsic to both humans and nonhumans whereby they entangle to form networks (Latour, 2005) and meshworks (Ingold, 2010), destabilizing conventional ontological distinctions between subjects and objects. Second, these theories of materiality underline the indispensable role of objects and things in performances of memory that needs to be contended with. Understanding performance in terms of material agency, however, implies that objects and things are no longer regarded as mere expedients for memory work but as potential agents of memory themselves, an issue to which we turn next.

\section{The Agency of Objects}

A central debate within material culture studies revolves around the issue of whether objects can be said to have agency (Knappett and Malafouris, 2008). Whereas there is general recognition of the 'vitality' of thingstheir capacity, as Jane Bennett puts it, 'not only to impede or block the will and designs of humans but also to act as quasi agents or forces with trajectories, propensities, or tendencies of their own' (2010, p. viii)this does not mean everyone agrees that we can speak of the agency of objects. On the one hand, there are those, such as Daniel Miller, who do not refrain from speaking of material culture as 'having agency all of its own. Things do things to us, and not just the things we want them to do' (2010, p. 94), a proposition for which Bruno Latour's (2005) discussion of both humans and nonhumans as 'actants' had already set the stage. Alfred Gell can be credited with being the first anthropologist to have developed a theory of art focused on the agency of art objects in his posthumously published Art and Agency (1998). On the other hand, Tim Ingold maintains that 'The idea that objects have agency is at best a figure of speech, forced on us (Anglophones at least) by the structure of a language that requires every verb of action to have a nominal subject' (2010). For him, the emphasis on material agency is 'a consequence of the reduction of things to objects and of their consequent "falling out" from the processes of life' $(2010$, p. 3). It is a way of giving things their due but only partly. For as we mistake things for objects-as we think of them as discrete objects rather than gatherings of materials and forces-we overlook the life of things, the flow of materials, the transformation of matter. As he states, 'In effect, to render the life of things as the agency of objects is to effect a double reduction, of things to objects and of life to agency' (p. 7).

Crucial to the debate is, of course, what one understands by 'agency'. In Vibrant Matter: A Political Ecology of Things, political theorist 
Jane Bennett surveys the philosophical literature on the subject to conclude that 'No one really knows what human agency is, or what humans are doing when they are said to perform as agents. In the face of every analysis, human agency remains something of a mystery. If we do not know just how it is that human agency operates, how can we be so sure that the processes through which nonhumans make their mark are qualitatively different?' (2010, p. 34). In consequence, she chooses to utilize anthropomorphism strategically, as 'a counter to human exceptionalism, to, that is, the human tendency to understate the degree to which people, animals, artifacts, technologies, and elemental forces share powers and operate in dissonant conjunction with each other' (p. 34). As she maintains, 'We need to cultivate a bit of anthropomorphism-the idea that human agency has some echoes in nonhuman nature-to counter the narcissism of humans in charge of the world' (Bennett, 2010, p. xvi). Similarly rejecting its alignment with human intentionality, subjectivity and the autonomous will, Karen Barad redefines the term altogether. In her definition,

Agency is a matter of intra-acting; it is an enactment, not something that someone or something has. Agency cannot be designated as an attribute of 'subjects' or 'objects' (as they do not preexist as such). Agency is not an attribute whatsoever-it is 'doing'/'being' in its intra-activity. Agency is the enactment of iterative changes to particular practices through the dynamics of intra-activity. (2003, pp. 826-827)

We can thus understand the nonhuman agency of things as something that interacts with us as much as we interact with it.

This debate is important for rethinking the role of things in memory practices. It signals the importance of acknowledging this role in the first place, recognizing that, for better or for worse, things shape human memory. According to Marius Kwint, 'In Western traditions, objects serve memory in three main ways. Firstly, they furnish recollection; they constitute our picture of the past. ... Secondly, objects stimulate remembering. ... Thirdly, objects form records: analogues to living memory, storing information beyond individual experience' (1999, p. 2). Such enumeration of the ways in which things serve memory places them firmly in the category of aide-mémoire, that is, of things designed to help remember (the term 'aide-mémoire' originally designated an abstract containing the essence of what the student had to know). Rather than conceiving of things as props for memory, however, in the present book we maintain that without things, there would be no (cultural) memory. Earlier, following Marita Sturken's (1997) application of the Foucauldian notion of technology to cultural memory, we discussed the dependency of human memory on things in terms of 'technologies of memory' (Plate and Smelik, 2009). In this book, we push the argument 


\section{4}

László Munteán, Liedeke Plate, and Anneke Smelik

of our previous work further by pursuing not only the materiality of technologies of memory involved but also their sociality.

We may recall how materiality is always already embedded in social relations. Writing in the 1920s, French sociologist Maurice Halbwachs already pointed out that it is in society that people acquire their memories, just as it is 'in society that they recall, recognize, and localize their memories' (1992, p. 38). For him, this means that individual memory is entangled with that of others; that individual memory is always already social, shaped by social frameworks. As he writes, 'our recollections depend on those of all our fellows, and on the great frameworks of the memory of society ... there are no recollections which can be said to be purely interior, that is, which can be preserved only within individual memory' (pp. 42, 169). Halbwachs evidently stands in the 'amnesic' tradition in social and cultural studies that looks at societies as if 'operating without the mediation of objects' (Olsen, 2013, p. 2; see also St. Pierre, Jackson, and Mazzei, 2016). Nevertheless, rejecting the distinction between interiority and exteriority, and faulting psychology for considering people as 'isolate beings' (1992, p. 38), he in effect lays the foundations for understanding human memory as entangled, not only with other humans, but also with nonhuman things. 'Wearables' are a case in point. As Lianne Toussaint and Anneke Smelik argue in their chapter on techno-fashion, contemporary technologies embedded in gadgets or garments display a specific and nonhuman kind of agency. Agency pertains to quite different 'things': the designer, the body of the wearer, the garment, but also the materials like fiber, fabric, and the hard and soft technological artifacts embedded in them. These technologies are not inert but have been created to act, do, and remember. The notion of agency highlights the fact that the technologies establish an interaction between the garments and the body, between human and nonhuman entities. Material agency, in other words, is not located exclusively in the technology but in the assemblage of wearer, fashion, and technology.

The architect Eyal Weizman's project called 'forensic architecture' further attests to this entanglement in the realm of human rights. Operating in a wide range of conflict zones around the world, Weizman's team examines material remains to find evidence of crime that belligerent powers seek to conceal from the public. In doing so, the ruins of a building and material traces of violence are called for as " "material witnesses": that is, they bear witness not only to the alleged criminal events but to the very sorting process they underwent in order to qualify as evidence' (Weizman, 2014, p. 21). Architecture, Weizman claims, 'is both sensor and agent.' It is " "political plastic"-social forces slowing into form' (2012, p. 7, emphases in original). In this sense, architecture performs a tripartite function insofar as it 'registers the effect of force fields, it contains or stores these forces in material deformations, and, with the help 
of other mediating technologies and the forum, it transmits this information further' (Weizman, 2014, p. 15). The forum, which stands at the root of the term 'forensics', is a discursive site where the 'interpreter' and the thing 'make up an entangled rhetorical technology' to facilitate the transmission of information $(2012$, p. 9). Weizman's project exemplifies how the prevalence of survivors' testimonies is entangled with the voice given to materiality in a legal setting.

Here, we may refer back to Appadurai's notion of a 'social life of things' (1986). For both Appadurai and Kopytoff to trace the cultural biography of a thing entails the unraveling of the specific value it has acquired in the course of its life. This seems to be a particularly relevant point for a materialist perspective on cultural memory. The practice of remembering endows a thing with affect and hence with psychological importance. The thing, however, may also have agency on its own not only in precipitating remembrance but also, potentially, in remembering on its own. At stake here are not only practices of memory woven around objects but memories gathered, stored, conveyed or concealed by objects as part and parcel of their social life.

Distinguishing between objects and things is, therefore, quite literally a matter of agency. As evidenced by the ever-growing body and interdisciplinary nature of theoretical works on the agency of objects, there are differing views as to what agency exactly means in the context of material culture and what effects this agency has on practices of memory. On the basis of the works above, however, a certain tendency becomes manifest. Whether construed as a rhetorical means to counter human narcissism or dismissed as a figure of speech that reinforces anthropomorphism, the burgeoning discourse around material agency has destabilized the centrality of the human as the arbiter of material processes and employed entanglement and intra-action to give rhetorical voice to nonhuman powers underlying humans' relation to objects, as well as objects' relations to each other. Memory is thus no longer conceived of as a sole privilege of human beings who use objects to remember but rather as an activity deeply entangled with nonhuman things and processes. Besides foregrounding the role of objects in human practices of memory, our use of the phrase 'materializing memory' in the title of this book also indicates our intention to locate and trace memory as a practice of and within the material world.

The chapters in Materializing Memory in Art and Popular Culture examine practices of memory through a focus on their very materiality. Multidisciplinary in scope, they account for the material world as a medium through which acts of remembering and forgetting take place. The authors testify to the diverse ways in which cultural memory is being formed and performed in the materiality of the object, be it ancient souvenirs, modern ruins, the Internet of Things, creative performances, literature, film, or a fashion design. The chapters address the ways in 
which objects and things are endowed with meaning, affect, and agency through the various memory practices that are centered on them. Some of the chapters show how memory is performed, mediated, and stored through the material world that surrounds us. Other chapters analyze the agency of objects as a key element in practices of remembering and forgetting. In pursuing the interrelation of memory and materiality within the realm of art and popular culture, this volume aims at opening up new horizons in memory studies.

\section{Material Remains: Ruins and Souvenirs}

The chapters in the first part of the book, 'Material Remains: Ruins and Souvenirs', present the entanglement of memory and materiality in remains such as modern ruins and ancient souvenirs. This section opens with Celeste Olalquiaga's evocative essay 'El Helicoide: Modern Ruins and the Urban Imaginary'. While much attention has been paid in the last few years to modern ruins, the connection between their literal manifestations and their figurative use as concrete vestiges of cultural memory has yet to be established. Olalquiaga discusses why modern ruins elicit a mix of fascination and repulsion, and how this ambivalence underlies the impact of modern ruins on the urban imaginary. Outlining a chronology of the conceptual use of ruins in cultural theory-from Walter Benjamin's 'dialectical image' to Raymond Williams's 'residual sensibilities' and Jacques Lacan's psychic 'leftover'-she analyzes this use in relation to George Bataille's and Julia Kristeva's notions of the abject. Olalquiaga illustrates the inextricable relation between matter and concepts, and memories and objects, through El Helicoide de la Roca Tarpeya, an emblematic modern ruin in Caracas, Venezuela. A fallen star from the bright universe of modernity, El Helicoide represents not only the contradictions and shortcomings of the modern impulse, but also the complex relationship between modernity and memory. In a cultural moment when the perception of material reality is being reconfigured by digital technology, modern ruins recall the organic nature that industrialization set out to conquer, which now comes back residually in the conceptual and material leftovers of a modernity that attempted to erase the living memory of things.

In 'Souvenirs and Memory Manipulation in the Roman Empire: The Glass Flasks of Ancient Pozzuoli', Maggie Popkin discusses how souvenirs are a commonplace of contemporary life in many parts of the world. As a result, there has been a tendency to universalize the phenomenon of souvenirs-to suggest that souvenirs, no matter where or when they exist, capture a fleeting experience and eternalize it as something extraordinary. Yet souvenirs, like all objects of material culture, are products of specific cultural and historical contexts, and while similarities might exist between souvenirs from different times and places, Popkin suggests 
seeking in souvenirs the historical and the particular rather than only the universal. This chapter offers an example of what might be accomplished by historicizing souvenirs: it examines a series of glass vases produced in the Roman city of Puteoli (modern Pozzuoli) on the Bay of Naples in the third and fourth centuries. These ancient Roman souvenirs challenge ideas that souvenirs 'capture' or 'freeze' memories and that the roots of modern souvenirs extend back only as far as Christian pilgrimage relics. Popkin argues that the glass flasks exported a vision of Puteoli as a miniature Rome-a city that enjoyed a special, favored relationship with the Roman emperors. The Puteolan flasks provide an object lesson in how souvenirs in the Roman world did much more than commemorate people's visits to places; they also constructed people's perceptions and memories of those places. The glass vases from Puteoli thus provide a secular precedent for souvenirs in the modern world and demonstrate the extraordinary potential of souvenirs to shape actively how we remember places.

\section{Entangled Memories}

In the second part of the book, 'Entangled Memories', we have brought together essays that pursue the ways in which memories are entangled with material and immaterial objects. In their chapter 'How Memory Comes to Matter: From Social Media to the Internet of Things', Elisa Giaccardi and Liedeke Plate discuss how social media and the Internet of Things change the complex set of memory practices through which we give meaning to the past in the present and thus shape our image of the future. They first consider the ways in which social media enable ordinary people to participate in the construction of memory through shared activities of collection, preservation, and interpretation. They maintain that a participatory approach to memory practice empowers people to engage in an active relationship with heritage objects: 'doing' or 'saying' around the object begins to become more important for human practices of remembering than the object in its straight materiality. With social media, memory is not just communicated, but actively constructed and performed through participatory practices of remembering. The Internet of Things works further the active, performative relationship between people and heritage objects that social media have introduced into digital heritage. As physical objects are connected to the Internet and can collect and exchange data, performances are carried out within a socio-material configuration in which objects are at the same time tangible (that is, embodied and localized) and intangible (that is, embedded with code, instructions, and histories). As objects begin to be constituted with code and algorithms, and to remember more about themselves and likely ourselves, Giaccardi and Plate argue that 'doing' and 'saying' around connected objects creates new spaces of 
remembrance. The authors conclude with a theoretical speculation on how shared practices of remembering between humans and nonhumans have the potential to create spaces of remembrance that challenge our anthropocentric understanding of what is 'possible' and 'worthwhile' to remember.

Lianne Toussaint and Anneke Smelik shift the focus to fashion in 'Memory and Materiality in Hussein Chalayan's Techno-Fashion'. They use the case of a now iconic series of self-transforming dresses from the British-Turkish fashion designer Hussein Chalayan to explore how the integration of technology reshapes processes of memory through fashion. Chalayan's 'One Hundred and Eleven' collection (2006) takes the audience on a time travel through a hundred and eleven years of fashion history. A high-necked Victorian gown transforms into a 1920s beaded flapper dress in mere seconds, a 1950s hourglass dress suddenly changes into a 1960 s metallic sheath, and so on. The authors show how cultural memory-in this case, the recent history of Western fashion-is performed and mediated by the combination of fashion and technology. Fashion entertains a particular dialectical and 'promiscuous' relation to time and history. Using Chalayan's collection as a case study, Toussaint and Smelik explore techno-fashion as a performance and technology of memory. In discussing the particular force of technology's as well as fashion's materialism, the analysis brings to the fore the 'agency' of things in highly technological times. As techno-fashion intertwines the embodied, technological, and cultural manifestations of memory, it paves the way for novel, softer and 'agentic' processes of memory.

In 'Size Matters: Karl Ove Knausgård's Min Kamp and Roberto Bolaño's 2666 as (Anti-)Monumental Novels', Inge van de Ven reflects on different meanings of monumentality in an age of digital proliferation of data. In cultural memory studies, the notion of the text as a monument is well established. It refers to literature's capacity to transmit historicity and to the ability of novels to achieve artistic greatness in their own right, thus assuring their proliferation. Van de Ven brings the monumental in terms of magnitude of length and scope into this discussion. She analyzes Karl Ove Knausgård's My Struggle (Min Kamp) series (2009-2011) and Roberto Bolaño's 2666 (2004), asking how the 'monumental effects' of these works-in size, scope and commemorative focus - come about. How do the material dimensions of these novels relate to their workings as vehicles of cultural memory? The author puts forth the argument that the increasing importance of the cultural form of the database in the current media culture influences the ways in which narratives are structured. The quantitative ordering principles identified in these novels-listing, the anaphoric singulative frequency, and interminable narration-are akin to the 'paradigmatic' structuring principles of the database and go against the compressions 
and selections of 'syntagmatic' narrativity. Where narrative meets the database, the result is a more inclusive textual monument that combines commemoration and bigness: a monumental novel in both senses of the term.

\section{Reenactment, Affect, and Remembrance}

The third part of the book, 'Reenactment, Affect, and Remembrance', shifts the focus to the material dimensions of corporeality and traumatic reenactment. Louis van den Hengel, in his chapter 'Archives of Affect: Performance, Reenactment, and the Becoming of Memory', addresses the potential of performance and performance reenactment to act as material processes of historical, cultural, and aesthetic memory that unfold onto a new ethics of art conservation. In contrast to traditional ontologies of performance as well as to the debates in the professional field that center on the so-called ephemeral or disappearing nature of live art, the chapter examines how memory is mediated through the distinct materiality of performance as an affective event. To this end, Van den Hengel brings postcolonial and queer contestations of traditional archival logics developed within contemporary studies of cultural memory into dialogue with the Deleuzian concept of affectivity as a material force of becoming. He argues that reenactment, by activating the sensations and affects of the body across multiple time zones, holds the power to open minoritarian modes of producing and proofing performance art histories. This argument is substantiated through the analysis of a number of performance works by Marina Abramović, Mary Coble, and a series of reenactments of Abramović's works by emerging artists from New York's radical queer underground. Van den Hengel develops a new materialist ontology of performance that considers performance not as the 'dematerialization' of the art object, but as a material practice for the transmission of affect, knowledge, and cultural memory.

In 'Crystal Tears and Golden Crowns: Materializing Memories of the Suffering Mother', Willy Jansen explores the memory work done through art objects in an important ritual in Spanish popular culture: the Holy Week processions in Andalusia. In recent decades, a material expansion of this ritual has taken place. An analysis of this change, based on data gathered during several ethnographic field studies of this event in Andalusia between 1976 and 2013, reveals its connectedness to a wide array of identification processes. Jansen argues that the objects simultaneously serve multiple memories on different levels. The first level is that of materializing a history and enacting specific social, religious, economic, and political identities. The second level is that of the materialization of personal emotions and family relations. By constantly elaborating on or renewing these objects, people 
remember where they belong. The Virgin Mary's crystal tears illustrate the ways in which these levels are intertwined. While symbolizing the suffering of the Mother of Christ and thus reminding participants of their collective religious and social history, they also symbolize the intimate suffering of mothers in everyday life and the emotional work involved in re-membering the family.

Anna Forné takes us to Argentina in 'The Staging of Memory in Los rubios by Albertina Carri'. This chapter deals with the materialization of memories in the feature film Los rubios (2003), in which the Argentine director Albertina Carri stages the story of the disappearance of her parents during the Dirty War (1976-1983) through the assemblage of different kinds of archival material, sewed together in a way that blurs the line between documentary and fiction. Moreover, in the movie Carri appears as herself (the director) accompanied by her crew, but she also introduces an actress, Analía Couceyro, who plays the role of Albertina Carri in search of the story of her parents. In other words, Carri not only searches for memories in the things of the past, but also turns herself into the object of the search when the camera loops and crosses the boundaries between the real and the constructed. Forné first examines the ways in which memories are materialized in Los rubios through the recovery and exposition of different objects of remembrance. She then looks into the strategies and effects of selfreflexive enactment in the film.

\section{Corporeality and Objects of Trauma}

In the fourth and last section of the book, 'Corporeality and Objects of Trauma', we turn to reenactments of violence. In her chapter, 'Chilling Burlesque: The Act of Killing', Aleid Fokkema discusses the documentary The Act of Killing (Oppenheimer, 2013). The film records the process of how perpetrators look back on the crime of killing (the allegedly communist) opponents of the military regime in Indonesia after the army's coup d'état in 1965-1966. This film is distinct from many other documentaries about war and conflict in that it uses neither the expository mode often employed for historical documentaries - the mode that tells the viewer confidently what happened, often by using survivor interviews, reenactment, and iconic historical props-nor the observational or 'fly-on-the-wall' mode dominant in contemporary war documentaries resulting from embedded journalism. Instead, this documentary employs a mix of performative and poetic frames. The challenge of 'representing the unpresentable' visibly informs the structure of the film, while the scope of the historical drama is evoked, not represented, by the materiality of props, costumes, and setting, which unsettles the viewer. The concepts of materiality and abjection help to account for this 
affective response. Fokkema discusses how such material scaffolding allows the main participants in The Act of Killing to reenact the drama of the past as the perpetrators they once were. Reenactment is in fact one of the key terms in the film, as it quietly establishes a veiled connection between trauma and performance (or performativity) that allows for a sense of continuity between the past and the present, on both the personal and political level.

In the final chapter, 'Modeling the Memories of Others: David Levinthal's I.E.D.: War in Afghanistan and Iraq', László Munteán discusses miniature dioramas and their photographic representations as vehicles of memory work. Ever since the early 1970s Levinthal has been known for his photo series of miniature dioramas depicting Western themes, pornography, the eastern front in World War II, and the Holocaust. I.E.D.: War in Afghanistan and Iraq differs from his earlier work in that it incorporates soldiers' first-person accounts of the war taken from the online military blog The Sandbox and re-creates these scenarios by using miniature figures and vehicles released by model kit companies. Instead of merely focusing on the photographs as re-mediations of soldiers' memories of the war, Munteán approaches Levinthal's work as a multifaceted and multilayered mnemonic device operating at the intersection of text, the miniature object, and photography. The memories that are performed materially and photographically are not Levinthal's own, nor do they constitute postmemories in Marianne Hirsch's (2012) sense. Rather, at stake here is the appropriation of the memories of others through the textual and photographic inscription of mass-produced model kits. Conventionally attributed to photographs, the affective quality of indexicality imbues the static model with documentary value, which is simultaneously undermined by the painted plastic surfaces of the model figures and military vehicles exposed by Levinthal's close-ups. Munteán investigates how the materiality of the model, filtered through photography and text, acquires the quality of 'thingness' in Bill Brown's sense-that which is unnamable and yet demands to be contended with.

Throughout Materializing Memory in Art and Popular Culture, the authors maintain a focus on materiality as an integral aspect of memory practices. The chapters attest to a large variety of disciplinary and theoretical approaches to the interrelation of memory and materiality, as well as to different understandings of material agency in processes of remembering and forgetting. Although the focus of these chapters is based on specific case studies, the materialist sensibility that they embody, as well as the theoretical apparatuses that they mobilize, transcends the individual works of art and popular culture discussed here. It is our hope that they will serve the reader as discursive models to continue 'materializing memory' in areas of culture beyond the scope of our volume. If they do so, we have already achieved our aim. 


\section{László Munteán, Liedeke Plate, and Anneke Smelik}

\section{Notes}

1 The classic example of brain plasticity is the larger hippocampus of the London taxi-driver due to spending years training the brain to remember the complex topography of London streets, as researched by Eleanor Maguire. See also Malabou (2008).

2 As a panel in the Museum der Dinge in Berlin explains, 'The "beautifully set table" was supposed to encourage or stabilize an intact family'. The Werkbund's ambition persisted well into the 1960s, when this agenda was criticized even within the Werkbund ('The Werkbund Boxes', Museum der Dinge, Berlin; visited on 25 October 2015).

3 Influential works rejecting the mind/body dualism include neurologist António Damásio's Descartes' Error: Emotion, Reason, and the Human Brain (1994).

\section{References}

Appadurai, A. (ed) (1986) The Social Life of Things: Commodities in Cultural Perspective (Cambridge: Cambridge University Press).

Assmann, J. (2008) 'Communicative and Cultural Memory' in A. Erll and A. Nünning (eds) Cultural Memory Studies: An International and Interdisciplinary Handbook (Berlin: de Gruyter). 109-118.

Barad, K. (2003) 'Posthumanist Performativity: Toward an Understanding of How Matter Comes to Matter', Signs: Journal of Women in Culture and Society 28.3: 801-831.

Barad, K., M. Juelskjær, and N. Schwennesen (2012) 'Intra-active Entanglements: An Interview with Karen Barad', in Kvinder, Køn og forskning/ Women, Gender and Research 1.2: 10-24.

Barrett, E., and B. Bolt (eds) (2013) Carnal Knowledge: Towards a 'New Materialism' through the Arts (London: I. B. Tauris).

Baudrillard, J. (1990) Seduction (Trans. B. Singer) (New York: St. Martin's Press).

Baudrillard, J. (2005) The System of Objects (Trans. J. Benedict) (London: Verso).

Bennett, J. (2010) Vibrant Matter: A Political Ecology of Things (Durham, NC: Duke University Press).

Bennett, T., and P. Joyce (eds) (2010) Material Powers: Cultural Studies, History and the Material Turn (London and New York: Routledge).

Bogost, I. (2012) Alien Phenomenology, or What It's Like to Be a Thing (Minneapolis: University of Minnesota Press).

Boscagli, M. (2014) Stuff Theory: Everyday Objects and Radical Materialism (New York: Bloomsbury).

Brown, B. (2001) 'Thing Theory' Critical Inquiry 28.1: 1-22.

Brown, B. (2003) A Sense of Things (Chicago: The University of Chicago Press).

Brown, B. (2015) Other Things (Chicago: The University of Chicago Press).

Bruno, G. (2014) Surface: Matters of Aesthetics, Materiality, and Media (Chicago: The University of Chicago Press).

Bryant, L.R. (2011) The Democracy of Objects (Ann Arbor: University of Michigan Library/Open Humanities Press).

Carri, A. (2003) Los rubios. Argentina and United States of America: Women Make Movies. 
Clark, A. (1997) Being There: Putting Brain, Body and World Together Again (Cambridge, MA: The MIT Press).

Coole, D., and S. Frost (eds) (2010) New Materialisms: Ontology, Agency, and Politics (Durham, NC: Duke University Press).

Damásio, A. (1994) Descartes' Error: Emotion, Reason, and the Human Brain (New York: Putnam's Sons).

Dolphijn, R., and I. van der Tuin (2012) New Materialism: Interviews and Cartographies (Ann Arbor: University of Michigan Library/Open Humanities Press).

Freeman, L. A., B. Nienass, and R. Daniell (2016) 'Memory I Materiality I Sensuality', Memory Studies 9.1: 3-12.

Frow, J. (2001) 'A Pebble, a Camera, a Man Who Turns into a Telegraph Pole', Critical Inquiry 28.1: 270-285.

Gell, A. (1998) Art and Agency: An Anthropological Theory (Oxford: Oxford University Press).

Gibson, R. (2015) The Memory of Clothes (Rotterdam: Sense Publishers).

Halbwachs, M. (1992) On Collective Memory (Trans. L. A. Coser) (Chicago: The University of Chicago Press).

Hallan, E., and J. Hockey (2001) Death, Memory and Material Culture (Oxford: Berg).

Harman, G. (2002) Tool-Being: Heidegger and the Metaphysics of Objects (Chicago: Open Court).

Harman, G. (2010) Towards Speculative Realism: Essays and Lectures (Ropley, Hants: Zero Books).

Heidegger, M. (2001) Poetry, Language, Thought (Trans. A. Hofstadter) (New York: Harper Perennial).

Hicks, D., and M. C. Beaudry (eds) (2010) The Oxford Handbook of Material Culture Studies (Oxford: Oxford University Press).

Hirsch, M. (1997) Family Frames: Photography, Narrative and Postmemory (Cambridge, MA: Harvard University Press).

Hirsch, M. (2012) The Generation of Postmemory: Writing and Visual Culture After the Holocaust (New York: Columbia University Press).

Hodder, I. (2012) Entangled: An Archaeology of the Relationships Between Humans and Things (Chichester, UK: Wiley-Blackwell).

Ingold, T. (2010) 'Bringing Things to Life: Creative Entanglements in a World of Materials', ESRC National Centre for Research Methods. Realities Working Paper \#15: 1-15.

Ingold, T. (2012) 'Toward an Ecology of Materials', Annual Review of Anthropology 41: 427-442.

Jones, A. (2007) Memory and Material Culture (Cambridge: Cambridge University Press).

Knappett, C., and L. Malafouris (eds) (2008) Material Agency: Towards a Non-Anthropocentric Approach (New York: Springer).

Kondo, M. (2014) The Life-Changing Magic of Tidying Up: The Japanese Art of Decluttering and Organizing (Trans. C. Hirano) (Berkeley: Ten Speed Press).

Kopytoff, I. (1986) 'The Cultural Biography of Things: Commoditization as Process' in A. Appadurai (ed.) The Social Life of Things (Cambridge: Cambridge University Press). 64-91.

Kwint, M. (1999) 'Introduction: The Physical Past' in M. Kwint, C. Breward, and J. Aynsley (eds) (1999) Material Memories: Design and Evocation (Oxford: Berg). 1-16. 


\section{László Munteán, Liedeke Plate, and Anneke Smelik}

Kwint, M., C. Breward, and J. Aynsley (eds) (1999) Material Memories: Design and Evocation (Oxford: Berg).

Latour, B. (1993) We Have Never Been Modern (Trans. C. Porter) (Hemel Hempstead, UK: Harvester Wheatsheaf).

Latour, B. (2005) Reassembling the Social: An Introduction to Actor-NetworkTheory (Oxford: Oxford University Press).

Law, J. (2004) After Method: Mess in Social Science Research (London and New York: Routledge).

Law, J. (2010) 'The Materials of STS' in D. Hicks and M. C. Beaudry (eds) The Oxford Handbook of Material Culture Studies (Oxford: Oxford University Press). 173-188.

Lipovetsky, G. (2005) Hypermodern Times (Trans. A. Brown) (Cambridge: Polity Press).

Malabou, C. (2008) What Should We Do with Our Brain? (Trans. S. Rand) (New York: Fordham University Press).

Margulis, L., and D. Sagan (2000) What Is Life? (Berkeley: University of California Press).

Miller, D. (ed) (2005) Materiality (Durham, NC: Duke University Press).

Miller, D. (2008) The Comfort of Things (Cambridge: Polity Press).

Miller, D. (2010) Stuff (Cambridge: Polity Press).

Miller, D., and F. Parrot (2009) 'Loss and Material Culture in South London', Journal of the Royal Anthropological Institute 15.3 (September): 502-519.

Nora, P. (1989) 'Between Memory and History: Les Lieux de Mémoire', Representations 26 (Spring): 7-24.

Olsen, B. (2013) In Defense of Things: Archaeology and the Ontology of Objects (Lanham, MD: Rowman and Littlefield).

Oppenheimer, J. (2013) The Act of Killing: Director's Cut (IDFA, Cinema Delicatessen).

Plate, L., and A. Smelik (eds) (2009) Technologies of Memory in the Arts (Basingstoke, UK: Palgrave MacMillan).

Plate, L. and A. Smelik (eds) (2013) Performing Memory in Art and Popular Culture (London and New York: Routledge).

Proust, M. (1956) Remembrance of Things Past (Trans. C. K. Scott Moncrieff) (New York: Modern Library).

Rigney, A. (2012) The Afterlives of Walter Scott: Memory on the Move (Oxford: Oxford University Press).

St. Pierre, E. A., A. Y. Jackson, and L. A. Mazzei (2016) 'New Empiricisms and New Materialisms: Conditions for New Inquiry', Cultural Studies - Critical Methodologies 16.2: 99-110.

Saltzman, L. (2006) Making Memory Matter: Strategies of Remembrance in Contemporary Art (Chicago: The University of Chicago Press).

Samuel, R. (2012) Theatres of Memory: Past and Present in Contemporary Culture (London: Verso).

Schlunke, K. (2013) 'Memory and Materiality', Memory Studies 6.3 (July): 253-261.

Serres, M. (1982) The Parasite (Trans. L. R. Schehr) (Baltimore: Johns Hopkins University Press).

Stallybrass, P. (1993) 'Worn Worlds: Clothes, Mourning, and the Life of Things', The Yale Review 81.2: 35-50. 
Sturken, M. (1997) Tangled Memories: The Vietnam War, the AIDS Epidemic, and the Politics of Remembering (Berkeley: University of California Press).

Sturken, M. (2007) Tourists of History: Memory, Kitsch, and Consumerism from Oklahoma City to Ground Zero (Durham, NC: Duke University Press).

Trentmann, F. (2016) Empire of Things: How We Became a World of Consumers, from the Fifteenth Century to the Twenty-First (London: Allen Lane).

Weizman, E. (2012) Forensic Architecture: Notes from the Fields and Forums / Forensische Architektur: Notizen von Feldern und Foren (Ostfildern, Germany: Hatje Cantz Verlag).

Weizman, E. (2014) Forensis: The Architecture of Public Truth (Oberhausen, Germany: Sternberg Press and Forensic Architecture).

Woodward, I. (2007) Understanding Material Culture (London: Sage).

Young, J. E. (1993) The Texture of Memory: Holocaust Memorials and Meaning (New Haven, CT: Yale University Press). 
This page intentionally left blank 


\section{Part I}

\section{Material Remains}

Ruins and Souvenirs 
This page intentionally left blank 


\title{
2 El Helicoide Modern Ruins and the Urban Imaginary
}

\section{Celeste Olalquiaga}

\begin{abstract}
While the relation of the present to the past is a purely temporal, continuous one, the relation of what-has-been to the now is dialectical: not progression but image, suddenly emergent.
\end{abstract}

-Walter Benjamin (1999, p. 462)

\section{Introduction}

The urban imaginary is full of ghosts. Some are fantasies about how cities were or should be; most are about how cities have been lived or imagined. Unlike human ghosts, this urban phantasmagoria is composed of material remains, the leftovers of eras that once filled the cityscape and are now barely backdrops, topographical layers of urban decay. Among these, the ruins of the twentieth century take a special place, for they are the paradoxical witnesses of a future that never happened.

One of the most outstanding of these modern ruins is El Helicoide de la Roca Tarpeya (Figure 2.1), a futuristic mall turned into a panoptical prison in Caracas, Venezuela. I propose to examine this extraordinary building and its peculiar history as an emblematic case of twentieth-century ruins. Rather than simply referring to past times, modern ruins help constitute our urban sensibilities, dreams, and memories. While much interest has been paid to these new ruins in the last ten years, connecting their literal manifestations to their figurative use as cultural metaphors, as I do here, will hopefully contribute to understanding the huge impact modern ruins have on our imaginary (Olalquiaga, 1992, 2003; Trigg, 2006; Boym, 2010; Hell and Schönle, 2010; Dillon, 2011; Cairns and Jacobs, 2014). The inextricable bond between matter and concepts is particularly relevant to comprehend the role of objects and memory at a moment when the perception of material reality is being dramatically reconfigured by digital technology. 


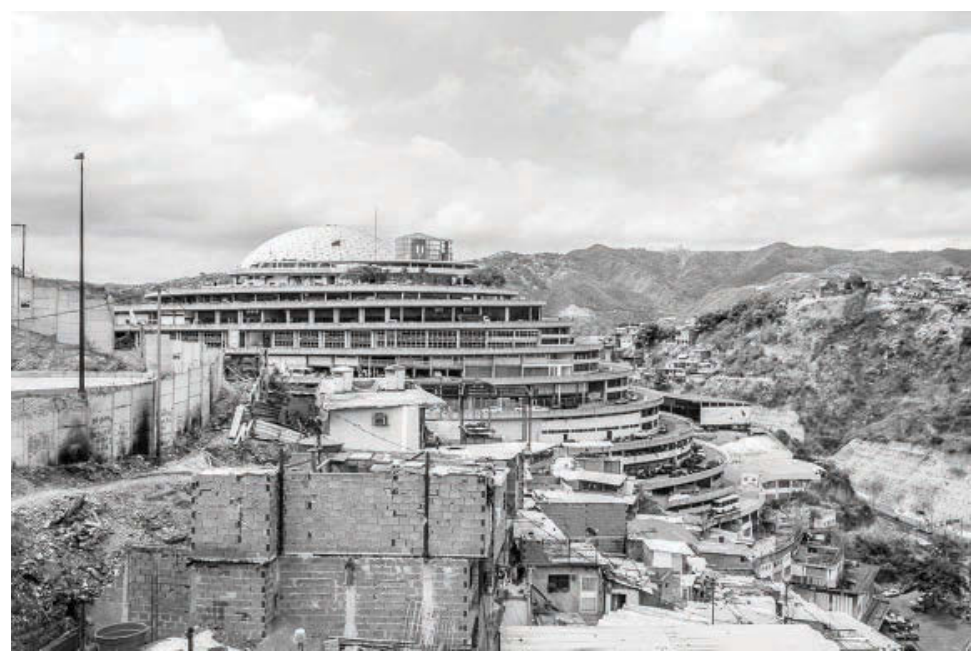

Figure 2.1 Partial view of El Helicoide. Photograph by Julio César Mesa, 2016.

\section{The Trash of History: Walter Benjamin and Modern Ruins}

Ruins were given a radical new twist almost a hundred years ago by a philosopher who understood and described the cultural value of things, particularly of modern things, long before anyone else: Walter Benjamin (1892-1940). With his massive and iconoclastic study of the Parisian passages, Benjamin inaugurated an entirely new way of looking at cities, their architecture, and also their oft-ignored urban furniture, as well as those apparently minor elements, such as street signs, that help organize urban space and experience.

Writing during and after World War I, Benjamin depicts a pervasive feeling of loss, which he explores and describes through the world of things, particularly the disappearing preindustrial world that the West European bourgeoisie was desperately clinging to. Benjamin (2008, p. 238) studies this 'extinct world of things' ${ }^{1}$ in two iconic places, respectively public and private, that developed in the mid-1800s: the Parisian passages and the interiors of bourgeois households. In the passages and interiors, Benjamin finds an archaeological mine of frozen, crystallized memories for a way of life on the brink of extinction, with buildings and things as its most tangible manifestation.

One of Benjamin's greatest insights was to present these reified memories, these ruined things, not as testimonials of a glorified, monumental past, as is the case with classical ruins, but instead as residues whose deteriorated condition portrays the contradictions and failures of the culture 
that produced them. His notion of the 'dialectical image' (Benjamin, 1983/1984), where the modern utopian desire is best apprehended through its material decay, shows how things are caught in a temporal quagmire, between the 'wish image' that produced them and what remains of this original wish after time (Buck-Morss, 1989, pp. 110-158). What lies in waste since the beginning of the twentieth century, the 'trash of history' (Benjamin, 1999, p. 461), is a modernity that was supposed to be ahead or at least in step with, rather than behind, us.

Benjamin's genius is his ability to ride the revolutionary wave of industrial technology, for instance, in his eulogy of photography and cinema in 'The Work of Art in the Age of Mechanical Reproduction' (Benjamin, 1968), while clearly showing that, doomed to become material traces, things gain in their postmortem condition a second and more lasting life that adds to, instead of taking away from, their comprehension. How this retrospective 'illumination' takes place is one of the most interesting aspects of Benjamin's dialectical image, an apparently contradictory notion, like many Benjaminian concepts and like much of modernity itself. For the utopian project underlying the wish image cannot be fully perceived in its initial manifestation in an object, but rather in the object's remains. As if the shiny glow of newness blinded us to the imaginary reality of objects, a reality that can only be revealed when they enter the realms of experience and history.

Like a photographic negative, an object's demise acts as the concrete surface through which its positive rendering can actually be seen. The wish image then becomes dialectical, illuminating its founding desire, much like Benjamin's famous 'angel of history' (Benjamin, 1968), thrown back by the blast of a future that it stares at in disbelief.

It's not that what is past casts its light on what is present, or what is present its light on what is past; rather, image is that wherein what has been comes together in a flash with the now to form a constellation. In other words, image is dialectics at a standstill.

(Benjamin, 1999, p. 462)

In this way, the dialectical image 'crystallizes' past and present into one image (such as the modern ruin) that both contains and surpasses them.

The paradox of a future that did not make it to the present, yet quickly became a thing of the past, can be appreciated in another Benjaminian notion key to the world of things and memories: the aura. Presented as a conceptual patina that covers preindustrial culture (objects, but also people and events) and confers upon them a one-of-a-kindness all the more valuable in the age of mechanical copies, the aura is defined by Benjamin as 'the unique manifestation of a distance, however near it may be' (Benjamin, 1968, p. 222). This is not a spatial distance, as Benjamin takes care to underline, but rather a temporal or, more 


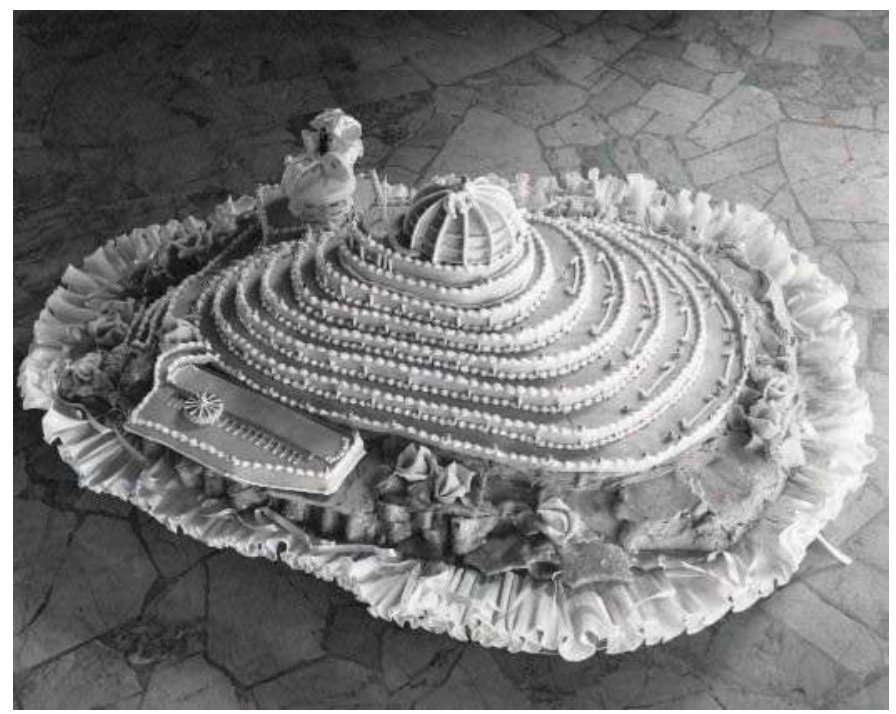

Figure 2.2 Architect Dirk Bornhorst's wedding cake in the shape of El Helicoide, Caracas, 1957. Courtesy of PROYECTO HELICOIDE/ Archivo Bornhorst.

specifically, an epochal one: the auratic object can be physically near and yet still convey a remoteness that places it at several removes from its onlookers.

This epochal distance, a blink to preindustrial uniqueness, points to what Benjamin distinguishes as 'cult' and 'exhibition' values (1968, pp. 223-225). These are the ritualistic and display equivalents of use value in that they are (or still were in the early twentieth century) related to direct experience; therefore, they are far from being marketable goods and farther even from the exchange value that determines worth in contemporary consumer society. The aura of a thing makes it an object of desire, raising its status from the familiarity of the immediate and known into the more exclusive and exciting one of distance and fetishism. The object becomes sacred in a nonreligious way. The aura may also be considered dialectical: it is distant while being close, and it can only be near from afar. As occurs with most use value, it begins to be cherished at a moment when singularity starts receding in the background. In this sense, the aura is a cultural ruin, which is precisely how Benjamin envisioned it, as he believed that the aura surrounding the extinct world of things was being literally hammered out of existence by mechanical repetition (Olalquiaga, 1998, pp. 80-95).

Whether dead or alive, the world of things survived and multiplied, creating a cultural overload that we can hardly handle 150 years after the 
beginning of the industrial revolution. It is a world of excess and waste in which the lifespan of things drastically diminished, not only because they can be immediately replaced, but mainly because contemporary things are often made for a spectacular or performative purpose, quite different from the ritualistic, aesthetic, or functional parameters of previous times. The world of things became extinct, yes, but in an ontological manner: things quickly become obsolete and useless, and the vacuum their active meaning - that is, whatever connects us to material reality in a meaningful way, whether use, cult, or affect-leaves behind is filled by an interminable chain of wish images that are never satisfactory enough.

This compulsive condition is exacerbated by high technology and its creation of a virtual reality where things are ubiquitous yet intangible. Industrial proliferation pales in comparison to the myriad replicas produced by digital technology, each outdoing the previous one in the scope of its reach and potential impact. Consequently, material things become the vestiges of a time when touch, or direct contact, still prevailed as a form of human perception and connection (Olalquiaga, 2002; Bruno, 2014). In this sense, one could argue that digital technology has reinforced the aura, much like industrial reproduction started doing a century and a half ago. For virtual reality is itself a form of distant nearness where things are within grasp but not physically there. Such intangibility generates a longing for what cannot be touched, as if concrete matter held a certain degree of reality that otherwise escapes us.

Material reality, in other words, becomes infused with an aura of 'realness' where perception is no longer a question of 'seeing is believing', but rather 'touching is believing'. In this context, it is hardly surprising that material remains, such as ruins, should hold a special attraction for a culture experiencing a virtual overdose. Modern ruins are a double, if not triple, ruin: the ruin of a utopian future, of concrete matter, and of things, like El Helicoide, that rematerialized in an unexpected manner, acquiring through ruination a life of their own. Modern ruins may be said to induce a new form of memory, one that, rather than anguished by the evanescence of human life or history, focuses on the brittleness of a material reality dear to the modern spirit.

\section{El Helicoide de la Roca Tarpeya}

I would like to illustrate this theoretical framework with a building that has haunted me since I was a teenager and which to this day remains one of the most unusual places on the planet. El Helicoide de la Roca Tarpeya was built in Caracas, Venezuela, in the late 1950s as a state-of-the-art mall. Named after its peculiar shape, this monumental building was constructed on and around a hill, La Roca Tarpeya, which was carved to fit it like a glove (Olalquiaga, 2013/2014; Villota Peña, forthcoming). The building is encircled by two miles of vehicular ramps, 


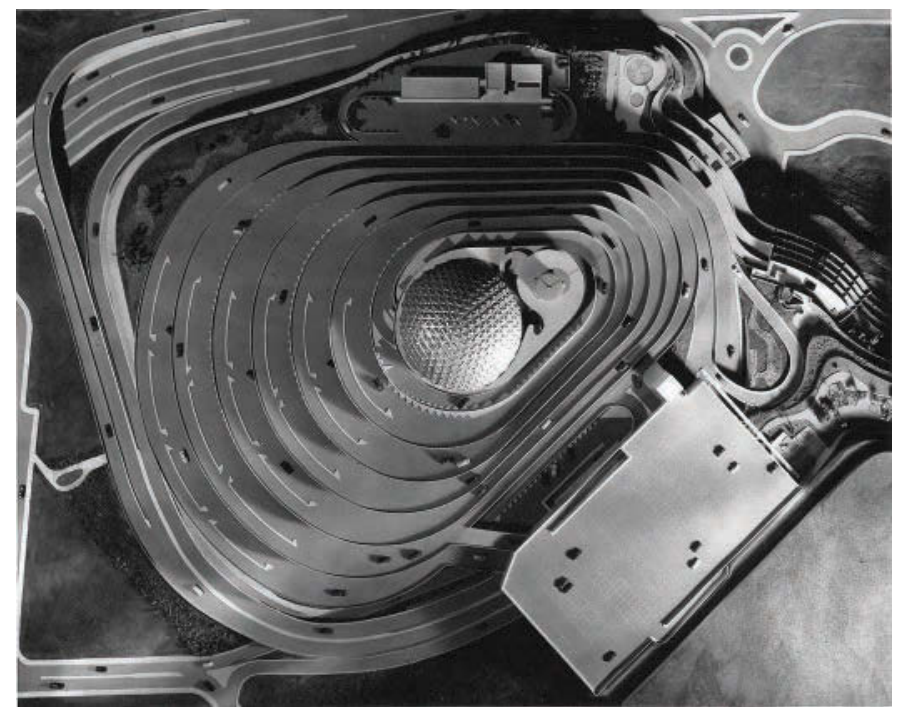

Figure 2.3 One of the models of the original 1956 project. Courtesy of PROYECTO HELICOIDE/Archivo Bornhorst.

which were meant to provide on-the-spot access to El Helicoide's retail businesses, combining two major elements of the 'American way of life': highway transportation and shopping centers.

Venezuela's oil industry was entering its golden age, and the country was eager to join the fast industrial modernity led by its northern neighbor. Combining the latter's pragmatism with Latin American extravagance, El Helicoide's futuristic design was so striking that the photos of its model were published worldwide and the building became the star of MoMA's 1961 show 'Roads'. As Roads' curators, Bernard Rudofsky and Arthur Drexler, state in the show's presentation: 'It is worth noting that this adventurous enterprise has been undertaken in Latin America rather than in the USA, where both highways and shopping centers are among our most ambitious efforts' (qtd. in Bornhorst, 2007, p. 26).

International fame notwithstanding, El Helicoide fell prey to political and financial disruptions and was never completed. Decades of abandon, failed projects, and informal occupations ensued. Originally a private initiative, the Venezuelan State took over the building in 1975 and ten years later gave the Venezuelan intelligence police a temporary permit to use it. Since 1985, El Helicoide has been a center of police training and political imprisonment, a penal character that has only increased with time, since the police presence there multiplied in the last decade, making this oppressive body El Helicoide's longest occupant. ${ }^{2}$ Ironically, the gradual transformation of the building into a disciplinary 
center has been largely ignored by the general public: One of the most striking aspects of El Helicoide is how invisible this monumental building is at the local and national levels, despite or maybe precisely because of its tortuous character. ${ }^{3}$ Until recently, few knew or remembered what this enormous structure was originally meant to be and how it has been used during the last thirty years.

In 2014, however, the building's occupation by different national security forces was thrown into public light by the brutal governmental repression of that year's student protests, when hundreds of students were taken to El Helicoide, where many are still being held two years later. Still, 'El Helicoide' usually appears in the national news only as a name, or at most as the entrance to a disturbing place. Rarely shown, the building, as a visual artifact, is dissociated from its use. Quite literally Caracas's white elephant in the corner, the structure that Time magazine dubbed an enormous 'stack of flying saucers' ('Art: Shapes of the Future', 1957, p. 90) managed to remain alive in people's minds during the first twenty years after its construction was paralyzed. Yet after many failed private and public recovery projects, and once police intelligence settled in the building's two lower levels in 1985, El Helicoide started fading out of the city's imaginary, a fate all too common for many monumental modern projects that either did not make it or whose grandeur fell out of step with their time. Always moving forward, modernity is unforgiving toward its own legacy, which it can leave behind without a second thought.

For most citizens of Caracas, El Helicoide is yet another fantastic project gone awry, and there is no point in recovering it from oblivion. This public dismissal is furthered by the enormous expansion of the barrios, or shantytowns, that surround the building. Housing the densely populated communities of San Agustín del Sur and San Pedro, the barrios around El Helicoide, among the oldest and nowadays most dangerous in Caracas, have grown in the same proportion as the building has faded. Contrary to popular belief, these barrios were not fully developed when El Helicoide was built, but they had been in formation since the mid1800 s, housing the rural migration from the interior of the country to the capital (Marrero, 2012). In this sense, the area is emblematic of the modern exodus to capital cities.

Morphing with the barrios' informal architecture, El Helicoide appears as a continuation of those irregular structures haphazardly made with bricks and tin roofs that hang from the hills in multiple levels, each floor built by a different generation. Conceived for temporary transit, the barrios have risen and surrounded the structure in the last six decades. Their architectural eclecticism contrasts with El Helicoide's solid curves, yet simultaneously blends with the building's raw concrete exterior and arbitrary furnishings, creating an extremely textural, topographical continuum. The building and the barrios act as inverted mirror images of one another, with the shanties reflecting El Helicoide's never-ending downward spiral. 


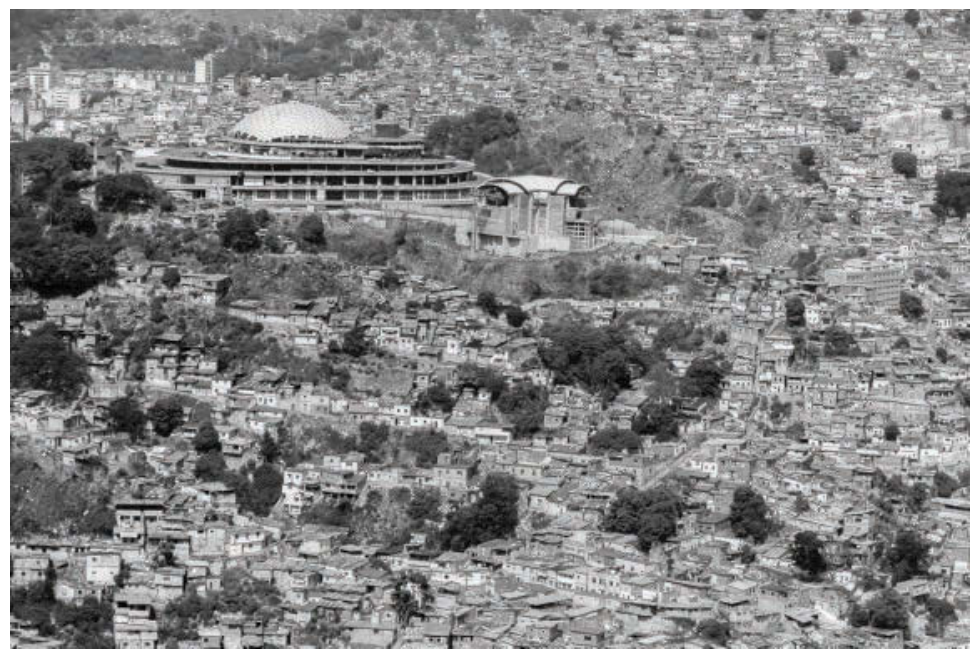

Figure 2.4 El Helicoide surrounded by barrios. Photograph by Julio César Mesa.

El Helicoide is the quintessential modern ruin. Built as a wish image, a spiral ascending to consumer heaven, it experienced a rapid demise that quickly transformed it into a dialectical image, displaying some of the main problems of a drastic modernization: a disproportioned commercial ambition with little or no concern for its impact on the surrounding communities, and a desire to conquer time through the taming of space in the reshaping of nature. Few places in the world portray such a frontal, dramatic contrast as El Helicoide and its neighbors. Together they form an extraordinary emblem of modernity's utopian dreams and their dystopian reality.

Despite their enormous disparities, El Helicoide and the barrios are both victims of an unbridled modernity that makes them equally invisible to the rest of the city. It is as if the building's contiguity to the shantytowns homogenized them, establishing a metonymical chain of ruination that goes from architectural and social failure to decay and finally trash. Despite their closeness, El Helicoide and the communities of San Agustín del Sur and San Pedro barely communicate, relating to each other as a fortress to its surrounding town, except that this particular fortress, rather than protect, towers threateningly over its neighbors from the heights of a hi-tech police surveillance system.

El Helicoide's failure and the rise of the shantytowns take the dialectical image one degree further, since this modern ruin is only partially abandoned, or rather half-occupied, making it a 'living ruin'4 that reproduces the reasons and consequences of its tragic destiny: discontinuity, abandonment, indifference. Whatever the many reasons for its ongoing 
fiasco, El Helicoide was broken from the very onset, a fate it shares with the Tower of Babel, one of its architectural inspirations. Legend and reality intertwine continually in El Helicoide, as if to make clear that things, no matter how modern or innovative, are bound up with the history that precedes them. ${ }^{5}$

As a leftover from Venezuela's impressive 1950s and 1960s modernist thrust, El Helicoide is a cultural residue, a material memory of what should have been but never was. It belongs to an architectural legacy that succumbed to a similar destiny, as is the case of the Universidad Central de Venezuela, whose main campus, located in the heart of Caracas, is a gem of modernist architecture that was declared World Heritage by the UNESCO in 2000, yet lies in sad disrepair. That bountiful moment of the city's wholesale modernization was forgotten, not only for political reasons, but mainly because Venezuela suffers from the modern malaise of instantaneous gratification, for which continuity and maintenance are secondary. What matters instead is the need to move on as if there were no tomorrow, or rather, as if tomorrow were all there is-the exact opposite of memory.

\section{Cultural Ruins: Residual, Leftover, and Abject}

I would now like to outline a tentative chronology of what might be called 'ruinous' concepts-fragments, residues, leftovers-in contemporary cultural theory. The almost simultaneous emergence of these concepts in different disciplines during the twentieth century indicates their relevance for a new understanding of the relationship between time, memory, and materiality. This phenomenon may be understood as the consequence of the vertiginous rise and fall of modern dreams and their wake of war-ravaged, industrially obliterated, and/or abandoned cities, as well as of an unprecedented production of short-span objects and ever-changing spatial arrangements.

While Benjamin was the first to apply the category of ruins-until then reserved to classical monuments, whether real or imaginary-to a modern urban setting, the idea of ruins as cultural traces rather than remains of bygone times derives from a discipline that marked the nineteenth century: archaeology, the science of discovering buried things. In turn, archaeology inspired what became one of the great human sciences of the modern era, psychoanalysis, the art of revealing hidden meanings. Sigmund Freud, a great collector and reader of archaeology, must be thanked once and over again for presenting the human mind as a repository of memories that are recycled ad infinitum.

As witnessed by Benjamin's distinction of two types of memory, the conscious and the unconscious, in 'On Some Motifs in Baudelaire' and 'The Image of Proust', respectively, psychoanalysis underlies his extrapolation of archaeology to modernity. Benjamin's theory of ruins is 
quite literally an archaeology of modern culture, where unrealized or degraded wish images constitute diverse urban layers according to their temporal pertinence or actuality. In short, Freud and Benjamin, two of the twentieth century's most influential Western thinkers, inaugurated with scarcely a few years difference psychological and cultural analyses in which space and time are articulated as active, intertwined agents of meaning: space as a locus or place where meanings materialize (however imaginarily); time as a continuum (however nonlinear or arbitrary) in which such meanings are displaced.

The theory of cultural ruins has its second great exponent in Raymond Williams (1921-1988), who in the late 1970s distinguished between primary and secondary cultural circuits, with their corresponding 'residual' and 'emergent' sensibilities (Williams, 1977, pp. 121-127). ${ }^{6}$ Williams showed how cultural hegemony is not merely a question of domination, but rather a balance, albeit precarious, between the discourses and objects in the foreground of cultural exchange and those that either have not reached this primary circuit or have fallen off it, yet are no less culturally active. He calls the latter 'residual', for they are often considered out of fashion and useless, much like modern ruins. Far beyond a simple repository of past and discarded objects and experiences, cultural residues make up secondary and even tertiary circuits of things that revalidate and re-create objects and meanings that have been excluded from both mainstream and so-called 'high' culture.

These secondary circuits can be extremely alive and also provide multiple discoveries, pleasures, and social subversion, as shown by Tim Edensor (2005), one of the few authors to explore at length the physical, sensorial dimension of modern ruins, which he studies as places of alternative meaning formation. Yet what is more fascinating about residual circuits, I believe, is how the objects they circulate, in their dual capacity as previously 'useless' and now 'recovered', are frequently defined by excess: as 'useless' they are a cultural surplus and have little currency; as 'recovered' their newly found signification is not immediate but rather 'second-degree', as Roland Barthes (1972) would have called it, in their reference to a certain period or style.

Residual objects are excessive in their peculiar combination of past and present, where neither is fully enacted while both are completely at play, feeding off each other in an endless game of mirrors. This excessive quality enables cultural residues to transcend the human subjectivity that reduces them to objects, permitting us to regard them as things instead. In Bill Brown's formulation, 'Temporalized as the before and after of the object, thingness amounts to a latency (the not yet formed or the not yet formable) and to an excess (what remains physically or metaphysically irreducible to objects)' (2001, p. 5). Excess contributes then to the thingness of cultural residues, allowing them to surpass their previous status as objects. 
Whether as not-enough (junk) or as too-much (trash), cultural residues are usually tittering on the edge of downfall. In consistence with our culture's unbridled production and fascination with continuous replacement, even at a symbolic level excess is an overflow of meaning. In excess, meaning transgresses the limits of signification and becomes senseless; therefore, it is highly pleasurable but also threatening to the point of inspiring disgust. As such, the lack of meaning paves the way to its refusal, the abject. Georges Bataille (1991) was one of the first to recognize this cultural ambivalence towards excess, which he proposed as la part mandite, the damned part or 'accursed share': a surplus of cultural energy that must be disposed of so that it does not turn destructively on the society that produced it. However, it is Julia Kristeva who best explains why excess produces such an intense rejection. In Powers of Horror, Kristeva (1982) proposes that the abject is an idealized object that fell out of favor: It is a 'fallen object' where desire turned into rejection. She claims that this experience originates in the excess of maternal fusion, which generates its opposite, a violent craving for detachment.

Inspiring fascination and repulsion, the abject is crucial for understanding why once beloved things are discarded. Like the dialectical image, abjection is not the product of linear or mechanical causeeffect logic, but rather of a culture that is organic and subject to contradictions, ambivalences, and imperfections. In this sense, the abject is intrinsically connected to the last of the ruination concepts I am threading here. It is the Lacanian reste or leftover, the psychic surplus that determines desire. Better known as the objet petit a (Lacan, 2014), the leftover is one of Jacques Lacan's more important and complicated concepts (Olalquiaga, 2008). Briefly, the objet petit $a$ is what remains after human beings have been socialized, that is, after our minds have integrated the Symbolic order (namely, language and the patriarchal authority it represents). This social integration, described by Freud in Civilization and Its Discontents, is far from perfect, and while Freud (1989) sees it as the origin of neuroses (in becoming social we lose touch with our drives and are fated to be walking bundles of nerves), Lacan, who continues and expands Freud's thinking, takes the Symbolic a step further and claims the lack it generates as the root of all desire.

When we are born, according to Lacan, we experience the world around us in a very direct, sensorial way that is not organized in any shape and form. This moment is determined by a fusional maternal relationship, producing an Imaginary situation in which the drives and sexuality are predominant. As we are socialized by our integration into the Symbolic, this fusion is disrupted, suppressing our primal drives, but also psychic dimensions such as the Imaginary. We are then left with a substantial lack, le manque. Desire would be based on this lack that we 
obsessively try to fill during our lives but are doomed never to satisfy, since desire is by definition an unfulfilled condition.

Lacan's manque is the Imaginary that escapes Symbolic organization. That remnant is le reste, the leftover, the objet petit $a$ that represents a reduced maternal alterity (the 'small a') whose enormous Imaginary power determines our unconscious lives. In other words, while desire may be determined by lack, the search for what we do not have, its peculiar configuration (our likes and dislikes) is constituted by excess, that Imaginary yet, for this same reason, extremely potent 'damned part' where Bataille recognized an obscure area that culture is unable to handle.

Lacan's leftover is to the psyche what Williams's residues are to culture. Together the psychic leftover and the cultural residue converge in the Benjaminian ruin, whose abject character materializes as modern decay-whether as Bataille's energy surplus or Kristeva's fallen Other. Far more than simple historical remains, modern ruins represent the devastated landscape of our contemporary cultural unconscious, portraying the failures of modernity's utopian aspirations in their spatial-temporal language. Rugged fragments of fantastic futures, these ruins are usually fetishized as the only palpable remnants of the period that created or rejected them wholesale for presenting this harsh truth unvarnished. In either case, as things they are forgotten, since their worth is measured mainly by the cultural failure they represent, as opposed to by what they are in and of themselves: material remains whose fragmentary and decayed condition is intrinsic to the modern dystopia.

\section{Modernity and Memory}

Memory and modernity are almost antithetical terms. Advocating the dangerous notion of the blank slate, twentieth-century modernity wanted nothing to do with a past whose traditions bogged it down, forcing it to look back when all it wanted was to go forward to that new time called the future. A modern invention issued along with the notion of progress (conceived as a gradual improvement over the past based on industrial development), the idea of the future broke with the cyclical time that characterized Western culture for centuries. Cyclical time is infinite; it is the constant return of the same. As such, it has little place for novelty and change. Modern time, on the other hand, is linear, or so it pretends, moving from the past toward the future with occasional stops in the present (Calinescu, 1987).

El Helicoide is a traumatic memory in a city that specializes in erasing or ignoring all traces of the past. This monumental building changed the cityscape forever, yet its dramatic failure has been repressed so completely that the rest of Caracas is barely aware of its existence, considering it at 
most an eyesore, a painful reminder of a Venezuela that almost made it to the top. And just like repressed memories, El Helicoide's bleak history, which many believe the result of a curse, keeps repeating itself, as if the building was fated to doom.

Failed, incomplete, occupied by armed forces and political prisoners, surrounded by shantytowns, El Helicoide has been left to rot away, a nasty leftover of a splendid impulse, a fallen object. Every so often, El Helicoide is proposed as the symbol of Caracas, whose once prosperous condition concealed a harsh, violent metropolis. Nowadays, the building represents a country divided by its inability to reconcile differences in the name of a common good. A modern Tower of Babel, El Helicoide seems to fulfill the destiny inherent in its mythical referent: a tower made to reach the heavens, whose ambitious builders, condemned to not understand each other, left incomplete. An unwilling tribute to modern vanitas, El Helicoide is the memory of an irregular modernity tucked away in the relative obscurity of those things that are thrown out, but that never cease to taunt us as a reminder not of what was but of what could have been.

Since their appearance in the early twentieth century, modern ruins have troubled both the urban landscape and its imaginary. A cultural paradox and material surplus, these ruins broke with the classic tradition of monumental ruins as historical vestiges (whether real or imaginary, as in the case of the fake ruins of the eighteenth century), inaugurating instead a new category of ruins that occupy a heretofore unknown temporal space: that of a future that became past without going through the present. Furthermore, and against the modernist dictum of straight lines and minimal visual distraction, a rationalistic impulse geared toward the industrial maxim of mechanical efficiency, these ruins literally 'littered' the cityscape with their eroding dreams, shapes, and textures.

Modern ruins are the dark face of modernity's bright moon. In this capacity they materialize all the contradictions of a discourse that had as little place for failure as for a past from which it wanted to rid itself wholesale. Yet these ruins' interest lies not only in how they provide a counterweight to the modern illusion of untainted progress as dialectical images, but, and perhaps more importantly in this early twenty-first century, in how they embody a material dimension that acquires increasing cultural relevance as it becomes secondary in the face of a technological, virtual reality. Modern ruins carry the burden of conveying a physical reality whose rough, gritty, fragmentary, and residual character recalls that organic nature which industrial modernity set out to conquer. This reality now comes back residually in the conceptual and material leftovers of a modernity whose forward thrust attempted, against all odds, to erase the memory of things. 


\section{Notes}

This chapter is one of three dedicated to El Helicoide. The other two are: C. Olalquiaga (forthcoming), 'El Helicoide: Venezuela's Emblematic Downward Spiral', in J. Gosseye, T. Avermaete, and B. de Meulder (eds), Acculturating the Shopping Centre (Hampshire: Ashgate); and C. Olalquiaga (forthcoming), 'El Helicoide and La Roca Tarpeya', in C. Olalquiaga and L. Blackmore (eds), El Helicoide: From Futuristic Mall to Panoptic Prison (New York: Urban Research).

1 Jephcott's translation (see Benjamin, 2008) uses 'outlived' as opposed to 'extinct', which is the way this concept is usually referred to.

2 El Helicoide's two lower levels were assigned to the DISIP (Dirección de los Servicios de Inteligencia y Prevención, now SEBIN, Servicio Bolivariano de Inteligencia Nacional) for fifteen years in 1985, but it remains there to this day. The UNEFA (Universidad Nacional Experimental Politécnica de la Fuerza Armada Bolivariana) has used the middle levels since 2006 and the UNES (Universidad Nacional Experimental Bolivariana de la Seguridad) from 2010 to 2014. The top level, conditioned in 1992 for the Department of Renewable Resources (Ministerio de Recursos Renovables), was turned over to the DISIP's directorate, which shares it with the PNB (Policía Nacional Bolivariana).

3 In an effort to bring El Helicoide and its history back into the public light, I founded the nonprofit organization PROYECTO HELICOIDE in 2013: www.proyectohelicoide.com.

4 The term goes back to the nineteenth century when it was used in travel descriptions, starting with O'Shea's Guide to Spain and Portugal (1868), which saw many editions. See also Lara Eggleton's “"A Living Ruin”: Palace, City, and Landscape in Nineteenth-Century Travel Descriptions of Granada' (2013). My thanks to László Munteán and Lilly Handley for providing these references.

5 For the contradictions of modernity in Venezuela, see Alfredo Coronil (1997).

6 The 1970s witnessed a surge of interest in modern ruins, particularly with Paul Virilio's groundbreaking Bunker Archaeology (1994) and the industrial typologies of the photographers Bernd and Hilla Becher (1970).

\section{References}

'Art: Shapes of the Future' (1957) Time 69.16 (22 April): 90.

Barthes, R. (1972) Mythologies (Trans. A. Lavers) (London: Paladin).

Bataille, G. (1991) The Accursed Share 1 (Trans. R. Hurley) (New York: Zone Books).

Becher, B., and H. Becher. (1970) Anonymous Sculptures: A Typology of Technical Construction (Düsseldorf: Art School).

Benjamin, W. (1968) 'The Work of Art in the Age of Mechanical Reproduction' in Illuminations (Trans. H. Zohn) (New York: Schocken Books). 217-251.

Benjamin, W. (1983/1984) 'Theoretics of Knowledge, Theory of Progress', Philosophical Forum 15 1.2: 1-40.

Benjamin, W. (1999) The Arcades Project, R. Tiedemann (ed) (Trans. H. Eiland and K. McLaughlin) (Cambridge, MA: Harvard University Press). 
Benjamin, W. (2008) 'Dream Kitsch' in M. W. Jennings et al. (eds) The Work of Art in the Age of Its Technological Reproducibility, and Other Writings on Media (Trans. E. Jephcott et al.) (Cambridge, MA: Harvard University Press). 236-239.

Bornhorst, D. (2007) El Helicoide (Caracas: Oscar Todtmann).

Boym, S. (2010) 'Ruins of the Avant-Garde: From Tatlin's Tower to Paper Architecture' in J. Hell and A. Schönle (eds) Ruins of Modernity (Durham, NC: Duke University Press). 58-85.

Brown, B. (2001) 'Thing Theory', Critical Inquiry 28.1 (Autumn): 1-22.

Bruno, G. (2014) Surface: Matters of Aesthetics, Materiality, and Media (Chicago: The University of Chicago Press).

Buck-Morss, S. (1989) The Dialectics of Seeing: Walter Benjamin and the Arcades Project (Cambridge, MA: The MIT Press).

Cairns, J., and J. Jacobs (2014) Buildings Must Die: A Perverse View of Architecture (Cambridge, MA: The MIT Press).

Calinescu, M. (1987) Five Faces of Modernity (Durham, NC: Duke University Press).

Coronil, A. (1997) The Magical State: Nature, Money and Modernity in Venezuela. (Chicago: The University of Chicago Press).

Dillon, B. (2011) Ruins (London: Whitechapel Gallery; Cambridge, MA: The MIT Press).

Edensor, T. (2005) Industrial Ruins (Oxford: Berg).

Eggleton, L. (2013) “"A Living Ruin”: Palace, City, and Landscape in Nineteenth-Century Travel Descriptions of Granada', Architectural Theory Review 18.3: 372-387.

Freud, S. (1989) Civilization and its Discontents (Trans. J. Strachey) (New York: Norton and Co.).

Hell, J., and A. Schönle (2010) Ruins of Modernity (Durham, NC: Duke University Press).

Kristeva, J. (1982 [1980]) Powers of Horror (Trans. L. S. Roudiez) (New York: Columbia University Press).

Lacan, J. (2014) Anxiety: The Seminar of Jacques Lacan, Book X, J. A. Miller (ed.) (Trans. A. R. Price) (Cambridge: Polity Press).

Marrero, A. (2012) San Agustín: Seguimos Pecando, Seguimos Creando (Caracas: Fundarte).

Olalquiaga, C. (1992) Megalopolis: Contemporary Cultural Sensibilities (Minneapolis: University of Minnesota Press).

Olalquiaga, C. (1998) The Artificial Kingdom: A Treasury of the Kitsch Experience (New York: Pantheon Books).

Olalquiaga, C. (2002) 'Look but Don't Touch: The Role of Tactility in an Era of Visual Excess' in Trevor Gould: Posing for the Public: The World as Exhibition (Hamilton, Canada: Art Gallery of Hamilton/Musée d'Art Contemporain de Montréal). 83-99.

Olalquiaga, C. (2003) 'The Trash of History: Modern Ruins in a Virtual Age', StadtBauwelt 48: 24-35.

Olalquiaga, C. (2008) 'Dead Stock: The Researcher as Collector of Failed Goods' in M. A. Holly and M. Smith (eds) What Is Research in the Visual Arts? Obsession, Archive, Encounter (New Haven, CT: Yale University Press). 33-46. 


\section{Celeste Olalquiaga}

Olalquiaga, C. (2013/2014) 'Tropical Babel' in Cabinet 52: 50-55.

O’Shea, Henry (1868) O’Shea's Guide to Spain and Portugal (4th ed.) J. Lomas (ed) (Edinburgh: Adam and Charles Black).

Trigg, D. (2006) The Aesthetics of Decay (Ann Arbor: University of Michigan Press).

Villota Peña, J. (forthcoming) 'Reshaping the Hill: from Sugarloaf Mountain to the Tarpeian Rock' in C. Olalquiaga and L. Blackmore (eds) El Helicoide: From Futuristic Mall to Panoptic Prison (New York: Urban Research Press).

Virilio, P. (1994) Bunker Archaeology (Trans. G. Collins) (New York: Princeton Architectural Press).

Williams, R. (1977) Marxism and Literature (Oxford: Oxford University Press). 


\title{
3 Souvenirs and Memory Manipulation in the Roman Empire
}

\author{
The Glass Flasks of Ancient \\ Pozzuoli
}

Maggie L. Popkin

\section{Introduction}

Souvenirs are a commonplace of contemporary life in many parts of the world. Who among us does not have a postcard, a snow globe, or some other keepsake to remind us of our travels? Such souvenirs-literally 'things to remember'- have fascinated scholars who study contemporary phenomena such as globalization, consumerism, modern tourism industries, museum displays, and postcolonial dynamics (Hitchcock and Teague, 2000; Cave, Jolliffe, and Baum, 2013). At the same time, there has been a tendency to universalize the phenomenon of souvenirs- to suggest, implicitly or explicitly, that souvenirs, no matter where or when they exist, capture a fleeting experience and eternalize it as something extraordinary (Gordon, 1986; Swanson and Timothy, 2012). Yet souvenirs, like all objects of material culture, are products of specific cultural and historical contexts, and while similarities might exist between souvenirs from different times and places, we must seek in souvenirs the historical and the particular rather than only the universal.

In this chapter, I provide an example of what might be accomplished by historicizing souvenirs. I take as my case study a series of stunning glass vases produced in the Roman city of Puteoli (modern Pozzuoli) on the Bay of Naples in the late third and early fourth centuries CE and sold to tourists as souvenirs.

The glass vessels from Puteoli have been treated almost exclusively as evidence for identifying archaeological remains in Pozzuoli (Painter, 1975; Ostrow, 1979; Künzl, 1990), but they raise a host of fascinating questions for students of material culture and memory. Specifically, by examining these vases, I hope to show how powerfully these Roman souvenirs manipulated the ways in which people in antiquity remembered the city of Puteoli. They do not record the city and its monuments 'as they were', despite this common interpretation by archaeologists. Rather, these glass flasks were active agents in constructing Puteoli's self-presentation 


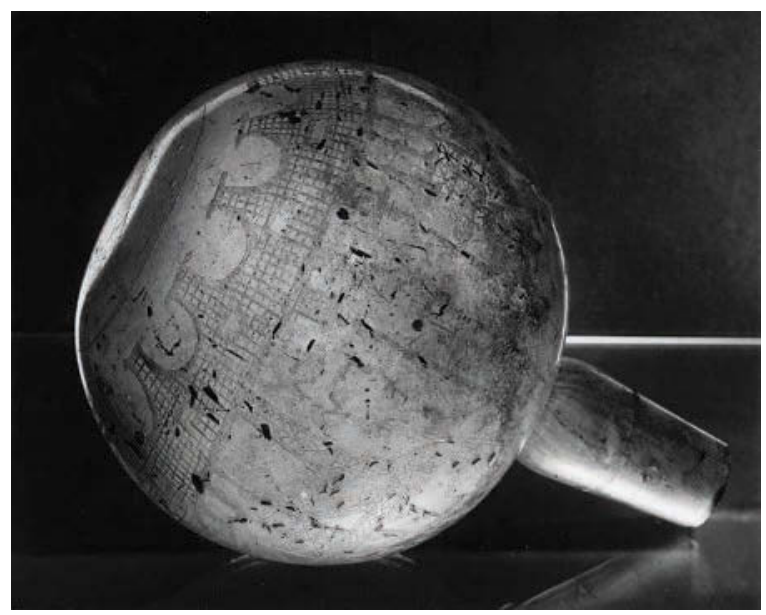

Figure 3.1 Prague Vase in the Collection of the National Museum, Prague, Czech Republic, inventory number 137. Photograph: National Museum, Prague, reproduced with permission.

to the Roman world; they thus exemplify the extraordinary potential of souvenirs to shape how ancient Romans remembered places.

As Susan Stewart (1999) has suggested in her theory of the souvenir, souvenirs are a particularly potent kind of visual image for manipulating memories. Souvenirs invite their owners to generate narratives evoked by the object itself, and they can thus have a greater impact on the memory of the site or event depicted than the actual site or event itself. As Celeste Olalquiaga (1998) has reiterated in her theory of the souvenir, the souvenir can become the primary source of memory rather than the original place visited or event experienced by its owner. The materiality of the souvenir therefore becomes essential in its ability to generate narrative and memory; it is people's sensory interactions with the physical object that make souvenirs such powerful generators of memory. Souvenirs' reliance on narrative, conveyed through material means, to complete their meaning is critical to understanding their social function, as we will see with the glass flasks from Puteoli. As Aleida Assmann (2008) has argued, when we embody our memories in the form of a narrative, we enable ourselves to share them with others, to transform an individual, autobiographical memory into a collective one.

The goal of this chapter is to explore how theories of the souvenir and of collective memory, such as those of Stewart, Olalquiaga, and Assmann, can help us understand the glass flasks of Puteoli as souvenirs-to understand why they were made, why they depict certain images of the city and not others, and how their materiality and image-bearing qualities impacted how people in the Roman Empire remembered Puteoli. 
I address these important questions and argue that these souvenir flasks present a carefully curated view of what Puteolans thought a tourist should remember about their city: that it enjoyed a special, favored relationship with the Roman emperors themselves, a relationship made evident in the city's many buildings that imitated famous imperial monuments in the capital city and that, when depicted on the souvenir vessels, redounded gloriously on Puteoli and its inhabitants.

\section{The City of Puteoli: History and Monumental Appearance}

Puteoli was founded as a Roman maritime colony in 194 BCE (Livy, 1936, p. 243) and quickly established itself as the economic and commercial giant in the region: Italy's premier port. Puteoli enjoyed a privileged relationship with Rome in the imperial period, gaining coveted colonial status under several emperors: first Augustus (Zevi, 2003), then Nero (Tacitus, 1937, p. 151; Cooley, 2012), and finally Vespasian (Tacitus, 1925, p. 425). Well into the second century CE and beyond, Puteoli flourished as a site of commerce and manufacture. Puteoli also had a robust tourist industry, located as it was on the beautiful Campanian coast, right by the celebrated resort of Baiae (modern Baia) (D'Arms, 1974; Jaschke, 2010).

The monumental remains of Puteoli demonstrate its status as a wealthy, flourishing city (Zevi and Jodice, 1993; Crimaco, Gialanella, and Zevi, 2003; Gialanella, 2012). The city has a well-known macellum (market) and a stadium, which is quite rare in Roman Italy; the only other cities in Italy known to have stadia are Naples and Rome itself. Puteoli is one of only a few cities in Roman Italy to possess two amphitheaters, a rare republican example and a monumental Flavian amphitheater that imitates the Colosseum, though on a somewhat smaller scale. It also is home to a remarkably well-preserved marble, Corinthian temple of Augustan date, encased in the cathedral of San Procolo on the city's acropolis. The temple's identification is controversial, with some identifying it as the city's Capitolium, or civic temple (Zevi and Manasse, 2005), and others as a temple to Augustus (McKay, 1972; Künzl, 1990). In either instance, it was a monument to the favor shown the city by Augustus, either by honoring the cult of the emperor or by commemorating the city's new status as a colony of Augustus.

In short, many of the city's most prominent imperial monuments imitated monuments in the capital city or honored individual emperors. The Augustan temple honored the emperor who had first made Puteoli an imperial colony or commemorated Augustus's generosity to Puteoli. The macellum reproduces on a smaller scale Rome's macellum magnum ('great market'), built by Nero, who refounded Puteoli as a colony in his name (De Ruyt, 1977). The large amphitheater and the stadium emulate the Colosseum and the Stadium of Domitian in Rome, both projects of the Flavian dynasts under whom Puteoli once again received an imperial 
colonial title. Puteolans clearly prided themselves on their close relationship with Rome and their favored status with the emperors, and they built in a manner that concretized this relationship for all to see.

\section{The Engraved Glass Flasks of Puteoli}

The buildings themselves were not the only way in which Puteoli broadcast its special, favored status with Rome. The glass flasks engraved with Puteoli's cityscape were another critical means for the city to advertise its desired image long after the monuments in question had already been built. We know of at least thirteen surviving vases produced in Puteoli that depict the city and neighboring Baiae; of these, seven depict Puteoli. The locations where they have been discovered are diverse, including Italy, Spain, Germany, and North Africa (Painter, 1975; Ostrow, 1979; Künzl, 1990; Roffia, 2002; Tafalla, Palomar, and Peralta, 2003; Bejarano Osorio, 2005; Fujii, 2009). The best-preserved flasks depicting Puteoli are the Prague and Pilkington flasks, named after the museums in which they now reside, and a flask recently excavated in Mérida, Spain (Bejarano Osorio, 2005).



Figure 3.2 Drawing of the scene of Puteoli engraved on the Prague Vase in the Collection of the National Museum, Prague, Czech Republic, inventory number 137. Drawing: National Museum, Prague, reproduced with permission.



Figure 3.3 Drawing of the scene of Puteoli engraved on the Pilkington Vase in the Pilkington Glass Collection, the World of Glass, St. Helens, United Kingdom, inventory number SAHGM.1974.002. Drawing by Maggie L. Popkin. 


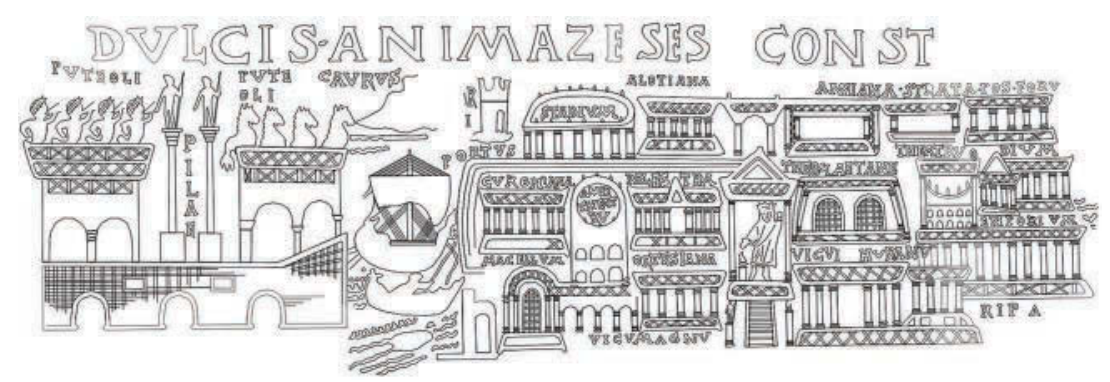

Figure 3.4 Reconstruction drawing of the Mérida Vase following the parameters known from other surviving vases, Consorcio Ciudad Monumental de Mérida, Spain. Drawing by Ana María Bejarano Osorio, 2005, reproduced with permission.

The vases show the cityscape of Puteoli seen from the city's harbor. All three vases prominently feature the great harbor mole, topped by arches and columns surmounted by statues. The vases also depict two amphitheaters and a theater, and the stadium appears on the Prague and Mérida vases. A large temple appears conspicuously on all three vases, its columns framing the male cult statue. The identification of the temple on the vases is as controversial as the identification of the actual marble temple in San Procolo, but the common interpretation of the temple as belonging to the Egyptian god Serapis (Ostrow, 1979) is highly problematic (Picard, 1959). The figure's drapery resembles a toga, and the headpiece looks like a radiate crown. Neither would be expected for a depiction of Serapis, but both would fit well with depictions of Augustus after his posthumous deification. If the temple on the flasks depicts the marble temple on the acropolis, then the vases intend to show a temple in some way honoring Augustus, who elevated the status of the city by making it an imperial colony.

Scholars almost always treat the flasks in question as documents of Puteoli's topography that can help identify monuments in the city. An inscription of $S O L A R I V(m)$ makes scholars search for a solarium among Pozzuoli's unidentified remains. An inscription $\operatorname{ISIV}(m)$ makes them search for a shrine to the goddess Isis. Scholars even take the layout of the inscriptions to be topographically documentary; thus, the Iseum is sought close to the water because it appears near the harbor mole on the Prague Vase (an approach typified by Ostrow, 1979). The glass vases are unquestionably of interest for the study of Puteolan topography, but they are schematic in fashion and take architectural and topographical liberties that one sees as well on Roman historical relief sculptures and coins. Most important, such an approach ignores questions of why these flasks were produced and why they were decorated with these images. Surely, 
the glassmakers of Puteoli were not etching these flasks to provide topographical evidence for future archaeologists. Instead, we should consider these flasks not simply as topographical documents, but rather as what they were intended to be: souvenirs sold to travelers, who would bring them back home with them. By doing so, we can ask questions, addressed below, about how these objects were intended to shape memories of Puteoli rather than faithfully reproduce the city's topographical and monumental appearance.

Travel and tourism were widespread in the Roman Empire (Casson, 1994). Puteoli was a bustling port, but it was also a tourist destination with a resort-like shore that attracted vacationers. Puteoli would thus have been doubly busy with travelers, some there for business, some for pleasure, some, one imagines, for both. At sites tourists frequented in the Roman world, from Athens to Alexandria to Ephesus, souvenirs were a common feature, as ancient literary sources and archaeological finds attest (Casson, 1994). Given that Puteoli was one of these heavily frequented sites, it is hardly unexpected that it should have produced souvenirs.

Further supporting the identification of the glass flasks as souvenirs are the inscriptions some bear on their upper sections, above the engraved images. We see on the Prague vase, for example: felix pie zesaes cum tuis, meaning 'fortunate one, drink, may you live with your (loved ones)' (translation by Cooley, 2012, p. 109). These inscriptions seem to have been added at the behest of the individual consumer (Picard, 1959; Roffia, 2002; Bejarano Osorio, 2005). They represent a personalization of the souvenir vases. John Frow has argued that tourist photography serves 'as witness, as commemoration' and that 'it performs the crucial task of establishing the concordance of an empirical and personally experienced reality with an ideal pattern' (Frow, 1997, p. 93). The inscriptions on the glass vases from Puteoli likewise attest that the purchaser has witnessed the sites of Puteoli and that the images on the vases represent the purchaser's personal experience, not just an artist's schematized vision of the port city. The personalization authenticates both the experience and the souvenir that recalls the experience.

Unfortunately, there is very little specific information available about the people involved in the production and consumption of souvenirs in antiquity: who made them, who sold them, who bought them. Sales receipts, store inventories, and interviews with merchants and tourists are unavailable to students of Roman souvenirs. It is impossible to say who exactly bought these vases. We know that many of them ended up in graves, which is how they managed to survive to the present day. This has led some scholars to insist that the vases had an exclusively funerary function (Cooley, 2012). Many objects used for other purposes during a person's lifetime, however, were subsequently repurposed for funerary use. Scholars do not assume that all Greek vases were exclusively 
funerary simply because many of them have survived in graves. ${ }^{1}$ As Arjun Appadurai (1986) and Igor Kopytoff (1986) have shown, objects have evolving biographies and can shift functions and meanings over the course of their 'lives'. A thing can start out as a commodity and end up as a family heirloom, for example. The glass vases from Puteoli were purchased as commodities but then transformed into souvenirs with greater sentimental value and, ultimately, into grave goods in some cases. The complexities of their biographies, however, do not change the fact that they spent parts of their 'lives' as souvenirs. ${ }^{2}$

An additional complication is that there is no way of knowing whether the flasks' original owners were the people with whom they were buried. Not all of these vases have been properly excavated, which means scholars often lack precise information about the contexts in which they were found. The vase said to have been found in a tomb at Ampurias in Spain was allegedly found with various gold objects, suggesting that the flask's owner was of an upper socioeconomic level (Tafalla, Palomar, and Peralta, 2003). We know that Puteoli was a cosmopolitan city, with a large international population. Merchants and businessmen from around the Mediterranean and beyond came and went, and visitors also came to the Gulf of Pozzuoli for its coastal resort amenities. All these people would have been candidates to purchase these glass souvenir flasks and to bring them home to areas as far ranging as Northern Europe and Northern Africa. Again, we cannot answer all the questions Kopytoff (1986) proposes for the biography of a thing, such as who precisely made it, who purchased it, and who owned it throughout its 'life'. Yet we can hypothesize that the purchasers of the glass flasks were engaged in what they would have considered the purchase of luxury goods as defined by Appadurai: 'goods whose principal use is rhetorical and social, goods that are simply incarnated signs' (1986, p. 38, emphases in original). That is, the purchasers acquired these souvenir vases to mediate between personal experience, power relations, and social status in Roman society.

\section{The Glass Flasks and the Creation of Memory and Metropolitan Identity}

The glass flasks of Puteoli represent surviving examples of an originally much larger series of vases produced as souvenirs - that is, as objects designed for sale to people who had traveled to Puteoli for pleasure or for business (or both) and who wanted a memento of the seaside city to bring back home, where they presumably would show the vases to other people, many of whom had never visited Puteoli themselves. The flasks provided a unique opportunity for Puteoli to self-fashion an identity, literally to create an image of itself that would come to represent the city abroad. They actively constructed and manipulated how people would remember the city of Puteoli. 


\section{Maggie L. Popkin}

Cognitive research has demonstrated repeatedly the extent to which human remembering is a (re)constructive process (Schacter, 1996; Loftus, 2005). Each time we recall a memory, the act of recollection changes that memory; as a result, our memories exist in a constant state of transformation, reacting to our present circumstances and external stimuli. Visual stimuli, such as representational images, are particularly effective at manipulating and even creating memories in people's minds. Researchers have discovered, for example, that showing photographs of an event to a subject can make that person believe he or she was at the event, even if this is not true (Wade, Garry, Read, and Lindsay, 2002; Lindsay, Hagen, Reed, Wade, and Garry, 2004; Morris, Laney, Bernstein, and Loftus, 2006). Human memory is so easily manipulated that people can generate false memories of people, places, and events they never met, visited, or experienced (Schacter and Addis, 2007; see Landsberg, 2004 for an analysis of this phenomenon in the age of mass media). Yet at the same time visual images can stimulate memories that are distorted or even patently false; repetition of those images can produce 'the illusion of truth' (Zaragoza and Mitchell, 1996, p. 294, emphasis added). This type of subconscious memory manipulation through images is not identical to the concept of memory as performance (Plate and Smelik, 2013), in which the conscious, agent-driven act of remembering brings the past into the present. In souvenirs, the two processes are distinct but intertwined; the act of looking at a souvenir and recalling the narrative it evokes is an example of performative memory, but, at the same time, the material souvenir acts upon the process of remembering and the resulting memories in ways of which the viewer is often unaware. As Bjørnar Olsen argues, objects actively determine how people are able to remember the past in the present (2010, p. 108; see also Jones, 2007). Considering cognitive as well as performative theories of memory reveals this duality of remembering with and through material objects such as souvenirs.

As observed in the chapter's introduction, referring to Stewart's (1999) theory of the souvenir, one sees that souvenirs have even greater power than a generic visual image to manipulate and distort how people remember places and events. According to Stewart, souvenirs as isolated objects exist only partially; a souvenir's existence is completed only when its owner creates a supplementary narrative of the circumstances surrounding its origin. She calls this mental process of completing the souvenir 'the invention of narrative' (1999, p. 135). Because a souvenir demands this invention of a narrative, it invites the creation of a story that correlates less to reality and more to the idea of that reality evoked by the souvenir's image. As Olalquiaga writes, 'the souvenir is unable to bring back anything beyond the immediate perception that triggers the process of remembrance' $(1998$, p. 78$)$. The original place or event fades away, replaced by the perception of the original experience generated by 
the souvenir. Olalquiaga's theory of the souvenir thus echoes Stewart's: an object functions as a souvenir only in the context of the narrative that its owner or viewer constructs around it.

Looking at the souvenir images on the glass flasks would thus have had several effects on how people remembered Puteoli. First, by encouraging the people looking at the souvenir to recall memories of Puteoli, the vases would have made those memories susceptible to transformation because, as stated earlier, the act of recalling a memory changes that memory. Second, each vase would have presented a carefully crafted image of Puteoli that not only prompted people to recall the city but also guided and manipulated what they were to remember when they thought of it. Finally, because souvenirs are intimate objects that are handled, discussed, and looked at frequently, the vases would have presented this manipulated image of Puteoli as increasingly 'true': people would have remembered their manipulated or even false memories with the same conviction as they would have remembered memories of true events (see Zaragoza and Mitchell, 1996). People would have believed in these memories regardless of their basis in any objective reality.

It is important to remember here just how intimate, as objects, the glass souvenirs from Puteoli would have been. Their material-glasswas significant in this regard. By the time the flasks from Puteoli were manufactured, glass was a relatively commonplace material for vessels, and objects could range from the luxurious to the more pedestrian (Matheson, 1980). Regardless of the economic and social value placed on different glass vessels, however, glass in the Roman Empire was a medium typically used for smaller-scale objects, such as tableware, funerary urns, and jewelry. The monumental glass sculptures of a Dale Chihuly would have been entirely foreign to ancient Romans. Glass objects were not meant to be viewed from afar in ancient Rome but rather to be interacted with on a personal, sensory level. Ranging from 11 to 19 centimeters in height, the glass vessels from Puteoli were meant to be touched, to be held, to be passed from hand to hand. Because they were breakable, their handling required additional care and attention. As James Porter argues, paying attention to objects in an aesthetic (that is, sensorial) mode causes them to accrue value: 'aesthetic processes, in their primary function of aesthesis (in their immediate connection to the senses ...), are actually indices of cultural value, and vice versa' (2012, p. 338, emphasis in original). The glass souvenirs from Puteoli would have attracted attention visually and tactilely and would have been aesthetically considered in people's homes; through these processes, they would have accrued much of their cultural value.

Indeed, the sensorial qualities of the souvenir flasks from Puteoli directly contributed to their ability to generate and disperse shared memories about the city they depicted. As Liedeke Plate and Anneke Smelik observe, 'Memories are not only shaped by the social context in which 
they are produced, but also by the material and technological means available to produce and reproduce, store, archive and retrieve them' (2009, p. 2; see also Plate and Smelik, 2013). The flasks' physicality-the glass of which they were made, the bulbous shape into which they were formed, and the scenes and words engraved on their surfaces-mattered. Michael Ann Holly has recently defined materiality 'as the meeting of matter and imagination' (2013, p. 15, emphasis in original). Materiality is the result of the combined medium and message of an object. For the Roman flasks, it was not just the message conveyed through the engraved scenes but instead the combination of that message with the small-format, touchable medium of fragile glass that imbued them with the intimacy-as objects shared with family and friends and handled with great attention - that would have contributed to the spread of their created narratives of memory. By literally embodying invented narratives, the souvenir vases enabled their owners to share the narratives with other people and thus to transform their individual memories of Puteoli into collective ones (see Assmann, 2008). This social aspect of memory is key to the formation of collective memory, even if it is individuals who ultimately do the acts of remembering (Halbwachs, 1980; 1992). Put in Stewart's terms, the glass flasks invited viewers to invent a narrative of their visit to Puteoli, or of their friend or relative's visit to Puteoli, that responded not to Puteoli itself but to the images of Puteoli in the engraved scenes. The souvenirs of Puteoli thus encouraged people to remember the city, create narratives about it, and share those narratives, but they also limited, constricted, and shaped the forms of those personal memories and stories. The depictions of Puteoli on the glass vases could lead a person to remember the city in a certain way, with an image of certain buildings in his or her mind. The reality of the souvenir and its images could supersede the reality of the city itself. This would have been true even for people who had seen Puteoli in person and would likely have been even more true for friends and family of travelers, who may never have laid eyes on the Campanian coast.

The vases thus emerge as material objects that could mediate among the physical city of Puteoli; people's experiences of the city, whether in-person experiences of travelers or vicarious experiences of those who had only heard descriptions of the city; and, ultimately, people's memories of the city. The souvenir flasks from Puteoli are not simply things that exist, inertly, but rather things that perform work on people, as Bill Brown's 'thing theory', among others, postulates (Brown, 2004; see also Jones, 2007; Miller, 2010; Olsen, 2010; Hodder, 2012). As Brown argues, objects can structure and organize people's relationship to and perception of their worlds. The souvenir vases, as things, could actively shape the narrative that people invented and remembered about Puteoli. Thus, they were powerful agents in the construction of how people perceived and knew Puteoli around the ancient Mediterranean. 
Considering the vases as things with agency, to channel Brown, we can ask: What sort of narrative did the glass flasks of Puteoli invite people to invent? How did these flasks present their city to the world? As a miniature Rome: a sort of ode to the capital city, whose splendid monuments, highlighted so carefully on the vases, reflected the enviable status of Puteoli as a favored city of the Roman emperors. Puteoli might no longer have been Rome's preeminent port in the third and fourth centuries, nor was it home to the increasingly peripatetic emperors of the Tetrarchy who made their imperial capitals at far-flung sites such as Trier in Germany and Thessalonica in Greece. But the glass flaskswhich emphasize monuments such as the temple, stadium, and amphitheaters that proclaimed Puteoli's link to various emperors and its status as an imperial colony several times over-curate a view of the city as still close to the emperors and still a leading city of the empire. The images of the city engraved on these souvenir flasks foregrounded what tourists should remember about Puteoli. They also, however, actually affected what people would remember, through the material and memorial interactions people had with them.

That souvenirs can represent tourist sites in particular ways that shape how individuals, and thus society more broadly, remember those sites is not a phenomenon unique to the Roman world. One might think of Pisa, a city that contains many beautiful buildings, including two stunning examples of Italian Romanesque architecture: the Cathedral and the Baptistery. Yet although these two monuments are masterpieces and appear in textbooks of art and architectural history, what monument do people most immediately associate with Pisa? The Leaning Tower, of course. This is true even for people, such as the present author, who are historians of art and architecture and have visited the Cathedral and the Baptistery as well as the Leaning Tower. Why does the Leaning Tower dominate people's memories of Pisa? In no small part because it appears on souvenirs of the city, including miniature replicas, snow globes, and even Christmas ornaments.

In this sense, there are important similarities between the ancient glass flasks and a modern snow globe. Both highlight the monuments of a city deemed most worthy of representation, on portable objects that can enjoy geographically wide-ranging distribution. As the findspots of the glass vases show, they were brought from Puteoli to sites all around the Mediterranean: Rome, Ostia, and Brescia in Italy; Odemira in Portugal; Cologne in Germany; Mérida in Spain; and an unidentified site in North Africa. That certain monuments were deemed representative of the city may be explained by Kevin Lynch's theory of the elements of the image of a city, particularly the element of landmarks (Lynch, 1960). Lynch defines landmarks as singular structures or signs within a city that are recognizable and help people navigate a city. Their defining characteristic is singularity: 'Landmarks become more easily 
identifiable, more likely to be chosen as significant, if they have a clear form; if they contrast with their background; and if there is some prominence of spatial location' (Lynch, 1960, p. 79). In his study of American cities, Lynch found that locals tend to use more intimate, personal landmarks to navigate their city, while newcomers and visitors rely more on large, well-known buildings. The glass flasks from Puteoli emphasize this latter type of landmark. They illustrate the major, public landmarks of the city that any visitor could recognize: the harbor mole and its decorations, the spectacle buildings such as the amphitheaters and theater, and the civic temple.

Moreover, the flasks make these landmarks stand out visually within the overall composition of the engraved scenes. All the landmark buildings just mentioned are architecturally individualized and recognizable, unlike the generic colonnaded buildings that surround them. The temple commemorating Augustus's relationship with the city is shown at an exaggeratedly large scale, highlighting its symbolic importance not just in the composition but also in Puteoli's self-presentation. Landmarks that might be deeply meaningful to a Puteolan native, such as a corner tavern or a friend's house, are absent. The vases' engravings do not seem particularly concerned with recreating a visitor's sensation of moving around the city; they do not represent paths, Lynch's element of a city having to do primarily with movement. Instead, they use major landmarks to make Puteoli imageable-'apparent, legible, or visible', as Lynch would have it $(1960$, p. 10) — to somebody not intimately familiar with the city, such as a tourist or businessman passing through. The flasks focus on monuments not only because they are Puteoli's most recognizable landmarks but also because, as Henri Lefebvre has demonstrated, monuments and monumental space constitute 'a collective mirror' in which individuals can create a group identity - and their sense of belonging to that group (1991, p. 220). The city's monuments are thus ideally suited to project Puteoli's constructed social image as a miniature Rome.

There are, however, critical distinctions between the ancient souvenir vessels and souvenirs produced today. One important difference between the world of the late Roman Empire and our society today is the advent of mass media and digital technologies, and their effect on our ability to access information. As Plate and Smelik note, 'The technologies for remembering, the social and cultural institutions, and the media to which we have recourse for storing, recording and otherwise keeping our memories all equally affect how we remember no less than what is remembered' (2009, p. 4; see also Plate and Smelik, 2013). The differing technologies of memory available in imperial Rome and contemporary American and European societies therefore result in different modes of remembering. Despite the proliferation of souvenirs showing the Leaning Tower of Pisa, many people today can easily hop onto Google to learn about the city's other monuments. For somebody 
with access to the Internet, it is relatively easy to find images of and information about the Baptistery and the Cathedral, not to mention other districts of Pisa. In the Roman world, in contrast, no such instant mass media was available. For some people in Roman Britain, for example, these sorts of souvenir flasks might have been the only way they ever 'saw' Puteoli. Alison Landsberg (2004) has written persuasively about 'prosthetic memory' in the age of mass culture, by which she means memories a person acquires through mass media about historical narratives he or she has not personally experienced. However, while she is correct that mass culture today makes memories more widely available to more diverse groups of people, she does not fully acknowledge that contemporary mass culture simultaneously makes 'prosthetic' memories more subject to fact checking. The effect of the ancient Roman images - their ability to shape memories of Puteoli and to create what Andreas Huyssen terms 'imagined memories', or memories grounded not in lived experience but from archival material, as it were (Huyssen, 2003) — would arguably have been more powerful in antiquity than today because supplementary or mitigating information would have been much harder to come by.

Another historical distinction between the glass flasks from Puteoli and modern snow globes or other trinkets is the value that their owners evidently placed on them. The Puteoli flasks are not the most luxurious goods made of gold or silver, but the fact that many of them were discovered in graves suggests that they held a significant status in the Roman world. Their owners valued them enough either to take them to their graves, literally, or to pass them down to others who then were buried with them. It is difficult to imagine somebody mounting a snow globe from Pisa on his or her gravestone. In fact, some studies suggest that souvenirs today diminish in importance to their owners over time, as photographs become more and more important for commemorating past experiences and as people travel more often and collect an increasing number of souvenirs (Collins-Kreiner and Zins, 2013). In contrast, the souvenir vases from Puteoli seem not to have diminished in importance over time. This is perhaps not surprising because, after all, photographs did not exist in antiquity, and travel was more difficult and thus less frequent than it is today. That people took the glass flasks to their graves indicates that, if anything, they increased or at the very least maintained their value over the course of their owners' lives. They were not throwaway objects, and they thus illustrate well Appadurai's (1986) and Kopytoff's (1986) concept of the 'social lives of things'. Scholars do not have the ancient literary and archaeological data to reconstruct the trajectory, as Appadurai terms it, of any individual surviving vase from Puteoli. Nonetheless, one can formulate a sound hypothesis about the transformations in the vases' use over time: they began their lives as commodities. Some may have been transformed into gifts. All, it seems, 
served for some time as souvenirs. They may have become family heirlooms, possibly passed down to future generations. And at least some of them ended their ancient lives as grave goods-objects valued sufficiently to accompany their owners to the afterlife.

\section{Conclusion}

Along with other souvenirs produced around the Roman world (see Künzl and Koeppel, 2002), the glass flasks from Puteoli stand as evidence of a souvenir culture, as it were, in the Roman world. As this chapter has demonstrated, souvenirs were a primary and effective means of manipulating memories of cities and thus of constructing and disseminating metropolitan identities in the ancient world, as they remain today. My exploration of the glass vessels from Puteoli and their engraved cityscapes suggests that souvenirs in the ancient world have much to contribute to our understanding of how cities presented themselves in antiquity. The materiality of the vases from Puteoli, or their combined medium and message, to return to Holly's formulation, played a critical role in their ability to manipulate memories of Puteoli. The small glass vases, which were designed to be held and examined up close, brought viewers into intimate and physical contact-material contact - with the carefully curated self-image of Puteoli as a favored city of Rome's emperors. Their status as things that acted on people, that had agency of their own, resulted in their outsize impact on manipulating how people around the Mediterranean conceived of Puteoli and thus on Puteoli's ability to fashion a metropolitan identity for itself. For some owners of these flasks, the vases might not have been much more than attractive mementos of an attractive place. Others, however, valued the vases highly enough to carry them to their graves. In either event, these flasks were powerful souvenirs, and in the latter case, they also had the potential to transform into family heirlooms, funerary accouterments, or both. Materializing memories, these 'things to remember' from the Roman Empire stand as tangible reminders of the power of souvenirs to act upon memories and perceptions of sites such as Puteoli, in antiquity and beyond.

\section{Notes}

1 For example, Panathenaic prize amphoras-ancient Greek vases produced to hold the olive oil given out as prizes at Athens' Panathenaic Games-have frequently been found in burials around the Mediterranean (Neils, 2001). These vases thus could acquire a secondary function as funerary objects, even though their primary function was not funerary.

2 Not all the glass flasks have been discovered in tombs. For example, a vase depicting Baiae was excavated in Spain in the 1980s in a thermal complex (Tafalla, Palomar, and Peralta, 2003). 


\section{References}

Appadurai, A. (1986) 'Introduction: Commodities and the Politics of Value' in A. Appadurai (ed) The Social Life of Things: Commodities in Cultural Perspective (Cambridge: Cambridge University Press). 3-63.

Assmann, A. (2008) 'Transformations between History and Memory', Social Research 75: 49-72.

Bejarano Osorio, A. M. (2005) 'Una ampulla de vidrio decorado con la planta topográfica de la ciudad de Puteoli', Mérida Excavaciones Arqueológicas 8: 513-532.

Brown, B. (2004) 'Thing Theory' in B. Brown (ed) Things (Chicago: The University of Chicago Press). 1-21.

Casson, L. (1994) Travel in the Ancient World (Baltimore: Johns Hopkins University Press).

Cave, J., L. Jolliffe, and T. Baum (eds) (2013) Tourism and Souvenirs: Glocal Perspectives from the Margins (Bristol, UK: Channel View Publications).

Collins-Kreiner, N., and Y. Zins (2013) 'With the Passing of Time: The Changing Meaning of Souvenirs' in J. Cave, L. Jolliffe, and T. Baum (eds) Tourism and Souvenirs: Glocal Perspectives from the Margins (Bristol, UK: Channel View Publications). 29-39.

Cooley, A. E. (2012) The Cambridge Manual of Latin Epigraphy (Cambridge: Cambridge University Press).

Crimaco, L., C. Gialanella, and F. Zevi (eds) (2003) Da Puteoli a Pozzuoli: Scavi e ricerche sulla rocca del Rione Terra (Naples: Electa).

D'Arms, J. H. (1974) 'Puteoli in the Second Century of the Roman Empire: A Social and Economic Study', Journal of Roman Studies 64: 104-124.

de Ruyt, C. (1977) 'L'importance de Pouzzoles pour l'étude du macellum romain', Puteoli, Studi di Storia Antica 1: 128-139.

Frow, J. (1997) Time and Commodity Culture: Essays in Cultural Theory and Postmodernity (Oxford: Clarendon Press).

Fujii, Y. (2009) 'Report on Four Roman Glass Fragments from the Gorga Collection: Attribution to the "Puteoli-Baiae Group" in K. Janssens, P. Degryse, P. Cosyns, J. Caen, and L. Van't dack (eds) Annales of the 17th Congress of the International Association for the History of Glass 2006, Antwerp (Antwerp: University Press Antwerp). 136-142.

Gialanella, C. (2012) 'Pozzuoli' in H. von Hesberg and P. Zanker (eds) Storia dell'architettura Italiana. Architettura Romana: Le città in Italia (Milan: Electa). 348-359.

Gordon, B. (1986) 'The Souvenir: Messenger of the Extraordinary', Journal of Popular Culture 20: 135-151.

Halbwachs, M. (1980) The Collective Memory (Trans. F. J. Ditter Jr. and V. Y. Ditter) (New York: Harper and Row).

Halbwachs, M. (1992) On Collective Memory (Trans. and ed. L. A. Coser) (Chicago: The University of Chicago Press).

Hitchcock, M., and K. Teague (eds) (2000) Souvenirs: The Material Culture of Tourism (Aldershot: Ashgate).

Hodder, I. (2012) Entangled: An Archaeology of the Relationships between Humans and Things (Malden, MA: Wiley-Blackwell).

Holly, M. A. (2013) 'Notes from the Field: Materiality', Art Bulletin 95: 15-17. 
Huyssen, A. (2003) Present Pasts: Urban Palimpsests and the Politics of Memory (Stanford, CA: Stanford University Press).

Jaschke, K. (2010) Die Wirtschafts- und Sozialgeschichte des antiken Puteoli (Rahdlen: Verlag Marie Leidorf $\mathrm{GmbH}$ ).

Jones, A. (2007) Memory and Material Culture (Cambridge: Cambridge University Press).

Kopytoff, I. (1986) 'The Cultural Biography of Things: Commoditization as Process' in A. Appadurai (ed) The Social Life of Things: Commodities in Cultural Perspective (Cambridge: Cambridge University Press). 64-91.

Künzl, E. (1990) 'Die Glasflasche mit dem Panorama der Stadt Puteoli im Nationalmuseum Prag', Eirene 27: 77-80.

Künzl, E., and G. Koeppel (2002) Souvenirs und Devotionalien: Zeugnisse des geschäftlichen, religiösen und kulturellen Tourismus im antiken Römerreich (Mainz am Rhein: Philipp von Zabern).

Landsberg, A. (2004) Prosthetic Memory: The Transformation of American Remembrance in the Age of Mass Culture (New York: Columbia University Press).

Lefebvre, H. (1991) The Production of Space (Trans. D. Nicholson-Smith) (Oxford: Blackwell).

Lindsay, D. S., L. Hagen, J. D. Reed, K. A. Wade, and M. Garry (2004) 'True Photographs and False Memories', Psychological Science 15: 149-154.

Livy (1936) History of Rome, Books 31-34 (Trans. E. T. Sage) (Cambridge, MA: Harvard University Press).

Loftus, E. F. (2005) 'Planting Misinformation in the Human Mind: A 30-Year Investigation of the Malleability of Memory', Learning and Memory 12: 361-366.

Lynch, K. (1960) The Image of the City (Cambridge, MA: The MIT Press).

Matheson, S. B. (1980) Ancient Glass in the Yale University Art Gallery (New Haven, CT: Yale University Art Gallery).

McKay, A. G. (1972) Naples and Coastal Campania 2, Ancient Campania (Hamilton, Ontario: Cromlech Press).

Miller, D. (2010) Stuff (Cambridge: Polity Press).

Morris, E. K., C. Laney, D. M. Bernstein, and E. F. Loftus (2006) 'Susceptibility to Memory Distortion: How Do We Decide It Has Occurred?', American Journal of Psychology 119: 255-274.

Neils, J. (2001) 'Panathenaics in the West' in M. Bentz and N. Eschbach (eds) Panathenaïka: Symposion zu den Panathenaïschen Preisamphoren, Rauischholzhausen 25.11.-29.11.1998 (Mainz: Philipp von Zabern). 125-130.

Olalquiaga, C. (1998) The Artificial Kingdom: A Treasury of the Kitsch Experience (New York: Pantheon Books).

Olsen, B. (2010) In Defense of Things: Archaeology and the Ontology of Objects (Lanham, MD: AltaMira Press).

Ostrow, S. E. (1979) 'The Topography of Puteoli and Baiae on the Eight Glass Flasks', Puteoli, Studi di Storia Antica 3: 77-140.

Painter, K. S. (1975) 'Roman Flasks with Scenes of Baiae and Puteoli', Journal of Glass Studies 17: 54-67.

Picard, C. (1959) 'Pouzzoles et le paysage portuaire', Latomus 18: 23-51.

Plate, L., and A. Smelik (2009) 'Technologies of Memory in the Arts: An Introduction' in L. Plate and A. Smelik (eds) Technologies of Memory in the Arts (New York: Palgrave Macmillan). 1-12. 
Plate, L., and A. Smelik (2013) 'Performing Memory in Art and Popular Culture: An Introduction' in L. Plate and A. Smelik (eds) Performing Memory in Art and Popular Culture (London and New York: Routledge: Routledge). 1-22.

Porter, J. I. (2012) 'The Value of Aesthetic Value' in J. K. Papadopoulos and G. Urton (eds) The Construction of Value in the Ancient World (Los Angeles: Cotsen Institute of Archaeology, University of California, Los Angeles). 336-353.

Roffia, E. (2002) 'Alcuni vetri incise' in F. Rossi, F. Morandini, and C. Stella (eds) Nuove ricerche sul Capitolium di Brescia: scavi, studi e restauri (Milan: Et). 413-434.

Schacter, D. L. (1996) Searching for Memory: The Brain, the Mind, and the Past (New York: BasicBooks).

Schacter, D. L., and D. R. Addis (2007) 'The Cognitive Neuroscience of Constructive Memory: Remembering the Past and Imagining the Future', Philosophical Transactions: Biological Sciences 362: 773-786.

Stewart, S. (1999) On Longing: Narratives of the Miniature, the Gigantic, the Souvenir, the Collection (Durham, NC: Duke University Press).

Swanson, K. K., and D. J. Timothy (2012) 'Souvenirs: Icons of Meaning, Commercialization and Commoditization’, Tourism Management 33: 489-499.

Tacitus (1925) Histories, Books 1-3 (Trans. C. H. Moore) (Cambridge, MA: Harvard University Press).

Tacitus (1937) Annals, Books 13-16 (Trans. J. Jackson) (Cambridge, MA: Harvard University Press).

Tafalla, M. T. A., M. E. O. Palomar, and J. A. P. Peralta (2003) 'Un "Souvenir" de Baiae en Asturica Augusta (Provincia Tarraconense, Hispania)', Journal of Glass Studies 45: 105-113.

Wade, K. A., M. Garry, J. D. Read, and D. S. Lindsay (2002) 'A Picture Is Worth a Thousand Lies: Using False Photographs to Create False Childhood Memories', Psychonomic Bulletin \& Review 9: 597-603.

Zaragoza, M. S., and K. J. Mitchell (1996) 'Repeated Exposure to Suggestion and the Creation of False Memories', Psychological Science 7: 294-300.

Zevi, F. (2003) 'Il complesso architettonico del Rione Terra a Pozzuoli' in L. Crimaco, C. Gialanella, and F. Zevi (eds) Da Puteoli a Pozzuoli: Scavi e ricerche sulla rocca del Rione Terra (Naples: Electa). 35-49.

Zevi, F., and G. Cavalieri Manasse (2005) 'Il tempio cosiddetto di Augusto a Pozzuoli' in X. Lafon and F. Sauron (eds) Théorie et pratique de l'architecture romaine: la norme et l'expérimentation. Études offertes à Pierre Gros (Aix-en-Provence: Publications de l'Université de Provence). 269-294.

Zevi, F. and M. Jodice (1993) Puteoli (Naples: Banco di Napoli). 
This page intentionally left blank 


\section{Part II}

\section{Entangled Memories}


This page intentionally left blank 


\title{
4 How Memory Comes to Matter
}

\author{
From Social Media to the \\ Internet of Things
}

\section{Elisa Giaccardi and Liedeke Plate}

\section{Introduction}

'The Internet of Things (IoT) ... will change everything-including ourselves' (Evans, 2011, p. 2). Thus opens a recent white paper on the emerging capacity of the Internet to connect objects in the physical world to online databases and enable them to collect and exchange data. This chapter reflects on these developments from a heritage perspective and critically discusses how the Internet of Things has begun to change the complex set of memory practices through which we give meaning to the past in the present and thus shape our image of the future. It contributes a critical account of pioneering heritage work from social media to the Internet of Things, with the goal of helping scholars and practitioners frame and design future technologies of memory. To this end, the chapter first considers the ways in which social media enable ordinary people to participate in the construction of cultural memory through shared online activities of collection, preservation, and interpretation. As discussed in Heritage and Social Media (Giaccardi, 2012), social media encourage a shift in heritage work from the mere safeguarding of material artifacts to the grassroots, human practices through which heritage objects are interpreted and valued-from online practices of remembering together on Facebook to the remix and mash-up of user-generated online content within and beyond the museum exhibit. In this chapter, we expand on this consideration and argue that a participatory approach to memory practice empowers people to an active, creative relationship with heritage objects: 'doing' or 'saying' around the object begins to become more important for human practices of remembering than the object in its straight materiality. ${ }^{1}$ With social media, memory is not just communicated to a 'passive' receiver of information, but is actively constructed and performed through participatory practices of remembering. For digital heritage, traditionally concerned with the digital preservation of material artifacts, this is an important step (Russo, 2012). But it is only the first one. 
We then move to examining how the Internet of Things gives new frontiers to the active, performative relationship between people and memory objects that social media have introduced into digital heritage. Connected to the Internet, a material artifact may know, for example, where it has been and with whom, and have the same knowledge about other artifacts within the same network. Connected artifacts are embedded with software, networked to online databases and cloud services, increasingly equipped with sensors and actuators enabling them to sense and physically act upon their environment, and are operated by algorithms performing data processing and automated reasoning. A classic example in consumer electronics is the 'smart fridge', which sends a notification to its owners' phone informing them about the grocery items they need and their location.

As illustrated by the heritage projects in this chapter-from dancing shoes stickered with memories of the Scottish dancing hall culture to photo printers reminiscing on their own-'doing' and 'saying' around connected artifacts does not just happen online. It happens in the social and environmental setting in which the material artifact is physically encountered, in situations uniquely informed by the shared practice that develops with and through the artifact. In the Internet of Things, these performances are carried out within a socio-material configuration in which memory objects are both tangible because embodied and localized in potentially always new ways, and intangible because embedded with code, instructions, and interaction histories. As memory objects begin to be constituted with code and algorithms, and to remember more about themselves and, likely, about ourselves in ways made easily accessible to ordinary people by data storage, we argue that 'doing' and 'saying' around connected artifacts creates new spaces of remembrance. This new relationship with 'things' is something that we may increasingly have to negotiate, and we believe it is the next step in digital heritage.

The chapter therefore concludes with a theoretical speculation on how shared practices of remembering between humans and nonhumans have the potential to create spaces of remembrance that challenge our anthropocentric understanding of what is 'possible' and 'worthwhile' to remember. Humans have used material artifacts as aide-mémoire and things have functioned as (involuntary) reminders since time immemorial. But as memory objects around us begin to exhibit autonomous forms of agency, to what purpose do they 'remember'? And for whom will they recollect?

\section{Problematizing Materiality in Human Practices of Remembering}

Human practices of remembering are as much about artifacts as they are about performances. This insight was first brought to heritage studies by scholars such as Thomas (2004), Lowenthal (2005), and Byrne (2008). 
Their work helped us to understand how we socially construct heritage in the context of our own lives and imaginations to interact meaningfully with our past and shape our vision of the future. Whether museum artifacts, historic buildings, private memorabilia, scrapbooks, the collective storytelling of historical events, or the enactment and reification of a living connection to land-heritage is not just about preservation; it is about making sense of our past and developing a sense of identity. Moreover, as heritage scholars such as Laurajane Smith in Uses of Heritage (2006) and Susie West in Understanding Heritage in Practice (2010) have shown, heritage is defined more by the cultural work of ordinary people than by official heritage organizations. This fundamental understanding emphasizes that heritage meanings and values are neither inherent nor attached to artifacts, buildings, or sites. Nor are they frozen in time. They are the results of repeated and ongoing interactions in the lived world of ordinary people, emerging from their dealings with artifacts, places, and practices, and thus forming 'chains of connectivity' in which humans and nonhumans are linked and 'work together to keep the past alive in the present for the future' (Harrison, 2013, pp. 4-5).

In the same way, research in digital heritage has moved past concerns of digitization, preservation, and communication only (Van Dijck, 2007). Over the last decade, researchers in the field have started to investigate how to use digital technologies to engage museum visitors in other ways than simply as receivers of information. For example, at the Hunt Museum in Limerick, Ferris et al. (2004) designed a pioneering interactive studio where visitors could explore stories of unknown museum objects and leave their own interpretations. At the Bunratty Folk Park, the same research group invited visitors to move physical artifacts from one place to another and used this mechanism to invite visitors to record and share their comments and reactions in real time (Ciolfi and McLoughlin, 2012). Similarly, for a major exhibition of John Constable's work at Tate Britain, an interface revealed the underlayers of a painting only if multiple visitors stood in front of it, thus fostering a form of collaboration among strangers (Vom Lehn et al., 2007). Fosh et al. (2013) used mobile devices to provoke visitors to look at and actively perform around the sculptures of Rufford Abbey's grounds, with the goal of supporting multiple trajectories of interpretation. And Warpas's design interventions at the Bantock House Museum (Warpas, 2014) used digital technology to animate neglected museum objects, invite children and their families to establish an emotional connection, and develop their own interpretation of the artifacts displayed behind glass.

Social media accelerate this understanding of heritage as cultural work of engagement and interpretation and provide a permanent platform for practicing memory through digital means. As argued in Giaccardi (2011), social media move beyond the 'pause' represented by the fairly 
brief moments of the visit to the museum or heritage site. By fostering mundane activities of collection, preservation, and interpretation of a broad variety of memory objects, social media enable ordinary people to 'arrange and rearrange their interpretations in always new orders of meaning' (Giaccardi, 2011, p. 37), both collectively and in the context of their own lives.

According to Jenkins and colleagues, a participatory culture is one in which 'not every member must contribute, but all must believe they are free to contribute when ready and that what they contribute will be appropriately valued' $(2009$, p. 6). A participatory culture values how engaging socially in creative activities changes the way we think about the others and ourselves. As emphasized in Jenkins, a participatory culture is not just about producing and consuming content; it is also manifested through diverse forms of affiliation, expression, and collaboration. In such a culture, argues Shirky (2008), people feel socially connected to one another, all the time. They also create a sort of 'cognitive surplus' by aggregating their free time and harnessing it for large, collective projects (Shirky, 2010). Of course, participatory cultures are not new. The Amateur Press Association of the middle of the nineteenth century is perhaps one of the most widely known historical examples. However, we are witnessing today a broader and more profound phenomenon, where digital social networks open up the margins of participation to potentially larger and more heterogeneous groups of people.

In digital heritage, we find examples of a growing participatory culture in grassroots, ordinary and everyday online memory practices as well as in museum settings. Digital Natives is an exhibition held at the Aarhus Centre for Contemporary Art in 2010, where social media streams, such as mobile updates, pictures, videos, and music playlists were combined with a participatory design process to let youngsters born with digital technologies represent themselves to future generations. Designed by Iversen and Smith (2012), the exhibition project uses social media to open up the boundaries of the museum visit and help create living connections between the everyday lives of digital natives and their audiences.

Launched in 2010 and initiated by the Danish government, 1001 Stories of Denmark is a similar online platform where people can share online their knowledge and memories of Danish heritage. ${ }^{2}$ The project invites everyone to explore their favorite places in Denmark and share their experiences. People can use the uploaded stories, images, and videos to be inspired by others and create their own travel routes. Another example is the early social media platform Silence of the Lands designed at the University of Colorado at Boulder in 2005 (Giaccardi, 2007), which encouraged local communities to share personal memories and experiences of the natural heritage through the sonic filter, and learn from each other in new and unexpected ways. Similarly, the commemorations organized 
via the Internet to remember the deadly gas leak that took place in a Union Carbide plant in the city of Bhopal, India, in 1984 (Liu, Palen, and Giaccardi, 2011) attempt to forge an historical present where people who did not participate directly in the event attend in their own 'ordinary' time and place to memories of social injustice and mass violence.

As illustrated by these examples, memory is not just communicated to an audience of visitors but is actively constructed and performed by ordinary people, enabling new kinds of 'co-memorations' (Burke, 2010). Social media empower people to forge an active, creative relationship with heritage objects. As a consequence, 'doing' or 'saying' around the object begins to become more important for human practices of remembering than the object per se. Rather than being concerned with the object's materiality and how to preserve it, what matters now are the long, meaningful connections with one another that ordinary people can create in 'ordinary' time and place-that is, in the everyday.

The guerrilla street art project Moving People (2015) by Dutch artists' collective Power of Art House is a dramatic illustration of how these meaningful connections may come about. In the fall of 2015, the artist collective placed 10,010 miniatures of refugees in various public spaces in Amsterdam and The Hague (the project was repeated in Ghent (Belgium) in the spring of 2016). The miniatures are modeled onto the $3 \mathrm{D}$ scans of real refugees, with a web address printed on each of them. The project aims to encourage empathy and strengthen social cohesion. To this end, the miniatures in the street allow those who stumble upon one of them to suddenly encounter the personal memories and stories of the refugee associated with the replica. Miniatures can then be carried to another location, and the experience of such encounters can be shared through social media. ${ }^{3}$ The project focuses on the idea of shared humanity; the miniatures themselves are mere excuses for civic engagement and creative participation: they may be taken home, and if found broken, one can simply repair them (Figure 4.1). Sustaining new civic rituals, Moving People is exemplary of a generation of grassroots, 'bottom-up' practices of remembering together, spread over a multitude of social media platforms and designed around the performance of memories (Plate and Smelik, 2013). Through a socially distributed process of curation of personal accounts, shared images, and shared political actions on Twitter, Facebook, and Instagram, new 'co-memorations' take place and countermemories are created and performed.

\section{Problematizing Agency in Practices of Remembering between Humans and Non-humans}

Now, what happens when even the most mundane objects begin to remember their lives, to speak of where they have been and what they have seen and heard? ${ }^{4}$ What happens when objects, too, begin to 'do' and 


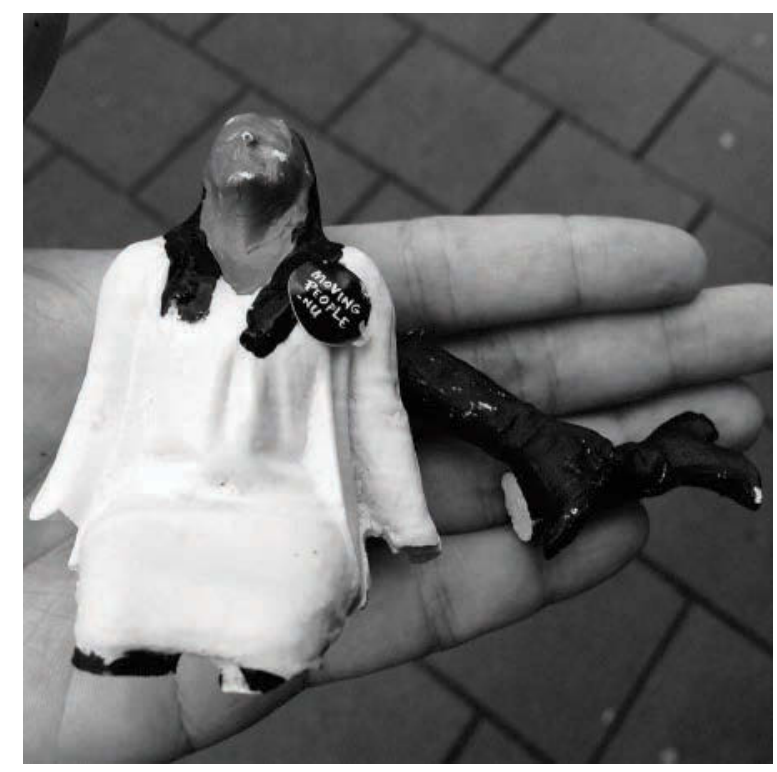

Figure 4.1 Moving People is more about shared humanity than about the materiality of the object. Photograph placed on Facebook by Wing-Ka Chung, 16 September 2015 (https://www.facebook.com/ powerofarthouse).

'say' and to establish connections-perhaps even do so independently? What happens, in other words, when objects begin again to matter (and do not only function as mere material support for human practices of memory)? More than 2 billion people use the Internet today to share data and communicate through different online media (Kende, 2014). Cisco predicts that 50 billion devices will be connected to the Internet by $2020 .^{5}$ Mundane artifacts such as cars, refrigerators, and washing machines but also clothing, shoes, and all sorts of 'wearables' will be a growing portion of the connected devices with and through which we will interact and communicate in the everyday.

Connected to the Internet and able to collect and exchange data, mundane objects become 'things'. The phrase Internet of Things is attributed to the Auto-ID research group at MIT in 1999 (Ashton, 2009) and refers to the emerging technological system of objects and materials that are becoming connected to the Internet. As argued by Richard Coyne (2011) and Tim Ingold (2012), here the 'thing' is not the object in its straight materiality but 'a gathering': specifically, a gathering of data, connections, and interactions to deliberate on an issue that matters. For example, a 'smart fridge' is not simply a physical artifact with reasoning skills. Connected to online databases and operated by algorithms, 
a fridge is a 'thing' that not only sends notifications to your phone but also makes informed judgments and helps you deliberate on what needs to be bought (Kuijer and Giaccardi, 2015).

This paradigm is producing a shift in how material artifacts are valued, interpreted, and operated. Many contemporary material practices across the fields of produce are beginning to develop artifacts with intangible counterparts: from old-fashioned barcodes and instruction manuals to connections to social media sites. In general, the relationship between these two parts-tangible and intangible-is largely passive. So far, many Internet of Things projects have used the Internet connection of artifacts to identify cost saving and process efficiencies (for example, vehicle manufacturers), to track goods within large networks (logistics companies, among other) or to monitor the health and safety of systems (for instance, aircraft manufacturers) within a streamlined process of production. But as connected objects become more common, argue Giaccardi, Speed, Cila, and Caldwell in a critical account of the Internet of Things (2016), the massive amounts of data that they collect will soon outweigh what we know about these objects-and thus about ourselves.

With the Internet of Things, connected objects develop the ability to remember their lives, to speak to humans of where they have been and what they have seen, heard, and experienced. As Chris Speed argues, 'As they [objects] move from one place to the next, they will gather mobility data; as people interact with them, they will gather social data; and even as they sit idly on a shelf, they may well be gathering data about the objects that are around them' (2012a, p. 194). Rather than using things to communicate with other people, then, people will communicate with things and things with people-and with other things. Within this landscape, the ontological distinction between human and nonhuman, and animate and inanimate becomes blurred.

What does this do in relation to memory? As humans devolve more tasks to things, and as human and nonhuman actors mix increasingly (Olsen, 2010; Ingold, 2012; Kuijer and Giaccardi, 2015), what happens to memory and to how 'we' remember? Humans have always used things to help them remember, and these things shape both how and what we remember (see Plate and Smelik, 2009). Plato was already concerned that writing would atrophy the human capacity to remember, and present-day doom-thinkers worry that we have 'been allowed to dedicate much more of our cognitive resources to active RAM than to maintaining our cerebral-storage hard drives' (Rushkoff, 2013, p. 5). Mnemotechnics such as the knot in the handkerchief-by which people sought to remember to remember (usually, to do something) — disappeared with the emergence of the disposable tissue, while the mobile phone and, later, the smartphone made that their owners no longer remember (nor need to remember) the phone numbers of regular contacts. Rather than thinking 


\section{2}

Elisa Giaccardi and Liedeke Plate

of such 'things' as aide-mémoire, should they not be viewed as integral to how people do memory?

In material cultural studies, it has become commonplace to speak of the agency of things. As anthropologist Daniel Miller puts it, 'Things do things to us, and not just the things we want them to do' (2010, p. 94). Feminist philosopher and theoretical physicist Karen Barad postulates that people and things constitute each other in the process of coming into being, that is to say, 'intra-actively'. This concept makes the idea of things as having agency relevant to the discourse about memory. According to Barad, agency is not something that people or things have; it is the emergent result of how the world continuously configures and reconfigures itself. Matter thus is 'a congealing of agency', 'a doing', 'a stabilizing and destabilizing process of iterative intra-activity' (2003, p. 812). In this light, 'the universe does not have memory, it is the memory of iterative materializations. This suggests that there's a sense in which even molecules and particles remember what has happened to them' (Barad, Juelskjaer, and Schwennesen, 2012, p. 21).

Such a view of memory accords well with neuroscientific accounts. According to neuroscientists, memory is constructive. Remembering is a creative process in which memories are re-created each time they are recalled-'iterative materializations', in Barad's terminology. Rather than 'consolidating' memory, as recall was long thought to do (Silva, 2010), remembering actually destabilizes memories. The conditions under which recall takes place affect this process. Neuroscientists Joseph LeDoux and Valérie Doyère have shown how the reactivation of a memory trace renders it unstable and prone to modification' (Craver, 2015, p. 120), and neuroscientist Alcino Silva maintains that 'interfering with consolidation mechanisms during recall weakens or even erases these memories' (2010, p. 48).

The emergent view of memory mechanisms as 'designed, not for accuracy and permanency, but instead, for constant editing and fine-tuning of information with experience' (Silva 2010, p. 49) changes the common view of memory and what its functions are. Memory's 'susceptibility to many internal and external factors that constantly update, change, edit, and even bend fact to self-serving fictions' (Silva, 2010, p. 47) also makes clear that memory is best understood as 'intra-action', to use Barad's neologism: 'particular material (re)configurings that stabilize and destabilize along specific material changes' (Barad, 2003, p. 818).

Social media enable this constant editing of memory. Through social media, people recall and establish meaningful connections in 'ordinary' time and place, beyond the brief moments of the visit to the museum or heritage site. Online communities are formed that engage in shared practices of remembering; as part of such communities, people 'do' and 'say' around any object to which they ascribe social significance. These objects help them read the past, make sense of themselves in 
the present, and write how they want to be remembered. But with the Internet of Things, things also begin to 'do' and 'say'. Embedded with code, instructions, and histories, they recollect, establish connections with other things and with people, and can actively participate in the construction of memory.

\section{Bringing Memory to Matter with the Internet of Things}

Experimental prototypes and speculative concepts that use the Internet of Things to transform practices of remembering bring two points to the fore. The first concerns implications for memory practice of how connected objects, or 'things', come to be situated within a specific social and material context. Their different embodiments are the result of different socio-material configurations-that is, of the different ways in which the connection between the localized materiality of the object (i.e., what is it, and where is it or where it has been) and its intangible counterpart (i.e., code, instructions, histories) has been designed. This is rarely a symmetrical relationship. The second point concerns the ways in which the 'agency' of things and their participation in shared practices of remembering change our ability to interpret the past and project the future, potentially opening up contested or unexpected spaces of remembrance. As expressions of agency vary with the autonomy of the connected object (from vessel to actor), practices and spaces of remembrance differ, too.

\section{Of Vessels and Meaningless Artifacts: Attaching Memories to Objects}

What can a dancing shoe remember of the past? When we consider old things such as Rembrandt paintings, antique artifacts, and heirlooms, we are quite familiar with the value that details of their provenance add to the object. Yet when it comes to ordinary artifacts, we are less used to recognizing that they, too, have 'lives' and that the information conveyed by their 'biographies' is valuable. Marxist and neo-Marxist theorists have long insisted on the ways in which consumer culture eclipses the memories of the social relationships involved in the commodity's production (Barthes, 1957; Bourdieu, 1977; Appadurai, 1986; Kopytoff, 1986). We argue that the Internet of Things helps counteract the 'genesis amnesia' of the commodity (Bourdieu, 1977, p. 79) by reconfiguring the connection among people, the materiality of the artifacts, and the stories we tell about their provenance and significance. In this first set of examples, this is achieved by enabling people to permanently 'attach' memories to the physical object in the form of textual narratives, photographic images, or video clips, and to retrieve these memories at any moment with the aid of a smartphone. Though the perspective is still that of 


\section{Elisa Giaccardi and Liedeke Plate}

the human who tells the story of the object, once connected, the object begins to actively support an unprecedented 'read/write' relationship. As the object is passed on and stories grow and stick onto it, its significance is transformed and possibly contested. People are encouraged to 'write back' and contest the veracity of any memory that is presented to them, thus opening up space for alternative associations and histories within the specific social and material context in which the object is situated. Memory is at the same time 'stabilized and destabilized' along the specific material changes to the data which are attached to the object (Tales of Things) or vice versa, along the material changes to the object that is associated with the data (The Earthquake Shelf).

Tales of Things (Speed, 2012b) is an early Internet of Things platform from the Centre for Design Informatics of the University of Edinburgh that uses the properties of connected objects to offer alternative associations and pasts. ${ }^{6}$ The platform enables people to print a paper tag, stick it on a material artifact, and use the Tales of Things app to attach to the artifact memories to share with others. People can tag an ordinary object with a QR code, and this code will link the object to an online textual narrative, photographic image, or video (Figure 4.2).

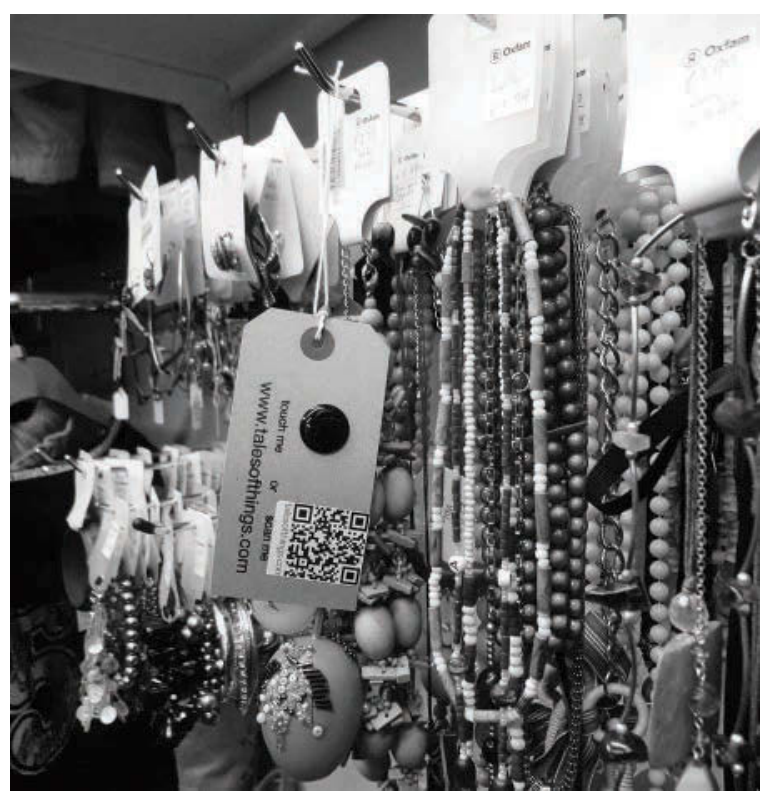

Figure 4.2 Tales of Things allows attaching personal memories onto ordinary artifacts (http://talesofthings.com). RememberMe at FutureEverything 2010: tag attached to jewelery in Oxfam shop, Manchester. Photograph by Jane Macdonald, 2010. 
Once scanned, the object will link the audio or video stories that the person has associated with it and help recall. As suggested by studies on the role of storytelling in history (Steedman, 1986, 2001; Leydesdorff, Passerini, and Thompson, 2005; Giaccardi, 2006; Speed, Khan, Baurley, and Phillips, 2015), personal accounts about particular artifacts may help correct erroneous historical assumptions about events of the past and challenge what counts as evidence. Ordinary tales can thus help a piece of history emerge, and can change the social significance and value of a particular material artifact. These memories are like the odds and ends found when one empties out one's pockets. Physically holding the object and experiencing it within the social context in which it is situated powerfully support the 'read/write' relationship enabled by the connected object. ${ }^{7}$ However, connected objects can push this 'read/write' relationship beyond the 'particular' material artifact. Tales of a Changing Nation (2011) is a design intervention at the National Museum of Scotland in Edinburgh that uses the Tales of Things platform to let visitors attach personal memories to $80 \mathrm{ob}-$ jects from Scotland's history in the twentieth and twenty-first centuries. These objects had been painted in white to accrue a wider variety of social memories. ${ }^{8}$ The use of white 'ghost' objects in the National Museum of Scotland grants mobility to memories, allowing them to be recovered from the past as a recollection and then transferred to the ghost object via the use of paper tags (Figure 4.3).

According to Waldner (2007, qtd. in Speed, 2012a), people in general surround themselves with between 1,000 and 5,000 objects, many of which are discarded and replaced through consumption and subsistence.

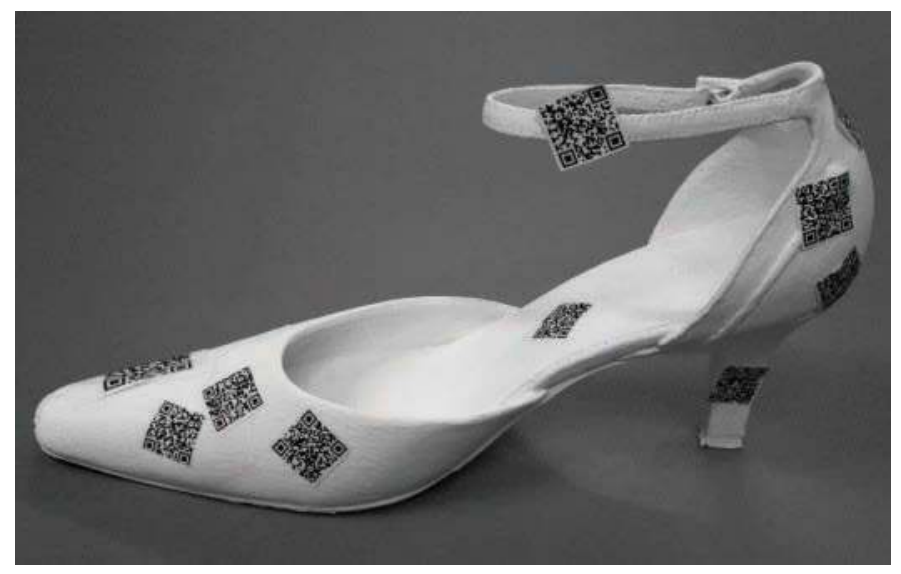

Figure 4.3 Ghostly vessel of a dancing shoe with accrued social memories in the Tales of a Changing Nation exhibition, National Museum of Scotland, Edinburgh, 2011. Photograph by Jane Macdonald, 2010. 


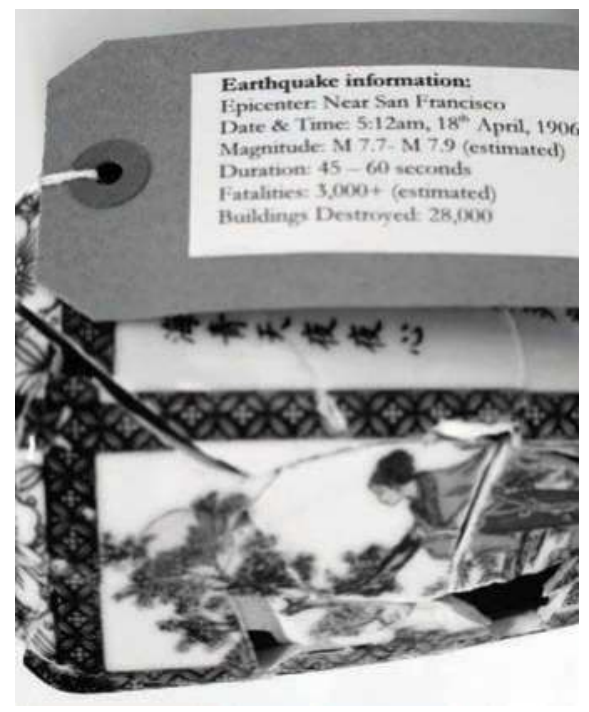

Figure 4.4 Memory of earthquake changes the materiality of the artifact in the speculative The Earthquake Shelf project (http://markmakedo. co.uk/portfolio/earthquake-shelf). Courtesy of Mark Selby.

However, some objects are lost, stolen, or mislaid forever and are irreplaceable because of the memories associated with them. As an artifact's data are likely to remain in the context of the Internet of Things, Tales of a Changing Nation explores how the unique materiality of a connected object can serve as a vessel also for those memories that have lost their tangible counterpart. ${ }^{9}$

A provocative illustration of how data can 'materially' change an object and thus alter memory along with those changes is The Earthquake Shelf (Selby and Kirk, 2015). ${ }^{10}$ The project uses real data and eyewitness accounts to fabricate mementos of earthquakes (Figure 4.4). It also uses scientific data such as magnitude, duration, and location, along with more personal descriptive accounts of events, to alter the material characteristics of existing objects. This work in progress is an investigation into how data could be used to shape the material qualities of otherwise 'insignificant' artifacts so that they are better able to reflect our personal experiences and tell stories about our past. ${ }^{11}$

\section{Of Kitchen Tables and Acoustic Guitars: Reviving the Social Life of Objects}

Arjun Appadurai (1986) and Igor Kopytoff (1986) usefully introduced the idea of things having social lives and thus life histories. Taking issue with the Marxian focus on production and looking instead to the 
commodity's total trajectory, from production to exchange, consumption, and disposal, they laid the ground for thinking about objects as having histories, biographies, and memories. With the Internet of Things, it becomes possible to 'read', trace, and retrieve these life-stories and memories of objects. Similarly to Tales of Things, the next set of projects we discuss makes use of machine-readable codes to associate online media content with material artifacts. However, because in these projects material changes are not reversible, the connected object here begins to 'bear witness'. More than active reminders for human storytelling, these objects have the ability to remember where they have been and with whom, and so to recollect, indeed re-call, their own memories. Such memories are not attached to the material artifact a posteriori; they are inherently part of the becoming of the connected object. As if it were 'incorporated' in the material embodiment of the object, data grow and decay with the object and with that, the patina of memories the object has accrued throughout its life. Here the perspective no longer is that of the human, attaching personal memories to the material artifact a posteriori; it is the perspective of the object 'bearing witness' to its own becoming, its mattering.

Chiocciola (Robbins, Giaccardi, Karana, and D'Olivo, 2015) is a 'personal memory tracer' designed by Mirsaeid Mousavi at Delft University of Technology as part of research conducted within the Connected Everyday Lab. Chiocciola (in Italian, 'snail') enables people to intentionally create and leave a trail of material traces onto ordinary objects as a way to inscribe, grow, and relive memories (Figure 4.5). Cherished family moments around the kitchen table, or the laughter

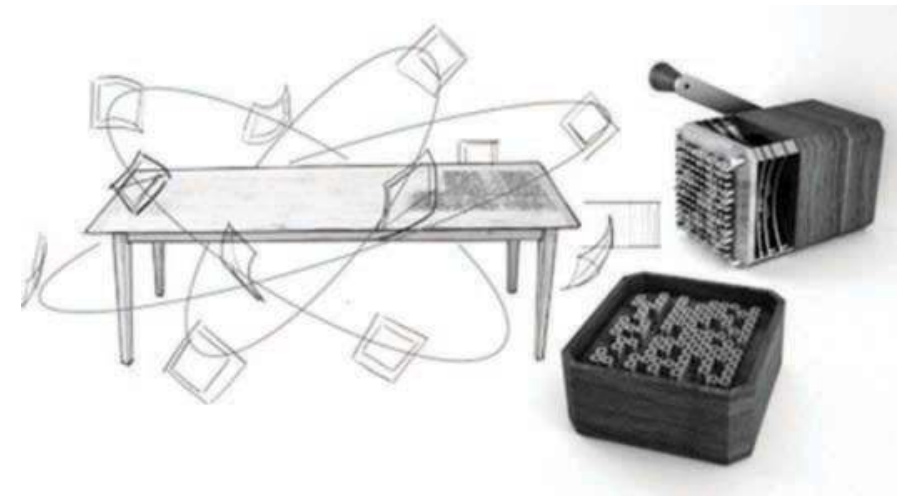

Figure 4.5 Chiocciola (in Italian, 'snail') enables people to intentionally create and leave a trail of material traces onto ordinary objects as a way to inscribe, grow, and relive memories. Courtesy of Mirsaeid Mousavi. 
that was caught during the first time the table was used at a dinner party, can be added to the object itself and become digitally accessible via a physical trace made on the material surface of the table. Slowly and carefully engraving the trace into a natural wooden surface allows this surface to 'mature' and develop a deliberate 'patina' subject to both intentional and unintentional memory practices, and possibly degrading environmental factors.

Similarly, Carolan Guitar (Benford, Hazzard, and Xu, 2015; Figure 4.6) is a guitar that tells its own story, from the sourcing of the tonewoods used to construct it through the processes of construction to the history of its ownership to the tunes that it has played. The finished instrument was named Carolan after the Celtic composer Turlough O'Carolan, the last of the great blind Irish harpists and an itinerant musician who roamed Ireland at the turn of the eighteenth century. Acoustic guitars are highly traditional and often valuable, especially when made by hand through the crafting of expensive and delicate tonewoods by a highly skilled luthier. Guitars also tend to be long-lived, existing for decades, sometimes even centuries, and consequently being passed down among owners and quite often outliving them. The project uses unique technology to hide digital codes within the Celtic-inspired decorative patterns adorning the instrument. This unusual technology enables the guitar to build and share a 'digital footprint' throughout its lifetime. Just as 'memory tracing' with Chiocciola requires time and physical effort on the material surface, so applying interactive surface decoration onto the Carolan Guitar requires that one becomes intimately familiar with the material properties arising from the quality and nature of wood and with

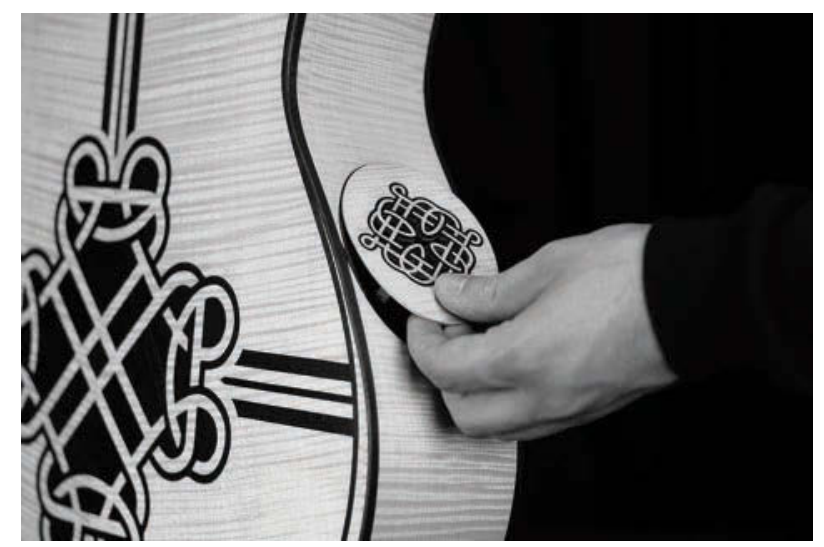

Figure 4.6 Carolan Guitar is a guitar that tells its own story. The project uses unique technology to hide digital codes within the Celtic-inspired decorative patterns adorning the instrument. Courtesy of Steve Benford. 
the techniques for etching, cutting, and inlaying the decoration. The perspective of the object is inscribed and brought to life only through a slow and meticulous material engagement that rejects the embedding of sensors, actuators, and displays that are typical of connected objects. By facilitating a way for traces to be made deliberately upon the object by those interacting with it, both projects attempt to speculatively explore new memory rituals. These new rituals traverse and celebrate the personal, collective, and material memories, which come to converge and blur within ordinary contexts.

\section{Of Gestures and Algorithms: Reminiscing Together 'with' the Object}

According to Jan Assmann, "Things do not "have" a memory of their own, but they may remind us, may trigger our memory, because they carry memories which we have invested into them, things such as dishes, feasts, rites, images, stories and other texts, landscapes and other "lieux de mémoire" (2008, p. 111). But if we grant objects agency, may we not also say that things have a memory of their own? This final set of examples illustrates the case of clocks, radios, and printers that begin to participate in shared practices of remembering by exhibiting an autonomous ability to recollect. These objects do not move, do not accrue stories, do not witness, but they have access to our storage of memories and, with that, the power to affect them. They help us to enter into a conversation with the familiar voices and images that define the sense of who we are and where we come from. Geist (in German, 'spirit') lets the ghost of the land of origin seep through in the day-to-day use of radios, clocks, and calendars, to help expat families negotiate their sense of identity through small, everyday gestures around those objects. Capable of autonomous reasoning instead, the Photobox and me.mento printers recollect on their own terms, within different temporalities and with distinct algorithmic preferences, and provoke their owners to serendipitous encounters and reframings.

Geist (2015) is a family of connected objects for people living outside their native country, developed by the Connected Everyday Lab at Delft University of Technology in collaboration with the design consultancy The Incredible Machine. Geist consists of a radio, a clock, and a calendar. Unapparent to outsiders, these objects provide a subtle link to a home far away and help expat families develop a sense of connectedness and belonging. By adjusting the knob of the radio, a family can navigate a bespoke spectrum of radio channels that ranges from their native country to the place where they currently reside or any other place a family may feel a social and cultural connection. The radio acts as a transponder, setting coordinates as a point of reference for the other Geist objects. If a family adjusts the knob on a frequency of their hometown, 


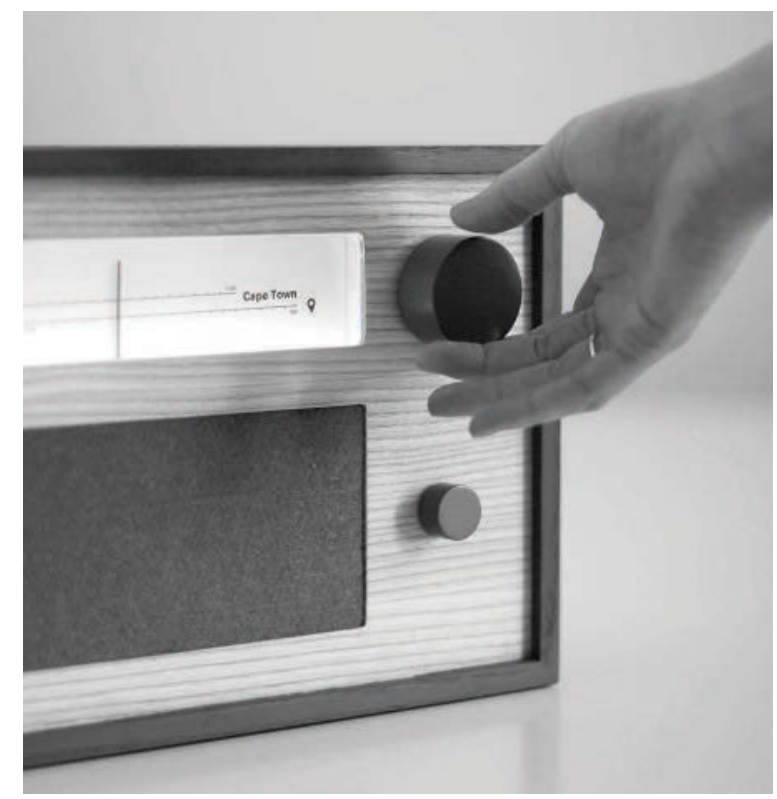

Figure 4.7 Turning the dial of the Geist (in German, 'spirit') radio enables expat families to transverse the space in between 'homes' and bridges the chasm that defines the social and cultural experience of being an expat. Courtesy of Connected Everyday Lab and The Incredible Machine.

for example, the radio will transmit local radio streams, the clock will set on a different time zone and glow in the colors of the sky back home, and the calendar will print out the date with local headlines. The mundane performance of turning the dial to transverse the space in between 'homes' physically manifests and bridges the chasm that defines the social and cultural experience of being an expat. It is through these small, everyday performances that the connected object helps expats reconcile and negotiate their sense of belonging and identity.

me.mento (2015) is another concept developed by Felix Marschner at the Connected Everyday Lab at Delft University of Technology. me. mento is a small photo printer that rummages in old photos to print a small memento for its owners' photo wall. By doing so, me.mento transforms the traditional picture wall in a space for unexpected memories and reflection (Figure 4.8). me.mento prints out pictures that are discarded, not shared publicly, or somehow forgotten in one's photo streamperhaps those pictures that turned out blurred or otherwise imperfect, like the one secretly taken with the smartphone by your child in a moment of distraction and that we often leave behind. Choosing according 


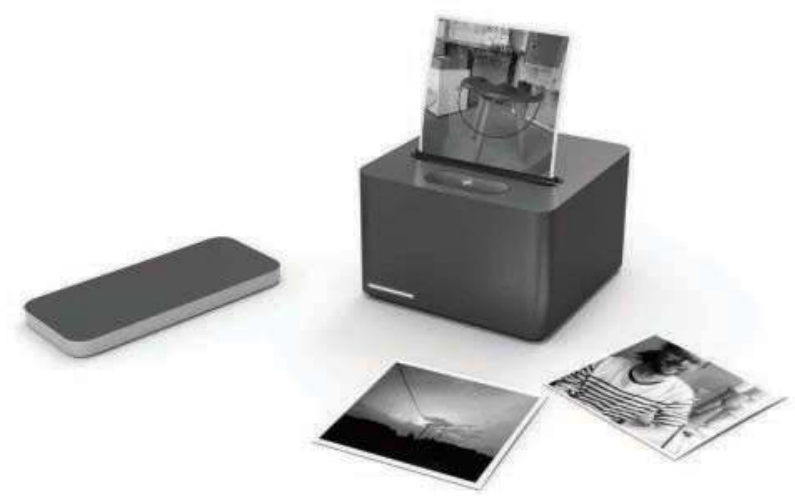

Figure 4.8 me.mento rummages in its owners' photo stream and prints out pictures that are discarded, not shared publicly, or somehow forgotten. Courtesy of Felix Marschner.

to its likings, me.mento has, as it were, feelings of its own. It is sentimental. People like snapping pictures with their smartphone of everything they feel is special. While the pictures of great events are curated and shared, pictures of small moments often get cluttered and probably forgotten at some point. me.mento recognizes faces and chooses those of friends and family the most, while avoiding those that are already publicly shared on social networks. In its algorithmic processing, me. mento searches for balance and will use a picture's metadata to print out a picture of a forgotten moment, thus inviting the re-collection of, for instance, the last evening together with one's friends after a busy week without photo updates. Prompting involuntary autobiographical memories, me.mento becomes a technology of memory that is also a technology of the self, shaping and affecting our sense of identity (Foucault, 1988; Plate and Smelik, 2009).

Similarly, Photobox (Odom et al., 2014) is a domestic technology that prints four or five randomly selected photos from the owner's Flickr collection at random intervals each month inside of a wooden chest (Figures 4.9 and 4.10). Photobox is slow. Its reasoning contests accelerated rates of photo accumulation to facilitate reflection and help find meaning. The behavior Photobox enacts is to search its owner's Flickr collection, randomly select a single image, and then print this image within the box where it will wait to be discovered. By exhibiting an autonomous ability to recollect, clocks, radios, and printers provoke us to remember. Actively selecting what is to be remembered and what is to be forgotten, they become not just instrumental to human memory but integral to it. ${ }^{12}$ 

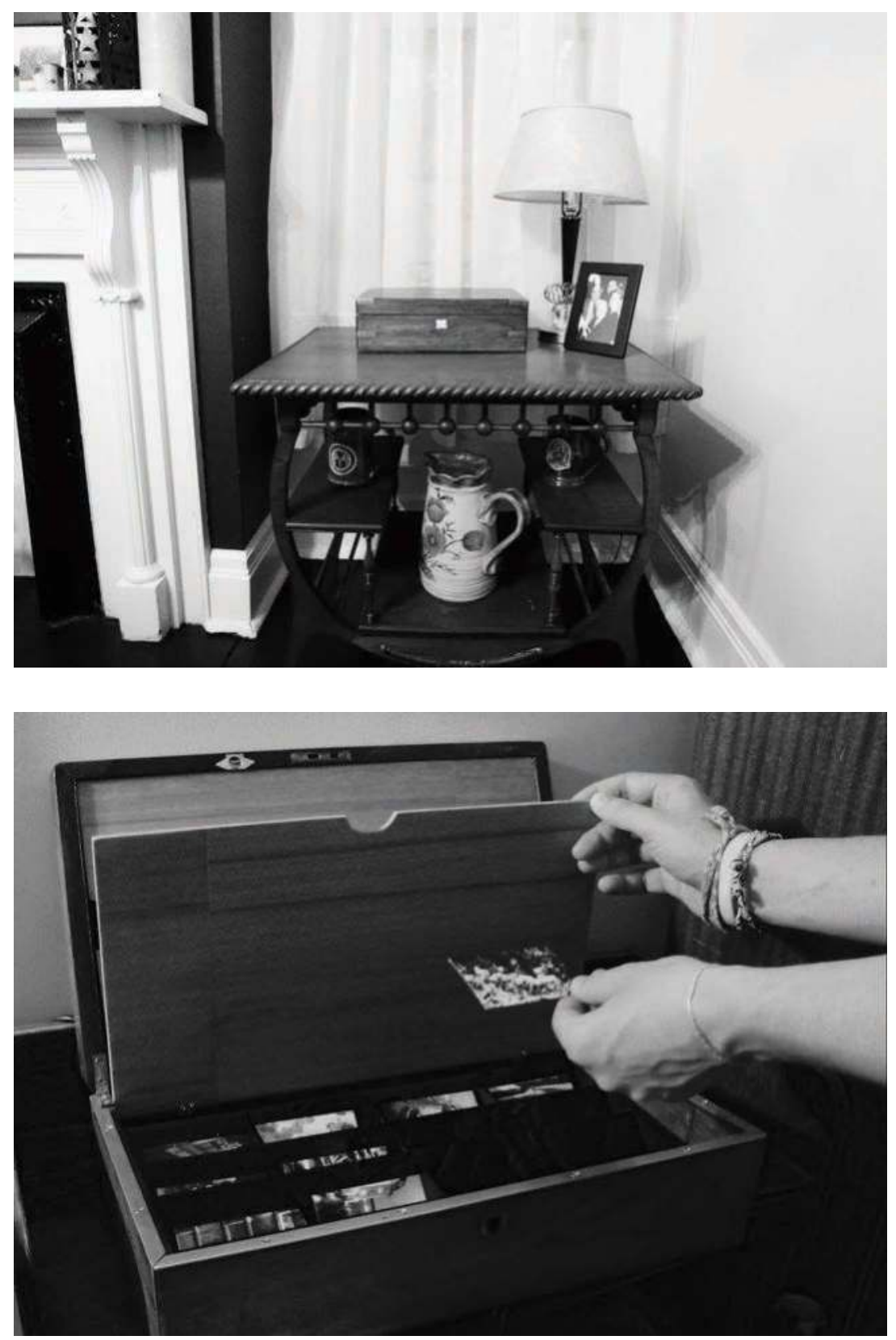

Figures 4.9 and 4.10 Photobox is a domestic technology that prints four or five randomly selected photos from the owner's Flickr collection at random intervals each month inside of a wooden chest. Courtesy of Mark Selby. 


\section{Remembering Beyond Anthropocentrism}

In the near future, designing technologies of memory will require the exploration of new gatherings between people and 'things', new ways for people to connect and interact with things and things with peopleand with other things. Because 'things' are socio-material frames that modify how memory practices are performed and more broadly influence the politics of remembering, the design of future technologies of memories will require sensitivity to how people, objects, and values can mutually come to constitute each other, in the options offered and not offered by the proposed technology.

According to Karen Barad,

It may seem perverse, unimportant, or meaningless, to attribute memory to an inanimate happening, but that speaks of a failure of imagination that gets stuck at the threshold of one of the most stubborn of all dualisms - the animate/inanimate dualism-that stops animacy cold in its tracks, leaving rocks, molecules, particles, and other inorganic entities on the other side of death, of the side of those who are denied even the ability to die, despite the fact that particles have finite lifetimes.

(Barad et al., 2012, p. 21)

In this chapter, we have explored the relationship between materiality and memory, focusing on the ways in which 'things' change our ability to read the past and write the future and how they open up spaces of remembrance that are beyond what we deem personally or socially significant and worthwhile to be remembered (for instance, grandma's rolling pin in Tales of Things or the blurred image recollected by me.mento). Within unique configurations of materials, data, and connections, connected objects 'do' and 'say' things to us that can help us reminisce (Geist, me. mento, Photobox), contest (Tales of Things), and even forget, eventually (Chiocciola, Carolan Guitar).

If social media allow long and meaningful connections to be established, technologies such as the Internet of Things allow using these connections to add to the materiality of the object, perhaps even reveal narratives that have been obscured by the apparent physicality of the artifact. As such, the Internet of Things works to counter the commodity's loss of the capacity to remind people (and other things) of where an object has been, its history and travels. Restoring this capacity to objects instead, the Internet of Things restores an ethical dimension to our relationship to things in that they become not only things worth remembering; but also things with a memory of their own and with which to negotiate spaces of remembrance. As the 
Internet of Things gives objects the ability to co-perform next to people (Kuijer and Giaccardi, 2015), it also offers alternative associations and histories, contesting the veracity of any memory that is presented to us, reminiscing, and interfering with what people remember and how they remember it. If we then acknowledge the difference between artifacts as carriers of human added content and artifacts collecting data through their own means (that is, sensors, connections, and algorithms enabled by their designers), we ought to ask: to what purpose will things 'remember'? And for whom will they recollect? This relationship is something that we will increasingly have to negotiate as information and communication technologies enable objects that are part of our lives to begin to articulate spaces of remembrance and significance beyond what humans can remember: remembering different things, and doing so in different ways, both in how they recall and how they recollect and communicate these memories. As objects are given the ability to connect and participate in practices of remembering on their own terms, they will increasingly challenge our anthropocentric understanding of what is 'possible' and 'worthwhile' to remember.

\section{Notes}

1 'Doing' and 'saying' are expressions borrowed from Schatzki (2002).

2 http://www.kulturarv.dk/1001fortaellinger/en_GB.

3 See http://movingpeople.nu; http://www.power-of-art.nl/campaigns/movingpeople-2/; https://www.facebook.com/powerofarthouse.

4 In computer scientist Michael Rubinstein's Ted Talk 'See Invisible Motion, Hear Silent Sounds' demonstrating the 'motion microscope', a videoprocessing tool that plays up tiny changes in motion and color impossible to see with the naked eye, things such as a bag of chips and a plant are shown to 'hear' music and conversations. As they are recorded on film and amplified, the tiny motions that sound waves create in them show things to be recording devices with memories of their own. See Rubinstein (2014).

$5 \mathrm{http}: / /$ www.cisco.com/web/solutions/trends/iot/portfolio.html.

$6 \mathrm{http}: / /$ talesofthings.com.

7 See, for example, the tale about grandma's rolling pin: https://www.youtube. $\mathrm{com} /$ watch?v=roMmntxj7FM.

8 See, for example, the memories of the Scottish dancing hall culture accrued around the 'ghostly' dancing shoe of Figure 4.3.

9 Similarly, Story Shell (Moncur, Julius, van den Hoven, and Kirk, 2015) is a bespoke connected object for a bereaved parent, serving as a vessel for memories of the lost child.

$10 \mathrm{http} / /$ markmakedo.co.uk/portfolio/earthquake-shelf.

11 Similarly, the broken probes explored by Ikemiya and Rosner (2013) are meaningless artifacts transformed through processes of intentional degradation into unique identifiers with which to associate and retrieve digitally recorded histories.

12 On forgetting, see Plate (2016). 


\section{References}

Appadurai, A. (1986) 'Introduction: Commodities and the Politics of Value', in A. Appadurai (ed) The Social Life of Things: Commodities in Cultural Perspective (Cambridge: Cambridge University Press). 3-63.

Ashton, K. (2009) 'That "Internet of Things" Thing', RFID Journal (22 June) http://www. rfidjournal.com/article/view/4986 (Accessed on 13 July 2016).

Assmann, J. (2008) 'Communicative and Cultural Memory', in A. Erll and A. Nünning (eds) Cultural Memory Studies: An International and Interdisciplinary Handbook (Berlin: de Gruyter). 109-118.

Barad, K. (2003) 'Posthumanist Performativity: Toward an Understanding of How Matter Comes to Matter', Signs: Journal of Women in Culture and Society 28.3: 801-831.

Barad, K., M. Juelskjær, and N. Schwennesen (2012) 'Intra-active Entanglements: An Interview with Karen Barad', in Kvinder, Køn og forskning/ Women, Gender and Research 1.2: 10-24.

Barthes, R. (1957) Mythologies (Paris: Seuil).

Benford, S., A. Hazzard, and L. Xu (2015) 'The Carolan Guitar: A Thing That Tells Its Own Life Story', ACM Interactions 2.3: 64-66.

Bourdieu, P. (1977) Outline of a Theory of Practice (Trans. R. Nice) (Cambridge: Cambridge University Press).

Burke, P. (2010) 'Co-memorations: Performing the Past', in K. Tilmans, F. van Vree, and J. M. Winter (eds), Performing the Past: Memory, History, and Identity in Modern Europe (Amsterdam: Amsterdam University Press). 105-118.

Byrne, D. (2008) 'Heritage as Social Action', in G. Fairclough, R. Harrison, J. H. Jameson Jr., and J. Schofield (eds) The Heritage Reader (London and New York: Routledge). 149-173.

Ciolfi, L., and M. McLoughlin (2012) 'Of Turf Fires, Fine Linen, and Porter Cake: Design for Living History', ACM Interactions 19.5: 18-21.

Coyne, R. (2011) 'No-Thing As It Seems', Reflections on Technology, Media and Culture, http://richardcoyne.com/2011/04/23/nothing-as-it-seems (Accessed on 13 July 2016).

Craver, C. (2015) Review of The Memory Process, by S. Nalbantian, P. M. Matthews, and J. L. McClelland (eds) Memory Studies 8.1: 117-124.

Evans, D. (2011) The Internet of Things: How the Next Evolution of the Internet Is Changing Everything, Cisco Internet Business Solutions Group (IBSG).

Ferris, K., L. Bannon, L. Ciolfi, P. Gallagher, T. Hall, and M. Lennon (2004) 'Shaping Experiences in the Hunt Museum: A Design Case Study', Proceedings of the 5th Conference on Designing Interactive Systems (DIS '04) (New York: ACM Press). 205-214.

Fosh, L., S. Benford, S. Reeves, B. Koleva, and P. Brundell (2013) 'See Me, Feel Me, Touch Me, Hear Me: Trajectories and Interpretation in a Sculpture Garden', Proceedings of the SIGCHI Conference on Human Factors in Computing Systems (CHI '13) (New York: ACM Press). 149-158.

Foucault, M. (1988) 'Technologies of the Self' in L. H. Martin, H. Gutman, and P. H. Hutton (eds) Technologies of the Self: A Seminar with Michel Foucault (London: Tavistock). 16-49. 
Freud, S. (1989) Five Lectures on Psycho-Analysis (Trans. J. Strachey) (New York: Norton).

Giaccardi, E. (2006) 'Collective Storytelling and Social Creativity in the Virtual Museum: A Case Study’, Design Issues 22.3: 29-41.

Giaccardi, E. (2007) 'Cross-media Interaction for the Virtual Museum' in Y. Kalay, T. Kvan, and J. Affleck (eds) New Heritage: New Media and Cultural Heritage (London and New York: Routledge). 112-131.

Giaccardi, E. (2011) 'On Pause and Duration, Or the Design of Heritage Experience', Proceedings of the 25th BCS Conference on Human-Computer Interaction (BCS-HCI '11) (Swinton, UK: British Computer Society). 35-40.

Giaccardi, E. (ed) (2012) Heritage and Social Media: Understanding Heritage in a Participatory Culture (London and New York: Routledge).

Giaccardi, E., C. Speed, N. Cila, and M. Caldwell (2016) 'Things as Coethnographers: Implications of a Thing Perspective for Design and Anthropology', in R.C. Smith et al. (eds) Design Anthropology Futures (London: Bloomsbury). 235-248.

Harrison, R. (ed), (2013) Heritage: Critical Approaches (Abingdon, UK: Routledge).

Ikemiya, M., and D. Rosner (2013) 'Broken Probes: Toward the Design of Worn Media', Personal and Ubiquitous Computing 18.3: 671-683.

Ingold, T. (2012) 'Toward an Ecology of Materials', Annual Review of Anthropology 41: 427-442.

Iversen, O., and R. C. Smith (2012) 'Experiences from the Digital Natives Exhibition' in E. Giaccardi (ed.) Heritage and Social Media (London: Routledge). 126-144.

Jenkins, H., R. Puroshotma, M. Weigel, K. Clinton, and A. J. Robison (2009) Confronting the Challenges of Participatory Culture: Media Education for the 21st Century (Cambridge, MA: The MIT Press).

Kende, M. (2014) Annual Global Internet Report 2014, Internet Society.

Kopytoff, I. (1986) 'The Cultural Biography of Things' in A. Appadurai (ed) The Social Life of Things: Commodities in Cultural Perspective (Cambridge: Cambridge University Press). 64-91.

Kuijer, L., and E. Giaccardi (2015) 'Considering Artifacts as Co-performers', paper presented at Symposium on 'Animals, Automated Devices and Ecosystems: Dynamic Non-humans in Theories of Social Practice', 9-10 October, Barcelona, Spain.

Leydesdorff, S., L. Passerini, and P. Thompson (eds) (2005) Gender and Memory (London: Transaction).

Liu, S., L. Palen, and E. Giaccardi (2011) 'Heritage Matters in Crisis Informatics: How Information and Communication Technology Can Support Legacies of Crisis Events' in C. Hagar (ed), Crisis Information Management: Communication and Technologies (Cambridge: Woodhead Publishing Limited). 65-84.

Lowenthal, D. (2005) 'Stewarding the Future', CRM: The Journal of Heritage Stewardship 2.2: 6-25.

Miller, D. (2010) Stuff (Cambridge, MA: Polity Press).

Moncur, W., M. Julius, E. van den Hoven, and D. Kirk (2015) 'Story Shell: The Participatory Design of a Bespoke Digital Memorial', Proceedings of the 4th Participatory Innovation Conference PIN-C 2015 (The Hague, Netherlands). 
Odom, W., A. J. Sellen, R. Banks, D. S. Kirk, T. Regan, M. Selby, J. L. Forlizzi, and J. Zimmerman (2014) 'Designing for Slowness, Anticipation and Revisitation: A Long Term Field Study of the Photobox' (1961-1970) Proceedings of the SIGCHI Conference on Human Factors in Computing Systems (CHI'14) (New York: ACM Press).

Olsen, B. (2010) In Defense of Things: Archaeology and the Ontology of Objects (Lanham, MD: AltaMira Press).

Plate, L. (2016) 'Amnesiology: Towards the Study of Cultural Oblivion', Memory Studies 9.2: 143-155.

Plate, L., and A. Smelik (eds) (2009) Technologies of Memory in the Arts (Basingstoke, UK: Palgrave Macmillan).

Plate, L., and A. Smelik (eds) (2013) Performing Memory in Art and Popular Culture (London and New York: Routledge).

Robbins, H., E. Giaccardi, E. Karana, and P. D’Olivo (2015) 'Understanding and Designing with (and for) Material Traces', Studies in Material Thinking 13.3: 1-24.

Rubinstein, M. (2014) 'See Invisible Motion, Hear Silent Sounds', Ted Talk, https:// www.ted.com/talks/michael_rubinstein_see_invisible_motion_hear_silent_ sounds_cool_creepy_we_can_t_decide/transcript?language $=$ en\#t-104439 (Accessed on 15 December 2015).

Rushkoff, D. (2013) Present Shock: When Everything Happens Now (New York: Penguin).

Russo, A. (2012) 'The Rise of the Media Museum: Creating Interactive Cultural Experiences Through Social Media' in E. Giaccardi (ed) Heritage and Social Media: Understanding Heritage in a Participatory Culture (London and New York: Routledge). 145-157.

Schatzki, T. R. (2002) The Site of the Social (University Park: Pennsylvania State University Press).

Selby, M., and D. Kirk (2015) 'Experiential Manufacturing: The Earthquake Shelf', Proceedings of the 2 nd Biennial Research Through Design Conference (RTD 2015), 25-27 March 2015, Cambridge, UK, Article 17.

Shirky, C. (2008) Here Comes Everybody: The Power of Organizing Without Organizations (London: Penguin).

Shirky, C. (2010) Cognitive Surplus: Creativity and Generosity in a Connected Age (London: Allen Lane).

Silva, A. (2010) 'Molecular Genetic Approaches to Memory Consolidation' in S. Nalbantian, P. M. Matthews, and J. L. McClelland (eds) The Memory Process: Neuroscientific and Humanistic Perspectives (Cambridge, MA: The MIT Press). 41-54.

Smith, L. (2006) Uses of Heritage (London and New York: Routledge).

Speed, C., A. W. Khan, S. Baurley, and M. Phillips (2015) 'Contemporary Governance Discourse and Digital Media: Convergences, Prospects and Problems for the "Big Society" Agenda' in D. O'Brien and P. Matthews (eds) After Urban Regeneration: Communities, Policy and Place (Bristol, UK: Policy Press).

Speed, C. (2012a) 'An Internet of Things That Do Not Exist', ACM Interactions 18.3: $18-21$.

Speed, C. (2012b) 'Mobile Ouija Boards' in E. Giaccardi (ed) Heritage and Social Media (London: Routledge) 179-196. 


\section{Elisa Giaccardi and Liedeke Plate}

Steedman, C. (1986) Landscape for a Good Woman: A Story of Two Women (London: Virago).

Steedman, C. (2001) Dust: The Archive and Cultural History (Manchester, UK: Manchester University Press).

Thomas, J. (2004) Archeology and Modernity (London and New York: Routledge). Van Dijck, J. (2007) Mediated Memories in the Digital Age (Palo Alto, CA: Stanford University Press).

Vom Lehn, D., J. Hindmarsh, P. Luff, and C. Heath (2007) 'Engaging Constable: Revealing Art With New Technology', Proceedings of the SIGCHI Conference on Human Factors in Computing Systems (CHI'07) (New York: ACM Press). 1485-1494.

Waldner, J.B. (2007) Inventer l'Ordinateur du XXIème Siècle (London: Hermes Science).

Warpas, K. (2014) 'Designing for Dream Spaces', ACM Interactions 21.3: 66-69.

West, S. (ed) (2010) Understanding Heritage in Practice (Manchester, UK: Manchester University Press). 


\section{Memory and Materiality in Hussein Chalayan's Techno-Fashion}

\section{Lianne Toussaint and Anneke Smelik}

... to put it more strongly, cloth is a kind of memory.

-Peter Stallybrass (1993, p. 38)

Textile memento moris are tactile.

-Anja Aronowsky Cronberg (2009, p. 9)

\section{A Technological Time Travel through Fashion History}

During the 2006 Paris Fashion Week, the Turkish Cypriot artist and fashion designer Hussein Chalayan resurrected 'the ghost of fashion past' with a groundbreaking and now iconic series of self-transforming robotic dresses (Blanks, 2006, p. 160). The grand finale of the catwalk show consisted of five hand-constructed mechanical outfits, which took the audience on a time travel through a hundred and eleven years of fashion history. The collection, entitled 'One Hundred and Eleven', started with a full-length, high-necked Victorian gown that transformed from a calf-length 1910s dress into a beaded flapper dress from the 1920s. The following piece was a 1920s dress morphing into a 1930s and then a 1940s style silhouette. Then an hourglass dress reminiscent of Dior in the 1950s turned into a 1960s metallic sheath (Figure 5.1), and so on. As the show drew to a close, supermodel Leah De Wavrin entered the catwalk wearing a diaphanous dress that was slowly absorbed into a flying saucer of a hat. Paradoxically, Chalayan's technological trip down fashion memory lane ended with an undressed model.

Hussein Chalayan's time-traversing 'One Hundred and Eleven' collection is a trailblazing example of techno-fashion, also known as 'fashionable technology', 'wearable technology', or simply 'wearables', which consists of the integration of fashion and technology by embedding electronics, smart materials, microprocessors, solar cells, LED lights, and interactive interfaces into textiles or clothing (Quinn, 2002a, 2010; Seymour, 2009, 2010). We take this example as an illustrative case study to explore how the integration of technology reshapes processes of memory through fashion. It also serves to show how assemblages of 


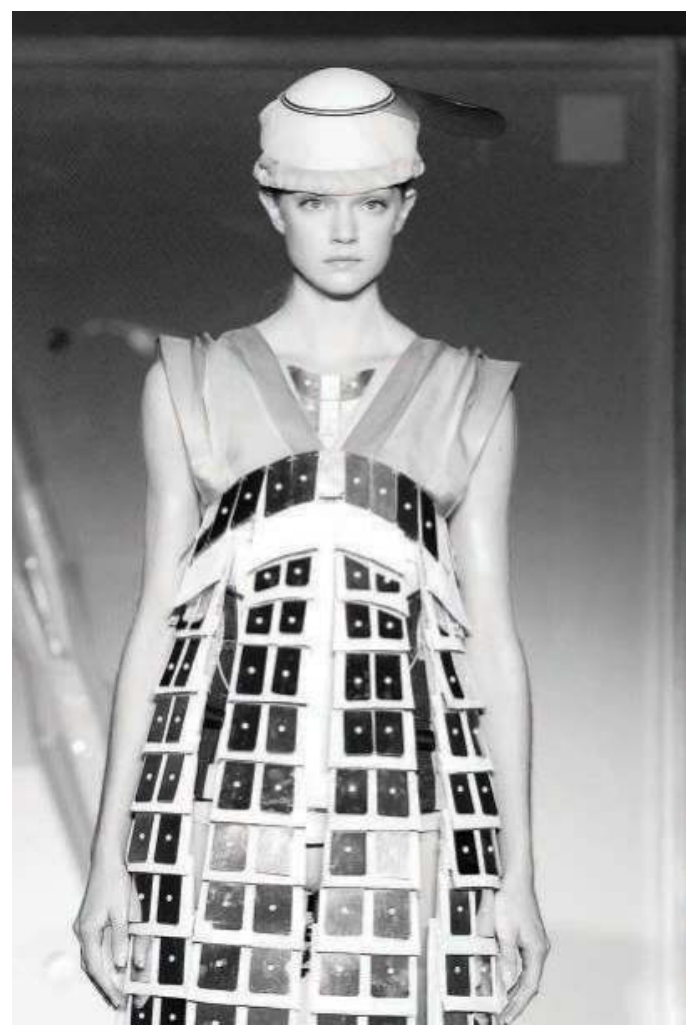

Figure 5.1 Hussein Chalayan, Ready-to-Wear Women, One Hundred and Eleven Collection, Spring/Summer 2007. Courtesy of FirstVIEW.

technology and fashion help us to rethink the relation between sartorial memory and materiality.

Chalayan is a designer renowned for his 'intellectual' and conceptual approach to fashion and fashion shows (Anderson, 2000, pp. 229-230). The clothes that we discuss in this chapter are hence very much part of a system of haute couture and remain firmly within the field of art and performance, without ever making it to the world of mass consumption. Yet, it is in such thought-provoking 'technological fantasies' (Ryan, 2014, p. 156) that the relations between memory and materiality, fashion, and technology can be freshly addressed, raising, for example, new questions about the material agency of 'things'. Moreover, we believe that techno-fashion such as Chalayan's is at the vanguard of a new field in creative fashion design that will become more available and acceptable in the near future. The integration of fashion and technology will change the cultural value of fashion, especially in its transformative relation to the human body, identity, and memory (Smelik, forthcoming 2017). 
Chalayan is a London-based fashion designer who works on the cutting edge between art, fashion, and technology. His work encompasses videos, art installations, and fashion designs, and makes extensive use of technologies ranging from memory wire and fiberglass to LEDs. He is also a politically engaged designer who combines modernist themes such as technological progress with reflections on migration, cultural identity, religion, social changes, and war (Evans et al., 2005; Violette, 2011).

With 'One Hundred and Eleven' Chalayan comments on time and history, creating an intricate game between past, present, and future (Golbin, 2011). Renowned fashion critic Sarah Mower described this collection as "fashion addressing the subject of fashion, a dissection of our contemporary habit of recycling "vintage," and an embrace of high technology, all at the same time' (Mower, 2006). Combining technological materials, including magnets, conductive wires, tiny circuit boards, and micro controllers with traditional textiles such as silk, Chalayan materially merges the old and the new in this collection. Of particular interest is the so-called shape memory material, which, as we will discuss, displays a specific kind of material agency by changing its shape from a temporarily deformed shape back to its programmed original shape (Cho, 2010, p. 189). For the purpose of this chapter, we foreground the particularly intricate relation between memory and the materiality of fibers, textiles, technologies, and clothes. We thus hope to reveal the dynamics of memory in and through the matter of fashion.

Wearables can function as body-mounted lifelogging gadgets, such as smart watches or the much-discussed Google Glass, or they may act as separate add-ons to fashion designs, such as the iPhone dress by Elie Tahari (Sumitra, 2014) or the Nokia skirt by designer Fyodor Golan (Skalnik, 2014), to give just a few recent examples. Whereas these instances of wearables remain firmly within the realm of mere gadgetry, Hussein Chalayan's collection 'One Hundred and Eleven' is an altogether different example of working with memory technologies in fashion because it integrates, rather than just adds, the technology. By changing the shape of the six dresses through wearable technology, a cultural history of fashion emerges before the eyes of the spectator. It is in the material folds, patterns, textures, and outlines that a century-old history of fashion acquires shape. Referring to silhouettes from one hundred and eleven years of fashion history, the collection at the same time re-creates and redefines that past through innovative materials and futuristic technologies. 'One Hundred and Eleven' thus foregrounds, in a highly material way, a collective and cultural memory that recalls well-known fashion designs from earlier decades. The inherent materiality of the technology, the fiber, and the clothes interrelate in an assemblage 'that reconfigures the authority of the past with that of the present' (Miller, 2005, p. 12).

In this chapter, we explore how cultural memory-in this case, the recent history of Western fashion-is performed and mediated 


\section{2}

Lianne Toussaint and Anneke Smelik

by techno-fashion. Drawing on cultural studies and sociological and anthropological approaches, this chapter aims at unraveling the innovative connection between clothing, memory, and technology instigated by techno-fashion. We first focus on fashion's relation to time and history, then explore techno-fashion as a particular performance and technology of memory, and finish by discussing the particular force of technology's as well as fashion's materialism. We advance the concept of 'softness' as a material and aesthetic category at the intersection of technology, materiality, and memory.

\section{Fashion Memory on the Move}

Many scholars have pointed to the particularly close, yet ambivalent, connection between dress, fashion, and memory. Ann Rosalind Jones and Peter Stallybrass have argued that clothing and textiles are by definition powerful memory systems because 'they are a form of material memory' (Jones and Stallybrass, 2000, p. 200). In addition, Stallybrass's seminal article 'Worn Worlds: Clothes, Mourning, and the Life of Things' (1993) has instigated studies of fashion that 'consider cloth as a type of memory "archive" in itself' (Hunt, 2014, p. 229). He reminds us that the wrinkles in clothes, for example in the elbow or in the crotch, are in fact called 'memory' in the 'technical jargon of sewing' (1993, p. 36). In other words, the technology of memory is deeply embedded in the technology of clothes. Fabrics and garments are perfect repositories for storing the wearer's experiences over time; as Prasad Boradkar poetically puts it, 'woven into the faded fabric and ripped seams are memories and stories' (Boradkar, 2010, p. 192). Clothes act as 'material remains', according to Carole Hunt (2014, p. 229); they are, Anja Aronowsky Cronberg writes, 'the material memories that ensure that the past is always carried with us into the future' $(2009$, p. 8 ; for another example of this approach, see Gibson, 2015).

Elizabeth Wilson claims that there is 'something eerie' about old clothes displayed in a museum or hanging in the closet of a deceased person because they 'are so much part of our living, moving selves' (Wilson, 2003 , p. 1). Old clothes are a visual and material reminder of bygone styles and former fashions. At the same time, they betray a most intimate relation to the private body of the wearer because they materialize memories of the wearer's body-a lingering scent of perfume, creases, stains, and wear and tear. Clothes, Wilson writes, 'are congealed memories of the daily life of times past' (2003, p. 1). Even the mechanical dresses from Chalayan's 'One Hundred and Eleven Collection' that have exclusively been worn during the 2006 Paris Fashion Week, bear visual traces of their only wearer. While visiting the Boijmans Van Beuningen Museum depot in Rotterdam, where two of the designs now reside, we noted the material traces of that one-time event: the dresses showed discolored 
spots from the models' perspiration as well as some creases and deformations. Chalayan's self-transforming creations thus echo Stallybrass's famous statement: 'Clothes receive the human imprint' (1993, p. 37).

Fashion has a privileged or perhaps, rather, a 'crumpled' relation to time and history, as Caroline Evans calls it (Evans, 2003, p. 22). The very definition of fashion is change and transformation: 'Fashion, in a sense is change', she writes $(2003$, p. 1). This idea of fashion as ephemeral and transitory came about at the end of the nineteenth century. In 1895, philosopher Georg Simmel referred to the inherent restlessness of fashion as follows: 'Fashion never is, but always becomes' (Simmel, 1895, p. 18). Walter Benjamin continued this line of thought in the 1930s, referring to modern fashion as satisfying the 'enigmatic need for sensation' and playing into the 'new velocities, which gave life an altered rhythm' (Benjamin, 1999, p. 65). Ulrich Lehmann argues accordingly that 'la mode' is inextricably linked to the modern and modernity (Lehmann, 2000, p. 9). This may imply that fashion is always in the moment of the present, but Benjamin is the thinker who points out fashion's dialectical relation to time: the present always already contains the past. Fashion's relation to history is therefore 'particularly promiscuous', as Caroline Evans puts it, because of 'its brief life span and its incessant trawling through the old to refabricate the new' (Evans, 2003, p. 22).

Considering fashion's promiscuous browsing through history and dialectical relation to time, Chalayan's collection 'One Hundred and Eleven' falls into a familiar pattern of citing well-known designs and styles from earlier decades. Presenting a chronological succession of silhouettes from distant to recent past, and progressing from decade to decade, each outfit in the collection represents a new chapter in the history of Western fashion. This is reminiscent of Chalayan's earlier collection 'Medea' (S/S 2002), of which he said:

The garment is a ghost of all the multiple lives it may have had. Nothing is shiny and new; everything has a history. ... The design is a wish or a curse that casts the garment and its wearer into a time warp through historical periods, like a sudden tumble through the sediment of an archaeological dig.

(qtd. in Evans, 2003, p. 57)

Unlike Chalayan's earlier work, however, 'One Hundred and Eleven' goes beyond the static or successive representation of memory and time. It not only presents a memory of the past, but also enacts that memory by merging fashion with performance and technology. '[N]arrating several transformations within a single dress', Susan Elizabeth Ryan writes, the collection 'perform[s] changes in fashion occurring over the course of a century' (2014, p. 156). The collection's fashion show thus is 


\section{4}

Lianne Toussaint and Anneke Smelik

performative; it performs memory before the very eyes of the spectator. This means that the fashion designs are not only a memory trace or visual reminder of the past, but that the technological feat of morphing from past into present and future draws attention to memory as an act, a practice, or an event. Indeed, as Chalayan himself says in an interview, he was 'looking at different shapes throughout the eras' and wanted 'to somehow demonstrate the change' with this collection (Chalayan, 2006). This notion of metamorphosis, Judith Clark argues, is what makes Chalayan's work so captivating, and suitable for a sequenced event like the catwalk show (Clark, 2011). In addition, Chalayan's work imagines a future 'matter-reality' for fashion, in which technological and textile matter meet. 'This way of thinking about fashion is still quite new to the fashion world', Chalayan self-reflectively notes, 'but it's what is moving things forward' (qtd. in Quinn, 2002b, p. 368).

The concept of transformation that lies behind 'One Hundred and Eleven' is reinforced by its remarkable soundtrack and decor. On the occasion of crystal company Swarovski's hundred-and-eleventh anniversary, Chalayan turned the runway into a glimmering silver surface with a gigantic glass clock at the end (Figure 5.2). Symbolizing the 'nonstop consumption of fast fashion, the cult of vintage and the feats of modern technology', the clock's time indicators light up as the pointer rhythmically rotates to the soundtrack (Doig, 2006). Having a nervous drum rhythm as its basis, the soundtrack combines unsettling audio fragments of jet engines, trench warfare, and aerial bombings (Golbin, 2011). Together with the metamorphosing dresses, these technological references to world history epitomize the ephemeral nature of fashion, as well as its ambiguous relation to time. As the clock of sartorial evolution ticks on, fashion moves in a perpetual cycle.

Liedeke Plate and Anneke Smelik argue that to think of memory as performance implies a 'shift from memory as the trace of what once was to memory as the past's present moment' (Plate and Smelik, 2013 , p. 6). Literally and gradually moving from one decade into the next, Chalayan's collection historically morphs fashion's past into something of the present. In the words of phenomenologist Maurice Merleau-Ponty: 'At each successive instant of a movement, the preceding instant is not lost sight of. It is, as it were, dovetailed into the present' (Merleau-Ponty, 2002, p. 162). Key to Chalayan's performance of memory is the mechanical metamorphosis of the final five dresses. A complex system of microcontrollers, motors, battery packs, micro switches, and magnets allows these garments to move, twitch, unzip, contract, and transform of their own accord (Rob Edkins, qtd. in Ross, 2006). The shock of the new is thus not so much contained in the show's retrospective chronology, but evoked by the technological transformation of the final six designs. The technology inside 


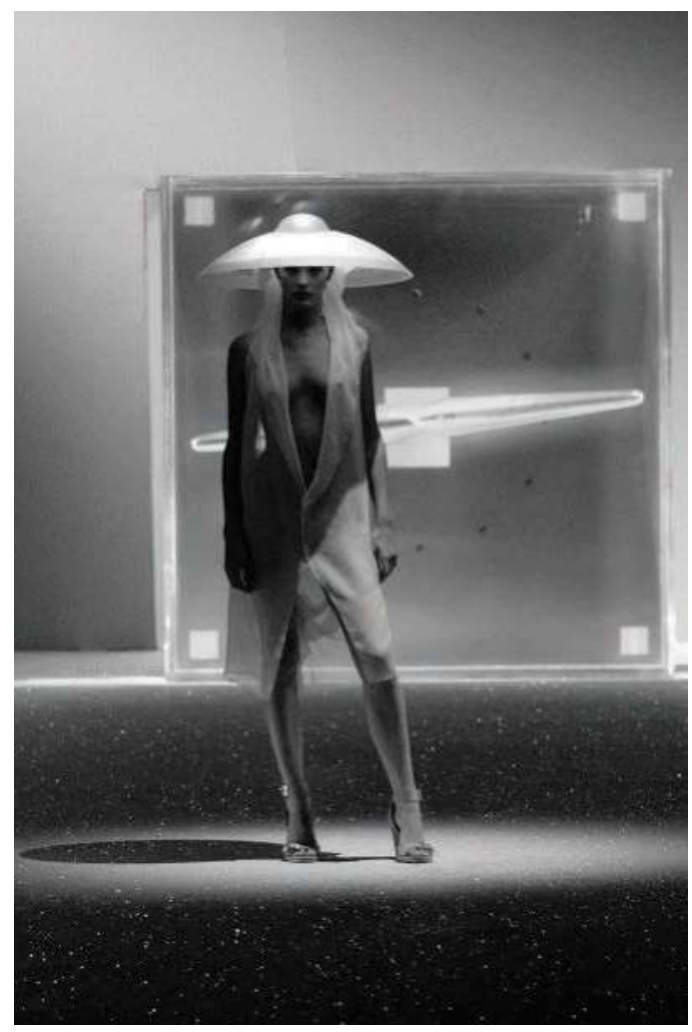

Figure 5.2 Hussein Chalayan, Ready-to-Wear Women, One Hundred and Eleven Collection, Spring/Summer 2007. Courtesy of FirstVIEW.

the mechanical dresses is what truly caused the show 'to astonish, provoke, and send a visceral sensation through its audience' (Mower, 2006). The collection blurs the boundaries between fashion and technology in such a way that, as Ava Chin writes, 'Indeed, techno$\log y$ is the fashion' (Chin, 2010, p. 35). 'Techno-fashion', or the integration of fashion and technology, becomes the vehicle to collapse past, present, and future.

Important for our purpose here is that the notion of performance draws attention to agency and embodiment in relation to memory: memory is an act of recalling and remediating the past that bridges the gap to an imagined future. Hussein Chalayan's fashion designs 'do' memory (Plate and Smelik, 2013, p. 4). To gain a better understanding of how and what the designs remember, we will now focus on the constitutive role of technologies and materiality in shaping memories. 


\section{Soft Technologies of Memory}

Chalayan's self-transforming garments are not just 'vessels of memory in which memory passively resides', but also 'objects through which memories are shared, produced, and given meaning' (Sturken, 1997, p. 9). Indeed, the high-tech dresses are the ultimate memory technologies because they perform and produce memory in a technological fashion. In other words, it is the technology itself that makes this peculiar (re-)collection possible.

As Plate and Smelik observe, 'both individual and cultural memory are more and more mediated by technology', which 'means that memories are not only collected and saved by media, but are also reproduced and represented by them' (Plate and Smelik, 2009, p. 6). We outsource huge amounts of data and information to numerous storage devices, caches, Internet archives and to 'the cloud'. In turn, countless technologies influence our individual as well as cultural memories (Neiger, Meyers, and Zandberg, 2011). Although human memory and technological memory have become inextricably intertwined, they are still distinctly different. Storage devices are wrongly assumed to accurately maintain their contents, whereas the human mind tends to select, revise, and forget (Van Dijck, 2007). Technological memory, Joanna Berzowska explains, 'acts more as a dumping group for data, as opposed to the rich, contextual space that makes up human memory' (2005b, p. 33). Technology does not forget things the way that human memory does, while memory cards, hard drives, or technological devices are unable to record the kind of embodied experiences that humans have (p. 33).

Chalayan's collection 'One Hundred and Eleven' involves cultural memory: through technology, it performs a limited selection of changing fashions, styles, and silhouettes that encompass a specific sociocultural and historical framework. Chalayan's designs can thus be understood as a conjunction of technology and culture in the way they shape memories. As such, the collection brings embodied, technological, and cultural manifestations of memory together. The five transforming dresses he designed to animate the changing shapes of fashion, however, also point to the pivotal aspect of materiality. That the history of fashion is acted out, indeed 'performed' through a combination of technology and fashion, was unconventional and innovative at the time (Clark, 2011, pp. 126-127). The physical carriers of technologically mediated memories are usually hardware, such as computers and laptops, digital cameras, hard drives, and smartphones. In contrast, what sets Chalayan's mechanical outfits apart from other technologies of memory is the fact that they fuse hard, technological materials with soft, textile materials. The combination of materials he used for 'One Hundred and Eleven' paves the way for softer, more wearable, memory technologies. Although the conceptual and philosophical nature of his catwalk shows may all too easily obscure 
the physicality and 'haptic element' of Chalayan's clothes, Caroline Evans points out, his designs are in fact compellingly wearable (2005, pp. 9-10).

Aside from circuit boards, wires, metallic sheets, magnets, and micro motors, the mechanical dresses are made of soft materials such as silk ( $\mathrm{H}+\mathrm{F}$ Collection). Here we want to draw attention to softness as both a material and aesthetic category. In order to create the self-transforming effects of the dresses, different kinds of hardware were carefully worked into softer components. Several 'bum pads' and wads of stuffing contain the tiny motors (of about a third of the size of a pencil and 9 millimeters in diameter) used to transform the dresses, as well as the batteries and circuitry required to control them. The cables connecting the micro motors to the wires in the outer layer of the garments are held in hollow tubes sewn into corsets (Edkins, qtd. in Ross, 2006). Chalayan's mechanical dresses thus bring together the soft and flexible materials of fashion with the hard and rigid components of common memory technologies such as hard disks, photo cameras, or smartphones. Successfully merging the two fields, the designs are predicated on what Berzowska has termed 'soft computation': digital and electronic technology that is composed of soft materials (such as textiles and yarns) and based on traditional textile construction methods (such as sewing and knitting) (Berzowska, 2005a; 2006). By encasing most of the technological components in relatively comfortable and soft materials and fabrics, Chalayan managed to fine-tune the challenge of mechanizing fabric and applying an engineering idea to something soft (Huckbody, 2014). The hardware animating Chalayan's trip down fashion memory lane is still present underneath and inside the fabrics, but in its encounter with fashion it is turned into something that both looks and feels softer and hence more wearable than other kinds of memory technology.

Chalayan's creation addresses but also reaffirms one of the main concerns of wearables today, which too often remain in the realm of gimmicks or gadgets while not offering anything beyond their technological function (Smelik, Toussaint, and van Dongen, 2016). When functionality is merely added to the textile, it may create 'smart textiles' or 'smart clothes', but issues of body, identity, and memory of the wearer are frequently overlooked. A design that is merely functional will simply not be worn if it is not also aesthetically pleasing, physically and socially comfortable, and fits with one's lifestyle (Dunne et al., 2014; Dunne, Profita, and Zeagler, 2014). This hampers the social and cultural acceptance of wearables and, hence, hinders them from finally conquering the streets. To be sure, this is also the case with Chalayan's designs for 'One Hundred and Eleven', which were presented on a catwalk show and survived only as museum pieces-significantly with failing technological functions due to corrosion and damage. Having 'nothing to do with function', his work primarily 'gives us a perspective on how [wearable 
technology] can evolve as dress' (Ryan, 2014, p. 156). In our view, the perception and relevance of wearable technology for potential future users can only be advanced when new meanings and values are created through interactions with the design. Although Chalayan's futuristic designs are not exactly ready-to-wear, they do represent a serious attempt to invest cultural memory with new meanings and values by adding technological and material agency to fashion.

\section{Making Memory Matter}

Daniel Miller has argued that openness to the materiality of fiber and cloth helps to understand the social domain, unraveling 'the warp of materiality and the weft of society', as he wittily puts it (2005, p. 17). Such attention to materiality reveals the connections between technology, innovation, and the end products-the garments (p. 6). For a focus on the agency of techno-fashion, we turn to the concept of materiality as it is theorized in what is known as 'new materialism' (Coole and Frost, 2010; Barrett and Bolt, 2013), 'renewed materialism' (Rocamora and Smelik, 2016, p. 14), or the many other terms that are currently available (for a fuller account of new materialism, we refer to the introduction of the present volume). From a new materialist perspective, matter cannot be thought of as merely passive and futile stuff on which humans act but should be considered as an active and meaningful actor in the world (Barrett and Bolt, 2012; Ingold, 2012). Taking this advice seriously, we look again at the technologies used by Chalayan in 'One Hundred and Eleven'. Usually, garments move along with the movements of the wearer's body, but here the wearable technologies enable the garments to move autonomously, irrespective or even in spite of the wearer. As Judith Clark describes it, Chalayan manages to give clothes 'a life of their own, their own trajectory' (2011, p. 127). The technologies embedded in the mechanical dresses display a specific and nonhuman kind of agency: they seemingly 'act' and remember by themselves.

The term 'agency' has different meanings in different contexts, yet we adopt Andrew Pickering's definition of agency as something that has to do with 'actions, human and non-human, in the material world and the interplay of those' (2010, p. 195). Transposed to fashion, agency pertains to quite different 'things': to the designer, the body of the wearer, the garment, but also to the materials such as fiber, fabric, and the hard and soft technological artefacts embedded in them. Kaori O'Connor aptly remarks: 'Man-made fibres are not inert, they have been created to do' (O'Connor, 2005, p. 53, emphasis in original). In the case of 'One Hundred and Eleven', the notion of agency highlights the fact that the technologies establish interaction between the garments and the body, between human and nonhuman entities. Material agency, in other 
words, is not located exclusively in the technology, but in 'the assembly' of wearer, fashion, and technology (Verbeek, 2011, p. 64).

The fact that technologies are worn on and by the body increases the urgency not just to acknowledge technological agency, but also to take into account the body's materiality. As Joanne Entwistle and Elizabeth Wilson argue, the body is not so much a submissive object to be draped in accordance with the whims of today's fashion, but dressing is rather an active embodied practice (Entwistle and Wilson, 2003). This is particularly relevant for techno-fashion because it brings technology closer to the body. Fashion is by itself a bodily practice, which is further enhanced by the embedded technology in Chalayan's designs. His application of technology to fashion is innovative in presenting memory, technological materials, and style as being closely connected to, and even literally worn by, the body. Causing garments to act, move, and metamorphose while worn by the wearer, the integrated technologies push the boundaries between body and technology. According to Fortunati, Katz, and Riccini, 'the body continually abolishes the border between nature and technology by converting one into the other' $(2008$, p. 216). It follows that the memories expressed by Chalayan's mechanical dresses point to embodied memory; they bring memory and body closer together. The garment becomes a kind of interface, a platform where technological, embodied, and cultural dimensions of memory perform and interact (Seymour, 2008).

The material world, Tim Ingold reminds us, is not so much made up of objects but of 'things' $-\mathrm{a}$ thing being 'a certain gathering together of the threads of life' (2010, p. 4). Interestingly, Ingold uses metaphors taken from the world of cloth and textiles, like 'threads' (p. 4), 'woven fabric', and 'the tracery of lace' (p. 12), in order to argue that 'things' are made up of 'knots' and 'entwinements' (p. 4). Ingold understands agency not as an act that is performed by an object (which would amount to an anthropomorphic view) but rather as an emergent flow that is inherent in the open-ended process of becoming that is 'a thing'. This dynamic view of the material world may help us to understand Chalayan's designs in 'One Hundred and Eleven' as unfinished products that illustrate the 'entanglement of things' (Ingold, 2010, p. 3). In changing shape continuously, the designs are never settled in one particular form but are always in the process of becoming in a Deleuzian sense (Smelik, 2016). By adhering to Ingold's call to follow 'flows of materials' (2010, p. 4), we can see how Chalayan's designs create alliances and encounters between fibers, fabric, and bodies; between garment and technology; and between between memory and materiality.

In the case of Chalayan's self-transforming designs, one material plays a special role in shaping and reshaping the collection's material flows of memory, the so-called shape memory material. Shape memory materials are materials that can change from a temporarily deformed shape 
back into their original form due to external stimuli, mostly changes in temperature (Mattila, 2006, p. 85; Cho, 2010, p. 189). When heated above a certain transition temperature, shape memory material can be programmed to 'remember' its precise previous shape, and will consequently transform the shape of the garments without intervention of the wearer. Once the memory shape has been set during the high temperature phase, shape memory material will always and repeatedly return to that shape. No matter how deformed it becomes; as soon as the material is heated it will pop back into its original form. Always returning to their original form, shape memory materials thus literally and actively turn the future into 'a thing' of the past and vice versa.

Carole Hunt suggests that the 'receptive surface of cloth makes it susceptible to deliberate inscription', to 'hold and trap information' (Hunt, 2014 , p. 216). As shape memory materials can be programmed to record and remember a particular shape from the past, they are a perfect example of inscribing a 'thingly', nonhuman memory into fashion. This technology not only foregrounds the materiality of the garments and of the human body, but it also materializes memory as a process, an act of doing. Chalayan's dresses show how agency, as well as cultural memory, can be performed by technology in such a way that they can no longer be understood as a strictly human property. His designs have been programmed to 'remember' and 'reenact' particular shapes from fashion's past and hence represent an 'agentic' yet nonhuman type of memory (Knappet and Malafouris, 2008). Allowing for a novel and less anthropocentric understanding of memory, the dresses highlight that 'new technological products provide us with fresh metaphorical perspectives on memory' (Jones, 2007, p. 43). 'One Hundred and Eleven' emphasizes the material, embodied, and self-transforming dimensions of cultural memory. It ultimately shows that, and how, objects can have memory (Berzowska, 2006, p. 452), revealing the dynamics of memory in and through matter.

So far we have explored how Chalayan's collection materializes cultural memory in focusing on how the technology and new materials enable the designs to change shape and dynamically visualize the history of Western fashion. Yet there is another side to the issue of memory and materiality. Peter Stallybrass revealed the two contradictory aspects of the materiality of cloth: 'its ability to be permeated and transformed by maker and wearer alike; and its ability to endure over time' (1993, p. 38). In the case of Chalayan's dresses, something different happens in relation to its temporality, which lies in its specific use of technology. Here we want to return to the notion of clothes as the 'congealed memories of the daily life of times past' (Wilson, 2003, p. 1).

As mentioned at the beginning of this chapter, the mechanical dresses were worn during a one-time catwalk show only. Coming back to the two dresses we studied at the Boijmans Van Beuningen museum depot, 
we recall how these garments act as a textile reminder of the wearer's bodily presence. 'The magic of cloth', Stallybrass poetically writes, 'is that it receives us: receives our smell, our sweat, our shape even' (1993, p. 36). Indeed, in the museum depot we witnessed the perspiration spots, folds and creases embedded in Chalayan's once-worn designs. In addition to these material traces of wear, the materialized memory of these dresses also has its technological side, which in this particular case is revealed by its failure: damaged by corrosion, moisture, and use, the embedded technologies are no longer operable. These kinds of material memories show how, in the words of Tim Ingold, 'Materials are not in time; they are the stuff of time itself' $(2012$, p. 439). The passing of time shows the wear and tear, and results in the failure of once-innovative but now-obsolete technology.

\section{Conclusion}

A perspective on the materiality of Chalayan's series of transforming outfits shows the possibilities of technology for fashion design. More importantly in the context of our study of cultural memory in fashion, the designs reveal the capacity to represent the dynamics of memory in and through matter: memory is encased in the very materiality of the garments. Another inspiring element of these technological fashion designs is their close connection to the human body; cultural memory and technology are literally worn by and on the body. Chalayan's designs thus ultimately reveal that technologies may amplify fashion's role as a vehicle of cultural, personal, and material memories (Berzowska, 2005b).

An analysis of Chalayan's mechanical dresses reveals that technologies may invade, yet also instigate and innovate, processes of memory through fashion. First, Chalayan's time-traversing 'robo dresses' resurrect the ghost of fashion's past through the use of advanced technologies and smart materials. The high-tech garments perform, embody, and generate the dynamics and transformations of one hundred and eleven years of fashion history as they literally move from one decade into the next. They therefore operate as the ultimate 'technologies of memory'. Moreover, 'One Hundred and Eleven' represents the ephemerality of modern fashion, and its complex relation to cultural memory.

Second, the way in which Chalayan combines the traditionally hard materials of technology with the softer structures common in fashion paves the way for the development of softer, even wearable, memory devices in the future. Encasing the hard materials of technology in fabrics, pads, pockets, and tubes, Chalayan took the first steps toward developing 'softwear', as opposed to hardware, memories. Softness is thus both a material and an aesthetic category that is fully played out at the intersection of technology, materiality, and memory in 'One Hundred and Eleven'. 
Finally, approaching Chalayan's mechanical dresses from a new materialist perspective, we have argued that the combination of fashion and technology highlights the agency of matter. Techno-fashion offers a brand-new repository for memories and thereby allows for unprecedented forms and ways of understanding memory. Finally, our sustained focus on the 'matter' of fashion, technology, memory, and the body shows that Chalayan's collection 'One Hundred and Eleven' is a convincing and tangible proof of 'the force of materiality' at work in recording, shaping, and reshaping memories (Coole and Frost, 2010). As Chalayan's self-transforming garments are still neither robust nor wearable, they reaffirm the pivotal role-and failure-of materials in designing techno-fashion. Analyzing Chalayan's self-transforming designs within the context of memory studies helps us to rethink as well as imagine memory matters in techno-fashion.

\section{Note}

An earlier and shorter version of this chapter will be published as L. Toussaint and A. Smelik, 'From Hardware to "Softwear": The Future Memories of Techno-Fashion' in D. Jaffé and S. Wilson (eds) Memories of the Future (Bern: Peter Lang, forthcoming).

\section{References}

Anderson, F. (2000) 'Exhibition Review: Hussein Chalayan', Fashion Theory 4.2: 229-234.

Aronowsky Cronberg, A. (2009) 'Editor's letter', Vestoj: The Journal of Sartorial Matters 1, Special issue on 'Material Memories': 8-9.

Barrett, E., and B. Bolt (eds) (2013) Carnal Knowledge: Towards a 'New Materialism' through the Arts (London: I.B. Tauris).

Benjamin, W. (1999) 'B. Fashion' in The Arcades Project (Cambridge, MA: Harvard University Press). 62-81.

Berzowska, J. (2005a) 'Electronic Textiles: Wearable Computers, Reactive Fashion, and Soft Computation', Textile: The Journal of Cloth and Culture 3.1: 58-75.

Berzowska, J. (2005b) 'Memory Rich Clothing: Second Skins that Communicate Physical Memory', Proceedings of the 5th Creativity and Cognition Conference (London: Goldsmiths College, University of London, 12-15 April): 32-40.

Berzowska, J. (2006) 'Personal Technologies: Memory and Intimacy through Physical Computing', AI and Society 20.4: 446-461.

Blanks, T. (2006) 'Hussein Chalayan Resurrects the Ghost of Fashion Past with Revolutionary Morphing Robo-dresses' in Sally Singer (ed) Vogue, The Transformer: View 196.12: 160.

Boradkar, P. (2010) Designing Things: A Critical Introduction to the Culture of Objects (Oxford: Berg).

Chalayan, H. (2006) [video interview on 'One Hundred and Eleven'] (Paris: Cosmicsdiscomix) https://www.youtube.com/watch?v=uTFl0rNNQrY (Accessed on 7 May 2015). 
Chin, A. (2010) 'Technology Shapes Fashion' in R. Scapp and B. Seitz (eds) Fashion Statements: On Style, Appearance and Reality (New York: Palgrave Macmillan).

Cho, C. G. (2010) 'Shape Memory Materials' in G. Cho (ed.) Smart Clothing: Technology and Applications (Boca Raton, FL: CRC Press). 189-227.

Clark, J. (2011) 'Metamorphosis' in R. Violette (ed.) Hussein Chalayan (New York: Rizzoli). 125-126.

Coole, D., and S. Frost (eds) (2010) New Materialisms: Ontology, Agency, and Politics (Durham, NC: Duke University Press).

Doig, S. (4 October 2006) 'Hussein Chalayan', Vogue UK www.vogue.co.uk/ fashion/spring-summer-2007/ready-to-wear/hussein-chalayan (Accessed on 11 February 2016).

Dunne, L. E., H. Profita, C. Zeagler, J. Clawson, S. Gilliland, E. Yi Luen Do, and J. Budd (2014) 'The Social Comfort of Wearable Technology and Gestural Interaction', 2014 36th Annual International Conference of the IEEE Engineering in Medicine and Biology Society, EMBC 2014, Institute of Electrical and Electronics Engineers Inc. 4159-4162.

Dunne, L. E., H. Profita, and C. Zeagler (2014) 'Social Aspect of Wearability and Interaction' in E. Sazonov and M. R. Neuman, (eds) Wearable Sensors: Fundamentals, Implementation and Application (New York: Academic Press). 25-44.

Entwistle, J., and E. Wilson (eds) (2003) Body Dressing (Oxford: Berg).

Evans, C. (2003) Fashion at the Edge: Spectacle, Modernity and Deathliness (London: Yale University Press).

Evans, C. (2005) 'No Man's Land' in C. Evans, S. Menkes, T. Polhemus, and B. Quinn (eds) Hussein Chalayan (Rotterdam: NAi Publishers). 8-15.

Evans, C., S. Menkes, T. Polhemus, and B. Quinn (eds) (2005) Hussein Chalayan (Rotterdam: NAi Publishers).

Fortunati, L., J. E. Katz, and R. Riccini (eds) (2008) Mediating the Human Body: Technology, Communication, and Fashion (Mahwah, NJ: Lawrence Erlbaum).

Gibson, R. (2015) The Memory of Clothes (Rotterdam: Sense Publishers).

Golbin, P. (2011) 'One Hundred and Eleven' in R. Violette (ed) Hussein Chalayan (New York: Rizzoli). 132.

H+F Collection, '111, Mechanical Dress 5' and '111, Mechanical Dress 2', Han Nefkens Foundation www.hfcollection.org/hussein-chalayan (Accessed on 11 February 2016).

Huckbody, J. (28 February 2014) 'Hussein Chalayan, the Designer's Designer', iD Magazine, Interviews https://i-d.vice.com/en_gb/article/hussein-chalayanthe-designers-designer (Accessed on 11 February 2016).

Hunt, C. (2014) 'Worn Clothes and Textiles as Archives of Memory', Critical Studies in Fashion and Beauty 5.2: 207-232.

Ingold, T. (2010) 'Bringing Things to Life: Creative Entanglements in a World of Materials', ESRC National Centre for Research Methods, Realities Working Paper \#15, 5.10: 1-15.

Ingold, T. (2012) 'Toward an Ecology of Materials', Annual Review of Anthropology 41: 427-442.

Jones, A. (2007) Memory and Material Culture (Cambridge: Cambridge University Press). 
Jones, A. R., and P. Stallybrass (2000) Renaissance Clothing and the Materials of Memory (Cambridge: Cambridge University Press).

Knappett, C., and L. Malafouris (eds) (2008) Material Agency: Towards a Non-Anthropocentric Approach (New York: Springer).

Lehmann, U. (2000) Tigersprung: Fashion in Modernity (Cambridge, MA: The MIT Press).

Mattila, H. (2006) Intelligent Textiles and Clothing (Boca Raton, FL: CRC Press).

Merleau-Ponty, M. (2002) Phenomenology of Perception (Trans. C. Smith) (London and New York: Routledge).

Miller, D. (2005) 'Introduction' in S. Küchler and D. Miller (eds) Clothing as Material Culture (Oxford: Berg). 1-19.

Mower, S. (4 October 2006) 'Chalayan, Spring 2007 Ready-to-Wear', Style. com www.style.com/fashion-shows/spring-2007-ready-to-wear/chalayan (Accessed on 11 February 2016).

Neiger, M., O. Meyers, and E. Zandberg (eds) (2011) On Media Memory: Collective Memory in a New Media Age (Basingstoke, UK: Palgrave Macmillan).

O'Connor, K. (2005) 'The Other Half: The Material Culture of New Fibres' in S. Küchler and D. Miller (eds) (2005) Clothing as Material Culture (Oxford and New York: Berg). 41-59.

Pickering, A. (2010) 'Material Culture and the Dance of Agency' in D. Hicks and M.C. Beaudry (eds) The Oxford Handbook of Material Culture Studies (Oxford: Oxford University Press). 191-208.

Plate, L., and A. Smelik (eds) (2009) Technologies of Memory in the Arts (Basingstoke, UK: Palgrave MacMillan).

Plate, L., and A. Smelik (eds) (2013) Performing Memory in Art and Popular Culture (London and New York: Routledge).

Quinn, B. (2002a) Techno-fashion (Oxford: Berg).

Quinn, B. (2002b) 'A Note: Hussein Chalayan, Fashion, and Technology', Fashion Theory 6.4: 359-368.

Quinn, B. (2010) Textile Futures: Fashion, Design and Technology (Oxford: Berg).

Rocamora, A., and A. Smelik (2016) 'Introduction' in A. Rocamora and A. Smelik (eds) Thinking Through Fashion: A Guide to Key Theorists (London: I.B. Tauris). 1-27.

Ross, R. (20 October 2006) 'Transforming Clothes: Computerized Motors Pulled the Strings at a Recent Paris Fashion Show, Dramatically Altering Dresses on the Runway', Technology Review, Computing News www. technologyreview.com/news/406705/transforming-clothes/ (Accessed on 11 February 2016).

Ryan, S. E. (2014) Garments of Paradise: Wearable Discourse in the Digital Age (Cambridge, MA: The MIT Press).

Seymour, S. (2008) 'The Garment as Interface' in J. Lumsden (ed.) Handbook of Research on User Interface Design and Evaluation for Mobile Technology (London: Information Science Reference). 176-186.

Seymour, S. (2009) Fashionable Technology: The Intersection of Design, Fashion, Science and Technology (Vienna: Springer).

Seymour, S. (2010) Functional Aesthetics: Visions in Fashionable Technology (Vienna: Springer). 
Simmel, G. (1895) 'Zur Psychologie der Mode: Sociologische Studie' www. modetheorie.de/Simmel-Georg.861.0.html (Accessed on 20 June 2015).

Skalnik, J. (14 February 2014) 'The Latest in Wearable Technology: A Skirt Made of Nokia Lumia 1520s' www.eyeonmobility.com/2014/latest-wearabletechnology-skirt-made-nokia-lumia-1520s (Accessed on 11 February 2016).

Smelik, A. (2016) 'Gilles Deleuze: Bodies-without Organs in the Folds of Fashion' in A. Rocamora and A. Smelik (eds) Thinking Through Fashion. A Guide to Key Theorists (London: I.B. Tauris). 165-183.

Smelik, A. (2017) 'Cybercouture: The Fashionable Technology of Pauline van Dongen, Iris van Herpen and Bart Hess' in A. Smelik (ed) From Delft Blue to Denim Blue. Contemporary Dutch Fashion (London: I.B. Tauris). 252-269.

Smelik, A., L. Toussaint, and P. van Dongen (2016) 'Solar Fashion: An Embodied Approach to Wearable Technology', International Journal of Fashion Studies 3.2 (Autumn). 287-303.

Stallybrass, P. (1993) 'Worn Worlds: Clothes, Mourning, and the Life of Things', The Yale Review 81.2: 35-50.

Sturken, M. (1997) Tangled Memories: The Vietnam War, the AIDS Epidemic, and the Politics of Remembering (Berkeley: University of California Press).

Sumitra (2014) 'Apple Fans Rejoice-iPhone Dress Now Lets You Wear Your Favorite Smartphone', Oddity Central: Collecting Oddities (24 September) www.odditycentral.com/news/apple-fans-rejoice-iphone-dress-now-lets-youwear-your-favorite-smartphone.html (Accessed on 11 February 2016).

Van Dijck, J. (2007) Mediated Memories in the Digital Age (Stanford, CA: Stanford University Press).

Verbeek, P. P. (2011) Moralizing Technology: Understanding and Designing the Morality of Things (Chicago: The University of Chicago Press).

Violette, R. (ed) (2011) Hussein Chalayan (New York: Rizzoli).

Wilson, E. (2003) Adorned in Dreams: Fashion and Modernity (London: I. B. Tauris). 


\title{
6 Size Matters
}

\section{Karl Ove Knausgård's Min Kamp and Roberto Bolaño's 2666 as (Anti-) Monumental Novels}

\author{
Inge van de Ven
}

In cultural memory studies, the notion of the novel as a monument is well established. Aleida Assmann (2011) has shown how textual monuments have for long periods been valued over their stone counterparts for their greater durability. The invention of writing and even more so of printing, she reminds us, once sparked the hope of eternal communication on permanent material carriers. The word 'monument' derives from the Latin noun monumentum, which in turn comes from the verb moneo: 'to remind, to bring to the notice of, to tell of'. This implies a temporal gap, and, in order to bridge that gap, an act of testimony is needed. Indeed, a monument should be able to manipulate our sense of time in such a way as to render the past present. It allows us to leave a deliberate physical marker for posterity, an 'I was here' or 'we were here' to an unknown future recipient.

Like stone statues, texts allow for the recollection of a person or an event from the past, and to bear witness to them in the present. Thus, the novel can be said to function as an object of remembrance or, in Pierre Nora's term (1997), a lieu de mémoire-albeit not literally, since it is not fixed on a certain location and can be reactivated by subsequent groups of readers in different parts of the globe and geographical regions. The novel constitutes an embodied and performative act of memory that generates an experience of the past in the present (Plate and Smelik, 2013, p. 2). As Ann Rigney (2004) further argues, literary texts are particularly well equipped as carriers of cultural memory because they are valued as art, which enhances their chance of an afterlife. Because people value novels for their artistic merits, they take care to preserve them as part of their cultural heritage. Literary texts, she claims, can function as 'portable monuments' (Rigney, 2004, p. 383). What is meant, then, by saying that a novel is a monument is both literature's capacity to transmit historicity and the ability of novels to achieve artistic greatness in their own right, thus assuring their proliferation.

A topic that up until now has received less attention in literary criticism is the other side of monumentality: the dimension of magnitude 
in length, bulk, and thematic scope of the 'big, ambitious novel'. Even though the term 'monumental novel' is commonplace in criticism, especially in reference to nineteenth-century works such as those of Émile Zola or Stendhal, the term has rarely been given substance. It seems somehow self-evident. As Alexander Rehding suggests in his book on monumental music of the nineteenth century, it is hard to move beyond stating 'the obvious, bare observation that monumentality is somehow about big gestures and grand effects' $(2009$, p. 4). This chapter focuses on two case studies that embody the monumental in both meanings of the term: commemoration and material bigness. In this chapter, I explore how these two dimensions of monumentality relate to each other, how they reinforce or go against the other. How do the material dimensions of these works and their expansive scope relate to their workings as vehicles of cultural memory?

Let me briefly introduce my case studies. First, My Struggle (Min Kamp) by the Norwegian author Karl Ove Knausgård (1968-) consists of a total of six autobiographical novels that amount to 3,600 pages, published between 2009 and 2011. His writing stands out for its excessive detail; critics have called him a Norwegian Proust (Hughes, 2014). Second, 2666 by Roberto Bolaño, with a focus on 'Book IV: The Part about the Crimes'. The Chilean Bolaño (1953-2003), on the brink of death from liver disease, strove to leave to posterity what he called 'the fattest novel in the world' (Valdes, 2009, p. 12); the resulting magnum opus was posthumously published in 2004. At first glance, these works do not seem to have a lot in common. Bolaño presents a fictionalized account of a particularly brutal instance of recent history, the Ciudad Juárez femicides; Knausgård relates his own intensely personal memories in painstaking detail.

Yet, a parallel between the two novels emerges when we consider their quantitative aspect. The effects of the monumental are, after all, a direct result of material characteristics of weight, length, bulk, size, and number of pages (1,128 in Bolaño's case, 3,600 in Knausgård's). Besides immediately and sensorially underwriting their status as important, 'weighty' works of art, these material aspects also metonymically point to what is between the covers. Indeed, as I will show, My Struggle and 2666 amass an enormous amount of memorial material. These are works that seem to strive to remember 'everything': personal memories in Knausgård's case, the fictionalized victims of horrific events in recent history in Bolaño's case. Length becomes the material foundation for the book-bound novel as a performative and quantitative act of memory.

In this chapter, I argue that material volume in these cases is a direct result of the wish to remember more. This corresponds to a 'deeply rooted desire in Western culture: to remember everything and forget 


\section{Inge van de Ven}

nothing' (Plate and Smelik, 2013, p. 2). With the expansion of storage space that digital media have facilitated, this desire has only become more pervasive. People currently record and archive memories on a larger scale than ever before. It is my claim that the novels under scrutiny become monumental by employing certain ordering principles that deviate from conventional, narrative treatments of memorial material. Knausgård and Bolaño, each in his own way, refrain from making a selection of what they commemorate. This makes for radically inclusive, materially embodied acts of memory. I will investigate this inclusive presentation by considering the shift in dominance from narrative to database as cultural forms. Following Liedeke Plate's and Anneke Smelik's approach in Performing Memory in Art and Popular Culture, I look at these works of literature as 'acts that produce textures of space decipherable for their memory effects ... for the ways in which they inscribe memory or incorporate it' (2013, p. 16). Along these lines, I explore narrative and database structures in the book-bound novel as material traces of the past that are actualized in acts of the present. First, I will map the differences between the two ways of structuring the world, the narrative and the database, by using Lev Manovich's The Language of New Media (2001). In the two sections that follow, I analyze My Struggle and 2666, identifying the following strategies that amount to the material volume of these novels through an inclusive urge to remember: interminable narration, listing, and the anaphoric singulative frequency. This will allow me to examine the materiality of representation in the book-bound novel under the implicit influence of new media.

\section{Narrative versus Database}

As media theorist Manovich has argued (2001), both narrative and database function as models, allowing us to make sense of the world, but they differ in how they do so. Narrating entails exclusions and restrictive conditions, as it is the outcome of a certain economy in selecting what is to be included in the contents of a story (Genette, 1980). One could call this a symbolic or synecdochal logic in which certain items in a narrative (themes, characters, events) are meant to stand for other items. When asked to tell our life story, for instance, most people tend not to include every single person they have ever met, only the most important ones. In other words, a narrative structure results from selection, which implies a hierarchical process of valuation. In this respect, it is a remnant of the compression of data that characterized media before what Marshall McLuhan has termed the 'Electronic Age' (1964).

For the archive, on the other hand, and even more so for the database as its digital counterpart, this compression is less inevitable. As Manovich writes, the database is more inclusive, less discriminatory than narrative: no items need to be made exemplary for others (2001, 
p. 220). As explanation, he invokes the difference between paradigm and syntagm, as the two structural dimensions of all sign systems. In a narrative the paradigm, the 'database' of elements out of which a story is built, is implicit, whereas the resulting narrative sequence itself is explicit (p. 231). Digital media have reversed this relationship: here the paradigm, which is the database, is materially present. Interactive interfaces, for instance, present the entire paradigm to the user through an explicit menu of all the choices available. The syntagm, however-the 'narrative' or string of subsequent choices actually made-is dematerialized and therefore loses its privilege.

Another, related, difference between the two forms is that narrative amounts to a cause-and-effect trajectory. The organizing principle of narrative is the plot, a structure of relationships by which the events narrated are given meaning by being identified as parts of an integrated whole. Closure is of vital importance, since the ending of the story drives the narrative; it serves as a point from which the meaning of beginning and middle can be determined (Brooks, 1984). For the database, by contrast, closure in any real sense is impossible. It represents the world as a list of items without beginning or end, and every item possesses the same significance as any other (Manovich, 2001, p. 218). It is always possible to add a new element to the list. This is the radical open-endedness of the archive that Jacques Derrida emphasized in Mal d'archive (1995, p. 68). The digital database, depending on its space for memory storage, is potentially infinite and all encompassing - the epitome of the archive.

Although as models for making sense of the world, database and narrative are often pitted against each other, they just as often come together to produce hybrid forms, as Manovich readily admits (2001, p. 234). In Knausgård's My Struggle and Bolaño's 2666, I will now proceed to demonstrate, there is a productive tension at work between narrative and database as modes of representation, each with its own principles of organization. In what follows, I argue that in these works, even if they do not explicitly mention digital culture, the two modes of representation are related in terms of inspiration and cross-fertilization. Feedback from the database informs and transforms narrative strategies. The strategies I explore here are not new-lists derive from the epic, interminability was important during Romanticism, and the anaphoric singulative mode goes back to at least Cervantes's Don Quixote (1605)—but they obtain a new urgency today.

\section{Proust for the Facebook Era: Knausgård's My Struggle}

Karl Ove Knausgård was prompted to write his autobiographic series in a midlife crisis, causing him to embark upon a frantic search for self-knowledge through life writing. 'How did I end up here? Why have things turned out like this?' he asks in the first volume, A Death in the 


\section{Inge van de Ven}

Family (2012, p. 33). His recollection can be described as 'an act of the self to retrieve its traces in the past in order to anticipate the future' (Plate and Smelik, 2013, p. 4). His modus operandi in answering these questions is an exceptionally digressive style of narration. When Knausgård tells of his teenage self going through great pains to transport some beer to a New Year's Eve party, for instance, he explores so many narrative by-ways that this minor event takes up over seventy pages. Indeed, the many digressions in his writings take over the narrative altogether, rendering the story arch secondary. The resulting 'interminable' narration stems from a desire to be comprehensive, to 'say it all'.

Besides postponing the ending through digressions, interminable narration is a strategy for pushing back the story's beginning in an infinite regression. Regression problematizes the act of situating an origin. In a famous passage from Laurence Sterne's Tristram Shandy (1759-1767), the eponymous hero, brusquely interrupting the narration of his life story, observes:

I am this month one whole year older than I was this time twelvemonth; and having got, as you perceive, almost into the middle of my fourth volume-and no farther than to my first day's life-'tis demonstrative that I have three hundred and sixty-four days more life to write just now, than when I first set out; so that instead of advancing, ... I am just thrown so many volumes back. ... I should just live 364 times faster than I should write. It must follow, an' please your worship, that the more I write, the more I shall have to write. (2009, pp. 195-196)

Shandy wants to tell his life story $a b$ ovo, so he starts with recounting the specifics of his conception. But he regresses ever further until his intended autobiography ends four years before he was born. Wanting to be 'all-encompassing' like Shandy, Knausgård, on his existential quest, cannot frame his own life story. In order to comprehend who the writer is, the reader must know his father, of whom he says in an interview: 'He made me, so a lot of the things in this book come from him' (De Geus, 2011). And to know why his father came to behave the way he did, the reader should know the story of his parents. The origins of the author's current crisis are pushed back in regression.

On the other end of the temporal spectrum, the ending of the series is digressively pushed forward. Near the beginning of the first volume, the author describes how, on an evening in 2008, when wife and children have gone to bed, he sits down to write the first pages of this autobiographical epic: 'Today is 27 February. The time is 11.43 p.m.' (2012, p. 22). These are the same pages the reader has just read. Recording his life, the author reports on how this process is unfolding, often with an emphasis on quantity, measuring his textual production in relation 
to time, and thus chronicling his writer's block: 'a page-and-a-half in a month-and-a-half'; 'three pages, two months' work' (2014b, p. 444). Knausgård here employs a mode of recording as an open-ended, timebound process.

The foreclosure of closure thus effected is reinforced by the fact that, during the writing and publication, many of the author's loved ones were drastically affected by publicity. Some of his relatives tried to prevent publication, threatening legal action for his revelations of painful details concerning his father's alcoholism and violent temper. His wife Linda, who suffers from manic depression, even went into a psychosis as a result of the enormous commotion around the books. These ramifications of previous publications have become the subject of the last volume in the series: it is as if the lack of separation between life and work forces the author to draw ever-larger circles around his memories in an unsuccessful, because interminable, attempt to encapsulate them in an oeuvre. Therefore, in a Shandian logic of infinite digression and regression, the more Knausgard writes, the more he shall have to write. His interminable narration borders on the infinite as it transgresses the limits at both ends of temporal linearity.

This effect of the infinite is further enhanced by yet another feature of these novels, namely, the inclusion of lists and enumerations. Knausgård lists objects in his mother's house that have been there since his childhood (2013, p. 312); all the people living in his street when he was a kid, including names and occupations, as well as their children's names (2014a, pp. 15-16); all his schoolmates, hierarchically organized into who excelled at certain activities (p. 174); and all the girls in his class, categorized by characteristics he remembers (Figure 6.1).

The list, as Ernst van Alphen explains in Staging the Archive (2014), is the most basic organizing principle of the archive (p. 91). Conventionally, one can recognize a list on the basis of the formal features applied to a sequential presentation of items. In Knausgård's lists, as the reader can see in Figure 6.1, such formal patterning is absent. Instead, one recognizes these by a repeated syntactical function: 'There was ... And there was ... Then there was ...' (2012, p. 40). Contained within one block of linear text, these collections of formally diverse items give the reader a sense of the list's potential infinity. And that is exactly the function of the list when incorporated in art and literature. As Umberto Eco argues in The Infinity of Lists (2009), lists are to evoke the infinite by way of the principle of addition, etcetera. Listing, like interminable narration, incorporates the open-endedness of the database into the book-bound novel.

Not surprisingly, considering their focus on personal memories and the scale of this project, Knausgård's novels have been compared to Marcel Proust's À la recherche du temps perdu (1913) on more than one occasion (e.g., Hughes, 2014). Yet an important difference lies in the modes 




Figure 6.1 Listing the girls in his class (Knausgård, 2012, p. 40). Photograph by Inge van de Ven.

of frequency they employ. As theorized in Gérard Genette's Narrative Discourse (1980), frequency is the relation between the number of times an event occurs in the story and the number of times it is mentioned in the text of the narrative. Proust's narration is characterized by a high degree of habit. To express repeated occurrences he often employs what Genette calls the iterative, where what happens often in the story is mentioned in the text only once (1980, p. 114). For instance, the first sentence of Swann's Way goes 'For a long time I would go to bed early' (Proust, 2003, p. 26). As Genette has remarked, the whole Combray episode is highly iterative (1980, pp. 31-34), the effect of which is compression: 'a single narrative assertion covers ... several analogical events considered only with respect to what they have in common' (p. 31). The iterative is a typical case of what Manovich calls 'syntagmatic' narrativity, since each subsequent element is the outcome of selection from an implicit and invisible paradigm. 
Knausgård deviates from this narrative convention by opting for the far less common anaphoric singulative mode. This is a subtype of the singulative, where what happened $n$ times $(n$ being $>1)$ is narrated $n$ times $(n \mathrm{~N} / n \mathrm{~S})$, with each mention in the text corresponding to one occurrence in the story. We find a parody of this practice in Miguel de Cervantes's Don Quixote (1605), when Sancho Panza tells the story of a fisherman who wanted to transport three hundred goats in a boat that had room to contain only one. As Sancho narrates, it becomes clear that he intends to tell the event three hundred times, once for each trip, causing Quixote to exclaim, impatiently: 'Take it that they are all across ... and do not go on coming and going like that, or you will never get them all over in a year' (1993, p. 154). This subtype of frequency is not commonly used since it obviously amounts to an inefficient way of storytelling, namely, narrating without compression. It brings narrative closer to the 'paradigmatic' ordering system of the database, where a whole range of possible choices is presented.

This anaphoric singulative frequency goes a long way in accounting for the extraordinary volume of the My Struggle series. In Boybood Island (2014a), for instance, the author seems to have felt the need to include all the girls he ever fell in love with as a boy. The reader learns how he admires the girl from a distance and then makes a third party ask her to be his girlfriend. He then takes his time to recount the joy he felt when she says yes, followed by insecurity because he does not know what to do with her. After a couple of days, she breaks up with him, allowing the reader to witness the dramatic heartbreak this causes. Then the whole sequence is repeated. Knausgård refuses to choose only the most important objects of his affection, to compress some of the characteristics of others and amalgamate them into one character, as a pars pro toto. Bound to take every minor episode of his life exceptionally seriously, he wants to preserve them all. If one wants to compare him to Proust, it would be more accurate to say that Knausgård is Proust for the Facebook generation, who does not need to choose between hundreds of 'friends'. His writing is the equivalent of sharing 'Too Much Information' on social media, 'instagramming' pictures of every meal, 'twittering' personal details, or posting overly revealing selfies. My Struggle lacks a (recognizable) plot because narrativity is dispersed and fragmented. The syntagm or narrative is secondary and implicit: If something resembling a plot emerges, it occurs when the reader, as the living equivalent of an algorithm, searches for patterns and meaningful connections in the mass of details. We must therefore accept the absence of a causal grand narrative to Knausgård's autobiographical recollections. The author leaves it to the reader to distinguish between the meaningful and meaningless.

This refusal to prioritize obviously makes for a highly democratic treatment of memories: there is no clear hierarchy in what is recorded. 


\section{Inge van de Ven}

The inclusive urge to preserve is further reflected in a plenitude of detail, with a tendency toward the trivial-sixteen lines are devoted to making tea, nine lines to the attacks of 11 September 2001. The overly familiar is described repeatedly, at length and in full detail. Memories of mundane objects and events are piled on top of each other. Put in a sequential order, everyday trivialities, personal milestones like the birth of the author's children, along with public events, are all put on the same level. One such series, for instance, comprises the events of two months in a few lines. The release of the debut single of Supergrass; his drunken attendance of a concert; all the clothes, records, and books bought in two months' time, his goings-about on a trip to London, and his successful wedding proposal to his girlfriend (2014b, p. 546). In contrast to the usual emphasis accorded to marriage in the narration of one's life, the last event presented in this list recedes and becomes one element in a chain of unrelated occurrences. Enumerations like these affect the scope of autobiography because they transcend the individual focus to convey a snapshot of the times: '808 State released 808:88:98, the Pixies Doolittle, Neneh Cherry Raw Like Sushi, The Golden Palominos A Dead Horse, Raga Rockers Blaff. People started purchasing their own computers' (p. 299). Obviously, the purchase of computers is by no means caused by the new release of Raga Rockers. The emphasis is not on a narrative unity of experience and causality, but on a cumulative effect of disparate data. The only equivalence of the elements in such a sequence is that they are remembered.

Starting as a quest to restore meaning to lost time, Knausgård's search leads to the creation of a monument so comprehensive that it finally exceeds the self-centered and exhibitionist perspective that we would expect from a six-volume autobiography. Like Proust, Knausgård saves 'wasted' moments from oblivion. But by refusing to select, by striving to preserve and accumulate even the most mundane of his memories (making tea, doing the dishes), he makes the reader retrieve these lost moments for herself. Knausgård's struggle becomes our struggle too. In what is in the final analysis an antimonumental gesture of the mundane and trivial, his specific branch of literary exhibitionism flaunts a life that is easily as mediocre as most of his readers'. Through Knausgård's sheer radicalism in exposing the smallest details of his life, what he describes far surpasses the scope of his life alone and starts to refer instead to all our lives. Breaking the narrative mold and the subjective scope of autobiography through quantification and seriality, Knausgård monumentalizes the self and the everyday.

Taken together, the strategies of listing, the anaphoric singulative, and interminability that I have analyzed amount to a mode of representation that incorporates the characteristic open-endedness and inclusiveness of the database into the book-bound novel, resulting in the monumental volume of the series. Bolaño's 2666 employs the same quantitative 
strategies of representation to memorialize a particularly gruesome episode in recent history which, as 2666 shows, has not yet attained the sense of closure that allows us to speak of 'history' at all.

\section{Losing (Body) Count: Bolaño’s 2666 as Inclusive Memorial}

Like Knausgård, Bolaño was driven by the unstoppable urge to tell stories, which only increased during his last years when he suffered from incurable liver ailment. Motivated by the need to support a family and the knowledge that his failing health would not grant him much time, through his last dozen years the author maintained an exceptional productivity (sometimes writing nonstop for 48 hours), writing seven novels, three collections of stories, and many essays and poems (Valdes, 2009, p. 12). The creation of 2666 , the novel he called his 'bestial work, ... the monster that devoured me' (Braithwaite, 2006, p. 113) became a one-man race against death. Rumor goes that the author even postponed a liver transplant in order to finish his work (Wimmer, 2011, p. 13). Waxing romantic, I could say that like Scheherazade in 1001 Nights, Bolaño narrated interminably in a vain attempt to postpone his own death.

His magnum opus 2666 consists of five books that are loosely related thematically by their links to the mysterious writer Benno von Archimboldi on the one hand, and the murders of women in Santa Teresa on the other. ${ }^{1}$ Here, I will focus on 'Book IV: The Part about the Crimes', since the structuring principles of the database are the most pervasive in this part. Rather than rendering the victims of the Santa Teresa (and, by analogy, Juárez) murders present, I will argue, Bolaño's use of database strategies to represent them results in an overwhelming effect of absence. This referential absence will, paradoxically, enable me to read the book as a radically inclusive memorial. Situated in a fictional Mexican border town called Santa Teresa in the desert of Sonora, this book is based on the mass killings of women in Ciudad Juárez in the 1990s.

In Santa Teresa, women are killed on a massive scale. 'They disappear. They vanish into thin air, here one minute, gone the next. And after a while their bodies turn up in the desert' (p. 287). In 'The Part about the Crimes', these crimes are presented in the style of forensic reportage. These fragmentary reports, chronologically ordered, cover the discovery of 110 corpses of girls and women over a period of five years. Each of these cases is 'told' separately in the anaphoric singulative mode. This obviously goes against the conventions of the crime genre, which typically tells in full detail a select number of cases in order to facilitate the reader's emotional investment. ${ }^{2}$ As an effect of this refusal to amalgamate on the author's part, the reader is bombarded with a veritable overload of dead bodies without symbolization or compression, to the point of desensitization. Each of the corpses discovered over a period of five 


\section{Inge van de Ven}

years is recorded in a separate entry. These case files meticulously and unsentimentally sum up time and date of the discovery, the conditions in which the body was found, name (if known), (estimated) age, clothes and hair color, cause of death, mutilated body parts, and the actions taken by the police.

These police reports are typographically delimited by a dot (Figure 6.2), together forming a list of smaller narratives. 2666 has been called Bolaño's Moby-Dick (see Wimmer, 2011). There is, however, an important difference between the two. Melville's masterwork famously includes epic lists, for instance the 'cetology' catalogue of types of whales in chapter 32. In Moby-Dick, these lists are embedded within the encompassing framework of the narrative. In Bolaño's 'Part about the Crimes', however, it is exactly the other way around: the many fragmented narratives are framed by the list. This reversal is typical of the current shift in media to the archival, as van Alphen has noted (2014, p. 12). Narrative is absorbed by the database structure, which becomes its environment.

In a manner comparable to the lists in My Struggle, the list structure in 2666 makes sure that no particular element stands out as more important than another. Moreover, listing again has the effect of openendedness and will not allow for closure. Here, interminability seems to reside in the events themselves, rather than a style of presentation. Like the 'endless' city of Santa Teresa that seems to be 'growing by the second' (p. 129), 'The Part about the Crimes' is boundlessly digressive. The narrative drive to comprehensively represent these crimes is frustrated from

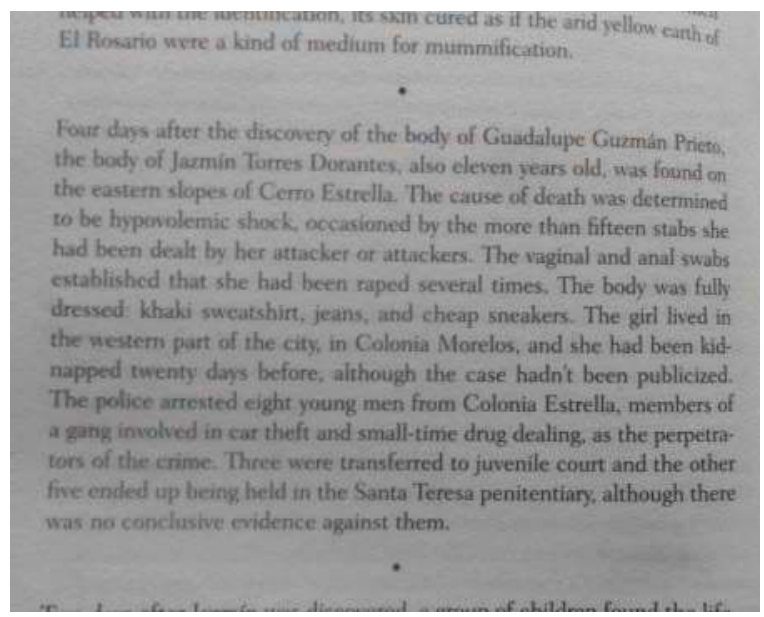

Figure 6.2 Example of an entry in a list of police reports (Bolaño, 2008, p. 546). Photograph by Inge van de Ven. 
the beginning because the beginning cannot clearly be demarcated. The first reported discovery of a corpse is dated 1993, but this date is immediately revealed as a construct, a conjecture: 'It's likely there had been other deaths before' (p. 353). And the end of the killings is proclaimed just as randomly as their commencement. Even though the murders continue unabatedly after one man has been captured, Santa Teresa's mayor performatively states in the media that

The serial killings of women have been successfully resolved. ... Everything that happens from now on falls under the category of ordinary crimes, what you'd naturally find in a city in a constant state of growth and development. This is the end of the psychopaths. (p. 539)

Over a hundred pages of new corpses follow after this 'successful' resolution, and the solution of the individual entries is equally left suspended. Ironically, most of these reports end with variations on the line 'The case was closed'. Yet, most cases are only 'closed' on this level of the performative statement. The entries do not conclude; they merely terminate. Due to this inability to demarcate the parameters of the murders, the list cannot restore a sense of order but can only attest to the disorder of the collected material.

Still, the discovery of the first body marks a significant event because from this girl on, 'the killings of women began to be counted' (p. 353). This notion of the body count is significant here, since it illuminates 2666's particular strategy of presentation as calculation. Wolfgang Ernst has pointed to the etymological affinity between the words for 'counting' and 'narrating' in different languages: verbs like conter, contar, raccontare, erzählen, vertellen, and 'to tell' all testify to an outlook on the world that oscillates between narrative and statistics. In the digital era, this meaning of narrative as counting becomes relevant (Ernst, 2013, p. 155). What counting and narrating have in common is that they put something in order: numbers in the first case, construing a sequence of causal relations out of seemingly insignificant facts in the second. The archival listing of victims in Bolaño's work is closer to ordering data in the first sense of counting, as becomes clear when in the months when no bodies are discovered, the count continues:

There were no deaths in July. None in August either. (p. 375)

The lack of contours of these killings renders it impossible to make a narrative plot out of them. Narrative simply fails as an ordering strategy 


\section{Inge van de Ven}

since its structures cannot encapsulate the mass of data. Consequently, this literal body count seems the only feasible alternative. But despite this meticulous statistical approach, an order is put ever further out of reach.

Besides the impossibility of fixing the temporal parameters of the murders, there is a lack of demarcation between the supposed serial killings and what in Santa Teresa seem 'everyday' occurrences of violence, such as attacks on prostitutes or domestic abuse. It is impossible to perceive the contours of the phenomenon since of course, 'what really happens' in Sonora is more encompassing and complex than the work of a single serial killer. Drug crimes, a capitalist system of gigantic factories where women are used as cheap laborers with no right to unionize, a sexist culture, extreme poverty, a corrupt police system, etcetera. One inspector sighs: 'I ... examine everything with a magnifying glass, over and over, until I can't see straight' (p. 470). He unwittingly points out the exact problem: he would do better to drop the magnifying glass and zoom out. These deaths could only 'make sense' relationally when understood in totality. But this totality is ungraspable, since the list of factors contributing to these crimes is simply too big. As a result, these murders are illegible: they can neither be written nor read.

What does this failure of the database structures to order the murders mean for the novel's potential to function as a monument-or in this case, a memorial? ${ }^{3}$ True to the real Juárez killings (see Wright, 2006), in 2666 the victims of the femicides were disposable in life, and they are literally and materially disposable after their deaths. Their bodies are carelessly done away with by their killers, and then after their discovery by the police they are 'tossed into the public grave' (Bolaño, 2008 , p. 575). Without reminders in literature and other arts and media, it would not be far-fetched to allege that these victims would sooner or later be dropped in what Bolaño terms the 'garbage pit of history' $(2008$, p. 228). This begs the question if this monumental novel functions as a memorial to the victims of the Juárez femicides. Does the text render them present, in an act of testimony to readers in the future? Does 2666 strive to account for these bodies that have gone unaccounted for in recent history by making them part of an order, an aesthetic structure?

Reading the first reports, the meticulous description of the remains of the victims still transmits a (very minimal) sense of 'presence'. Then, as the list progresses, the sheer quantity of bodies prevents any such order from materializing. As more cases are added, the last becomes ever more indistinguishable from the preceding ones. The victims are presented as separate data entries, but they exist not for themselves-rather, only in relation to the series that precedes and follows. In trying to keep track of the grisly body count, the reader experiences what van Alphen calls the 'mass-induced dissolution of referentiality' (2014, p. 103) of the archive. Through repetition, the representation effaces its referent. The female victims soon become interchangeable, and their singularity is annihilated even within the commemoration of their senseless deaths. 
This annihilation is performed by the most powerful aesthetic component of Bolaño's textual monument, its rhythm. In the enumeration of the crimes, rhythm is created by the repetition of inconclusive sentences like 'the case was left unresolved' (p. 495) and 'no one came to claim the body' (p. 126), and reoccurring characteristics like 'she had long black hair' (p. 126), 'fracture of the hyoid bone' (p. 545), or 'the victim was anally and vaginally raped' (p. 423). The details of the separate entries begin to blur. The effect is more poetic than narrative, and the relentless flow of data is almost hypnotizing. The plot of the novel at times dissolves completely and leaves the reader with myriad ungraspable patterns flashing before her eyes, disappearing as soon as they emerge. In spite of the horrors of the reports' contents, all affect is soon emptied out from the representation.

Because of this mass-induced dissolution of singularity, the listing of individual names fails to make its subjects referentially present. It cannot transcend the absence of these victims as a memorial would. But this does not mean that 'The Part about the Crimes' is a failed memorial altogether. For exactly by failing to order these crimes, Bolaño's text manages to evoke an overwhelming sense of absence. It is the powerful effect of memorials such as Washington, D.C.'s Vietnam Memorial, designed by Maya Lin in 1982, and many Holocaust memorials that have been modeled as lists of names (van Alphen, 2014, pp. 102-103). It is the uncountable number of victims that overwhelms us, their innumerability that cannot be imagined. Where the list fails to attain a resolution in denoting the specific victims to whom it referentially points, it succeeds as an aesthetic strategy to convey the monumental scale of the absence of its subjects. The list then takes on a symbolic load and is transformed into a memorial to something far surpassing the 'uncountable' number of victims included in the book. This sublimity of lists justifies Bolaño's choice to represent these crimes in the more inclusive form of a database: the economy of narrative compression would fall short of commemorating the victims of such a grand scale of atrocities. Just as Homer conveyed the disastrous effects of the Trojan War by enumerating them in a list of warships in the Iliad (2.494-2.759), Bolaño quantifies the enormity of the horrors reigning in Santa Teresa by enumerating the victims in a paratactic list of case files. As a textual memorial, 2666 becomes massively inclusive. In Marcela Valdes's words, Bolaño aimed 'to write a postmortem for the dead of the past, the present and the future' (2009, p. 15). Only the monumental can do justice to these monstrosities; size, here, is a direct correlate of commemoration.

\section{Conclusion}

In this chapter, I began with the question of how size and memory, as two dimensions of monumentality, relate to each other in contemporary 'monumental novels'. First, I considered the notion of the 


\section{Inge van de Ven}

novel as a monument. Then I brought the material aspects of volume and bulk into the discussion. I claimed that, in order to understand the monumentality of these novels, size, memory, and matter should be discussed as interrelated. I argued, moreover, that in the cases of Knausgård and Bolaño we should understand an expansion of material and memorial scope in terms of the shift from narrative to database. Contrary to Manovich, who presents these modes of representation in opposition to one another, we have seen that database structures affect narrative, which results in hybrid forms. The works under scrutiny are specifically monumental because of their use of narrative strategies that are akin to the database's 'paradigmatic' mode of representation. A general drive to preserve as much as possible of the past and the present without compression manifests itself more specifically in a number of devices and structural principles of narration, such as lists, the anaphoric singulative mode of frequency, and digression and regression (or 'interminability'). I demonstrated how, under the (unacknowledged) influence of digital media, these novels employ a quantitative mode of narrating-as-counting in which causality and closure make way for seriality and open-endedness.

From my analysis of My Struggle it became clear that Knausgård employs a digressive and regressive mode of memory writing as an open-ended, time-bound process. Through strategies of listing and interminable narration, I argued, he incorporates the open-endedness of the database into the book-bound novel; his use of the anaphoric singulative frequency amounted to a 'paradigmatic' ordering system, where a whole range of possible choices was presented. Here, size and memory were two sides of the same coin. In Bolaño's 'The Part about the Crimes' the same ordering principles and devices resulted in an 'endless' list of victims that did not succeed in communicating a sense of presence (making the past present), as we would expect of a monument. However, it is precisely through this failure to monumentalize the victims of the Santa Teresa femicides that this text succeeds in transmitting an overwhelming effect of absence that makes it into a radically inclusive memorial.

The 'hybrid' strategies between database and narrative as employed in the works of contemporary writers like Bolaño and Knausgård amount to a literary monumentality in both senses of commemoration and material bigness. Both works are marked by an inclusive urge to preserve what is judged as important and valuable, which, coupled with an unwillingness to select, results in novels of extraordinary volume. Yet, precisely because of their open-ended structures, it would be more accurate to categorize these texts as antimonuments. After all, 2666 foregrounds loss and absence rather than making the past present, and My Struggle emphasizes the mundane, the trivial, and the ephemeral. Together these works exemplify how the new possibilities for scale brought about 
by digitalization have reinforced a widespread cultural drive to capture and preserve 'everything', and they show how this affects literary representations.

\section{Notes}

1 Bolaño originally intended the five books to be published separately, one volume per year, to provide for his children's future. His friend and designated literary executor Ignacio Echevarría chose otherwise, prioritizing the artistic integrity of the whole (Echevarría, 2008).

In the case of My Struggle, it was exactly the other way around: in the sixth and last volume, Knausgård describes how he first preferred his magnum opus to be published in one single volume, in order to make a statement with 'the fattest novel in Norway' (2011, p. 61), until his editor Geir Gulliksen convinced him of the serialized format.

2 The film Bordertown (2006, dir. Gregory Nava), for instance, like 'The Part about the Crimes' based on the Ciudad Juárez femicides, has one of the victims escape and join forces with a female journalist (played by Jennifer Lopez) so that the truth about the murders would get out to the public.

3 Whereas monuments are generally celebratory, memorials commemorate victims of the past. The memorial is more democratic as it commemorates ordinary people and the everyday instead of exclusively celebrating 'high points' and heroes.

\section{References}

Assmann, A. (2011) Cultural Memory and Western Civilization: Functions, Media, Archive (Cambridge: Cambridge University Press).

Bolaño, R. (2008) 2666 (Trans. N. Wimmer) (New York: Farrar, Straus and Giroux).

Braithwaite, A. (2006) Bolaño por si Mismo: Entrevistas Escogidas (Santiago de Chile: Ediciones Universidad Diego Portales).

Brooks, P. (1984) Reading for the Plot: Design and Intention in Narrative (New York: Knopf).

Cervantes Saavedra, M. de (1993) Don Quixote (Trans. P.A. Motteux) (London: Wordsworth).

De Geus, Breda. 'Interview with Karl Knausgård. Part 3', Youtube, clip uploaded 16 November 2011, http://youtube.com/watch?v=Pb3SckzdBC4 (Accessed 30 March 2014).

Derrida, J. (1995) Archive Fever: A Freudian Impression (Trans. E. Prenowitz) (Chicago: The University of Chicago Press).

Echevarria, I. (2008) 'A Note from the Author's Heirs' in R. Bolaño 2666 (Trans. N. Wimmer) (New York: Farrar, Straus and Giroux).

Eco, U. (2009) The Infinity of Lists (Trans. A. McEwen) (London: MacLehose Press).

Ernst, W. (2013) 'Telling versus Counting: A Media-Archeological Point of View' in J. Parikka (ed) Digital Memory and the Archive (Minneapolis: University of Minnesota Press). 147-157.

Genette, G. (1980) Narrative Discourse: An Essay in Method (Trans. J. Lewin) (Ithaca, NY: Cornell University Press). 


\section{Inge van de Ven}

Homer (2015) The Iliad: A New Translation by Peter Green (Berkeley: University of California Press).

Hughes, E. (2014) 'Karl Ove Knausgård became a literary sensation by exposing his every secret', New Republic, 7 April, http://newrepublic.com/ article/117245/karl-ove-Knausgård-interview-literary-star-struggles-regret (Accessed 01 June 2014).

Knausgård, K. O. (2012) A Death in the Family: My Struggle: 1 (Trans. D. Bartlett) (London: Harvill Secker).

Knausgård, K. O. (2013) A Man in Love: My Struggle: 2 (Trans. D. Bartlett) (London: Harvill Secker).

Knausgård, K. O. (2014a) Boyhood Island: My Struggle: 3 (Trans. D. Bartlett) (London: Harvill Secker).

Knausgård, K. O. (2014b) Schrijver: Mijn Strijd 5 (Trans. M. Molenaar) (Breda: De Geus).

Knausgård, K. O. (2015) Vrouw: Mijn Strijd 6 (Trans. M. Molenaar) (Breda: De Geus).

Manovich, L. (2001) The Language of New Media (Cambridge, MA: The MIT Press).

McLuhan, M. (2001) Understanding Media: The Extensions of Man (London: Taylor and Francis).

Nava, G. (2006) Bordertown (United States of America: Möbius Entertainment).

Nora, P. (ed.) (1996-1998) Realms of Memory: The Construction of the French Past Vols 1-3 (Trans. A. Goldhammer) (New York: Columbia University Press).

Plate, L., and A. Smelik. (2013) 'Performing Memory in Art and Popular Culture: An Introduction' in L. Plate and A. Smelik (eds) Performing Memory in Art and Popular Culture (London and New York: Routledge). 1-22.

Proust, M. (2003 [1913]) In Search of Lost Time Vol. 1: Swann's Way (Trans. C.K. Scott Moncrieff and T. Kilmartin) (New York: Random House).

Rehding, A (2009) Music and Monumentality: Commemoration and Wonderment in Nineteenth-century Germany (Oxford: Oxford University Press).

Rigney, A. (2004) 'Portable Monuments: Literature, Cultural Memory, and the Case of Jeanie Deans', Poetics Today 25.2: 361-396.

Sterne, L. (2009) The Life and Opinions of Tristram Shandy, Gentleman (London: Wordsworth).

Valdes, M. (2009) 'Introduction: Alone among the Ghosts' in Roberto Bolaño: The Last Interview and Other Conversations (Trans. S. Perez) (New York: Melville House). 9-40.

Van Alphen, E. (2014) Staging the Archive: Art and Photography in the Age of New Media (London: Reaktion Books).

Wimmer, N. (2011) 'Roberto Bolaño and the Savage Detectives', http:// us.macmillan.com/uploadedFiles/custompagecontents/titles/bolanobiographicalessay.pdf (Accessed 1 April 2013).

Wright, M. (2006) Disposable Women and Other Myths of Global Capitalism (London and New York: Routledge). 


\section{Part III}

\section{Reenactment, Affect, and Remembrance}


This page intentionally left blank 


\title{
7 Archives of Affect \\ Performance, Reenactment, and the Becoming of Memory
}

\author{
Louis van den Hengel
}

In the spring of 2010, I spent three months at the Museum of Modern Art (MoMA) in New York to observe and participate in Marina Abramović's performance The Artist is Present, a long-durational work that formed the centerpiece of an exhibition of the same name devoted to Abramović's performance art career. In addition to the eponymous performance, the exhibition featured live reenactments of five of Abramović's earlier works-the first ever to be performed by other people in a museum setting-in an attempt to transmit the artist's presence and make her historical performances accessible to a contemporary audience. ${ }^{1}$ Supplementing the mix of documentary photographs, video, and digital displays that filled the galleries on the sixth floor of the museum, the re-performances were enacted continuously by a team of forty performers, mainly younger dancers and artists selected and trained by Abramović herself, who worked in shifts throughout the exhibition for a total of over 700 hours.

As the MoMA show approached its ending, I was informed that a group of young artists from New York's radical queer underground were staging an alternative series of reenactments under the title The Artist Is Absent. While conceived as a tribute to the work of Abramović, the event also served as a kind of protest to the curatorial decisions that informed the retrospective at MoMA. As the organizers explained on their website, The Artist Is Absent aimed to give visitors the opportunity to experience Abramović's artworks 'in a context closer to their original presentation', by openly engaging, and revitalizing, the anti-institutional and activist ethic that marked the emergence of performance as an autonomous art form during the 1960s and 1970s. ${ }^{2}$ In addition, the show was directed against what was perceived as the overly normative body politics of the reenactments presented at MoMA. In contrast to the performing bodies at The Artist Is Present, whose visibility remained curiously unmarked in its proximity to the cultural norm of young, white, cisgender, thin, and able-bodied corporeality, the performers of The Artist Is Absent were largely drawn from the queer, transgender, BDSM, leather and kink communities of the city. In the process of recruitment, the curators had explicitly prioritized a more varied and contrasting group of bodies, 


\section{Louis van den Hengel}

which they considered to be 'uniquely equipped to deal with the public intensity and vulnerability' required by Abramović's work. ${ }^{3}$

And so I found myself over Memorial Day weekend at the $25 \mathrm{CPW}$ Gallery, an alternative art space on the Upper West Side less than a mile away from MoMA, to behold this queer corrective to the Marina Abramović retrospective. Over the course of four to five hours, I witnessed a variety of re-performances, including several reenactments of Abramović's earliest works: harrowing pieces often involving dangerous forms of self-violation that would have been clearly impossible to execute within the institutional environment of MoMA. While the re-staging of these works did not fail to affect the audience, myself included, on the visceral level of immediate sense experience, I could not escape the thought that my visit was, in fact, an awful waste of time. I lost my patience during a reenactment of Light/Dark, a work first performed by Abramovic and her then-collaborator and partner Ulay in Cologne in 1977, which featured the artists kneeling opposite each other, their faces lit by strong spotlights as they took turns slapping each other. Whereas the original piece gradually developed a rhythm that relentlessly pushed the performance forward, the re-performers seemed unfocused, even giddy, as they made their way through what increasingly started to look like an inadvertent parody of the initial work. Frustrated with what I perceived as the performers' poor technique, and fearing that their inferior copy would taint my memory of the original work-a memory which, incidentally, is not derived from the performance itself but from the archival documentation of its reenactment by Abramović and Ulay, who re-performed the piece for film in 1978-I did something that I still regret today: I stood up and left. I left and went back to MoMA, to see the 'real' thing.

The purpose of this chapter is to actualize, in retrospect, what I failed to achieve during my encounter with The Artist Is Absent in 2010. In what follows, I seek to explore, and affirm, the potential of performance and re-performance to act as material processes of historical, cultural, and aesthetic memory-a multiple folding of time that carries the past into the present, and affirms the presence of the present as the living force of memory. This affirmation, as I will explain, entails a new materialist ontology of performance with the potential to unfold an alternative ethics of performance art conservation. In contrast to the debates within performance theory and in the professional field that center on the ephemeral or fleeting nature of live art, my focus is on how memory is mediated through the distinct materiality of performance. I want to locate this materiality in the affective operations of performance as a time-based, yet profoundly untimely, art form. In this view, it is the expressive event of performance itself that creates an enduring archive in which the forces of matter and memory meet in co-shaping motion. 
Memory, as Gilles Deleuze (1991) reminds us, is not merely the recollection of experience but a creative power for inventing the new: rather than re-presenting a past present, memory presents itself as a ceaseless process of difference and change. In this sense, memory, although it expresses itself through particular bodies and individuals, cannot be contained in any single place but rather operates by way of affective interconnections or creative encounters. In other words, memory works as a performative practice: 'a process that takes place in the present and that is embodied, material, and susceptible to inferences from its context of production' (Plate and Smelik, 2013, p. 14). In the following sections, I will discuss how current strategies of reenactment activate this performative dimension of memory in the context of the debates about the institutionalization of live art today, as well as in relation to traditional ontologies of performance. Subsequently, I will examine how performances of memory, and memories of performance, come to matter. To this end, I will bring some of the critical contestations of traditional archival logics developed within contemporary studies of cultural memory into dialogue with the Deleuzian concept of affectivity as a material force of becoming. I will argue that reenactment, by mobilizing the body's affects across the boundaries of the present and the past, holds the power to open minoritarian modes of producing and proofing performance art histories. To substantiate this argument, I will examine a number of performance works by Marina Abramović and Mary Coble, before I return, finally, to my own recollection of The Artist Is Absent.

\section{The Drive to the Live}

In the first decade of the twenty-first century, performance and live art have experienced a remarkable resurgence in popularity. Performance programming is thriving at biennials and art festivals worldwide, and departments dedicated to the collection and presentation of live artsuch as those at MoMA or Tate Modern-are progressively incorporated into the contemporary art museum. Landmark exhibitions such as the Marina Abramović retrospective or the Tino Sehgal show at the Guggenheim Museum in 2009 have brought about a startling repositioning of performance, which has moved not only from the margins to the mainstream of contemporary art, but also increasingly takes center stage in today's popular cultural imaginary. The notorious collaborations of Abramović with celebrities such as Lady Gaga, James Franco and Jay-Z, or her partnership with Adidas timed to the 2014 World Cup, serve as recent examples of the great shifts in the field of live art, now that traditional art institutions, as well as major media corporations, have become aware of the potential of performance art histories within a burgeoning experience economy. 


\section{Louis van den Hengel}

Against this background, questions about the ontology of performance and the preservation of its art-historical legacy are put firmly on the agenda of art scholars, cultural theorists, museum professionals, and artists or practitioners. Whereas performance throughout the 1960s and 1970s actively resisted the object status of visual art as it was privileged, and commodified, in the context of the art market and finance capitalism, live art today is increasingly entering public and private collections. Performance reenactment, as a form of what Claire Bishop has termed 'delegated performance', has gained significant cultural and economic currency in this context. Delegated performance, which involves the hiring of nonprofessionals or specialists from other fields to enact live works, enables performance to exist independently from the artist, allowing it to be bought and sold by institutions and individuals not in spite of but rather because of its processual nature (Bishop, 2012). At the same time, the ongoing re-creation of live art, which brings into question the uniqueness and authenticity of any 'original' event, requires a critical reconsideration of the ontology of performance in relation to its temporal condition.

Peggy Phelan's well-known claim that 'performance in a strict ontological sense is nonreproductive' (1993, p. 148) has turned into a refrain that continues to haunt any discussion of live art today. The life of performance, writes Phelan, exists only in the present:

Performance cannot be saved, recorded, documented, or otherwise participate in the circulation of representations of representations: once it does so, it becomes something other than performance. To the degree that performance attempts to enter the economy of reproduction, it betrays and lessens the promise of its own ontology. Performance's being ... becomes itself through disappearance. (p. 146)

For Phelan, the inability to be reproduced or repeated is the greatest strength of live art because it resists the ideologies of capital indexed on systems of reproductive representation (p. 149). The ontology of performance as disappearance, often understood in terms of ephemerality and loss, has played a central, even constitutive, role within performance studies, especially under the impact of the linguistic turn. It has also become a truism-albeit an increasingly contested onewithin the professional field, where it translates into a practical need to develop new skills, approaches, and networks to collect and maintain performance-based art (Laurenson and Van Saaze, 2014). The result is that the acquisition of 'immaterial' works is habitually framed as incompatible with the progressive or critical qualities of performance art under late capitalism.

I take issue with this melancholic-and essentially Lacanian-belief that performance can only attain symbolic status within the cultural 
realm if its social and political potency is somehow cut off. An ontology of performance, and its preservation, premised on notions of loss and death may be concerned with re-membering and re-valuing the immaterial, but in fact denies the future of performance art. Where, after all, is the place for the living history of the genre if it cannot persist on the margins of contemporary art, nor survive in the center? How can the transitory movement of performance be secured in art history if its preservation can only succeed if it fails? If we want to capture, or protect, that elusive quality that gives life to live art, we need to adopt an alternative, more affirmative, ontology of performance: one that recognizes how performance itself remains in and through the materiality and temporality of supposedly fleeting events.

\section{Beyond Disappearance}

To escape the double bind sketched above, I propose a different conception of performance not as a mode of disappearance but as an active force of creation, knowledge, and cultural memory. More precisely, I want to replace the melancholic understanding of performance as the site of an irreparable lack or loss of being with a new materialist ontology of affect based on an ethics of becoming. I understand the notion of affect here with Deleuze as the change or variation that occurs when bodies enter into new relations, or, in other words, as the dynamic and unpredictable force of becoming-different (Deleuze and Parnet, 2006, p. 45). Affect, crucially, is at once an experiential force and a 'material thing', and as such it can 'compel systems of knowledge, history, memory and circuits of power' (Colman, 2005, pp. 11-12). For present purposes, I am particularly interested in the power of affect to invent intensive sensations of memory in which the representation of the past turns into a performative enactment-a creative return-of history in the present.

The move toward a new materialist ontology of performance entails the refusal of two key assumptions within performance studies: first, the definition of performance as that which disappears, and second, the association between ephemerality and immateriality upon which that definition rests. For Phelan, performance may be reminded, but it does not remain: 'It saves nothing; it only spends' (1993, p. 148). As we have seen, however, this view on performance, far from being an ontological fact, is itself intimately invested in the idea of liveness and immateriality as critical forces within contemporary art. If, by contrast, we consider performance not as the 'dematerialization' of the art object but as a material practice in its own right, it becomes possible to recognize how performance endures rather than disappears within the perpetual flow of the present.

For Rebecca Schneider (2011), who discusses Phelan's ontology of performance in relation to the notion of the archive, performance is 
indeed here to stay. Schneider usefully suggests that the definition of performance as disappearance is not the disruption but the effect of the archival logics it seeks to oppose: 'If we consider performance as of disappearance, of an ephemerality read as vanishment and loss, are we perhaps limiting ourselves to an understanding of performance predetermined by our cultural habituation to the logic of the archive?' (p. 98). What is given to the archive, commonly understood as a collection of enduring materials (records, objects, documents), is what is 'recognized as constituting a remain' (p. 98), that which is capable of being documented or which has become a document itself. To the extent that performance is not its own document-another truism of performance studies-it is by definition that which does not stay: 'As the logic goes, performance is so radically "in time" (with time considered linear) that it cannot reside in its material traces and therefore "disappears" (p. 98). This is a problematic view, says Schneider, because if we consider performance primarily as disappearing, 'we ignore other ways of knowing, other modes of remembering, that might be situated precisely in the ways in which performance remains, but remains differently' (p. 98).

The logic of the archive, crucially, is shaped according to patrilineal and Western conceptions of knowledge and cultural memory: as a regulatory fiction, the archive rests on a white and decidedly straight logic that privileges material artifacts, such as visual and textual documents, as archival objects, while embodied and performative practices are disqualified as modes of storing and transmitting knowledge (Cvetkovich, 2003). The conflict, as Diana Taylor points out, is not between the written and spoken word, but between the archive of supposedly enduring objects and what she calls the 'repertoire of embodied practice/knowledge' (p. 19). Writing about the transformations of cultural memory in the Americas, Taylor highlights the violence with which archival memory has been valued over the traditions of embodied mnemonic practices that compose the repertoire. Colonial systems of power and knowledge indeed function to a large degree by rejecting indigenous performative practices, such as ritual, dance, and storytelling, as proper historical practices, so that the enactment of living memory comes to lie beyond the archive, and outside the official histories sanctioned by that archive. The embodied practice of performance, then, is scripted as a matter of disappearance, not because it actually disappears but because its particular temporality is denied as a proper form of material evidence.

Against this background, it becomes clear that there is an imperialist logic at work in the association of performance with ephemeral and nonreproducible knowledge, regardless of how progressive the political commitments of those who hold that view may be. In fact, if the authority of the archive depends on the idea that performance's nature is to disappear, or indeed, as Schneider argues, if the archive 'performs the equation of performance with disappearance, even as it performs 
the service of "saving" (2011, p. 99), then any ontology that links the subversive ephemerality of performance to disappearance, pace Phelan, necessarily betrays and lessens the promise of its own politics. If, by contrast, we take performance seriously as 'a system of learning, storing, and transmitting knowledge' (Taylor, 2003, p. 16), we can begin to think with the potentiality of performance to act, to create, to materialize the past in the present. In the following sections, I will trace how the performative practices of Marina Abramović and Mary Coble enact, and reenact, a material-affective transmission of knowledge in which the archive and the repertoire collide and collapse into the vital becomings of memory itself.

\section{Flesh Memory}

Marina Abramović's performance series Seven Easy Pieces, created in 2005 at the Guggenheim Museum in New York, examined the possibilities of documenting and preserving performance art history through the creative reenactment of singular performance works. Presented daily over a period of one week, with each performance lasting from 5:00 PM to midnight, Abramović re-created five seminal performances from the 1960s and 1970s: Bruce Nauman's Body Pressure (1965), Vito Acconci's Seedbed (1972), VALIE EXPORT's Action Pants: Genital Panic (1969), Gina Pane's The Conditioning (1973), and Joseph Beuys's How to Explain Pictures to a Dead Hare (1965). To this she added a remake of her own work Thomas Lips (1975), now retitled Lips of Thomas, and a newly commissioned piece called Entering the Other Side that premiered on the seventh night.

Abramovićs stated aim was not only to give the public an opportunity to gain first-hand experience of these iconic performance works, but also to open a discussion about the ethics of performance art conservation:

The project confronted the idea that documentation rarely existed in the critical early period of performance history. One often had to rely on testimonial witnesses, poor quality video recordings, and photo negatives. Due to the dire conditions of performance art documentation, these substitutable media never did justice to the actual performances. The only real way to document a performance art piece is to re-perform the piece itself. $(2007$, p. 11)

The arrangement of Seven Easy Pieces established what the artist considers the proper conditions for re-staging the performance pieces of other artists, which include obtaining permission from the original artists or their estates, paying them for copyrights, and studying and exhibiting any extant documentation material of the original works. At the same time, Abramović insists on interpreting past performances 'as one would 


\section{2}

a musical score'-a written composition 'that anyone who is properly trained can re-play' $(2007$, p. 11). This suggests that while Abramović does remain invested in traditional notions of authorship, she avoids the tendency to locate the authenticity of performance in a long-lost originary event: the life of performance, in her view, rather lies in an ongoing process of re-invention, re-vision, and re-articulation.

By performing the body simultaneously as a matter of record and as a means of recording, ${ }^{4}$ Abramović unsettles any clear-cut ontological distinctions between live art and its documentation. Whereas for Phelan the document of a performance is 'only a spur to memory, an encouragement of memory to become present' (1993, p. 146), for Abramović memory is always already present within the bodies and things through which performance continuously materializes itself. Abramović, then, does not present reenactment as 'the site where the authentic meaning of the original event is to be found', as some critics have presumed (Jones, 2011, p. 26), nor does she privilege the live act as such as 'delivering an authentic and "present" body' (p. 17). Even though, as Jessica Santone points out, 'each document organizes itself around the idea of an "original experience"' (2008, p. 150), Seven Easy Pieces privileges neither the body of the artist nor the act of documenting as a means of accessing the reality of performance. As experimentations with what performance can do, Abramovićs reenactments do not seek to re-present the past, but rather to dissolve the borders between the past and the present, the document and the event, to create what is not yet given: an audience to come.

It is significant that Abramović explicitly acknowledges her dependence on archival materials both for the retrieval of knowledge about the works reenacted in Pieces, which she did not witness herself, and for the form of their reexecution. In fact, several of the re-performances are direct re-stagings of documentary images: for example, an unedited video recording in the case of the Beuys performance and a number of photographs in the case of EXPORT's work (Figures 7.1 and 7.2).

The latter example is the most complex, since none of the images of EXPORT documents the actual performance, which is said to have taken place in a pornographic movie theatre in Munich. EXPORT has reportedly asserted that she went into the theatre wearing pants with the crotch cut away and carrying a machine gun, but later refuted the claim that the cinema showed pornography, while also denying the presence of the gun. The photographs were created after the event, and it is possible that the weapon was added to translate the potentially violent dynamics of the live action into an image (Widrich, 2012). ${ }^{5}$ In any case, the fact that Abramović chose to re-create an image that has given canonical status to a performance whose reality is as unclear as it is contestedinformation well known to Abramović and the curators of Seven Easy Pieces-emphasizes that she is less interested in accessing 'authentic' 


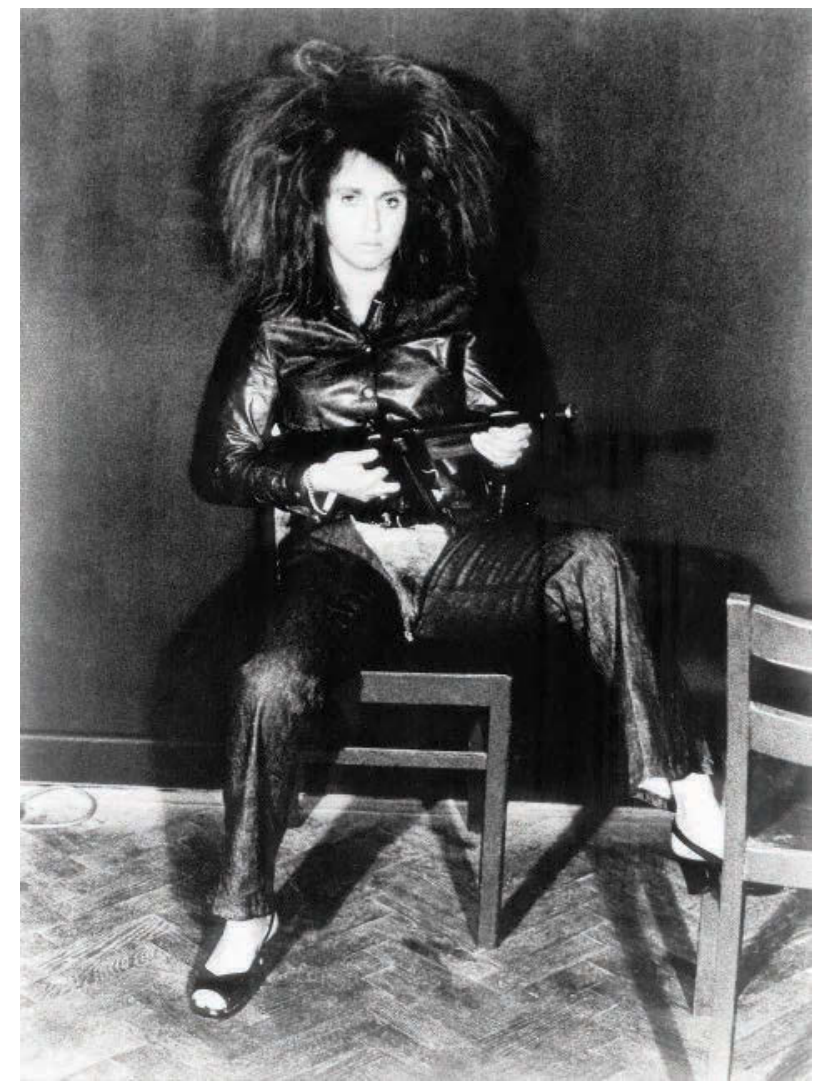

Figure 7.1 VALIE EXPORT, Aktionshose: Genitalpanik (Action Pants: Genital Panic, 1969), photo serial, self-staging. Photograph by Peter Hassmann. Courtesy of VALIE EXPORT and Bildrecht, Vienna, 2016.

events than in staging the power of the performance archive to produce its own realities.

As Philip Auslander points out, it is often assumed that the event of performance is'staged primarily for an immediately present audience', whereas the document is 'a secondary, supplementary record of an event that has its own prior integrity' (2006, p. 4). Auslander, in contrast, draws on J. L. Austin's theory of speech acts to argue that 'the act of documenting an event as a performance is what constitutes it as such' (p. 5). Unlike Phelan, who locates the ontology of performance in the co-presence of living bodies in a given time and space, for Auslander the live event itself is contingent upon the possibility and practice of its mediation: 'It is not the initial presence of an audience that makes an event a work of performance art: it is its framing as performance through the 


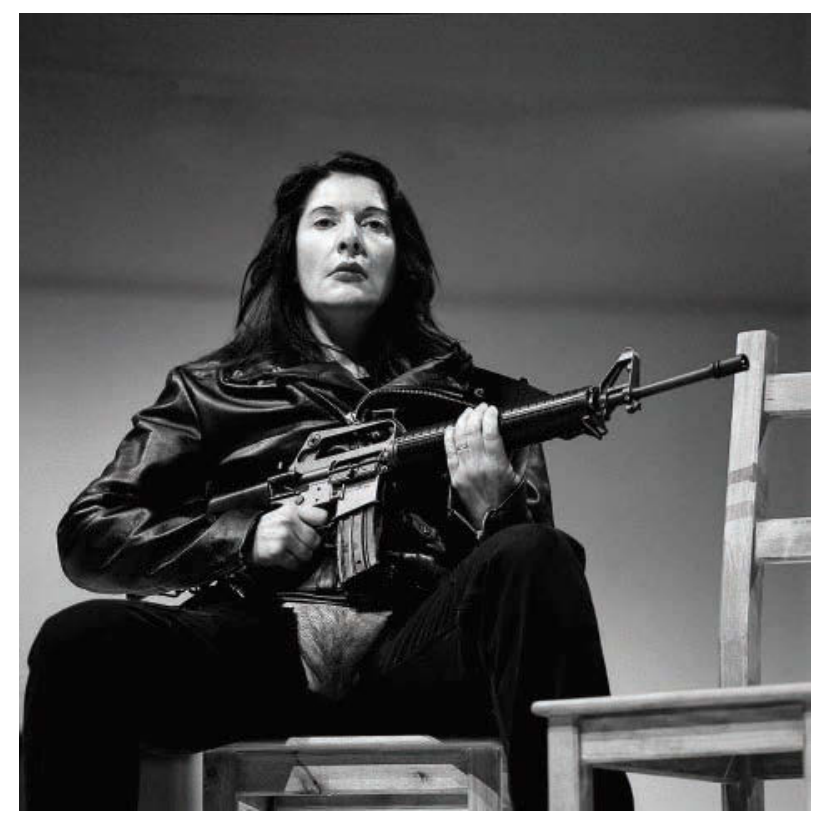

Figure 7.2 Marina Abramović performing VALIE EXPORT's Action Pants: Genital Panic, 1969, Seven Easy Pieces, Solomon R. Guggenheim Museum, New York, 2005. Photograph by Attilio Maranzano. Courtesy of Marina Abramović Archives.

performative act of documenting it as such' (p. 7). Abramović's approach to documentation as a kind of composition, a musical score that inaugurates an embodied event, clearly resonates with Auslander's insistence on the interdependency of performance and documentation. This is further underlined by the juxtaposition of re-performances and documentation materials as equally vital testimonies of performance art history during Abramović's retrospective at MoMA.

At the same time, Abramović resists Auslander's tendency to eliminate the encounter between artist and audience as a constitutive force in the materialization of a performance. The reenactments of Seven Easy Pieces, as well as those of The Artist Is Present, are first and foremost embodied events, material acts that renegotiate the conventional hierarchies between the live (present) and the recorded (past) in and through the affective relational field between the artist and the audience. Whereas Auslander asks 'whether performance recreations based on documentation actually recreate the underlying performances or perform the documentation' (p. 2) - and he in fact mentions Seven Easy Pieces as a work that plays with this 'slippery question'-Abramovic avoids the dichotomies on which that question is based. By creating a form of 'embodied 
documentation that can shift and mutate over time' (Spector, 2010, p. 39), Abramović affirms an ontology of performance not as an effect of representation (Auslander), nor as a site of perpetual loss (Phelan), but as a persistent re-turning of affective encounters where matter and memory, the present and the past, meet in a vital process of transformation.

Materializing the cultural memory of performance through the interrelations among performers, audiences, and artistic bodies of work, performance reenactment unfolds what I want to call an archive of affect, an archive that enacts a body-to-body transmission of art-historical knowledge and aesthetic consciousness. Affect, as the visceral force of becoming or 'intensity' (Massumi, 2002) that is produced through the relations between people, artworks, and environments, operates not on the register of representation and signification but within the materiality and temporality of performance itself, through its forces of intensity, movement, and duration. In re-performance, the transmission of affect happens across multiple temporalities, engaging the audience directly in a 'nonlinear sensation of time' (Wortel and Smelik, 2013, p. 195) that allows us to experience the past as it coexists and becomes with the present. Reenactment, in other words, operates as an embodied mode of collective or social memory, or what Paul Connerton would call an 'incorporating practice' (1989, p. 72), not because it approaches the body as a site where memories of the past can be stored and retrieved in one and the same form, but because it affirms the creative force of memory in and through the physicality of performance as an indefinite and ever-emergent event. The affective power of reenactment as an archival (or counterarchival) practice, then, takes form as the materialization of 'flesh memory' (Schneider, 2011 , pp. 104-105), a performance of the past that remains precisely to the degree that it continuously differs from itself.

\section{Ephemeral Evidence}

As Erika Fischer-Lichte (2008) notes, performance implicates the artist and the audience in processes of physical and mental change that elude the scope of traditional hermeneutic and social aesthetics. The new materialist ontology of performance presented in this chapter therefore seeks to complement the linguistic or representational models in which live art is scripted as a form of disappearance with a more affirmative approach that takes performance itself seriously as a material force of remembrance. In this section, I will explore some of the political implications of this ontology by tracing the ways in which archives of affect may be creatively mobilized for the production of minoritarian knowledge and the becoming-memory of histories of pain. I want to think this question through the work of the American artist Mary Coble, whose bodily enactment of archival memory constitutes a profoundly queer politics of becoming. 


\section{Louis van den Hengel}

Coble's performance work traces the individual and collective histories of violence and social injustice often suffered by marginalized subjects through focused acts of memory and countermemory, or what Foucault (1977) with Nietzsche has termed 'effective history'. Through strategies of corporeal confrontation that clearly link her work to the histories of feminist and queer activism that have co-shaped the development of performance art, Coble has turned her own body into a living archive that incorporates queer histories of trauma. For example, Note to Self (2005; Figure 7.3) was a 12-hour performance during which the names of 436 lesbian, gay, bisexual, and trans victims of hate-crime murders were tattooed across the artist's body in block letters. No ink was used, so the tattooing created a series of empty puncture marks or tiny wounds in the skin that with the passing of time turned into delicate scars whose physical presence is more felt than seen. The transcript started and ended with the word 'anonymous' to acknowledge

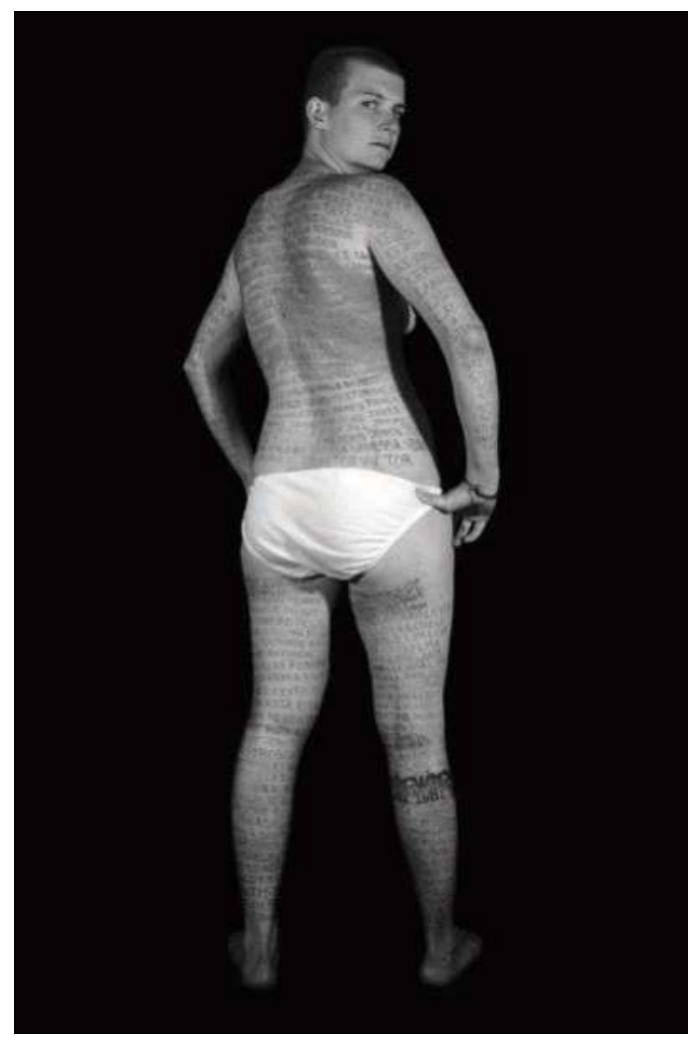

Figure 7.3 Mary Coble, 'Untitled 1' (from Note to Self, 2005). Photograph by Brian Twilley. Courtesy of Mary Coble. 
the many lives and deaths that were not included in the list, which Coble compiled through news reports, online research, and official and unofficial documentation. ${ }^{6}$ A 'blood painting' was made of each name by pressing a sheet of paper directly against the fresh incisions, creating a mutual enfolding of archival and fleshy documents in which the past and the present continuously bleed into each other.

For the performance Blood Script (2008; Figure 7.4), Coble had 75 hateful words and phrases tattooed onto her skin, again without ink, in a very ornate script whose visual appeal belied the ugly meanings of the words. The artist had assembled them through the documentation of three of her previous performances called MARKER, which were executed in New York (2006), Washington DC (2007), and Madrid (2008). For these works, Coble remained passive for three hours, inviting the audience to write on her body derogatory words that had been spoken against them or slurs that they used or heard being used against others. As Coble recalls, many participants in these performances 'commemorated their own painful experiences' of physical or verbal assaults by inscribing hate-filled epithets such as 'dyke', 'nigger', or 'faggot' on her body. ${ }^{7}$ Blood Script re-creates these earlier performances of memory at the same time as it reenacts the injurious moments of hateful speech acts in order to resist and rework their wounding force. In addition, the words that appear in blood as the needles puncture the artist's skin vividly recall the slurs that were violently carved into many of the bodies

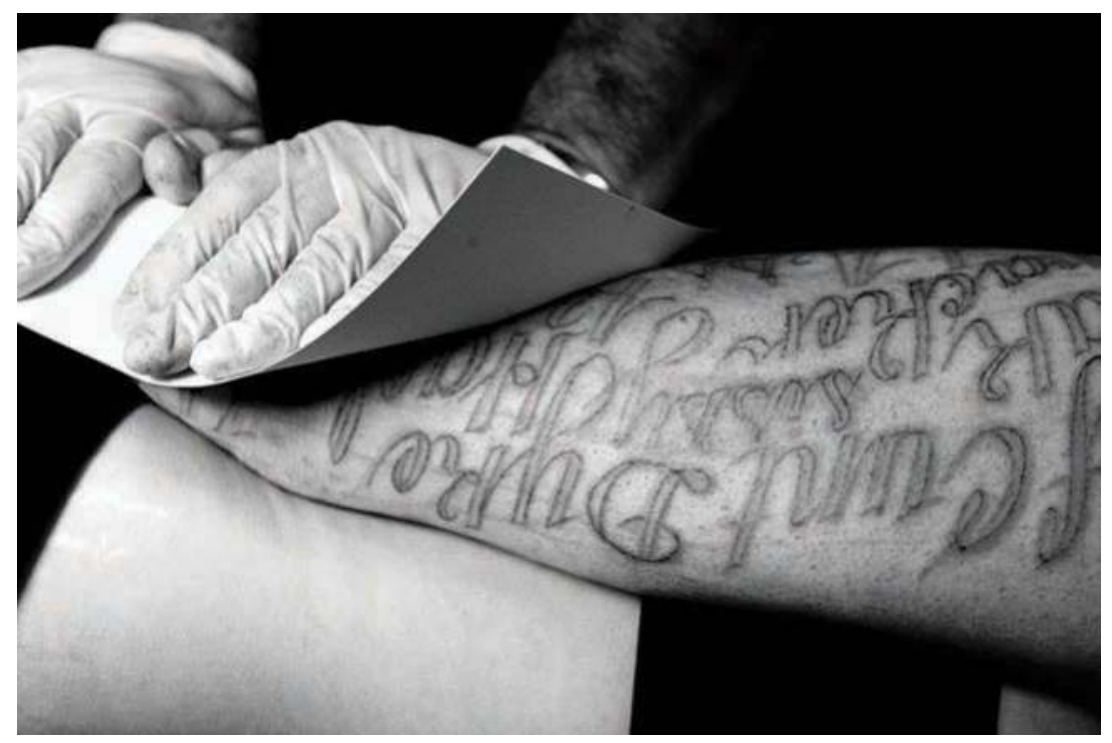

Figure 7.4 Mary Coble, 'Untitled 3' (from Blood Script Portfolio, 2008). Photograph by Kenny George. Courtesy of Mary Coble. 


\section{8}

Louis van den Hengel

of the murder victims whose names still shimmer through the densely layered palimpsest that is Mary Coble's body-archive.

Coble's marking of the skin, the site of encounter between the self and the social world, is at once an act of signification, inscribing the body with discursive meanings that may be 'read' by an audience, and an affective event through which memory itself becomes creatively transformed. By archiving traumatic memory into and onto the body, Coble does not merely re-present marginalized life histories through their evocation in language, but creates a sensation of the past as it persists in the present, effectively queering the straight linearity of chronological time. Coble's queer archive, moreover, reclaims the ephemerality of performance as a mode of archival evidence by foregrounding the affective and enfleshed dimension of memory as a material act of inscription. In this way, she resists the traditional reduction of performance to immateriality and disappearance that has often been used to disqualify queer acts as proper ways to preserve and transmit history. In light of the institutional neglect of LGBT histories both within and beyond the art world, archives of the ephemeral-or what José Esteban Muñoz has described as the 'traces, glimmers, residues, and specks of things' (1996, p. 10)-become vital, and necessary, historical resources. Like Muñoz, who calls for a revaluation of the ephemeral, the anecdotal, and indeed the performative as evidence, Coble affirms the affectivity of the body as a distinctly material mode of proofing and producing queer histories.

Activating the most vulnerable and most volatile material-a human body-as a thing to remember, Coble transforms our habitual understanding of archival memory at the same time as she goes beyond what André Lepecki has aptly termed the 'cenotaphic' notion of performance as 'that which only passes away' (2010, p. 39). By storing, reenacting, and transforming histories and memories of trauma in and through enduring processes of physical change, Coble shapes the dynamism of matter itself into an archive that chronicles moments and movements of intensive affect: visceral shifts in-between the past and the present that open breaches in the line of time as it is presently lived or actualized. Such archives of affect preserve cultural memory not by adding a substance to make the ephemeral last, but by affirming the queer physicality of performance itself as a perpetual process of variation, an ongoing reenactment of presence as a living force that does not disappear into nonexistence but continuously materializes itself differently: in difference, as difference. ${ }^{8}$

\section{Coda: Creative Returns}

Performance and re-performance, as I have argued throughout this chapter, actualize the material becomings of the body-its capacity to affect and be affected-across different time zones, producing an archive of 
affect in which the past and the present, matter and memory, coexist in and as an endless process of creative variation. When we see performance in the melancholy light that has structured traditional ontologies of live art no less than my own initial response to The Artist Is Absent, reenactment, especially if it takes place in a museum context, can only be considered as an inevitable failure to capture, or copy, a long-lost originary event in the present. But since the present-any present-is itself a matter of 'pure becoming, always outside itself', as Deleuze notes (1991, p. 55), it is more accurate to approach reenactments, no less than performance itself, as new actualizations of an artwork's immanent potentiality—an infinite 'field of inventiveness and creativity' (Lepecki, 2010, p. 45) that is enfolded into any performance work as the capacity to become different.

In this view, The Artist Is Absent did not simply operate as a tribute to a series of performance art classics, nor was it a mere rejection of the sanitized reenactments at MoMA. It also manifested a genderqueer sensibility that was not yet, or not yet fully, actualized in the works' previous expressions. Consider, for example, the reenactment of Rhythm 0 , Abramović's well-known piece of 1974, in which the artist made herself completely vulnerable to the unpredictable and sometimes violent actions of the public. The instructions for the performance were simple: Abramović had made available 72 objects, ranging from flowers and feathers to scissors, knives, a gun and a bullet, which the public could use on her as desired for a duration of six hours while the artist remained passive. The original performance was an exploration of the limits of consciousness as much as it was an investigation into the highly gendered and sexualized lines along which power operates. The re-performance, in contrast, turned into an S\&M enactment of queer pain and pleasure, and the event derived much of its energy from the joyful erotic encounters between the performer and the audience. If this is indeed how things happened-I rely on the anecdotal evidence of hearsay here-the reenactment of Rhythm 0 did not only displace any binary conception of gender, but also put considerable pressure on the fundamental premise of the work: the becoming-object of the artist. In this way, the re-performance not only traced the interconnections between the work of Abramovic and BDSM (Bondage and Discipline, Dominance and Submission, Sadism and Masochism) culture, which have rarely been made explicit, but also released the queer potentiality of the performance itself.

If performance, as I have suggested, becomes itself not through disappearance but through a material and messy flow of creative re-turns, that is, if the life of performance is pure difference or becoming, then the ephemerality of live art is not an obstacle to the practice of conservation, but is its precondition and primary material resource. The power of performance to endure, in other words, resides precisely in its material-affective operations, in its infinite capacity to engender creative 
transformations in which habitual modes of memory and perception become undone and time itself begins to stutter and fold. It is precisely to the extent that performance, which is always already re-performance as it constantly renews and re-creates itself, alters our relations to the duration of this world that live art becomes a thing to remember: a material mode of preserving the past in the present that works not by giving ephemeral events a stable grounding in art history, but by opening the past and the present to the pure movement of difference, to the ceaseless becoming and unbecoming of memory that we could simply call life itself.

\section{Notes}

1 A description of the retrospective and an impression of Abramović's performance can be found on MoMA's exhibition website: http://www.moma.org/ interactives/exhibitions/2010/marinaabramovic (Last accessed on 21 June 2016).

2 See http://www.theartistisabsent.com (Last accessed on 13 October 2014). The website is currently defunct but can be retrieved through the Wayback Machine provided by the nonprofit organization known as the Internet Archive: http://web.archive.org/web/20100527055238/http://www.theartistisabsent. com (Last accessed on 21 June 2016).

$3 \mathrm{http} / / / \mathrm{www}$. theartistisabsent.com/?page_id=14 (Last accessed on 13 October 2014).

4 For all its emphasis on performance as a primary conservation strategy for time-based art, Seven Easy Pieces was itself carefully documented through conventional means. Next to a catalogue with still photographs and textual explanations of the event, including transcripts of audiotape recordings of conversations among the visitors, experimental filmmaker Babette Mangolte created a feature-length documentary that premiered at the Berlin Film Festival in 2007.

5 The live performance was created in Munich on 22 April 1969 at the Augusta Lichtspiele, an independent art cinema where experimental filmmakers were showing their work. In an oft-cited 1979 interview, however, EXPORT is quoted as saying that her action took place in a pornographic film theatre: 'I carried a machine gun. Between films I told the audience that they had come to this particular theater to see sexual films. Now, actual genitalia was [sic] available, and they could do anything they wanted to it' (Askey, 1981, p. 15). EXPORT has later emphatically denied this version of events: 'I never went in a cinema in which pornographic movies are shown, and NEVER with a gun in my hand' (Stiles, 1999, p. 32, note 7). In an e-mail to the author (25 May 2016), the artist confirmed this position, furthermore adding that no film was shown during the performance, although the screen was lighted.

6 Descriptions and visual documentation of Coble's work can be found on the artist's website: http://www.marycoble.com (Last accessed on 21 June 2016).

7 See http://marycoble.com/performances-installations/marker-2006-20072008/34 (Last accessed on 21 June 2016).

8 The ephemerality of performance is indeed profoundly queer in the way it materializes memory, not because the ephemeral is 'the stock-and-trade of the gay and lesbian archive', as Ann Cvetkovich points out (2003, p. 243), nor because the term 'ephemera', as used by librarians and archivists, refers 
to materials that are labeled as 'fugitive' or 'miscellaneous' because they resist conventional classification and treatment. The queerness of performance rather obtains in the aesthetics of the ephemeral itself: the temporality of the event that creatively transforms conventional understandings of what constitutes the very materiality of matter, setting matter into motion by bringing its self-identity into the play of what Deleuze would call 'the more profound game of difference and repetition' (Deleuze, 1994, p. xix).

\section{References}

Abramović, M. (2007) 7 Easy Pieces (Milan: Charta).

Askey, R. (1981) 'VALIE EXPORT interviewed by Ruth Askey, Vienna 9/18/79', High Performance 4.1: 14-19.

Auslander, P. (2006) 'The Performativity of Performance Documentation', PAJ: A Journal of Performance and Art 84: 1-10.

Bishop, C. (2012) 'Delegating Performance: Outsourcing Authenticity', October Magazine 140: 91-112.

Colman, F. J. (2004) 'Affect' in A. Parr (ed.) The Deleuze Dictionary (Edinburgh: Edinburgh University Press). 11-13.

Connerton, P. (1989) How Societies Remember (Cambridge: Cambridge University Press).

Cvetkovich, A. (2003) An Archive of Feelings: Trauma, Sexuality, and Lesbian Public Cultures (Durham, NC: Duke University Press).

Deleuze, G. (1991) Bergsonism (New York: Zone Books).

Deleuze, G. (1994) Difference and Repetition (New York: Columbia University Press).

Deleuze, G., and C. Parnet (2006) Dialogues II (London: Continuum).

Fischer-Lichte, E. (2008) The Transformative Power of Performance: A New Aesthetics (London and New York: Routledge).

Foucault, M. (1977) 'Nietzsche, Genealogy, History' in D. F. Bouchard (ed.) Michel Foucault: Language, Counter-Memory, Practice (New York: Cornell University Press. 139-164.

Jones, A. (2011) "“The Artist Is Present": Artistic Re-Enactments and the Impossibility of Presence', TDR: The Drama Review 55.1: 16-45.

Laurenson, P., and V. van Saaze (2014) 'Collecting Performance-Based Art: New Challenges and Shifting Perspectives' in O. Remes, L. MacCulloch, and M. Leino (eds) Performativity in the Gallery: Staging Interactive Encounters (Oxford: Peter Lang). 27-41.

Lepecki, A. (2010) 'The Body as Archive: Will to Re-Enact and the Afterlives of Dances', Dance Research Journal 42.2: 28-48.

Massumi, B. (2002) Parables for the Virtual: Movement, Affect, Sensation (Durham, NC: Duke University Press).

Muñoz, J. E. (1996) 'Ephemera as Evidence: Introductory Notes to Queer Acts', Women and Performance: A Journal of Feminist Theory 8.2: 5-16.

Phelan, P. (1993) Unmarked: The Politics of Performance (London and New York: Routledge).

Plate, L., and A. Smelik (2013) 'Performing Memory in Art and Popular Culture: An Introduction' in L. Plate and A. Smelik (eds) Performing Memory in Art and Popular Culture (London and New York: Routledge). 1-22. 


\section{Louis van den Hengel}

Santone, J. (2008) 'Marina Abramović's Seven Easy Pieces: Critical Documentation Strategies for Preserving Art's History', Leonardo 41.2: 147-152.

Schneider, R. (2011) Performing Remains: Art and War in Times of Theatrical Reenactment (London and New York: Routledge).

Spector, N. (2010) 'Seven Easy Pieces' in K. Biesenbach (ed.) Marina Abramović: The Artist Is Present (New York: Museum of Modern Art). 36-39.

Stiles, K. (1999) 'Corpora Vilia: VALIE EXPORT's Body' in VALIE EXPORT: $\mathrm{Ob} / \mathrm{De}+\mathrm{Con}($ Struction), exhibition catalogue (Philadelphia: Moore College of Art and Design). 17-33.

Taylor, D. (2003) The Archive and the Repertoire: Performing Cultural Memory in the Americas (Durham, NC: Duke University Press).

Widrich, M. (2012) 'Can Photographs Make It So? Repeated Outbreaks of VALIE EXPORT's Genital Panic since 1969' in A. Jones and A. Heathfield (eds) Perform, Repeat, Record: Live Art in History (Bristol, UK: Intellect). 89-103.

Wortel, E., and A. Smelik (2013) 'Textures of Time: A Becoming-Memory of History in Costume Film' in L. Plate and A. Smelik (eds) Performing Memory in Art and Popular Culture (London and New York: Routledge). 185-200. 


\title{
8 Crystal Tears and Golden Crowns
}

\section{Materializing Memories of the Suffering Mother}

\author{
Willy Jansen
}

\section{Introduction}

A large Internet store selling religious art objects, Siglo Barroco in Seville, advertises crystal tears for $€ 10$ each. It is one of the least costly items for sale. For instance, a silver-plated incense burner costs $€ 350$, a goldplated crown for Mary $€ 3,500$, and-the most viewed item-a life-sized Mater Dolorosa is $€ 4,000 .{ }^{1}$ These objects are meant to be used in one of the processions during the Semana Santa (Holy Week), held in most of the larger towns in southern Spain. In a public celebration of the Passion of Christ in the week before Easter, life-sized statues of Jesus, Mary, and other saints are carried through the streets accompanied by bands playing music and people dressed up as penitents, Romans, mourners or biblical figures. In recent decades, both the number of processions and participants has expanded enormously, and hence also the quantity of ritual objects.

In this chapter, I will describe the proliferation and renewal of these religious objects and explore some of the reasons people spend so much money, time, and effort on costly religious art objects in a secularizing world. What social and cultural memories are articulated in these popular objects? The objective of this chapter is to show the mechanisms of materialization of a wide array of identities through religious objects. It will be argued that the objects serve multiple memories all at the same time and on two different levels. The first level is that of materializing a history and enacting specific social, religious, economic, and political group identities. By constantly working on these objects, elaborating on them or renewing them, people remember who they are and where they belong. The second level is that of the materialization of personal emotions and family relations. The way in which these levels are intertwined can be illustrated by singling out the tears that are bought for the numerous faces of Mary and the meanings and emotions connected to them.

Working with Henk Driessen, we gathered data for this project during six ethnographic field studies of the Holy Week events in different towns 
and villages in Andalusia between 1976 and 2013, mostly in Málaga in 2012. We combined observation of the rituals with systematic small talk with both ritual participants and onlookers-small talk being a central, yet taken-for-granted ingredient of ethnographic fieldwork, as we have argued (Driessen and Jansen, 2013a) - held interviews with representatives of various groups, and analyzed written and visual sources. This chapter is part of a series of publications on gender and ritual in Spain (Driessen and Jansen, 2013b; Jansen and Driessen, 2013, 2016).

\section{Objects that Matter}

Recent theories of materiality that deal with the relationship between people and things have shifted the attention from things as functional items to seeing them as integral to human action and informing people's sociality. Our relationship to things says something about our relationship to people, as Daniel Miller argued: 'the closer our relations are with objects, the closer our relationships are with people' (2008, p. 1). For this reason, following Igor Kopytoff's (1986) notion of the 'biography of objects', archaeologists such as Chris Gosden and Yvonne Marshall have suggested inquiring into the biography of objects, that is, to consider the different moments of production, exchange, and consumption, and to set each phase in the object's life within its social contexts and consequences (1999, p. 169). Crucially, the biographical approach does not consider the object as merely 'a passive, inert material to which things happen and things are done' but as 'the way social interactions involving people and objects create meaning' (p. 170).

Objects are very much part of everyday religious practice. Analyzing things, alongside and in their interaction with words, rituals, and beliefs, is increasingly recognized as an essential part of the study of lived religion (see, for instance, the journal Material Religion; Cort, 1996; Derks, 2009a; Derks, 2009b; Houtman and Meyer, 2012; Jansen, 2009, 2012; McDannell, 1995; Notermans and Jansen, 2011). A biographical approach to objects is particularly relevant in the religious domain, as the meaning of an object at the time of production (for instance, as a commodity designed for a specific market) can change by its ritual use during a procession (for example, by becoming a symbol of connection with the divine). In line with this approach, I will unravel the cultural biography of a few objects and look into their use and the contested meanings attached to them. In particular, I will examine the ways in which they function in constructing group and individual identities. How do objects become transformed from mere matter to objects that matter?

Consumption has long been recognized as a basic cultural ritual and as a social, value- and meaning-giving activity (Douglas and Isherwood, 1979; Miller, 1987). By way of buying and donating objects for religious use, relations are established between the donors and the divine. In his 
seminal study on the principles of exchange underlying the gift, that is, the obligations to give, to receive, and to reciprocate, Marcel Mauss called 'giving to the gods' the fourth obligation (Mauss, 1990, pp. 14-17; Morehart and Butler, 2010, p. 588). Offering material things to saints or gods in the hope of having favors granted is a widespread practice found in many different cultural contexts, religions, and forms (Derks, 2009a, 2009b). Catholics may do so by offering ex-votos, personal material gifts placed in the vicinity of a saint, to underscore a vow made (Notermans and Jansen, 2011) or by making more general donations to the church. Such an exchange of (symbolic) goods for blessings or favors can be seen as a kind of 'spiritual economy' (Derks, Jansen, and Notermans, 2012) or 'sacred economy' (Renfrew, 2001). The exchange is usually indirect and symbolic - a sign of what Pargament (1997) calls a collaborative approach through which humans cooperate with the divine as a form of coping. The materiality of the object, its more or less permanent place in the sacred space, and its public visibility extend and reinforce the relationship between the devotee and the divine.

Gifts to the gods, however, also impact on the relationships between and among people. They define the devotee's relation not only to the divine but also to fellow human beings. The qualities of the object contribute to the making of several identities that position the giver in the social context. Before going into how the objects in the Semana Santa (Holy Week) matter in people's social identity construction, I will first describe the Holy Week rituals and their recent material expansion.

\section{Ritual and Material Expansion}

The Holy Week celebrations in Málaga find their origins in the processions of fourteenth-century penitential associations, called cofradias or hermandades (brotherhoods). With various fluctuations and periods when they disappeared, these associations have been active for centuries, functioning as self-help organizations and basic democratic institutions. Since the 1970s, and in particular in the 1980s, there has been an unexpected increase in the number, membership, and size of the floats carried in the processions and on which the saints are displayed. It is unexpected because this increase takes place in a context in which Europe, including Spain, is witnessing a secularization process. The causes for this ritual expansion must therefore be sought not only in a spiritual revival, but rather in its complex interplay with an economic expansion due to Spain's membership in the European Union, the political exploitation by, as well as reaction to, the Franco regime, as well as the growing gender equality that has allowed for women's increasing access to the public domain, including the penitential brotherhoods (Driessen and Jansen, 2013b; Jansen and Driessen, 2013).

The social relevance of the celebrations and their organization should not be underestimated. Local inhabitants participate in great numbers in 
the associations; in Málaga alone there are forty-two cofradias with a total of 70,000 paying members in a population of approximately 500,000. The groups have 14,000 people to carry the floats, accompanied by 17,000 nazarenos: penitents in tunics, capes, and pointed hoods in the colors of their group. Together they organize forty-three processions in the week from Palm Sunday to Easter, each lasting several hours. Nearly all groups carry more than one statue of a saint, but only one of them functions as the key symbol to indicate the group. ${ }^{2}$ In the newspapers, complaints are voiced that the number of participants has increased so much that the time slots for the processions no longer suffice and that it becomes tedious to watch thousands of nazarenos. Moreover, the event draws tens of thousands of spectators, including not only townspeople and tourists but also many migrants who return for the occasion to relive memories of their youth. The center of the town is closed off for a whole week to give space to the celebrations. In short, it is a total social event.

The Holy Week celebrations are also of considerable economic importance. People spend large amounts of money on membership dues, processional dress, and sacrificial gifts. Members are expected to participate in fundraising activities and to make donations toward the upkeep and expansion of their group's activities and possessions. Over time, new cofradias and new floats have been added. The floats, aptly called thrones, have become larger and heavier, and some now need up to three hundred men to carry them (Figure 8.1). They have been embellished with new precious woodwork and more silver candles. For some, new statues have been made; for others, the statue has been given new clothes or a more elaborate crown. The number of banners, maces, crosses, staves, and candles carried along by the participants has also multiplied.

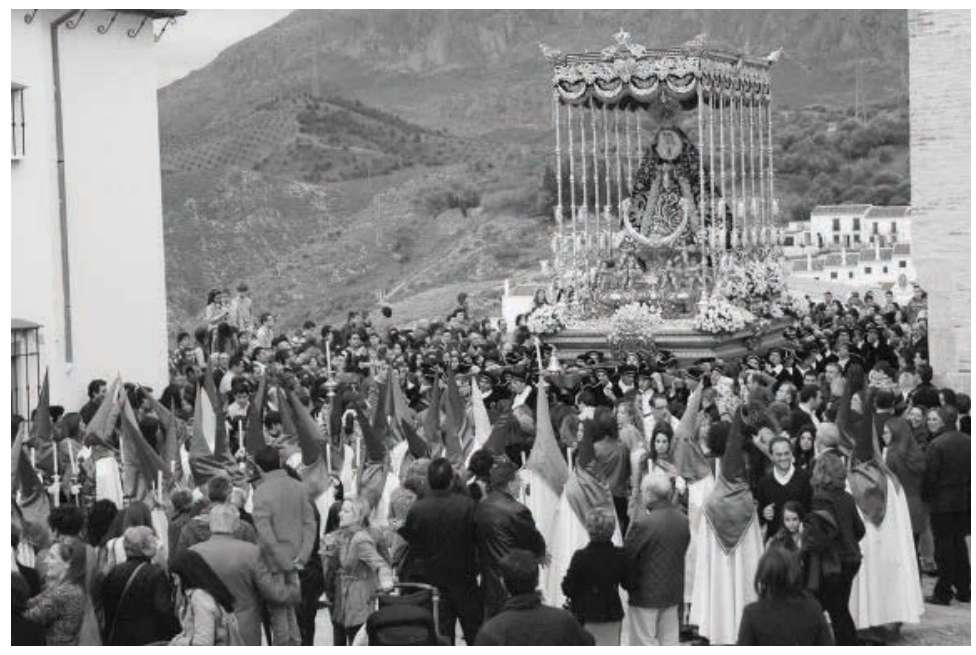

Figure 8.1 The float with the Virgin leaves the church, Antequera, 2013. Photograph by W. Jansen. 
A comparison of the basic and simple throne and statue of the Virgin of Servitas, whose appearance has hardly changed over the past half century, with that of the exuberantly rich Virgin of Esperanza, indicates the extent of this material expansion. Servitas, founded in 1695 in Málaga, is not a regular cofradia but has been allowed to participate because it was the first pious group to make a procession after the civil war in 1937. Only forty-two men carry this Virgin, while the sizable float of the Virgin of Esperanza now needs two hundred and fifty carriers. The Servitas Mary is clothed in 'strict mourning dress' (Lanzas, 2014) and not in lace, satin, and embroidered velvet like the Esperanza. She has no gold crown, but a modest circle of stars around her head; no gilded float, no flower decorations apart from the three carnations that women from one family are allowed to place below her dress after a vow made in 1940, and she is not accompanied by a band but only by a muted drum. Her followers do not have to give her anything material, only their promises. Her face even lacks crystal tears. The only things that devotees are allowed to offer her are the flames of their candles while they meditate the seven sufferings of the Virgin when walking behind her throne in a darkened town after midnight. The sobriety of Servitas stands in stark contrast with the lavish dress, crystal tears, glimmering silver decorations, shining gold crown, and other costly items bestowed on Esperanza and the other personifications of Mary carried around in the streets.

In Andalusia, a significant craft industry kindles and serves the increased demand for ritual attributes-tailors who manufacture the costumes of the participants, embroiderers working on velvet robes with gold or silver thread for Jesus and Mary (Aguilar Majarón, 2010). There are silversmiths who on demand make the most beautiful staves, candleholders, crowns, and lanterns, woodworkers who carve the thrones, and artists who give life to new statues for the increasing number of groups who want to participate. Thus, the economic interests of local producers and the product demands of buyers are closely interwoven with the religious ritual. This brings us back to the question of what motivates people to constantly refurbish, embellish, and add to these religious objects.

\section{Social Competition and Identity}

The voluntary associations that prepare and carry out the Holy Week celebrations provide a basic and extensive form of social organization in Andalusia. Working together to prepare, beautify, carry, and accompany their thrones creates social cohesion. By way of buying precious goods and giving them to the saint, new meanings are ascribed to things. Emotional relations and social identifications are established, which are then publicly reinforced by ritually celebrating important additions and renewals, for instance, the ritual coronation of Mary, or by celebrating her first 
appearance in a new cape. These significant moments in the biography of the object also mark the relationships of the members to their saint and to each other. They deepen their attachment to the main icon of the group and their collaboration as a group. People feel that this particular manifestation of Mary, Christ, or saint is 'theirs'. The Lady of Solitude is not only the image, or the abbreviated name of the group, but also the group itself. The central image is replicated in numerous ways to reconfirm the group identity-the jewelry that its members wear, the photographs on their phones, and the decorations in their homes and on their relatives' graves all attest to the variety of ways in which people constitute a collective identity. Different collective identities-socioeconomic, religious, or political - separately or overlapping, are being constructed and exhibited through religious objects and the way they are handled.

Socioeconomic identity construction is visible in the fierce competition between the groups for the prettiest, largest, and most impressive float and for who draws the largest audience. When their Virgin is passing, people yell 'guapa, guapa, guapa' (beauty, beauty, beauty) and point out to their children which one is theirs and thus the one to be most loved and admired. Consumption of religious goods spirals as each group does its utmost best to buy the most magnificent outfit and accessories for its saints in order to bring them out on the street with pride. The competition is fueled by the local newspaper, which reports in a section entitled Estreno (Première) on the new items that each group has managed to acquire over the year. This can be the restoration of an antique cape, lighter carrying beams, or the employment of a larger band to accompany the float.

The groups are very proud and protective of their material possessions and often exhibit them to the general public year-round in a museum setting. This pride concerns especially the statue from which the group derives its popular name. Biographical details of the objects, such as the date of production, the artist who crafted it, the date of acquisition, and the main donor are mentioned and also recounted in narratives, booklets, and on the Internet. Group identity is further reinforced and inscribed in the collective memory by special celebrations, such as the coronation of the Virgin.

Because of the art status of the objects, their costliness, and the fragility of the materials of which they are made, the associations become highly protective when the abundant rains of spring threaten to spoil the procession. A special rain official advises the board on whether it is safe to bring one's prized possession out into the street. Unexpected showers are dealt with by quickly covering the statue with plastic or seeking refuge in a nearby church. In fact, many tears are shed when it is not possible to bring the saint out into the streets. Everyone remembers exactly the years in which their saint, their gift to the divine that the group has worked, paid, and hoped for all year, could not be shown to all because of weather circumstances. The size, beauty, and cost of the float reconfirm the social status of the group. A form of 'conspicuous 
consumption' (Veblen, 1899), it shows what the associations can afford. This social status, however, can only be gained when everyone can see the float in its full glory.

Before the 1970s, floats in Málaga were carried by paid laborers, usually harbor workers, but after a strike for more wages during a procession in 1972, regular members took over. Since then, a gentrification process has taken place. At present, men who want to lead or carry a float have to pay to do that. Once a lower-class paid job, carrying a float has become a middle-class voluntary physical and economic sacrifice and privilege, rewarded with respect and applause (Driessen and Jansen, 2013b). The status increase is reflected in the term used for the carriers, which changed from costaleros (dockworkers) to hombres del trono (men of the throne). Although some women can be seen as carriers, it is still mostly a show of masculine power. As a result, within the group, participants compete for the most respected and high-status roles, and in this context changing roles from nazareno (penitent) to costalero (carrier) can mean a significant change in masculine status. Analyzing the autobiographical narrative of such a status transition, Schrauf (1997) focuses on the cognitive side of such remembering, yet also mentions how the status change is marked by a change of dress, when the costalero leaves aside the tunic and takes up the costal (carrying towel) (Schrauf, 1997, p. 35).

Interwoven with a specific socioeconomic identity, the Holy Week processions also express a religious identity. Certainly, the clerics are very intent on connecting the processions with religion. The processions and objects indeed express the life and death of Christ. Yet, this religious past is what Bouwsma (1990) and others would call a 'usable past', whereby history is adapted to fit the needs of the present. Mary's dresses are fit for the queen that the devotees see in her, rather than the young rural woman she was. Jesus wears a gold-embroidered velvet robe and even when semi-nude and tied to a torture post he might still be dressed in a silk embroidered loincloth. Such material adaptations evoke emotions of joy, beauty, and adoration, but also of collective pride, social dignity, and social standing.

The Holy Week processions mask a wide range of religious identities. The performances may express highly personal religious motivations, yet people also have other reasons for participating. Several participants confessed that they were actually not particularly religious but participated to do their father a favor or to bond with old friends by performing together. Others said they just liked the fun: as one carrier in a village said, 'It is just like Carnival'. The liberal consumption of alcohol by him and many others led to boisterous behavior and even dangerously swaying statues. As a result, the village priest refused to lead those processions and joined in the chorus of staunch Catholics who complained about the unreligious behavior of some participants from certain lower-class neighborhoods. He gladly supported the Catholic landed elite in counteracting 
this religious disgrace by introducing a new, sober procession with no music and no float but a bare horizontal cross and solemn prayer. Locals not only loosely classify the groups according to class and social standing but also on the basis of the seriousness of their religiosity.

A last and more subdued memory is that of one's political identity. The political trauma Spain experienced during the civil war in the 1930s and the ensuing fascist regime of Franco that lasted until 1975 is still vivid. In Málaga, the home base of military regiments, this trauma is played out on both political sides by sharing biographical details of the material images. While waiting for a procession, an aristocratic elderly lady standing next to me disclosed her great emotions from the day before when she had participated in the Way of the Cross of the Mutilated in the cathedral. The Mutilated is the epithet of a Christ figure that was severely damaged in the iconoclastic fury that took place on 12 May 1931, by what their opponents call 'the Marxist hordes'. ${ }^{3}$ The Mutilated Christ became a national symbol in political processions under Franco's fascist regime. At present, now that political power has changed sides and the majority of Spaniards want to forget the horrors of the civil war and overly politicized religion, the town authorities have decided that the Mutilated is no longer allowed to leave the cathedral and can only be carried in procession within the building. A group of politically driven devotees, however, is lobbying for allowing it on the streets to remind people of the sacrilege committed. Other groups deal with such political memories in a more subdued way and mention in their historical writings that their antique images, for example, that of Christ of the Good Death (MENA) or Mary Dolorosa (Servitas), were destroyed and have been replaced by new ones. People's preferences for particular cofradías and their saints are thus informed by their political memories.

\section{Memories of the Suffering Mother}

Dígnate pues, Madre Santa, a unir nuestras lágrimas a las Tuyas. [Deign then, Holy Mother, to unite our tears to Yours] ${ }^{4}$

In poems and songs dedicated to the Virgin and her tears, people share in her sorrow but also connect it to their own lives and their own anguish. The Holy Week is not only a ritual performance of collectively remembered social, economic, religious, and political identities, but also relived personal and family histories, in particular those of lost loved ones. As the retired landowner José said, 'I go to my apartment in Benidorm because the Semana Santa makes me very sad nowadays. Especially when [the image of] Cristo comes out, I get very sad, because it makes me think about my mother who was very fanatic about Cristo. And then I have to think of her and I become very sad'. In commemorating the death of Christ, one also commemorates the deaths of family 
members. This sentiment can be so strong that some, like José, even flee the scene. The object itself becomes like a family member. People speak to the Virgin as if she were their mother. They also usually refer to their group's central icon as 'Mi Virgen' or 'Mi Cristo', despite the sermons of priests that they should address the blessed divine being with a more respectful general title. The object, as family member, connects them to other loved ones and invites reliving and re-experiencing one's deepest personal emotions. The tears of Mary remind people of their own tears.

Rituals, as in this case the stylistic reenactment of the passion of Christ, are 'bodily social memory' performances (Connerton, 1989, pp. 71-72) that enable societies to remember and individuals to relive emotions. Ritual objects provide stability, tactility, and visualization of the memory of past cultural events and personal experiences. And the repetitive gestures and movements when handling the objects lead to sedimentation of this memory in the body. As a result, the mere sight of Mary's face or the sound of the muted drums makes the body tremble with emotional memories of the past.

Although both men and women express their sorrows, there is a clear gender divide in people's association with tears, mourning, and suffering. A comparison of the various statues of Mary with those of Jesus shows that crystal tears are only bought to enhance the emotive feelings on Mary's face (Figure 8.2). Even a tortured Jesus or a Jesus bearing a heavy cross does not cry. Various names given to Mary, such as Dolores, Soledad, or Mayor Dolor, and the daggers in Mary's heart, refer to a mother's sorrow and agony in seeing her child die.

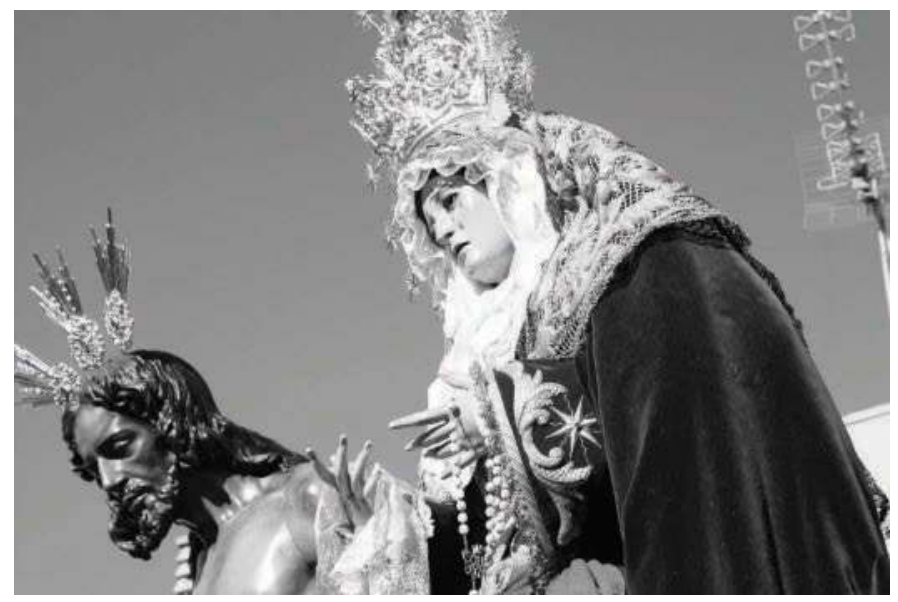

Figure 8.2 Malaga, 2012. Photograph by W. Jansen. 
Mary's suffering is symbolic of, and can be extended to, all women. Women are expected to cry and mourn more than men. Certainly, women and men both show penitence or make vows to Mary, but women tend to do so more often than men. Vows are colored by the gender assumptions of the participants. When we asked men what kind of vows they made, they answered that they prayed to the saint to be cured from a disease, get their driver's license, or land a job. ${ }^{5}$ In contrast, women mostly prayed for a cure for someone else, their mother, child, aunt, or neighbor. In both the frequency and the content of their vows, women assume their culturally assigned role as caregivers of the family and of the neighborhood.

Moreover, even though the Semana Santa event is about the Passion of Christ, it is the Virgin, Mother Mary, who is most popular. In the formal names of the cofradias, the name of the Christ image is mentioned first, but most of the short abbreviated names refer to a personification of Mary. All groups that have a float with Jesus also have a float with Mary, but those that have only one float-Servitas and Piedad-have only Mary. Also, people cheer more loudly for Marian floats, and visitors of the webstore Siglo Barroco click most often on a Mater Dolorosa and not on one of the Christ statues. In general, people spend more money on Mary than on her Son. She has received the most beautiful baldachins, the largest gold crowns, the greatest number of silver candleholders, and the longest, most elaborately embroidered capes. In giving these objects, people connect to her as beloved mother, as mediator, and as supernatural powerful being, as well as to the members of their family and social group. The objects materialize the sorrow, the promises made, and the gratitude felt for favors obtained for themselves and their family members, whether alive or dead.

Women participate actively in the Holy Week processions to express their worries and sadness for their loved ones. Antonia, who made us breakfast every morning during the Holy Week in Antequera in 2013, showed us a picture of herself wearing a black mourning dress with a mantilla draped over a high comb on her head and explained:

Last year I even participated in three processions because I had made a promise. You ask something for your family or for the children, and then you promise to participate. I had promised to do so three times because my mother had breast cancer. So I walked in the Rescate, one in Archidona, and in the Socorro, but there only with a candle. Happily my mother is now much better due to the radiotherapy. But even if all goes well, you still have to go.

Whereas the landowner José fled his suffering, Antonia offered her bodily suffering by walking three exhausting processions to plead for the health of her mother. Others add to the sacrifice by going blindfolded, carrying 
a cross, or walking barefoot. Teresa Hidalgo Fernandez volunteered as the first female carrier of Christ the Rescate to fulfill a vow for another woman who was diagnosed with cancer (Guerrero Clavijo, 2013, p. 80). The commemoration of culturally valued suffering is thus as it were sedimented in individual bodies, and cultural norms about women's care for their loved ones become incorporated.

Our data show that women more often than men use a religious discourse, materialized in votive offerings to Mother Mary especially, to deal with their at times overwhelming caring tasks. The passionate sorrow connected to the story of Christ's Passion consoles them when dealing with sadness and problems in their personal lives. The prayer-line quoted above shows that people find comfort just by looking at Mary's tearful face and that Mary's own great suffering as a mother will make her understand the anguish of the believers.

Through the memory work of participating in the Holy Week processions, not only the Holy Mary but all women are constructed as suffering, caring, and connecting mothers. Through the tears of Mary, the dichotomy of collective and personal emotions and memories is being resolved (White, 2006, p. 326). The growing presence of women in other roles, as officeholders, as carriers, or as penitents hidden under a gender-neutral all-covering garb, indicates that gender roles and relations are changing. The development of alternative gender roles, however, is slow. The most coveted image on people's phones remains that of a weeping Mother of All.

\section{Re-membering the Family}

Rituals are first and foremost reenactments of connectedness. Numerous Holy Week objects function as a means to establish and nourish memories of kinship. Miniatures, paintings, and prints of the saintly images are bought as presents for family members and displayed in cupboards or on the walls of homes. Mutual exchange of such gifts creates kinship bonds. When offered to the deceased, they also weave kinship ties between the living and the dead. Most tombs in the graveyard display an engraving or a bronze or plastic statue of the particular saint that had been venerated by the deceased. In the graveyard chapel, all kinds of miniature reproductions of saints and the Holy Child have been put on the altar and on the walls as ex-votos, to underscore a request to the supernatural to pray for the soul of the deceased and the peace of mind of the survivors.

All members of the family, whether deceased, absent, or ill, are reconnected to the family again by the emotional work done by the participants in the Holy Week. The term 're-membering' (Myerhoff, $1982,1984)$ is valuable here in understanding the outcome of such collective commemorative processes. For Myerhoff the term describes a special type of recollection that calls attention to the re-aggregation of 
members, the figures who belong to one's life story (Myerhoff, 1982, p. 11; Russell and Carey, 2002). The Holy Week can be understood as what Myerhoff calls a 'definitional ceremony' that honors not only the deceased and reincorporates the dead person as member of the group, but also strengthens the survivors' sense of belonging. While Myerhoff discusses this re-membering work in the context of elderly Jewish people in Southern California, the concept has been taken up in narrative therapy whereby all people who have in one way or another played a part in one's life are re-membered and given their deserved place in what White calls 'the club of life' (White, 1997).

During the Holy Week processions, these narratives are not just told, but also physically and materially performed and experienced. Migrated family members often return to their native towns this week not only to meet family and friends or to watch the processions, but also to actively participate as carriers, penitents, or other roles. By performing with others close to them, they perform and relive the memory of connection (Plate and Smelik, 2013). With their buying power earned abroad, they have contributed to the many objects with which to play out this re-membering. By selecting, paying for, and displaying the ritual objects during the processions, the past is rewritten, memories are manufactured, and identities are fabricated, restored, and changed. In short, both the popular religious acts and the artistic things, including Mary's crystal tears and golden crown, are what Plate and Smelik (2009) have called 'technologies of memory' in art and popular culture. The artisanal crafting of objects for the Holy Week can be seen as a way of 'manufacturing memories (re)produced for consumption' (Plate, 2011, p. 35). Memories become more real when all the senses are involvedsight, smell, touch, sound, and taste. Therefore, it is not just the beauty of the object, enhanced by the light of dawn or sunset or the many candles, but also the sound of the drums, the smell of incense, flowers, and candles, the heavy weight on one's shoulders, or the taste of dried cod that etch the memory in one's body. Through this combined memory work, connectedness is relived and engrained in the body. Even group differences are transcended occasionally by what the Turners would call feelings of 'communitas' - that is, exalted feelings of union, of 'full unmediated communication, even communion, between definite and determinate identities' (Turner and Turner, 1978, p. 250). At these moments of exaltation, people forget the group competition and work together to reenact the past and celebrate togetherness.

\section{Conclusion}

Objects reinforce the commemorative function of rituals. Rituals mark the transition points in the biography of things at which they acquire a different meaning, from a piece of glass to a tear expressing Mary's 
suffering and that of all women, and from a piece of gold-plated alpaca to a crown celebrating Mary's imperial reign. By exhibiting, describing, and photographing the different stages in the lives of their most precious things, groups create and sustain a symbolic focal point for their identity construction. Through their care for things, they develop internal cohesion and distinguish themselves from others. Through the proliferation of religious objects and the ritual handling of them during the Holy Week in Southern Spain, a variety of identities-social, religious, political—are being manufactured, solidified, and embodied. The objects are reminders not only of the collective devotion to Mary, Jesus, or a saint, but also of several social identities. They are the materializations of multiple collective memories.

On the personal level, objects help to tie, strengthen, and remember relations with loved ones. Crystal tears serve to relive both the religious narratives of suffering and, through collective mourning, rebind the emotional bond between humans and the supernatural. They also assist in mourning loved ones, by expressing sorrow and consolation. While symbolizing the suffering of the Mother of Christ and thus reminding participants of their collective religious and social history, the crystal tears simultaneously symbolize the intimate suffering of mothers in everyday life and the emotional work women in particular perform in caring for loved ones and keeping the memory of deceased or departed family members alive, thus re-membering the family. Personal emotions conflate with collective emotions, and personal memories fuse with collective memories by articulating them in beloved objects such as crystal tears and golden crowns.

\section{Notes}

1 See: http://www.siglobarroco.com/103/lÁgrimas/477 (Accessed on 21 January 2016). Other large Internet stores are http://www.articulosreligiososbrabander. es/articulos-cofrades (Accessed on 21 January 2016). For silverwork see, for instance, http://www.orfebreriaildefonso.com (Accessed on 21 January 2016).

2 For instance, the Venerable Hermandad y Cofradía de Nazarenos de Nuestro Padre Jesús de la Soledad, Negaciones y Lágrimas de San Pedro, María Santísima del Dulce Nombre y San Franscisco de Asís, according to its name has four saintly images, but its abbreviated name is Dulce Nombre, after its central icon, the Holy Mary of the Sweet Name.

3 According to the Cofradía de la memoria historica El Mutilado de Málaga that tries to keep this memory alive on:http://simplementecapillita.blogspot. nl/2013/09/la-cofradia-de-la-memoria-historica-el.html (Accessed on 27 May 2014).

4 Prayer to Our Lady of Tears, http://www.devocionario.com/maria/lagrimas_1. html (Accessed on 25 July 2016).

5 Cancer patient Guerrero Clavijo described how people like him seek redemption and hope, to muster all the strength possible for their struggle against this disease (Guerrero Clavijo, 2013, pp. 79-80). 


\section{References}

Aguilar Majarón, I. (2010) 'El Bordado en Oro de Archidona', Revista ph. Instituto Andaluz del Patrimonio Histórico 75: 55.

Bouwsma, W. (1990) A Usable Past: Essays in European Cultural History (Oakland: University of California Press).

Connerton, P. (1989) How Societies Remember (Cambridge: Cambridge University Press).

Cort, J. E. (1996) 'Art, Religion, and Material Culture: Some Reflections on Method', Journal of the American Academy of Religion 64.3: 613-632.

Derks, S. (2009a) 'Religious Materialization of Neo-Liberal Politics at the Pilgrimage Site of the Virgin of Urkupiña in Bolivia' in A. K. Hermkens, C. Notermans, and W. Jansen (eds) Moved by Mary: The Power of Pilgrimage in the Modern World (Aldershot, UK: Ashgate). 117-132.

Derks, S. (2009b) Power and Pilgrimage: Dealing with Class, Gender and Ethnic Inequality at a Bolivian Marian Shrine (Berlin: LIT Verlag).

Derks, S., W. Jansen, and C. Notermans (2012) 'Miniatures and Stones in the Spiritual Economy of the Virgin of Urkupiña in Bolivia' in D. Houtman and B. Meyer (eds) Things: Religion and the Question of Materiality (New York: Fordham University Press). 198-211.

Douglas, M., and B. Isherwood (1979) The World of Goods: Towards an Anthropology of Consumption (New York: Basic Books).

Driessen, H., and W. Jansen (2013a) 'The Hard Work of Small Talk in Ethnographic Fieldwork', Journal of Anthropological Research 69: 249-263.

Driessen, H., and W. Jansen (2013b) 'Staging Hyper-Masculinity on Maundy Thursday: Christ of the Good Death, the Legion and Changing Gender Practices in Spain', Exchange 42: 86-106.

Gosden, C., and Y. Marshall (1999) 'The Cultural Biography of Objects', World Archaeology 31.2: 169-178.

Guerrero Clavijo, A. J. (2013) 'Cuando el Cancer te Lleva a Buscar su Redención', Semana Santa 2013 (Antequera: El Sol de Antequera). 78-80.

Houtman, D., and B. Meyer (eds) (2012) Things: Religion and the Question of Materiality (New York: Fordham University Press).

Jansen, W. (2009) 'Marian Images and Religious Identities in the Middle East' in A. K. Hermkens, W. Jansen, and C. Notermans (eds) Moved by Mary: The Power of Pilgrimage in the Modern World (Farnham, UK: Ashgate). 33-48.

Jansen, W. (2012) 'Old Routes, New Journeys: Reshaping Gender, Nation and Religion in European Pilgrimage' in A. K. Hermkens, W. Jansen, and C. Notermans (eds) Gender, Nation and Religion in European Pilgrimage (Farnham, UK: Ashgate). 1-18.

Jansen, W., and H. Driessen (2013) 'Gender Dynamics in Andalusian Religious Brotherhoods', Anthropos 108: 543-552.

Jansen, W., and H. Driessen (2016) 'The Lost Child: Age and Gender in Ritual in Southern Spain', Journal of Ritual Studies 30.2: 25-39.

Kopytoff, I. (1986) 'The Cultural Biography of Things: Commoditization as Process' in A. Appadurai (ed.) The Social Life of Things: Commodities in Cultural Perspective (Cambridge: Cambridge University Press). 64-91. 
Lanzas, R. (2014) 'Servitas: La imagen de una Dolorosa', Religión Digital, www.periodistadigital.com/religion/opinion/2014/04/12/servitas-la-imagende-una-dolorosa-malaga-semana-santa-dios-jesus-religion-iglesia.shtml (Accessed 23 May 2016).

Mauss, M. (1990) The Gift: The Form and Reason for Exchange in Archaic Societies (New York: Norton).

McDannell, C. (1995) Material Christianity: Religion and Popular Culture in America (New Haven, CT: Yale University Press).

Miller, D. (1987) Material Culture and Mass Consumption (Oxford: Basil Blackwell).

Miller, D. (2008) The Comfort of Things (Cambridge: Polity Press).

Morehart, C. T., and N. Butler (2010) 'Ritual Exchange and the Fourth Obligation: Ancient Maya Food Offering and the Flexible Materiality of Ritual', Journal of the Royal Anthropological Insitute (N.S) 16: 588-608.

Myerhoff, B. (1982) 'Life History among the Elderly: Performance, Visibility and Re-membering' in J. Ruby (ed.) A Crack in the Mirror: Reflective Perspectives in Anthropology (Philadelphia: University of Pennsylvania Press). 99-117.

Myerhoff, B. (1984) 'Rites and Signs of Ripening: The Intertwining of Ritual, Time and Growing Older' in D. J. Kertzer and J. Keith (eds) Age and Anthropological Theory (Ithaca, NY: Cornell University Press). 305-330.

Notermans, C., and W. Jansen (2011) 'Ex-Votos in Lourdes: Contested Materiality of Miraculous Healings', Material Religion 7.2: 168-193.

Pargament, K. (1999) The Psychology of Religion and Coping: Theory, Research, Practice (New York: Guilfort Press).

Plate, L. (2011) Transforming Memories in Contemporary Women's Rewriting (Basingstoke, UK: Palgrave Macmillan).

Plate, L., and A. Smelik (eds) (2009) Technologies of Memory in the Arts (Basingstoke, UK: Palgrave Macmillan).

Plate, L., and A. Smelik (eds) (2013) Performing Memory in Art and Popular Culture (London and New York: Routledge).

Renfrew, C. (2001) 'Production and Consumption in a Sacred Economy: The Material Correlates of High Devotional Expression at Chaco Canyon', American Antiquity 66: 14-25.

Russell, S., and M. Carey (2014) 'Remembering: Responding to Commonly Asked Questions', Narrative Practices Adelaide, http://narrativepractices. com.au/attach/pdf/Remembering_Common_Questions.pdf.

Schrauf, R.W. (1999) ' $i$ Costalero Quiero Ser! Autobiographical Memory and the Oral Life Story of a Holy Week Brother in Southern Spain', Ethos 25.4: $428-453$.

Turner, V., and E. Turner (1978) Image and Pilgrimage in Christian Culture: Anthropological Perspectives (Oxford: Blackwell).

Veblen, T. (1899) The Theory of the Leisure Class (New York: Macmillan).

White, G. (2006) 'Epilogue: Memory Moments', Ethos 34.2: 325-341.

White, M. (1999) Narratives of Therapists' Lives (Adelaide, Australia: Dulwich Centre Publications). 


\title{
9 Matters of Memory in Los rubios by Albertina Carri
}

\author{
Anna Forné
}

In postdictatorial Argentina, the labors of memory are a highly public and political concern, and one of the most salient topics in contemporary narrative and film is the memories from the Dirty War (1976-1983). Parallel to the commemorations of thirty years of democracy in 2013, the trials of the militaries responsible for the abduction and disappearance of what has been estimated at 30,000 people continued, alongside the inexhaustible search for their children and grandchildren, carried out by the Mothers and Grandmothers of Plaza de Mayo since 1977.

During the past decade, the children of the disappeared have received a lot of attention for their ethically and aesthetically defying cinematographic representations of their memories of the years of repression and of their parents. ${ }^{1}$ In these stories of personal search for a genealogy interrupted by violence, repression, and disappearance, the personal and the political acquire new nuances, and the relationship between fact and fiction, as well as between subject and object, is renegotiated in order to reconsider the predominant public discourses on the memories of these times.

Released in 2003, Albertina Carri's docufiction film Los rubios ('The Blonds') on the disappearance of her parents during the Dirty War was not only aesthetically groundbreaking but also anticipated future developments in cultural representations of the disappeared in Argentina. Albertina Carri was born in Buenos Aires in 1973, the daughter of the Montonero militants Roberto Carri and Ana María Caruso, who both disappeared in 1977. At the time of its release, Los rubios received harsh criticism from some of the most influential cultural figures in Argentina, who principally disapproved of its depoliticizing suppression of 'a reality, that of political violence ... just as the movie already suppressed the past, or the practice of memory, or the possible connections to a possible identity' (Kohan, 2004, p. 29, my translation). ${ }^{2}$ The critics also objected to its indifferent or even inconsiderate approach to the testimonies of Carri's parents' political comrades and to its accentuated subjectivity (Kohan, 2004, p. 28; Sarlo, 2005, pp. 146-151). These objections could be explained as the result of an obsolete model of reading, limited by a depleted horizon of expectations belonging to a dated generational 
paradigm, just as Cecilia Macón (2004) signalled in her reply to Kohan's critical review of Los rubios. As Antonio Gómez and Verónica Garibotto put it:

The terms of the discussion and the obvious need to adjust the perspectives and extend concepts however point out that Los rubios, far from being a new variation within an old format, obliquely reveals the outdatedness of the model and confronts us with a way of reading that has become hegemonic and which seems exhausted. (2006, p. 109, my translation $)^{3}$

In Los rubios Carri explores the story of the disappearance of her parents through the assemblage of different kinds of materials such as photographs, videotaped interviews, books, and toys, staged in a way that blurs the conventional boundaries between documentary and fiction. In the movie, Carri appears as herself (the director) accompanied by her crew, but she also introduces an actress, Analía Couceyro, who plays the role of Albertina Carri in the search for her parents' story (Figure 9.1). In her quest, Carri not only searches for memories in the things of the past, but she also turns herself into an object of investigation when the camera loops around, in order to capture the interaction between the real event and its representation. In other words, Carri turns Albertina Carri into an object-maybe even a thing-when she creates the character of Albertina. ${ }^{4}$

As several critics have remarked (Aguilar, 2008; Andermann, 2012; Nouzeilles, 2005; Page, 2005, 2009a, 2009b), Carri uses various narrative strategies to expose the incompatibility of the demands of transparency and coherence when representing memories of dictatorship (as claimed by Kohan, 2004, and Sarlo, 2005, among others) and the gaps and incongruences of her own memory of her parents. No critic, however, has paid attention to how memories are materialized in Los rubios through the exhibition of various objects and how the representation of the changed relationship between subject and object raises questions over authorship and authenticity. In what follows, I will examine both of these dimensions, taking Bill Brown's Thing Theory as a point of departure in the first section, on 'Objects of Memory', then moving on to discuss the film's aesthetics of authenticity in the second section, 'The Subject as an Object of Memory'.

\section{Objects of Memory}

In Los rubios, the material traces of the past are the starting point for a search that evolves as an inquiry into the sociopolitical, cultural, and emotional dimensions of material objects. As such, the objects represented in Los rubios could be conceived as things in the meaning Bill Brown gives 
to the term, by which he means that ordinary objects become knowable things when their conventional meaning is interrupted and surpassed. In Thing Theory, Brown posits that when we start looking at instead of through the everyday objects that surround us, they turn into things. Speaking of 'occasions of contingency-the chance interruption-that disclose a physicality of things', Brown explains:

We begin to confront the thingness of objects when they stop working for us: when the drill breaks, when the car stalls, when the window gets filthy, when their flow within the circuits of production and distribution, consumption and exhibition, has been arrested, however momentarily. (2001, p. 4)

In Los rubios, an exposition of different kinds of memory objects is carried out by drawing the spectator's attention to the numerous devices used in the reconstruction of the past, almost as a kind of exhibition of different techniques of scrapbooking. In this filmic display of cutting, reorganizing, and staging, not only of the objects of memory but also of the modus operandi, the importance of materiality in collective as well as individual labors of memory is highlighted. In the movie, the changing symbolic values of the depicted objects of memory are exposed by means of various self-reflexive, distancing techniques that ultimately invite the spectators to engage in the production of meaning beyond the filmic diegesis. As such, the purpose of the representation of a changed relationship between subject and object is political.

Considering the inevitable intertwinement of personal and public narratives of memory, the objects of memory exposed by Albertina Carri-as protagonist and director-in the film could be thought of as things. The concept of things, as developed in Brown's Thing Theory, emphasizes the changed relationship between the subject and the object contemplated (in Los rubios also staged and exposed), which implies both retardation and a change in the level of affect. According to Brown, the object is revealed as a thing when the relationship between the human subject and the object is altered because the habitual perception of the object changes. Furthermore, the deferred interaction between subject and object produces what in Brecht's aesthetic theory would be called an estrangement effect (Verfremdungseffekt in German), which leads to a renewed perception of things: 'Temporalized as the before and after of the object, thingness amounts to a latency (the not yet formed or the not yet formable) and to an excess (what remains physically or metaphysically irreducible to objects)' (Brown, 2001, p. 5).

The movie presents no pictures of Carri's parents as adults either verbally or visually. However, the conception of them as beautiful, intelligent, and heroic is constantly communicated through the various interviews with family members, as well as with former political 
comrades, which are intercalated in the film as videotaped conversations. In that respect, a contrast is created between what is verbally articulated in the inserted interviews and what is visually displayed in the framed exposure of Albertina Carri's response-as director and protagonist-when gathering and organizing the objects of memory. Whereas Albertina (the protagonist) seems to remain impartial, even indifferent, to the videotaped testimonies, her own inventory of the objects of remembrance from the past produces, as we will see, effects as well as affects beyond the testimonial repertoire that is represented and enacted in the movie. Albertina's detached response as a spectator to the gathered and projected objects of memory, especially the videotaped testimonies, could be thought of in terms of the discursive patterns required not only in the courtroom but also by the testimonial and documentary genres. Indeed, in order for the witness to turn the individual experience as victim into evidence, emotion had to be erased from the testimonial regime. Although the videotaped testimonies in some instances are emotional, singing her parents' praises, Albertina, who is also a witness, seems reluctant to engage in the repetitive narrative that they present.

In 1983, the first democratically elected president after the dictatorship, Raúl Alfonsín, created a National Committee (Comisión Nacional sobre la Desaparición de Personas - CONADEP) to investigate the disappearances during the Dirty War. The massive recollection of testimonies and material of proof resulted in a report called Nunca más (Never again), describing the methods and scale of repression as well as the conditions in the military jails and clandestine detention centres that operated in the country during the dictatorship. The official importance of the report was strengthened when it was accepted as evidence in the trials of the military junta. In the context of postdictatorial Argentina, the interpretation of political violence and disappearance presented in the Nunca más report and the ways the

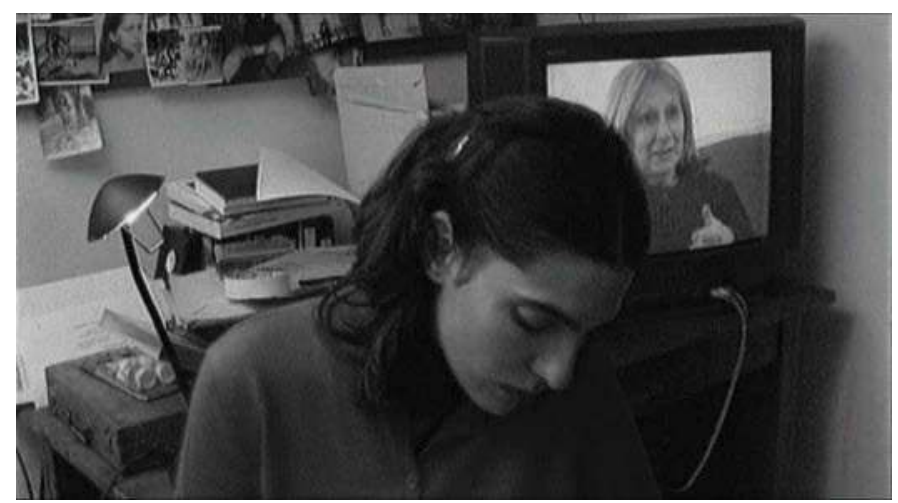

Figure 9.1 Analía Couceyro as Albertina in Los rubios. 


\section{Anna Forné}

material was organized soon came to constitute an emblematic memory, a kind of matrix for the ways of telling memory stories of dictatorship and repression in Argentina. As such, from the first moments of transition to democracy, the discourse of memory was organized top-down and the strategies of telling and interpretation employed in Nunca más were to be reproduced for a long time, not only in judicial testimonies but also in public opinion, the political debate, and cultural texts on memories of the dictatorship (Crenzel, 2008, p. 23). The imperative of the first narratives on dictatorship was primarily pragmatic, and they responded to the urgency to tell the truth and let the world know what had happened in Argentina during the military rule. In these texts, the content is thought to be more important than the forms of representation, according to the epistemological premise that both words and images can truthfully mirror reality. These claims of truth, and the darkening of the ambiguous relationships between fact and fiction, were later exploited by the 'second generation', which played with the registers of authenticity and veracity in order to highlight the idea that the representation of memory is more complicated than the conventional repertoire of the documentary acknowledges. In this respect, Nouzeilles (2005, p. 266) mentions how Carri in Los rubios revises both the discursive protocols of the Nunca más report as well as the consecrated memory of the disappeared by means of avant-garde aesthetics, a questioning of the revolutionary ideals of the 1960s and 1970s, along with a 'pantomimic destabilization' of the imposed ideas and expectations of a daughter of the disappeared.

In Los rubios, the displayed objects, expected to embody memories, do not generate any affect or emotion until they are read against the prevalent and publicly ratified understanding of their symbolic value. It is only when Albertina Carri refuses to comprehend them according to the predominant discourse that they acquire new meanings. As Gabriela Nouzeilles observes in her timely article on Los rubios: 'There is a pendular movement between rejection and re-inscription that the movie openly addresses in both its formal choices and its use of materials, as well as in some of the film crew's discussions on camera' (2005, p. 273).

Performativity has been central to the opposition to dictatorial violence ever since the first marches of the Mothers of Plaza de Mayo in 1977, which were later continued and developed by the children of the detained-disappeared in the form of street actions and interventions in public space. The ID photos of the disappeared, as a form of evidence of a lost past, have had a particularly crucial importance to the representation of terror and disappearance ever since the first public showings of private photographs carried out by the Mothers of Plaza de Mayo. In their artistic activism, members of HIJOS (the organization of the children of the detained-disappeared, formed in 1995) ${ }^{5}$ recycle and reiterate the 
performative practices of the Mothers and Grandmothers of the disappeared in what Diana Taylor has labeled the 'DNA of performance':

Just as the generations share genetic materials, which these groups have actively traced through DNA testing, there are performance strategies (DNA of performance) that link their forms of activism.... One clear strategy that reveals both the continuation and the transformation of cultural materials becomes recognizable in the use of the photo IDs to bring together the scientific (DNA testing) and performative claims in transmitting traumatic memory. Strategies, like people, have histories. In this case, the strategies work to reappear those who have been erased from history itself. (2003, pp. 168-169)

Although never an active member of the organization HIJOS, ${ }^{6}$ in her memorial practices Albertina Carri literally intervenes in the institutionalized, political uses of the photographs of the disappeared when she cuts the received images into pieces in order to put them into new contexts and constellations of meaning, visualized in the movie as fragmented collages of pieces of photographs (Figure 9.2). By overturning the politically and culturally established relationship between subject (daughter of the disappeared) and objects (photographs of the disappeared), it is possible to conceive and represent memories in new ways, in discordance with habitual usages of the family photo album in postdictatorial Argentina. What is enacted in Los rubios is a scrapping and remapping of the objects of memory that are turned into things by means of a performance, producing an experience of the past in the present (Plate and Smelik, 2013, p. 2). In this sense, in Los rubios the interruption of the habitual relationship between subject and object is not entirely accidental, caused by the breakdown of the object, as described by Brown in Thing Theory. In this case, the thingness of the object is generated by the agency of the subject, whose actions express in the present an experience of the past. The reconstructed experience in Carri's film is that of the disappearance of the people depicted in the cut-up photographs, and the act of re-presentation mirrors the scattered memories of the remembering-performing subject: 'Memory is always re-call and re-collection (the terms are frequently used as synonyms), and, consequently, it implies re-turn, re-vision, reenactment, re-presentation: making experiences from the past again in the form of narratives, images, sensation, performances' (Plate and Smelik, 2013, p. 6).

Even though the performance is carried out by an active subject, the re-presented memories always interact with and renegotiate established, institutionalized discourses and memory practices. When Albertina Carri cuts the inherited pictures of the past into pieces, she also literally as well as figuratively does away with the received significances of what Susan Sontag names 'the routes of reference' of the photograph 




Figure 9.2 Analía Couceyro as Albertina in the process of scrapping and remapping.

(Sontag, 2003, p. 85). As Sontag contends, memory can only be individual, and what we conceive of as collective memory is only a sociocultural construction: 'Ideologies create substantiating archives of images, representative images, which encapsulate common ideas of significance and trigger predictable thoughts, feelings' (Sontag, 2003, pp. 85-86).

The idea of a disruption of the indexicality of the recovered pictures of the past, conceptualized as 'postmemory' (Hirsch 2008, 2012), has frequently been invoked in the critique of Argentinian postdictatorial representations of the second generation. According to Marianne Hirsch, the images of the past only preserve an aura of indexicality in postmemorial practices: 'the index of postmemory (as opposed to memory) is the performative index, shaped more and more by affect, need, and desire as time and distance attenuate the links to authenticity and "truth" (2012, p. 61). Along the same lines, Katrina Schlunke suggests that memory and materiality could be understood as interconnected producers of memory effects: 'To appreciate memory as an effect experienced through and with materiality is to understand materiality ... as a "continuously enacted relational effect"' (Schlunke, 2013, p. 253). As she asserts, memory is simultaneously material and temporal, and it is our perception of the objects of memory-imbued with the senses of the past but still ever changing - that creates new meanings: 'Here perception is memory-not a relayed or represented after-effect but a way in which meaning is experienced' (p. 260). In Los rubios, this kind of memory effect, theorized by Hirsch and Schlunke among others, is produced only when the conventional heroic story about Carri's parents is dismantled and the perception of the abandoned child finds its forms of expression in the re-encounter with objects of the past. However, no simple truth is uncovered, and the intention to organize the objects of memory is frustrated, as visualized by the exposed collages as well as by 
the disruption of the conventional causality of the testimonial documentary. As Gabriela Nouzeilles observes, the accumulation of objects of memory in Los rubios does not have the expected effect of reality, even though Carri eventually comes up with an alternative to the dominant narrative forms of the official, totalizing, heroic (hi)stories of the disappeared through the assemblage of different sources: 'notwithstanding the efforts of the film crew, the search for the real and the authentic is always imperfect, unsatisfactory. The larger amount of data, the more distant the object of their quest appears, continuously receding behind the veils of representation' (2005, p. 268).

Albertina Carri's only wish expressed in the movie is that her parents will be present at her next birthday, and it is that desire that incites the quest and the affective investment in the recovered objects of memory. In this way, the emotional emptiness in relation to the predominant representations of Carri's parents is inverted by means of an aesthetic practice suggesting that the objects of remembrance produce both memory and the remembering subject. As we have seen, Albertina Carri's collages not only expose the objects but also interfere in the prevalent discourse so as to produce an alternative representation caused by the changed relationship between the subject and the contemplated objects, which are turned into things. As Hirsch points out, postmemorial narratives of the past are always mediated by the public ones (2008, p. 112). This is clearly also the case in Los rubios, an artifact in which Carri intervenes metadiscursively in order to suggest new perspectives and modes of perception.

\section{The Subject as an Object of Memory}

In New Argentine Cinema, Jens Andermann suggests that the performative memory practices brought into play by the Mothers and Grandmothers of Plaza de Mayo, and later developed by the children of the disappeared, reverberate in contemporary Argentine cinema, in which 'questions of staging, reenactment and representational self-reflexivity are also of key importance for the numerous films-fictional as well as documentary-dealing with the recent past of leftist struggle and dictatorial terror' (2012, p. 106). The use of these narrative strategies, he argues, entails a shift of focus from the representation of a testimonial truth to the representation of the act of memory (p. 107). As we have seen, this reconfiguration of the prevalent discursive modalities on political violence and disappearance is partly carried out in Los rubios through a rearrangement of the public narratives and images of Carri's parents. In what follows, I will look into how the paradoxical intertwinement of the world of the telling and the world of the told, staged through a self-reflexive reenactment, turns the premises of the established ways of telling the (hi)story of the disappeared around to rewrite it from the position of the fragmented subjectivity of the orphan. 
Reenactment is generally understood as the practice of re-performing a precedent event, and it is characterized by its syncopated time 'where then and now punctuate each other' (Schneider, 2011, p. 2). In its contemporary revival, cinematographic reenactment seems to favor reflexivity 'to older, realist forms, where the staging of history is meant to have evidentiary value' (Kahana, 2009, p. 51). In this respect, Ivone Margulies, taking Andrea Tonacci's Serras da Desordem (2006) as an example, argues that the inherent belatedness of reenactment opens the way for a critical and aesthetic reconsideration of testimony, history and authenticity, since it metafictionally addresses 'the contradictions involved in mimetically reproducing a going-back in time and place' (2011, p. 5). What is at stake here is the ontological ambiguity between doing and performing, and between reality and construction:

Filmed reenactments are thus of a piece with the problems apparently posed in a new way by those more recent forms of docudrama or metafictions which place 'in abeyance,' according to Hayden White, 'the distinction between the real and the imaginary. Everything is presented as if it were of the same ontological order, both real and imaginary-realistically imaginary or imaginarily real, with the result that the referential function of the images of events is etiolated'.

(Kahana, 2009, pp. 53-54)

In a frequently quoted article, Bill Nichols writes about reenactment having the effect of a temporal vivification, which he describes as a quest for a lost object in which past and present merge to 'bring desire itself into being' (2008, p. 88). As he explains, documentary reenactment has a fantasmatic effect when it abandons the indexical connection to the original event. Instead of being evidentiary, documentary reenactments are affective and persuasive interpretations of a past event that engage not only the author but also the viewer: 'Reenactments vivify the sense of the lived experience, the vécu, of others. They take past time and make it present. They resurrect a sense of a previous moment that is now seen through a fold that incorporates the embodied perspective of the filmmaker and the emotional investment of the viewer' (p. 88).

In Los rubios, Carri not only remediates the things of the past, but also turns herself into an object of the search by way of a metalepsis, which is a contradictory mingling of the world of the telling and the world of the told, crossing the boundaries between the real and the constructed in order to question the evidentiary value of the tangible. A number of critics (Andermann, 2012, p. 115; Nouzeilles, 2005, p. 269; Page, 2009a, p. 172) have pointed out that at least three versions of Albertina Carri appear in the film: the authorial figure behind the camera, the 'auteur' inside the film (enacted by the director herself), and finally the 
remembering daughter Albertina, portrayed by an actress (Couceyro). However, I believe that the framing and stratification of the different authors and actors in the film is even more complex and multifaceted than that. In fact, in Los rubios, Carri (the director) appears on screen as herself (the director-daughter). This staging is further complicated as Carri also appears in the film as the director holding the camera filming her double, played by an actress (Couceyro). The relationship between reality and construction is additionally intricate since both Carri and Couceyro appear as actors in the movie, filmed by someone else (Figure 9.3). Moreover, Couceyro appears in some scenes holding the camera, as if she had switched roles with the 'authentic' Carri (director) in the present moment of the filmmaking. Finally, the camerawomen (Catalina Fernández and Carmen Torres), as well as the rest of the crew, are present in several scenes. As a result, instead of confirming the authenticity of the physical (the body), the reenactment in Los rubios generates ambiguity by staging a series of interconnected, though not merged, representational spaces that trespass the conventional referential thresholds.

As Stella Bruzzi points out, this kind of performative documentary brings about a more complex representation of the relationship between reality and image, as well as of the relationship between intention and execution, as it accepts authorship as an intrinsic characteristic of the genre. The creative process is exposed in order to involve the spectator in the meaning making:

What emerges is a new definition of authenticity, one that eschews the traditional adherence to an observation or Bazin-dependent idea of the transparency of film and replaces this with a performative exchange between subjects, filmmakers/apparatus and spectators.

(Bruzzi, 2000, p. 6)

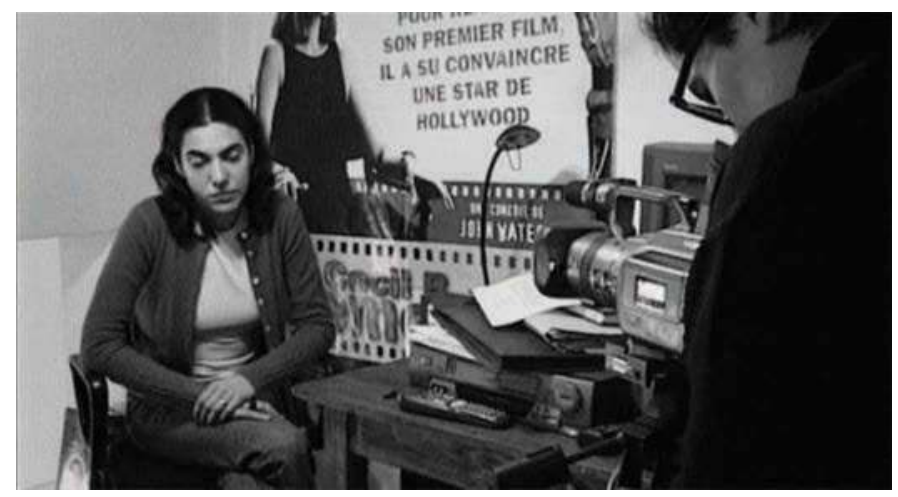

Figure 9.3 Analía Couceyro as Albertina and Albertina Carri as Carri in Los rubios. 


\section{8}

Consequently, the intrusion of artifice in Los rubios suspends the spectators' belief in authenticity, as an effect of Carri's enacted disbelief in the possibility of filling in the gaps of her own memories of her parents, as opposed to the dominant testimonial narratives on the fate of the disappeared. Moreover, the reenactment gives voice to the fragmented and pained subjectivity in the search for a lost object that turns out to be herself.

In a review of an exposition of artwork by children of the disappeared, Mariana Eva Pérez argues that the disintegration of perspectives revealed in these works of art is a consequence of their splitting themselves into two temporalities (past and present) that the artists of the second generation seem to suffer from. On the one hand, there remains the child who cannot understand, while on the other stands the grown-up artist who, apart from his or her personal memories, is affected by the public narratives and nonetheless apprehends his or her story as incomplete. The need to stage a self-reflexive narrative, shaped between the personal and the collective, between the factual and the imaginary, and between past and present thus seems to spring from a desire to get to know oneself both backward and forward in time. According to Pérez (2010), this desire is constantly frustrated because the one who sees and the one who creates perform separately. This contrast between the infantile gaze and the adult hand is staged in Los rubios in the scenes shot in the neighbourhood where Albertina Carri last lived with her parents before their disappearance and where she in the present conducts interviews with her former neighbors. By means of a metalepsis, the interviews that Carri and her crew carry out are shot so as to emphasize the coexistence of several representational spaces and temporalities. In the staging of the interviews with the woman who turns out to be the one who gave Albertina Carri's parents away to the military, the world of the telling contaminates the world of the told as we see the 'real' Carri holding the camera, filming Albertina (Couceyro) conducting the interview. The story of the traitor, who claims her innocence, is complemented by the story of the child, narrated by Albertina (Couceyro) in a set of rehearsals directed by the voiceover of Carri. In this reenactment of the story of the disappearance of Carri's parents, the hand thus belongs to Carri (director), while the gaze is Albertina's, trying to reconstruct her story in a series of tryouts, directed by Carri as 'auteur'. It is in those rehearsals that the staging in Los rubios gets closest to the idea of reenactment as a 'temporal convulsion that weaves past and present together' (Nichols, 2008, p. 76) because it is here that the fantasmatic effect Nichols mentions comes into play. For a moment, the sense of the lived experience is reanimated and vivified when the child and the adult, the past and the present, momentarily coexist through the reiterative gesture of reenactment (p. 88).

In Los rubios, a fictional repetition of the key historical moment of the narrative is never produced by way of a reenactment, since the exact 
moment of the abduction is at no time represented in a documentary approach, and no strict temporal interweaving of past and present is produced through reenactment in the film. Carri explained in a recent interview that at the moment of filming, staging the abduction in terms of a 'live action' seemed impossible because she only retains frozen images of that moment (Cirulo, 2013). In other words, Carri does not reenact the moment of disappearance, but it is nonetheless dramatized in a series of fragments of stop-motion animation featured by Playmobil figures in the roles of the Carri family and the abductors. Clearly, what seemed beyond the reach of conventional reenactment was not beyond representation.

In his typification of reenactment, Nichols mentions animations as a kind of stylization, which diminishes 'the elements of realist dramatization. The viewer remains vividly suspended in that moment between before and after embodied in signifiers that possess an iconic rather than indexical relation to what has already happened' (2008, p. 86). The Playmobil sections of Los rubios thus re-present the abduction and disappearance of Carri's parents from the gaze of the child. Taking His Mother's Voice (dir. Denis Tupicoff, 1997) and Superstar: The Karen Carpenter Story (dir. Todd Haynes, 1987) as examples of animations that reenact personal tragedy and trauma, Nichols suggests that the obvious separation between reality and construction in the doll scenes may bring about a more multifaceted interpretation than a realist dramatization would do $(2008$, p. 87). Furthermore, recognizing the toys as 'technologies of memory' (Plate and Smelik, 2009, pp. 3-4), that is, as objects and representations through which memories are created and shared, can help us to better understand not only the interaction between the individual recalling of a past and the collective memory, but also the relationship between event and representation.

In Los rubios, the Playmobil figures do not seem to be exhibited as biographical objects containing a life-story and a personal meaning, as would be the case with a collection of toys with sentimental value chosen for an exhibition of everyday objects, like the ones described by Elizabeth Wood in 'The Matter and Meaning of Childhood through Objects' (2009). Nor do the Playmobil animations seem to fit into a broader narrative, as part of a collective memory of childhood distinguished by continuity and sameness, commonly conceived as nostalgia (Wood, 2009, p. 128). Instead, the Playmobil animations function as a kind of countercurrent technology of memory in emphasizing discontinuity and discrepancy. In that regard, Jordana Blejmar reads the Playmobil sections in Los rubios as an expression of a 'playful memory', which by means of the child's gaze demonumentalizes and desacralizes the cultural and collective memory of the disappeared, beyond conventional sentimentality and nostalgia (2013, p. 49). In the stop-motion fragments, the perception of the child saturates the everyday objects of consumption with new meanings. At the same 


\section{Anna Forné}

time, it raises questions about the representation of memory by adding yet another frame to the many diegetic windows already open in the movie. Blejmar maintains that 'the toys are deployed in the film not to bring the past back to the present but rather to confirm absence' (p. 51). In response to that observation, I would like to suggest that absence is confirmed by means of an excess of presence, created through the multiplication of representational spaces, the unfolding of subjectivity, and the reenacted rupture of the conventional symbolic value of the objects of memory.

\section{Conclusion: Memory as Presence and Thingness}

The starting point for Albertina Carri's memory practices, staged and reenacted in her renowned and controversial feature film Los rubios (2003), is the physical and emotional void of the child, orphaned because of the systemized abduction and disappearance of militants, which was carried out in Argentina during the years of the dictatorship (1976-1983). In the movie, Carri's exploration of the story of the disappearance of her parents is constructed by means of a self-reflexive staging and rearranging of different kinds of memory objects such as photographs, videotaped interviews, and toys. Furthermore, Carri explores the filmmaking milieu, turning herself into an object of memory, as she appears as herself both actively and figuratively (sometimes simultaneously) in the film. Instead of confirming the authenticity of the physical (the body) and the material (the objects of memory), the reenactment in Los rubios generates ambiguity when staging a series of interconnected representational spaces that expose the factitiousness and constructedness of memory. In the movie, the initial emotional emptiness, as well as the visualized physical absence of her parents, are reversed by way of an excess of presence in the present, when the objects of memory become knowable (a thing) as a consequence of a renewed relationship between subject and object. Not only are the received meanings (symbolized by the memory objects not yet turned into things) literally cut into pieces and rearranged by the hand of the author, but Albertina Carri herself is turned into an object of memory. In the movie, reenactment and metalepsis are deployed to point out the difficulties of going back in time to represent events the way they really happened. By crossing the boundaries between the real and the constructed, Los rubios brings about a more complex representation of the relationship between reality and construction, as well as of that between intention and execution. Ultimately, these representational mechanisms invite the viewers to engage in the production of meaning beyond the filmic diegesis. As such, the purpose of the representation of a changed relationship between subject and object is political. 


\section{Notes}

1 For example, Benjamín Ávila's Nietos (Identidad y memoria) (2004) and Infancia clandestina (2012), Andrés Habegger's (H) Historias cotidianas (2001), Nicolás Prividera's M. (2007) and María Inés Roqués Papá Iván (2004).

2 'una realidad, la de la violencia política ... tal como antes en la película se había suprimido el pasado, o el ejercicio de la memoria, o los posibles lazos de una posible identidad' (Kohan, 2004, p. 29).

3 'Los términos mismos de la discusión y la evidente necesidad de ajustar perspectivas y de estirar conceptos ponen de relieve, sin embargo, que Los rubios, lejos de ser una variación nueva dentro de un formato viejo, denuncia oblicuamente la caducidad del modelo y nos confronta con una matriz de lectura que se ha vuelto hegemónica y que parece agotada' (Gómez and Garibotto, 2006, p. 109).

4 In order to avoid confusion, I will refer to the real Albertina Carri (director and producer) as Carri and to the fictional one (the protagonist) as Albertina. When referring to both indistinguishably, I will use Albertina Carri.

5 Hijos por la Identidad y la Justicia contra el Olvido y el Silencio.

6 In Los rubios: cartografía de una película, Carri (2007, p. 111) explains that she never participated in the activities organized by HIJOS because she felt she could not identify her own pain with that of other children of the disappeared.

\section{References}

Aguilar, G. (2008) New Argentine Film: Other Worlds (New York: Palgrave Macmillan).

Andermann, J. (2012) New Argentine Cinema (London: I. B. Tauris).

Blejmar, J. (2013) 'Toying with History: Playful Memory in Albertina Carri's Los rubios', Journal of Romance Studies 13.3: 44-61.

Brown, B. (2001) 'Thing Theory', Critical Inquiry 28.1: 1-22.

Bruzzi, S. (2000) New Documentary: A Critical Introduction (London and New York: Routledge).

Carri, A. (2003) Los rubios. Argentina and United States of America: Women Make Movies.

Carri, A. (2007) Los rubios: Cartografía de una Película (Buenos Aires: Ediciones Gráficas Especiales).

Cirulo, D. (2013) 'Reflejos en la Oscuridad: Entrevista con Albertina Carri', GRUPOKANE (Revista de Cine y Artes Audiovisuales) http://www. grupokane.com.ar/index.php?option=com_content $\& v i e w=$ article \&id $=642$ : artentreviacarri\&catid=36: catficcion\&Itemid=29 (Accessed 15 July 2016).

Comisión Nacional sobre la Desaparición de Personas (1984) Nunca Más (Buenos Aires: Editorial Universitaria de Buenos Aires).

Crenzel, E. (2008) La Historia Política del Nunca Más: La Memoria de las Desapariciones en la Argentina (Buenos Aires: Siglo Veintiuno Editores).

Gómez, A., and V. Garibotto (2006) 'Más allá del 'Formato Memoria': La Repostulación del Imaginario Postdictatorial en Los Rubios de Albertina Carri', A Contracorriente: Revista de Historia Social y Literatura en América Latina 3.2: 107-126.

Hirsch, M. (2008) 'The Generation of Postmemory', Poetics Today 29.1: 103-128. 


\section{Anna Forné}

Hirsch, M. (2012) The Generation of Postmemory: Visual Cultures after the Holocaust (New York: Columbia University Press).

Kahana, J. (2009) 'Introduction: What Now? Presenting Reenactment', Framework: The Journal of Cinema and Media 50.1-2: 46-60.

Kohan, M. (2004) 'La apariencia celebrada', Punto de vista 78: 24-30.

Macón, C. (2004) 'Los rubios o del Trauma como Presencia', Punto de Vista 80: 44-47.

Margulies, I. (2011) 'Reenactment and A-filiation in Andrea Tonacci's Serras da Desordem', Cinephile 7.2: 5-14.

Nichols, B. (2008) 'Documentary Reenactment and the Fantasmatic Subject', Critical Inquiry 35.1: 72-89.

Nouzeilles, G. (2005) 'Postmemory Cinema and the Future of the Past in Albertina Carri's Los Rubios', Journal of Latin American Cultural Studies 14.3: $263-278$.

Page, J. (2005) 'Memory and Mediation in Los rubios: A Contemporary Perspective on the Argentine Dictatorship', New Cinemas 3.1: 29-40.

Page, J. (2009a) 'Digital Mimicry and Visual Tropes: Some Images from Argentina' in M. Haddu and J. Page (eds) Visual Synergies in Fiction and Documentary Film from Latin America (New York: Palgrave Macmillan). 201-217.

Page, J. (2009b) Crisis and Capitalism in Contemporary Argentine Cinema (Durham, NC: Duke University Press).

Pérez, M.E. (2010) 'Los Abrazos Rotos', Página 12, May 9, http://www.pagina12. com.ar/diario/suplementos/radar/9-6143-2010-05-09.html (Accessed on 14 July 2016).

Plate, L., and A. Smelik (eds) (2009) Technologies of Memory in the Arts (Basingstoke, UK: Palgrave Macmillan).

Plate, L. and A. Smelik (eds) (2013) Performing Memory in Art and Popular Culture (London and New York: Routledge).

Sarlo, B. (2005) Tiempo Pasado: Cultura de la Memoria y Giro Subjetivo: Una Discusión (Buenos Aires: Siglo Veintiuno Editores Argentina).

Schlunke, K. (2013) 'Memory and Materiality', Memory Studies 6.3: 253-261.

Schneider, R. (2011) Performing Remains: Art and War in Times of Theatrical Reenactment (London and New York: Routledge).

Sontag, S. (2003) Regarding the Pain of Others (New York: Picador).

Taylor, D. (2003) The Archive and the Repertoire: Performing Cultural Memory in the Americas (Durham, NC: Duke University Press).

Wood, E. (2009) 'The Matter and Meaning of Childhood through Objects' in Plate, L. and A. Smelik (eds) Technologies of Memory in the Arts (Houndmills, Basingstoke, UK: Palgrave Macmillan). 120-131. 


\section{Part IV}

Corporeality and Objects of Trauma 
This page intentionally left blank 


\title{
10 Chilling Burlesque The Act of Killing
}

\author{
Aleid Fokkema
}

\section{Introduction}

As film titles go, the one for Joshua Oppenheimer's documentary The Act of Killing (2013) is as offputting as it gets: robust, shocking, direct, and unpoetic. But it is also a double-entendre, referring both to the deed of killing and its theatrical representation-to doing and performance. It documents how scenes of the past, buried in an uneasy mix of pride and guilt, are re-created and reenacted in a stunning mix of contemporary, local popular culture and Hollywood gangster style. The film thus documents how, as Liedeke Plate and Anneke Smelik argued, memory is generated, brought into the present, 'in the act of performing it' (2013, p. 3). Reenactment, one of the stock-features of the type of 'expository' documentary (Nichols, 2001) focused on presenting past events in a didactic way, is the film's central idea and feature: Past acts of killing such as they happened nearly five decades ago in a prolonged post-coup purge in Indonesia are reenacted in seemingly endless variation. However, the didactic element usually associated with the expository mode (such as the BBC History of World War II series (1989-2005)) does not prevail in these reenactments. Rather, as I shall argue, the theatrical stagings of The Act of Killing border on the grotesque. They provoke both horror and laughter, ${ }^{1}$ an affective response of the film's audiences often summarized as 'surreal' (Horeck, 2014, p. 157). Played out openly in contemporary Indonesia and involving lots of participants who at least initially are willing and enthusiastic, the reenactments lay bare the participants' lack of shame or repentance about these war crimes of the past. Only when the film is well on its way and when the reenactments become ever more grotesque do feelings of unease and discomfort concerning that past slowly emerge for the film's participants. Conforming to what Schneider (2011, p. 54) sees as an essential feature of reenactments, this past is not finished or sealed off, and it continues into the present moment.

This chapter explores how 'things that matter'-Daniel Miller's (2005) apposite phrase-are conducive to creating an affective response of alienation and discomfort in participants and audiences such as they are involved in performing and watching the reenactments of 
The Act of Killing. These reenactments are central to the film, in the sense that they structure and characterize it. The grotesque aspects of these reenactments as staged performances and the scale of affective responses they generate in audiences and participants are deeply dissociative. As we shall see, critical approaches to laughter in the face of trauma, tragedy, and horror help account for this affective response: in artistic engagements with the traumatic past, comedy creates scope for an almost liberating cognitive dissonance connected with the affect of alienation (Kristeva, 1982; Des Pres, 1988; DeKoven Ezrahi, 2001). Affect in The Act of Killing also has to do with the particular nature of national trauma in Indonesia: in the last months of 1965 and the early months of 1966, a coup d'état was followed by a violent anticommunist purge, whose victim count ranges between half a million and one million dead. The uncertainty of these numbers alone points to the precarious position the purge takes up in collective memory. Some of the challenges of representing a massacre on a scale never officially acknowledged in Indonesian history can be understood, as I shall argue, in terms of the 'barbaric' nature of such an enterprise (Hejinian, 2000). In fact, the single term of barbarism with its cultural and critical connotations perhaps best encapsulates the mix of performing memories of massacre, affective alienation, and the grotesque.

These considerations are in turn informed by the film's powerful engagement with objects that matter. Daniel Miller illuminatingly describes how everyday objects have meaning ascribed to them by users and audiences who actively engage with these objects in material culture. They matter, he argues, in a personal way and 'at the scene of action' (2005, p. 13). The Act of Killing can be taken to illustrate this idea with excessive performances where props and buildings come to figure significantly as the scene unfolds. The houses, offices, town squares, or patios that form the casual backdrop to the scene and the objects used for 'dressing up' performance appear to be mundane and generic but become uncannily meaningful because of the way they come to matter to the people who interact with them. In The Act of Killing, collective space intrudes on memory: former locations of torture and killing simply continue to be there, in the present, as ordinary buildings and offices, but through the reenacted memories in the film, they become suffused with their somber history. The film visualizes how place has a way of invading the body in the act of retrieving and reliving memory (Trigg, 2012). Such bodily affect is momentary and transient, as the transformative power of things that matter is, within the diegetic frame of the film narrative, forever latched onto action in process. Therefore, memory retrieval does not provide closure and does not appear to have any lasting effect-it is restricted to the scene of action, to performance as it happens, as it is witnessed. In this, it illustrates how performance is embodied practice, privileging 'presence over absence and praxis over product' (Plate and Smelik, 2013, p. 9). 
To fully explore the meanings of reenactment and how reenactment can be understood as material practice, I will first present an analysis of the film and its past and present historical contexts. In this respect, I will also address the sense of place and how meaning is ascribed to it. Next, I will discuss how reenactments affect the body and how the body does not lie. Subsequently, drawing on theories of documentary film, I will discuss the way the film interrogates the stock feature of historical reenactment, in order to pave the way for some final observations on how material objects become mementos of the past while also withholding closure or redemption.

\section{Past and Present Context in The Act of Killing}

The Act of Killing exposes the rotten pillars that uphold a large, modern society. As a relatively new constitutional democracy that could be regarded as still developing, Indonesia faces a number of unresolved 'horizontal' conflicts along the lines of ethnicity, class, regional and religious differences, and gender relations (Manan, 2010, pp. 127, 131). Although selected groups are prospering, economic welfare on the whole is precarious (Rosser, 2013). Both the political and the economic state of contemporary Indonesia follow from its complicated colonial and postcolonial history where successive governments have tended to obscure historical events and manipulate collective memories of the past. The Act of Killing penetrates the cracks in the patina that covers past histories by exhibiting how Indonesia is still suffused with unacknowledged memories as well as the material traces of bloody political and racial killings committed decades before.

The documentary's political and historical fields of reference are not immediately made clear in the film's opening scene, where-as yetobscure prolepsis and enigmatic metonymy reign. The start of the film, in other words, lacks the objectifying frame of the expository documentary mode conventionally used for the didactic depiction of historical events. Instead, it shows a scene that cannot be categorized right away, devoid as it is of any comfortable cultural or historical anchor-holds. The film begins with the rushes of what appears to be a colorful musical act faintly reminiscent of Bollywood song and dance. The first image is surreal: shot from a long angle, tiny female figures climb out of a huge construction in the shape of a carp. Next, robed in black, an elderly man takes up a central position, raising his hands in priestly blessing. He is surrounded by a corpulent lady in a light blue evening dress who might represent some sort of goddess, as well as gracious female dancers clad in shiny costumes. A director keeps shouting admonishments toward the dancers-the English subtitles read: 'Smile, show your teeth!' 'This isn't fake!' 'Peace, peace, peace!' But it is fake: as the scene unfolds and the camera zooms in, it becomes clear that the dancers are shivering from 
the damp of a huge cataract in the background, while the lady in blue is more of a drag queen than a pristine goddess.

This strange and alienating first impression, whose significance becomes clear only toward the end of the documentary, then gives way to the next scene. Here, the film appears to touch solid ground, providing stable, lingering focus on a city's nighttime landscape that with a few material props (billboards, motorized rickshaw) can be identified as Asian. A few people are having dinner at a globally known American cafeteria. We are on familiar territory once the caption appears, informing viewers of the historical background, the kind of informative message associated with the conventions of expository and observational documentary (Bonner, 2013). The audience learns about a coup d'état in Indonesia, decades ago, and about the anticommunist purge that followed it. This event provides the frame of the film.

The caption's information is brief but to the point and historically accurate: The entire episode lasted about six months and took place during the last months of 1965 and the first of 1966 . The coup by army general Suharto and its bloody aftermath are generally seen to have laid the foundations of present-day Indonesia (Anderson and McVey, 1971). The post-coup purge of 1965-1966 was directed at (alleged) members and supporters of the Indonesian Communist Party, the PKI. At a rough estimate, between 500,000 and one million people were killed by militia and paramilitary groups (Vickers, 2005, p. xiii). President Sukarno was expelled: He had played a major role in the years following independence in 1949, but his communist leanings were feared by players both inside and outside Indonesia. That is, the CIA was involved in the preparations and aftermath of the military coup, which is now established fact (Vickers, 2005, pp. 140, 149, 153). The CIA's involvement is not explicitly mentioned in the documentary caption, though the image of an American food chain that serves as the caption's backdrop meaningfully highlights America's continued influence in the region.

The coup meant that General Suharto installed a regime to last for over thirty years (Vickers, 2005). The gradual transition toward a relatively successful constitutional democracy since then has been praised in some quarters (Horowitz, 2013) but criticized in others, if only because the loosely organized paramilitary forces involved in carrying out the postcoup purge came to be firmly entrenched in society. They are lauded and applauded as 'free men' or (in Indonesian) 'preman', though 'in fact it is the preman themselves who use violence, extortion, and intimidation against ordinary Indonesians on a regular basis' (Tyson, 2014, p. 159). Numerous scenes of The Act of Killing show how, to this day, these organized 'free men' are a visible force with overt political ties in the government. They organize mass rallies, and its members march around in fear-inspiring uniforms decked out in camouflage print-except that the camouflage is dyed an angry red, signaling there is no reason to hide. 
Its funding channels are unclear, but The Act of Killing suggests that extortion is part of the game. This organization is known as the Pemuda Pancasila (PP) or Pancasila Youth. Its leaders are, overall, quite senior, as is one of Pemuda Pancasila's honorary members, Anwar Congo.

Anwar Congo appears in the next scene and is the documentary's central figure, its principal actor or main character-admittedly a confusing set of designations, but he does take up these different roles: main participant, scriptwriter, cameraman, and a director assigning roles and using a megaphone. He can be recognized as the priestly figure of the opening rushes. He is a thin, wiry, mostly white-haired man with elegant movements, who in the course of the film turns out to have firm ties with some high-ranking political and governmental persons and, as mentioned above, with the Pemuda Pancasila movement. As a young man, he was personally involved in the abduction and killing of, as he brags, at least a thousand people. Seizing the opportunity of his encounter with the young, foreign director, Joshua Oppenheimer, he sees it as his task to inform the world about his part in the post-coup purgeinitially without any regret at all, boastful even.

Anwar Congo appears to be on friendly terms with Oppenheimer, calling him 'Josh' and often addressing him directly. He guides Oppenheimer to the dismal historical locations of his former field of operation. But soon he clings to the idea that a proper film should have more than just historical scenery and recounted memories. The documentary form as such has no appeal to him, and he becomes convinced that some kind of script should emerge, with him, Anwar Congo, as the leading star. What he has in mind does not become fully clear, and it changes over time-the shooting period took, on and off, about seven years, and Oppenheimer had been around working on this project even longer-but it looks like Anwar Congo intended a crossover of Hollywood noir and Bollywood gangster movie. Another cultural reference for Anwar must have been the gruesome but popular, frequently screened Indonesian propaganda film from the Suharto era called Pengkhianatan G30S/PKI, a film that completely justified the purge and 'reinforced the idea that the nation was saved from communist terror' (Cooper, 2013). Clips of this film figure in the director's cut of The Act of Killing, available on DVD (The Act of Killing, Director's Cut, 2013). Anwar therefore sees a heroic role for himself and is taken by the idea that he will become world famous with the help of Oppenheimer. As it turns out, however, this project is not fully carried out in the way Anwar expected. Rather, The Act of Killing shows the garishly amateurish, failed attempts at making a proper movie. In that respect, it is reminiscent of some of Werner Herzog's films such as Fitzcarraldo (1982) that expose grotesque failure in a similar way. Incidentally, Herzog later became involved as co-producer, which undoubtedly helped promote the film. Reports of what Anwar Congo thought of the eventual film are conflicting, but there are some indications that he 
distanced himself from the project altogether when the film came out (Tyson, 2014, p. 157).

\section{Places that Matter}

It becomes evident that Anwar is basically interested in creating reenactments of the past. The settings are in part historical-a dilapidated cinema, a forgotten rooftop patio. Insignificant as such, they become the charged, ugly, nonephemeral material lieux de mémoire scattered in the present-day cityscape of North Sumatra (Anwar's former and presentday field of operation). An example of how place matters as the former scene of action (Miller, 2005) is the cinema. All performances in The Act of Killing are heavily theatrical and imbued in film lore, and especially for the killings reenacted in the film's earlier scenes, as they take place in a building in front of the city's main cinema (the building still stands). This used to be Anwar's habitat. He would either be involved in black market peddling of cinema tickets or in other criminal activities, but in any case he certainly enjoyed watching a movie-Hollywood movies, as he makes clear. The paramilitary headquarters used for interrogation faced the cinema across the square. Anwar relishes demonstrating the swagger in their American gangster walk as he and his fellow thugs crossed the square from the cinema to this building, where they would torture and kill countless victims. ${ }^{2}$

Such sites then are unofficial, unacknowledged memorials. They are public material places, but their significance is overwhelmingly immaterial. Dylan Trigg in The Memory of Place: A Phenomenology of the Uncanny (2012) explores the tension between the indifference of place, the silent witness to our actions, and the meaning we ascribe to it: we inform places with our bodies and our memories. One needs to know what happened in these places to 'see' that they are haunted, but this 'seeing' is attributive. Seeing knowingly, so to speak, informs memorynot just of perpetrators who bring us to these places but of victims and their children too. The locations are intensely local; day after day, people walk past those seemingly indifferent buildings. Everybody knows. It may seem that it is Anwar's reenactments that transform insignificant matter to places of complicity, but this is an immaterial supposition, a transference of complicity by bystanders, beholders, and of course the protagonists of the reenactments. The sites are charged with scenes of violence all along; these places cannot be dissociated from collective memory that now is resurrected through the reenactments. Once places are known to be the scenery of reenacted abduction, interrogation, torture, killing, looting, and sexual violence, once an entire kampong (compound) is torched in celebratory reenactment of the real incidents in 1965-1966, as occurs in the film, collective memory acquires a foothold in the landscape. 
The reenactments are first carried out lightheartedly, but soon the giggly mood gives way to a darker, though also ever more grotesque one, with scenes involving an expanding group of amateur actors playing the roles of victims and perpetrators of days bygone. These scenes are interlaced with documentary screenings of present-day Pancasila meetings and election campaigns. In the meantime, Anwar shares his thoughts about the past with us. He watches the rushes of a scene on his television at home while talking to the director about the reenactment at hand and his own role in it. Sometimes there is just silence, while the camera steadily films his facial expressions.

Thus, there are at least three intersecting narrative levels in the documentary: the reenactments of past atrocities that are played by Anwar and his cronies and by a large number of other participants, all drawn exclusively from Pancasila Youth's members and their relatives (Oppenheimer and Herzog, 2013); scenes of Pancasila political rallies; and finally Anwar's own reflections when watching himself playing the role of perpetrator and victim. This disjointed form ensures a constant awareness of how the layers of a buried past erupt into the present moment both at the personal and national levels. Anwar Congo in this respect is also the central character of the film, a vessel for the process of beginning to recognize and acknowledge trauma. His bragging fades. He suffers from nightmares. He acknowledges, with his co-perpetrators, that their share in the atrocities might well bring them to the International Court of Justice in The Hague. And though the film defies summary, one could say that its basic narrative is that Anwar Congo is proud of his acts at first, but that acting the victim role opens the sluices for remorse until he breaks.

\section{The Matter of the Body}

Anwar's falling apart is a physical, material process he can no longer control with his mind or cover with his charm and wit. Telltale signs evince his disintegration-the body does not lie. Gradually, his facial expression begins to give away some doubt and hesitancy. He decides toward the end of the film to play the victim of his own preferred method of killing, which was strangling someone with a long wire that at one end is firmly attached. Swaggering-and just a little fearful-he sits down, is tied up, and subjects himself to the make-believe act of killing, to be carried out by his trusted helpmate Herman. When the noose is around his neck and Herman pretends to pull really hard, however, it becomes clear that this material confrontation with the past through his body and the props of improvised torture at last tears down the stronghold of his mind. His hands start shaking uncontrollably, and when he cannot bear it any longer he indicates wordlessly that it should stop. He barely recovers, and his body remains slumped and exhausted from the strain, while 
Herman, bearing a puzzled expression betraying that this particular moment was not foreseen in the script, tenderly cares for him. Still, the moment is no lasting turning point, and Anwar appears to recover his usual unrepentant, witty, boastful self, inviting his grandchildren to watch the fun of granddaddy being strangled when playing back the rushes, while a voice behind the camera, presumably Oppenheimer, protests wildly, 'no, no, Anwar, this is way too violent for them to see'! But then, as he watches this awful scene, his body betrays him again: his jaw drops, his eyes become cloudy, he shoves his grandchildren away. Tears well up. He cries and tells Oppenheimer that now he knows what his victims must have felt. Oppenheimer interferes again, protesting that he does not, that he cannot know, as for the victims of the past the predicaments were all too real, whereas Anwar in every instance of the reenactment knew it was all make-believe.

These physical, material manifestations of great inner conflict result from gaining insight, through reenactment, into his past. They are triggered by, and directly linked to, the materiality of that past as it plays out in the present. In that final torture scene, it is not just the wire, though that wire figures significantly as the key material symbol of the act of killing in the eponymous movie; it is also the blade held in threat against his throat, the banging on the wooden table that (at Anwar's own instigation) should inspire fear, the hemp rope tying up his wrists in a fake knot, the old-fashioned typewriter used for typing up his socalled confession. The props used in the reenactment therefore provoke, in their simple, uncluttered materiality, the physical eruption of that past into the present moment. They mediate the past, not into the present, but into the person, such as he is, in the moment of the present; illustrating Miller's observation that material objects challenge 'our common-sense opposition between the person and the thing, the animate and the inanimate, the subject and the object' $(2009$, p. 5).

That physical eruption is even more literally embodied by Anwar's uncontrollable retching in the film's long final scene. Again, this is triggered by material mementos. Years of shooting the film have passed, and the crew can pay another visit to the rooftop patio where Anwar, decades ago, used to beat up and strangle the military regime's alleged opponents. ${ }^{3}$ Early on in the film, Anwar had shown the crew around. He was as indifferent to the executioner's site as the building itself. Then he was a jaunty figure who proudly introduced the most chilling material prop of The Act of Killing, the long piece of strangling wire tied up at one end to a supporting pillar and at the other to a piece of wood for better grip. He more or less claimed the patent for this simple invention. He also asked one of his helpmates to pose as the victim because he wanted to show in detail the technical dexterity of his self-invented murder weapon; he closed off with a display of his supple cha-cha-cha dancing steps, dispelling horror with fun. Now, in the film's final scene, 
he is a bent, solitary figure who, on reentering this location, which, as I argued above with reference to Trigg (2012), has become charged with attributed meaning, and seeing the discarded wire, starts making horrible retching noises while his body bends over. He tries to vomit but to little avail, as if relief is withheld. Whereas in the first take he was shown skipping up the stairway to a spot that then did not matter to him, we now see him in weary descent, his head bowed, his eyes avoiding the camera. The site has invaded his body.

Whether or not his violent, uncontrollable physical reaction, his nausea, can or should be seen as a sign of retribution is beside the point. It is certainly not a sign of closure. This scene, the asymmetrical mirror image of an earlier scene, is preceded by another mirroring scene: the musical act from the beginning, now a final cut. Again we see the close-up of Anwar who lifts his arms in blessing and gratitude. His beatific smile belies any notion of nausea or repulsion. Two amateur actors are dressed as prisoners. They wear the symbolic necklace of strangling wire, lift it, decorate the priest/Anwar with a medal, and thank him for strangling them and sending them to heaven. The campiness and unpalatable grotesquery of all this is reinforced by the rushes serving as background to the credits that come immediately after Anwar's sad nausea at the rooftop: again, we see dancing figures in pinkish costumes (one couple actually seems to be dancing the cha-cha-cha). Here, then, performance is less the live act of generating or creating memory (Plate and Smelik, 2013, pp. 3-9); rather, the burlesque elements appear to defuse memory and distract from historical reality: performance as the embodied act of denying accountability and escaping that past.

\section{Defying Reification: Documentary Modes}

This instance of the comedy of camp taking precedence over Anwar's full disintegration, this denial of the past that offsets and precludes avowal, is not restricted to a single case: on more than one occasion a scene that seems to allow for inspection of the main character's naked soul is juxtaposed to another, over-the-top, burlesque scene. The bewildering, self-justifying musical acts, which in mood and atmosphere are far removed from the gruesome reenactments of killing, foreground the idea of performance. The montage of the film therefore deliberately denies the comfort of closure and instead instigates an affective response of discomfort and alienation by exploring the role of material props as mementos of a past that state-directed historiography attempted to bury forever. In this regard, the unique position in the genre of warand-conflict documentaries that The Act of Killing takes up can be fully appreciated.

Documentaries are a representational genre sui generis; they show, narrate, and explain. Often, a form of exposition is used to confidently 
tell the viewer what happened. This is especially true for documentaries about present and pasts conflicts. A voice-over narrator or a caption (Nichols, 2001, p. 107) summarizes crucial events and supplies some dates, while interviews with survivors and experts alternate with historical footage, sometimes supplemented with historical reenactment played by modern actors (Bonner, 2013, pp. 66-67). They make use of iconic, therefore public, historical props whose materiality has clear symbolic power and are sometimes exhibited in national museums dedicated to the memory of war. Think of the martial artifacts ranging from military orders to missiles at the Imperial War Museum in London or the iconic molten sewing machine bearing testimony to the May 1940 bombing of Rotterdam on display at the Museum of War and Resistance in Rotterdam.

The Act of Killing uses elements of similar objectifying frames but only somewhat haphazardly. As noted, a caption is used at the beginning, but it is very concise. The neutral voice-over is absent, but the director's voice is occasionally heard to participate in dialogue with the film's most important participants. There is no faded historical footage, while the reenactments allow for more insight into unspoken and half-realized affect than into factual information concerning deployment or political maneuvers. The unique present-day footage of Pancasila Youth rallies gives the impression of the neutral 'fly-on-the-wall' camera techniques, but, in the context of the film, such footage highlights the performative aspects of this paramilitary organization. The same characters that are involved in representing the past in amateur reenactments can also be seen wearing the Pancasila uniforms-the blood-red camouflage print a parody of army attire.

As for the representational outlook that characterizes conventional documentary, the objectifying frames associated with it are undercut by the plethora of performances. The documentary then is referential only in structure: historical reality provides the scaffolding of the film, but representing the unrepresentable forms its core. Aesthetically, it stands in line with late-twentieth-century efforts to represent the Holocaust by the conscious effort of eluding the trap of reification that Adorno saw as the major impediment to 'poetry after Auschwitz' (Rothberg, 2000). As Patrick Pritchett argues, Adorno's pronouncement is most helpfully understood as the challenge to write self-consciously and self-critically, that is, 'rejecting positive aesthetic values of unity and closure, turning instead to negational values of disruption and apophasis' (Pritchett, 2014, p. 130). Both disruption and apophasis are relevant to The Act of Killing: disruption because of the continuous in-your-face gestures saturated in campy grotesquery; apophasis (that is, writing in the face of the perplexity to express or represent disaster and horror) because of the invocation of 'a thing's presence through a trope of absence' (p. 129). Ephemeral objects and places that appear to signify nothing are suffused 
with meaning: they come to life and become present through reenactment. Material memory is enfolded in places and objects; it comes forth, as it were, in performances that are the transit zone between past and present, but those performances are too disruptive to lead to the finality of reification. Thus, the film cuts through all of the more or less objectifying modes according to which documentaries are usually classified. Instead, it could be said to prioritize the 'performative' documentary mode, typified by Stella Bruzzi as a documentary form 'that uses performance within a non-fiction context to draw attention to the impossibilities of authentic documentary representation' (2006, p. 187).

But this is not all, of course. The film is no meta-documentary exploration of the limits of representation; it evokes what Frances Bonner (2013, p. 69) calls a 'reality of affect' associated with the designation of the poetic documentary mode. Rather than the tell-tale material objects that in the first instance can be taken to produce verisimilitude, or the 'reality effect' of realist fiction, the cinematic reality of affect mediates experience rather than knowledge. This is what the heady, confused, and confusing experiences of creating memory through embodied performance amount to. Reenactments that involve former perpetrators taking up different roles, including those of former victims, confuse the safe subject-object divisions that kept collective memory under the lid; performances that fuse camp with terror create affect connected to the evocation of the remembered past in the present moment.

This foray into attempts to characterize The Act of Killing by way of the modes it does and does not employ leads once more to the things and places that matter in this film. Materiality reinforces the interplay of the historical, objectifying modes on the one hand and the poetic, performative modes on the other. Things that (come to) matter sustain the evocation of affect. Props, costumes, and settings help create a subliminal understanding of a complex pattern of feelings that connect, as well as affect, victims and perpetrators; what is more, these matters also conduct the affect of audiences watching the film (Horeck, 2014). The material props are no historical, symbolical artifacts such as the deformed Singer Sewing machine in Rotterdam. They are simple, remade or found objects, often just generic, that acquire meaning only when in use. They define the act as well as the actor who uses them in the reenactments. In other words, they form a continuous dialectic of object and subject, where meaning and value are attributed, not fixed (Miller, 2009). The strangling wire contraption is made from easily available household items. Scraps of furniture signify an interrogation scene: simple wooden tables and chairs moved into darkened rooms-used, chipped, old, and therefore suggestive. Precisely because they are quite clearly not 'the real thing' do these artifacts foreclose reification. They create a passage to the landscape of the imagination, a form of humanistic understanding or Verstehen such as Dilthey understood it, causing the viewer to have 
an affective grasp of the historical events different from objective knowledge (Tuttle, 1969). They withhold objectification and suffuse not just the subject in an abstract sense, but also the body. This is perhaps best illustrated in another distressing scene toward the end of the film, when Anwar, now acting as victim, is lying face up and half-buried in the jungle while his real-life companion, who in this scene plays a revenant ghoul from Anwar's nightmares, is chewing on a piece of raw meat that, as the deadpan dialogue makes clear, stands for Anwar's cut-out liver. Here too, Anwar is barely able to contain an urge to vomit.

Unlike the mundane props, the costumes in the later reenactments are extravagant, lurid, and clearly tailor-made. Anwar's overt interest in the materiality of clothes in general shows how he invests them with meaning: not only is a new set of clothes ordered for each reenactment, but the cowboy's and gangster's outfits he orders are the metonymic expressions of Hollywood cowboy and gangster stereotypes that inspired his real-life abductions, interrogations, and killings, illustrating that often it is not just the clothes, but also the very act of dressing up that produces one's sense of being (Miller, 2009). Meanwhile, the camera lingers on Anwar choosing and donning clothes as if to illustrate this point. As the film develops, however, these outfits border on parody: Anwar's cowboy hat is pink, the fringe on his light trousers acquires a golden hue, and drag costumes designed for Herman, his helpmate, are pure fantasy. Herman wears the dresses and accompanying hats or tiaras with a certain aplomb. It is important to point out here that cross-dressing is a historical stock ingredient of theatrical culture in West Sumatra as well as other regions in Indonesia (Cohen, 2003; Spiller, 2012). In other words, cross-dressing forms part of a material culture of theatrical entertainments; thus, Herman's costumes, as well as the female roles he comes to play, heavily underscore the reenactments' performative aspect. They appear to contrast sharply with Herman's real-life thuggish masculinity as Anwar's closest bodyguard. But in fact there is no contrast at all, just dissociative affect: cross-dressing also throws his attempt at acquiring political legitimacy into relief, to the effect that when at one point we see him practicing the rhetorical gestures of an Obama speech in front of a television set in preparation for his own campaign to run for parliament (he loses), political life is framed as just another performance. The ease with which he slips from one role into another, wearing a different set of clothes for each role, underscores the performative nature of politics and the paramilitary organization Herman adheres to. The range of costumes may then show how someone's sense of being is instilled by clothes, as Miller (2009) argues, but also exposes the counterpart of such 'sense': a lack of groundedness.

Thus, the documentary's mixture of objectifying, expository modes (in registering present-day political and social practice) and poetic and performative modes (mediating memory affect) are linked by the matter 
of props, clothes, and buildings. That mixture works to both register the performative nature of everyday social-political life in contemporary Indonesia and evoke the past by means of performances where the matter of objects, buildings, and clothes take center stage as the conduit of memory.

\section{Conclusion}

We are left with the question of how the comedy of cross-dressing is reconciled with the act of remembering war crimes. What about those moments of comic relief when fancy dress turns reenactment into burlesque? Comedy brings forth an essential cognitive dissonance in the attempt to come to terms with a past that had been sealed off for more than forty years. While public managing of collective memory in Indonesia procured closure and acceptance, the comic mode that infiltrates perpetrators' recollections of historical tragedy results from the eruption of that buried past into the frame of the present. Dissociation is the essential feature of comedy in the face of tragedy. As DeKoven Ezrahi argues in her discussion of another film that explores the transgressive strategies of comedy, La Vita è Bella, the comic 'undermines the authority of a certain kind of positivist realism' through its 'simultaneous enactment of more than one scenario' (2001, p. 298). On the face of it, the burlesque scenes bypass all aesthetic and ethical laws; but even so those scenes are affecting all the more because of that-because of the funny, horrible, and ultimately uncanny mixture. This is the realm of abjection, where laughter and repulsion meet, the 'double stance between disgust and laughter, apocalypse and carnival', as Kristeva put it (1982, p. 138). In other words, it is the contaminated mixture of comedy and horror that produces affect of cathartic power, with the contrary logic Kristeva identifies as 'an impure process that protects from the abject only by dint of being immersed in it' (p. 29). The Act of Killing, with its well-chosen theatrical and dramatic title, produces catharsis, then, by the deliberate contamination of genres and feelings. But it is also the realm of the barbaric, not in the way Adorno intended it when he pronounced that 'to write poetry after Auschwitz is barbaric' (Adorno, 2003, p. 162), but in the way barbarism can be appropriated as a way to address a culture's horrors. In this respect, Lyn Hejinian proposes a useful reading of the 'barbaric' that invokes the term's primary etymology of strange, foreign, and alien and that envisages posttraumatic art forms that assume a 'barbarian position, taking a creative, analytic and often oppositional stance, occupying (and being occupied) by foreignness-by the barbarism of strangeness' (2000, p. 326).

So the generic but evocative material props that form the skeleton of The Act of Killing provide leverage in pushing off the sealed lid of a past thought to be closed off forever. They help create an affective mode of 
repulsion triggered by laughter. It is in fact appropriate that The Act of Killing has this rampant, burlesque undertone, if one compares it to the very different, silent mood of The Look of Silence (Oppenheimer, 2014). This sequel and counterpart in Oppenheimer's diptych is a film about the same historical events, but it is more exclusively centered on the traumas of victims and their children. When compared, the striking difference in mood between the two films illustrates how the tragic 'quietens us with awe' while 'laughter revolts' (Des Pres, 1988, p. 220).

The Act of Killing documents how memories of acts of killing that took place some forty to forty-five years ago keep returning, despite the mechanisms of repression and suppression, via the cluttered matter of everyday objects, anonymous buildings that bore witness to war crimes, and lurid costumes needed in outrageous reenactments. Simple, everyday household items testify to the materiality of memory, to memory being 'a function of material duration' (Olsen, 2010, p. 120): they bear the traces of a past that continues to claim a place in the contemporary. Lieux de mémoire that by happenstance continue to exist as ordinary landmarks in the cityscape assert their material affect by conducting access to the immaterial past of unofficial historical recollection and trauma. And, as becomes evident in the chilling burlesque of the reenactments that undercut any sense of reification, facing the past involves something more than coming to terms with it. It does not concern the representation of the historical real, but the hard, distressing, yet cathartic process of allowing memory to materialize.

\section{Notes}

1 The running thread of blog reports on audience responses to the film seems to be that audiences are both stunned and silenced by horror, but giggling quite a lot too. Talking to people who have watched the film in the cinema or at home confirms this mixed affective response, which appears to typify the unique experience of watching this film. See, for example, Roberts (2013).

$2 \mathrm{He}$ certainly is not the only criminal to draw inspiration from midtwentieth-century Hollywood films in interrogating his victims (Friedrich, 1979 , p. 83), but this acquires another edge when considering how before the 1965 coup, there had been several attempts to ban Hollywood films and Western culture in general (Vickers, 2005, p. 134). This explains why in the final interrogation scene the alleged subject (Anwar) is heckled for wanting to ban Hollywood movies.

3 In the commentary to the Director's Cut, Oppenheimer explains how they were no longer allowed to visit that patio, which was situated above a shop, when the shop owner found out the reasons for their visit. But then on the very last day of shooting, they heard that the shop had changed hands, and they immediately grabbed the opportunity to pay this final visit. The discarded props of the earlier visit were still there (Oppenheimer and Herzog, 2013). 


\section{References}

Adorno, T. (2003) Can One Live after Auschwitz? A Philosophical Reader, Rolf Tiedeman (ed.) (Trans. Rodney Livingstone) (Stanford, CA: Stanford University Press).

Anderson, B. R., and R. T. McVey (1971) A Preliminary Analysis of the 1 October 1965, Coup in Indonesia (Ithaca, NY: Cornell Modern Indonesia Project).

Barthes, R. (1986) 'The Reality Effect' in The Rustle of Language (Oxford: Blackwell). 141-148.

Bonner, F. (2013) 'Recording Reality: Documentary Film and Television' in S. Hall, J. Evans, and N. Nixon (eds) Representation (London: Sage). 60-99.

Bruzzi, S. (2006) New Documentary (London and New York: Routledge).

Cohen, M. I. (2003) 'Look at the Clouds: Migration and West Sumatran "Popular" Theatre', New Theatre Quartely 19.3: 214-229.

Cooper, C. (2013) 'The Act of Seeing The Act of Killing', Guernica: A Magazine of Art and Politics https://www.guernicamag.com/daily/caroline-cooper-theact-of-seeing-the-act-of-killing/ (Accessed on 4 May 2014).

Des Pres, T. (1988) 'Holocaust Laughter?' in B. Lang (ed) Writing and the Holocaust (New York: Holms and Meier). 216-233.

DeKoven Ezrahi, S. (2001) 'After such Knowledge, What Laughter?', The Yale Journal of Criticism 14.1: 287-313.

Friedrich, O. (1979) City of Nets: a Portrait of Hollywood in the 1940s (New York: Harper and Row).

Hejinian, L. (2000) The Language of Inquiry. (Berkeley: University of California Press).

Horeck, T. (2014) “"A Film that Will Rock Your Core”: Emotion and Affect in Dear Zachery and the Real Crime Documentary', Crime, Media, Culture 10: 151-167.

Horowitz, D. (2013) Constitutional Change and Democracy in Indonesia (Cambridge: Cambridge University Press).

Kristeva, J. (1982) Powers of Horror: An Essay of Abjection (New York: Columbia University Press).

Manan, M. (2010) 'Constitutional Democracy for Divided Societies: The Indonesian Case', Journal of Politics and Law 3.1: 125-132.

Miller, D. (2005) 'Why Some Things Matter' in D. Miller (ed) Material Cultures: Why Some Things Matter (Durham, NC: Duke University Press). 3-25.

Miller, D. (2009) Stuff (Cambridge: Polity Press).

Nichols, B. (2001) Introduction to Documentary (Bloomington: Indiana University Press).

Olsen, B. (2010) In Defense of Things: Archeology and the Ontology of Objects (Lanham, MD: Rowman and Littlefield).

Oppenheimer, J. (2013) The Act of Killing (Denmark: Final Cut for Real).

Oppenheimer, J. (2013) The Act of Killing: Director's Cut (IDFA, Cinema Delicatessen).

Oppenheimer, J. (2014) The Look of Silence (Denmark: Final Cut for Real).

Oppenheimer, J., and W. Herzog (2013) Audio Commentary to Director's Cut with Werner Herzog in Oppenheimer, J. The Act of Killing (Denmark: Final Cut for Real). 
Plate, L., and A. Smelik (eds) (2013) Performing Memory in Art and Popular Culture (London and New York: Routledge).

Pritchett, P. (2014) 'How to Write Poetry after Auschwitz: The Burnt Book of Michael Palmer', Journal of Modern Literature: 127-144.

Roberts, S. (2013) 'The Act of Killing: A Study in Uncomfortable Laughter', CreativeCOW.net https://forums.creativecow.net/readpost/267/5500 (Accessed on 2 May 2014).

Rosser, A. (2013) The Politics of Economic Liberalization in Indonesia: State, Market, and Power (London and New York: Routledge).

Rothberg, M. (2000) Traumatic Realism: The Demands of Holocaust Representation (Minneapolis: University of Minnesota Press).

Schneider, R. (2011) Performing Remains: Art and War in Times of Theatrical Re-Enactment (London and New York: Routledge).

Spiller, H. (2012) 'How Not to Act like a Woman: Gender Ideology and Humor in West Java, Indonesia', Asian Theatre Journal 28.1: 31-53.

Trigg, D. (2012) The Memory of Place: A Phenomenology of the Uncanny (Athens: Ohio University Press).

Tuttle, H. N. (1969) William Dilthey's Philosophy of Historical Understanding: A Critical Analysis (Leiden: Brill).

Tyson, A. (2014) 'Multiple Acts of Killing', Critical Asian Studies 46.1: 157-161. Vickers, A. (2005) A History of Modern Indonesia (Cambridge: Cambridge University Press). 


\title{
11 Modeling the Memories of Others \\ David Levinthal's I.E.D.: War \\ in Afghanistan and Iraq
}

\author{
László Munteán
}

Toys are essential to our initiation into the world. It is by playing with toys that we understand how things work, act out situations, learn about rules, and imagine alternative worlds with different rules. Anything can be used as a toy as long as it lends itself to be played with. For toys, as Miguel Sicart remarks, 'are the matter of play' $(2014$, p. 43). As vehicles for the imagination, toys have traditionally taken the form of miniature replicas of real-life objects and people. Their legacy persists even in the era of computer games. Toy stores offer a large variety of miniatures from teddy bears to action figures to Lego and Playmobil sets. The miniature toy 'opens an interior world, lending itself to fantasy and privacy' (Stewart, 1999, p. 56) and empowering the one playing with it. 'The cleverer I am at miniaturizing the world, the better I possess it', as Gaston Bachelard asserts (1994, p. 151). At the same time, miniature toys are also the means for the world to possess us. From dollhouses to action figures, miniature toys operate as tools to indoctrinate children with a set of values and norms (Sutton-Smith, 1986; Kuznets, 1994; Fleming, 1996; Merlock Jackson, 2001; Perry, 2013, p. 76).

Unsurprisingly, a great many artworks have capitalized on contrasting 'proper' modes of play with alternative possibilities that toys afford (Valli and Dessanay, 2011). Zbigniew Libera's Lego Concentration Camp Set (1996) is a case in point. Using Lego bricks, Libera unraveled the endless possibilities that Lego bricks offer, including a theme as incompatible with the world of Lego as the Holocaust (Feinstein, 2000). The American artist and photographer David Levinthal probed similar taboos in his photo series Mein Kampf (1994-1996), which features original Nazi soldier figures from the period of the Third Reich positioned in diorama settings with Japanese erotic dolls staged as their female victims. With such 'repurposing' of the dolls, Levinthal foregrounded the sexual victimization of Jewish women, perpetuating the dolls' original function (Young, 2000, p. 55; Young, 2009; Hirsch, 2012, p. 147). Controversial as they were at the time, Libera's and Levinthal's projects spearheaded the entry of a postwar generation of artists into Holocaust art (Van Alphen, 2005, p. 183). Never having experienced the horrors of the camps, their projects tapped into the memories of others 


\section{2}

that had been passed onto them via the stories and images they grew up with. Marianne Hirsch (2012) calls these inherited imprints of a traumatic past 'postmemories'. In a broader context, to underline the role of (digital) media in producing an experiential archive that is nevertheless not rooted in lived experience, Alison Landsberg (2004) writes about 'prosthetic memories' as shapers of subjectivity.

Levinthal has dedicated his entire career to photographing toys in staged settings, exploring how these seemingly benign objects could take on such incredible power and personality simply by the way they were photographed' (qtd. in Coleman, 2013). In this chapter, I am interested in the power of his work to operate as a mnemonic device. In particular, I focus on his 2008 photo series, I.E.D.: War in Afghanistan and Iraq, for which he uses miniature soldier figures assembled from kits to fabricate images of what was then still a war with American 'boots on the ground'. Levinthal's first digital project, I.E.D. (a military abbreviation for improvised explosive device), has been acclaimed for its tantalizing precision in simulating widely circulated journalistic images of the conflict (Knoblauch, 2010; Coleman, 2013; O'Sullivan, 2013). The book version of this project (2009), however, in which the photographs are arranged in a sequence and accompanied by textual excerpts from a military blog The Sandbox, has received minimal critical attention. I explore I.E.D. as a mixed-media project that operates at the intersection of materiality, photography, and text. Beginning with a discussion of the model kits that serve Levinthal as the raw material for his project, I trace the transformations of this materiality once mediated through photography and, on the pages of the book, infused with the textually conveyed memories of the soldiers. I conclude with a discussion of the mnemonic potential of Levinthal's project five years after the official withdrawal of American troops from Iraq, a country ravaged by violence ever since.

\section{The Reality of Toys}

The fascination with miniatures, according to Bachelard, forges a link between childhood and adulthood. He writes, 'the tiny things we imagine simply take us back to childhood, to familiarity with toys and the reality of toys' (1994, p. 149, emphasis in original). Bachelard's emphasis on the reality, rather than the realism, of toys is significant because it foregrounds the performative role of the imagination as key to the child's engagement with the world of toys. The miniature is a portal to a different world, a realm where 'geometrical contradiction is redeemed, and Representation is dominated by Imagination' (p. 150). Thus, the reality of toys denotes a realm beyond representation where the toy, in its materiality, is transubstantiated by the imagination. The objects Levinthal uses for I.E.D., though far less controversial and subversive than those in 
Mein Kampf, constitute a category that sheds new light on Bachelard's notion of the reality of toys. The soldier figures and the military equipment featured in I.E.D. are plastic kits, produced by a number of manufacturers at a 1:35 scale. Unlike the 1950s playsets in his Wild West (1986-2012) and SITES (1996) series, the model kits used in I.E.D are of a different sort. They are for display rather than play. That is to say, while the toy offers itself to be played with, the model kit is to be meticulously constructed and then showcased on a shelf or in a vitrine to be observed and valued for its realism. Indeed, the appeal of the model kit lies in its realism; once built, the quality of the job is measured against the model's accuracy of detail.

Plastic, which Roland Barthes describes in his Mythologies as an imitation material par excellence (1993, p. 98), lends itself particularly well to such purposes. The malleability of thermoplastics has made it the material of choice for a great many toy manufacturers since the beginning of its mass production over a hundred years ago, and model kits are no exception. It allows for the mass production of miniature particles with high precision while leaving enough room for model builders to apply their sanding, gluing, and painting techniques to make plastic 'pass for' the materials that the model imitates. Paint on the fuselage of an aircraft should consequently look different from the paint applied to the uniform of a miniature serviceman. Indicating signs of wear and dirt on vehicles, for instance, are commonly used methods to make models appear more realistic (Mrosko, 2014; Paine, 2000). Levinthal admits in the acknowledgments that he had a model builder, Jeffrey Gutzman, prepare the figures and the military equipment for him to photograph (2009, p. 95). Gutzman's involvement in I.E.D. is far from tangential. Quite the contrary, his work, as we shall see below, exemplifies model building as a cultural practice imbued with mnemonic overtones.

If the realism of the model, be it of a military vehicle, a landscape feature, or a soldier, is measured against the builder's skill to camouflage the model's materiality, dioramas represent another level of visual artifice. They are miniature sets, complete with details of urban or natural environments, built to create the illusion of an event by way of positioning the individual models in relation to each other. Avid modelers go to great length to find the most resourceful solutions to give realism to these staged events 'congealed' in plastic. Dramatizing the heat of combat, military equipment under reparation and armor riddled with bullet holes are things highly popular among war diorama builders, as evidenced by Chris Mrosko's instructional book Building Dioramas (2014). Such scenes allow modelers to flex their skills in making plastic look like other materials as they expose the insides of engines, damaged aircraft, and ruined buildings. With ever-developing technologies of 3D printing, model manufacturers produce a wide array of accessories that modelers apply to enhance their dioramas. The UK-based 
manufacturer and distributor company Fields of Glory Models, for instance, offers entire assortments of 1:35 scale ruins labeled 'Middle Eastern flats', 'European damaged wall', and 'Arabian block of flats' as diorama accessories. 1

These labels point to a paradox that underlies attempts at achieving realism. For as much as the elaborate details of these dioramas fetishize the particular, the events they simulate are typical. Taking their inspiration equally from documentary footage and representations of war in popular culture, these diorama accessories are informed by collective imaginaries, which they materially reiterate. Roland Barthes's (1986) notion of the 'reality effect' unravels the experiential basis of realism. Taking his cue from the lengthy descriptions of objects, places, and characters in nineteenth-century French realist novels, Barthes identifies the function of these descriptions as an aesthetic expedience on the one hand and an authenticating device operating as a 'referential illusion' on the other: 'Flaubert's barometer, Michelet's little door finally say nothing but this: we are the real; it is the category of "the real" (and not its contingent contents) which is then signified'. Barthes calls this illusion 'the reality effect' (p. 148, emphases in original). Dioramas work by a similar rationale. As Mrosko recommends, 'You can add a lot of life to even a small scene. Whether it's a bit of stonework and a bridge, a little lizard hiding behind a rock, or a dog in the yard, incorporate it! These small details add up' (2014, p. 14).

In a diorama setting, this fetishization of material detail is mitigated by the illusion of movement induced by the placement of models in relation to each other. The reality effect no longer rests on a particular miniature object but on an event that needs to be imagined on the basis of what is materially given. That is to say, as a viewer I am compelled to imagine what happened before and after the instance 'captured' in miniature. The diorama, in this sense, cajoles me into an alternative spatiotemporal realm. As Susan Stewart contends, 'In its tableaulike form, the miniature is a world of arrested time; its stillness emphasizes the activity that is outside its borders. And this effect is reciprocal, for once we attend to the miniature world, the outside world stops and is lost to us' $(1999$, p. 67). To be enfolded by this miniature world is to be offered the chance to 'toy' with possible narratives as part of the diorama's affordances.

Designing, manufacturing, distributing, and building model kits constitute 'performances of memory' (Plate and Smelik, 2013) whereby the past is materialized and miniaturized in the present. Assembling and painting models, as well as arranging them in diorama settings, are phases of an embodied engagement with the affordances of the materials provided by manufacturers to give form to the past, which, in the case of I.E.D., was the past of yesterday or even of the past hour, televised on news cable networks such as $\mathrm{CNN}$ and BBC. Model manufacturers 
did not waste any time in responding to America's War on Terror. As Levinthal discloses in his introduction, 'Not only are there now models covering every facet of the war and every imaginable vehicle, but all of these figures exist in every degree of quality, from the most simple representation to the most complex and exact replica' $(2009$, p. 5). Gutzman's work on I.E.D. attests not only to his 'skills and willingness to readily build, paint, and customize these models', as mentioned in the acknowledgments (p. 95), but also to model building as a cultural practice. Even if the work is usually done in monastic isolation, the countless clubs, societies, websites, and blogs dedicated to different facets of model building provide evidence of the social dimensions of this practice. ${ }^{2}$ Sharing and commenting on photographs of models and dioramas posted on the Internet have given rise to a style of photography that aims at enhancing realism through the use of optical adjustments and rendering the world outside the diorama invisible. ${ }^{3}$ In their effort to maximize the reality effect, these visual representations-with varying degrees of successenvelop dioramas in the phantasmatic realm of Bachelard's 'reality of toys'. Without doubt, Levinthal's photographs of American soldier figures in I.E.D. hark back to these practices and, by doing so, take the materiality of the miniature to a different experiential level.

\section{Photographic Materialities}

I.E.D. is Levinthal's first digital project after decades of working with Polaroid cameras (Mamiya Leaf, 2008). The Leaf Aptus mechanism allowed him to make more extensive and targeted use of soft focus than he could in his earlier analogue work. The diorama's stillness, as Stewart points out, 'emphasizes the activity that is outside its borders' (1999, p. 67). No matter how immersive the diorama, we remain 'trapped outside the possibility of a lived reality of the miniature' (p. 66). Levinthal's photographs reverse this logic. They engage viewers by leaving the world outside the diorama invisible, literally entrapping them inside the miniature world. As Rachel Wells observes, 'His extension of scale in two different yet simultaneous directions results in the viewer of his photographs looking at both a miniature and an enlargement, an expansion in two opposing directions compressed into one unified image' (2013, pp. 129-130). Moreover, Levinthal's use of soft focus and subdued tonality blurs the material details of models, generating an experience that differs from the reality effect of high-quality miniature replicas that I discussed in the previous section. The contrast between blurred elements and details in focus is crucial to the effect that these images impart.

The notions of optical and haptic visuality help us conceptualize this affective dimension. Drawing on Aloïs Riegl's distinction between optical and haptic visuality, Laura Marks (2000) describes optical visuality as a practice of looking that privileges the representational power of 
images. As such, it is geared toward recognizing and identifying forms and the relationships they share with each other. In other words, optical visuality is predicated on the image's representational power and the observer's ability to decipher what the image depicts. Haptic visuality (relating to the Greek word haptikos, meaning 'able to touch or grasp') entails a more corporeal disposition toward images. It 'tends to move over the surface of its object rather than to plunge into illusionistic depth, not to distinguish form so much as to discern texture. It is more inclined to move than to focus, more inclined to graze than to gaze' (Marks, 2000, p. 162).

Levinthal's implementation of sharp and blurred zones activates both modes of visual engagement. Attending to these modes helps to examine the experiential dimensions of the way in which miniature materialities are transformed into photographic materialities. I will trace this transformation through a photograph from I.E.D., which depicts a soldier running or climbing toward the camera with his rifle in his right hand (Figure 11.1). In order to articulate the affective quality of the image, I will occasionally use the first person singular. The figure is captured from a slightly higher angle, as though from the perspective of one of his comrades looking back from further uphill. The soldier is positioned in the center of the photograph, the bulk of which is completely blurred. His dark boots are hardly discernible, though identifiable on the basis of the rest of his body which appears less blurred the closer it is to the camera. The equipment behind him is so out of focus that it is difficult to identify its shape and function. The only detail brought in clear focus is the man's helmet with a darker brown patch of a desert camouflage



Figure 11.1 A photograph from I.E.D.: War in Afghanistan and Iraq. Courtesy of David Levinthal Studio. 
pattern exposed on the left side and a bit of sand stuck on the other side, indicating that its wearer has been in the heat of action. My reading so far has exhibited an optical disposition toward the image. I have described the event that I read into the photograph on the basis of details that I could invest with meaning. In this mode of viewing, the blurred zones were perceived as logical extensions of discernible details.

Filling in the blurred zones, in a phenomenological sense, is an act of pattern recognition; it is to perceive what Maurice Merleau-Ponty calls an 'immanent significance' (2005, p. 26) that sets the stage for memories to be recalled. James Young's self-reflexive reading of Levinthal's Mein Kampf illustrates this aspect of perception and adds a slight twist to Barthes's reality effect. He argues that

the soft focus deflects the mind's eye away from the object and inward, back into itself. In the seemingly iconic image of guard tower, fence, soldier, and dog, it is the rich black and blue tints of the sky that absorb the eye, pulling the mind through the figures into the space behind them. This is a kind of reverse reality effect: I stare and realize that the darker and less discernible the dog and soldier are, the more real they become in the mind. (2000, pp. 52-53)

In a paradoxical sense, what Young's reading reveals is that his inability to clearly discern objects in the blurred zones is conducive to an 'immanent significance' that takes shape 'behind' the objects. While Barthes locates the reality effect in the accumulation of detail, Levinthal's images derive their reality effect from the blur. It is this perception of patterns upon which memories of actual Holocaust photographs can be projected that Young subsequently analyzes (p. 54). In the case of I.E.D., however, no emblematic images are activated. Instead, the different shades of brown, drab, and khaki, as well as the neon green patches against pitch-dark backgrounds, form familiar patterns of a certain type of image that I associate with American involvement in wars in the Middle East.

Rather than simulating specific images, I.E.D. activates a sense of déjà $v u$ that renders the photographs in the series uncannily familiar, an effect corroborated by the typicality of the themes and postures in dioramas. Even if they do not hark back to specific images as some of the photographs in Mein Kampf do, I.E.D. 'expertly simulates the digital images made by embedded photojournalists' as Kaitlin Booher points out $(2013$, p. 107). Taken at the height of battle, many of these photojournalistic images are blurred and unpolished but nonetheless recognized as authentic (Ullrich, 2009, p. 98; Van Gelder and Westgeest, 2011, pp. 59-63).

Drawing on this characteristic of war photographs, Levinthal's technique continues the work of the modeler through photographic means. 
If paint seemingly transforms plastic into other materials, the reverse reality effect of the soft focus de-specifies materials. At work here is what Landsberg calls prosthetic memories, which emerge 'at the interface between a person and a historical narrative about the past, at an experiential site such as a movie theater or museum' (2004, p. 2). Levinthal's photograph and, by extension, the book represent a similar experiential site where the zones are blurred just enough to be invested with immanent significance, which, in turn, lends itself as a platform for mnemonic inscriptions of a highly mediatized recent past. In Landsberg's words, 'the technologies of mass culture and the capitalist economy of which they are a part open up a world of images outside a person's lived experience, creating a portable, fluid, and nonessentialist form of memory' (2004, p. 18).

Even so, Levinthal's implementation of the soft focus never completely dematerializes the diorama. As I look at the image of the soldier climbing uphill, my efforts to decode what the blurred zones depict are simultaneously interrupted by the texture of the image. In this experience the blur foregrounds the photograph's fabric, those tiny pixels that make up the digital fog that obscures every detail except for the soldier's helmet. Whereas in the optical mode the helmet constitutes a reference point that structures the blurred details along a narrative that highlights the sand on its side as evidence of the soldier's involvement in a mission, the haptic mode of looking dwells on material details that unsettle this mode of viewing. In her reading of Sally Potter's film Yes (2004), Giuliana Bruno (2014) describes blurring as a process that 'constructs a moving strategy for building surface materiality, and, in this sense, it joins other material operations of becoming that can enhance surface tension with depth' (p. 242). Bruno's description of Potter's 'visual brushstrokes' (p. 242) deflects attention from the film's narrative and probes the ways in which the camera's soft focus transforms the mise-en-scène and offers it up as a texture for haptic engagement. Likewise, as much as they serve optical sense making, as haptic surfaces the blurred zones in Levinthal's photograph exceed their function as vehicles of a reverse reality effect and constitute, instead, a 'surface materiality' that exposes the fabric of the digital image. In this sense, the shades of brown, drab, and khaki can be perceived as 'layers of coating' (p. 241) in much the same way as Potter's film unfolds in Bruno's text, conducive to atmosphere rather than meaning.

This is not to say that only the blurred zones are conducive to this experience. Quite the contrary, the haptic mode allows for the materiality of plastic to manifest itself in the image. While the photographs that diorama builders circulate on the Internet seek to disguise the materiality of their models as much as they can, the gaze Levinthal adopts when applying sharp focus borders on the forensic, as though putting 
objects under a magnifying glass and making miniatures larger than life. As a result, the helmet, which I optically perceive as part of the soldier's outfit, comes to the fore, in its miniature materiality, as painted plastic. At stake here is a kind of surface materiality that differs from Bruno's use of the term as an atmospheric register resulting from the camera's use as a brush in the hand of a painter. Here, it has more to do with Walter Benjamin's conceptualization of the camera's ability to enlarge details of the material world, revealing secrets that lie hidden in what he calls the 'optical unconscious' (1999, pp. 510-512). This potential of the camera serves Levinthal as a means to foreground the haptic qualities of the object and render its topography visually tactile. Such an exposure to visual tactility enlarges the miniature-an experience that corresponds to Bill Brown's formulation of things in contradistinction to objects. While objects can be named on the basis of the functions they serve, he argues, 'the thing seems to name the object just as it is even as it names some thing else' (2001, p. 5, emphasis in original). In other words, the thingness of an object indicates an excess that refuses to be accommodated within the object's preordained functions. Enlarged and in focus, the thingness of the helmet materializes in the form of its ability to 'remember' the process of its production in much the same way that brushstrokes on a wall recall the activity of painting. Imperfections become apparent and reveal, for instance, that the strap that runs around it is part of the same plastic object, differentiated only by the dark green paint that covers it. Similarly, the grains of real sand stuck to the helmet's side are disproportionately large compared to its size.

The thingness of these minuscule material details lies in their power to challenge my disposition toward the photograph. They are, in Brown's characterization of things, 'occasions of contingency-the chance interruption-that disclose a physicality of things' (p. 4). While our familiarity with objects allows us to look through them, a thing 'can hardly function as a window. We begin to confront the thingness of objects when they stop working for us. ... The story of objects asserting themselves as things, then, is the story of a changed relation to the human subject and thus the story of how the thing really names less an object than a particular subject-object relation' (p. 4). In this sense, my encounter with the materiality of the miniature object as a thing bespeaks what and how I perceive as a pattern. If the blur renders the miniature a translucent surface to look through, the sharp focus discloses the former as an illusion. The affective residue of this encounter is a sense of disorientation. What appears to be a dynamic spur-of-themoment snapshot of a soldier is now revealed as motionless matter and the scale of the event, in a literal sense, is reduced to miniature.

At the same time, my initial identification with details as objects and things and my engagement with details in the optical and haptic modes 
reflect only half of my experience of the photograph. For insofar as the exposed materiality of plastic engenders the sensation of the object's thingness, it also works the other way around. The plastic materiality of the soldier figure, if recognized as a miniature, also serves as an interpretive reference point that structures my visual engagement with the image. Once all the details of the diorama fade out of focus, the reverse reality effect of the blur enfolds what I previously recognized as plastic and frames it as a human being. Thingness, in this sense, results not so much from the exposure of the model's materiality to the detriment of realism as it does from the opposite, the blur's potential to endow inanimate matter with life-like qualities. This recalls Bachelard's remark on the reality of toys, albeit with an edge of the Freudian uncanny, the strange sense of aliveness embodied by wax figures, dolls, and automatons (Freud, 2003, p. 135). As sharp details are engulfed in soft focus, fixity morphs into movement, and motionless matter comes alive: the plastic soldier appears as though fighting his way through a terrain where danger lies in wait. If thingness, as Brown has it, manifests itself in a changed subject-object relationship, it comes to the fore in my sensation of inanimate plastic transgressing its material limitations.

Therefore, the transformation of objects into things does not follow a linear sequence. The materiality of plastic can interrupt the flow of imagined events just as much as it can be absorbed by them. The photograph I have discussed gains its unsettling power from the holographic alteration of these two sensations, depending on the immanent significance of an organized pattern in Merleau-Ponty's sense. In some images in I.E.D., the materiality of plastic is more obvious than in others. Images of wounded bodies and close-ups on soldiers' faces (Levinthal, 2009, pp. 54-63), for instance, elicit instant recognition of plastic, while photographs that show contours of vehicle and personnel with the source of light behind them (pp. 42-43) easily lend themselves to be perceived as documentary footage. Although Levinthal's work is exhibited in a number of galleries (Levinthal, 2016), his projects are initially published in book format. We have already seen how Levinthal's pictures evoke prosthetic memories of the American military presence in the Middle East. The book edition of I.E.D. combines images and texts in ways that complicate the interrelation of memory and materiality.

\section{Paratextual Memories}

The book edition of I.E.D. is more than a collection of photographs. What genre it belongs to, however, is difficult to define. Each photograph occupies about half a page, except for some larger ones that take up almost two facing pages and some smaller ones that form short sequences depicting night missions, as though stills from a film (Levinthal, 2009, pp. 28, 31). The photographs are clustered in five consecutive chapters 
named after military abbreviations and slang: 'ROE Rules of Engagement', 'Boots on the Ground', '2300 ZULU', 'IED', and 'Embrace the Suck'. Underneath and sometimes next to the images, filling up roughly one-eighth of a page, short excerpts from the military blog The Sandbox appear, with the names of the contributors listed at the end of the book (p. 91). In addition to the introduction, the book features a bibliography that gives evidence of the extensive research Levinthal has invested in the project. In the acknowledgments, he gives credit to the work of his family, friends, and associates, including the model builder Jeffrey Gutzman, and the authors of the military blog 'whose words enriched this project considerably' (p. 95).

These enrichments can be regarded as 'paratexts' (Hutcheon, 1986/1987; Genette, 1997) framing the main text, which, in the case of I.E.D., are the photographs. Paratextual elements entail all textual and visual additions, as well as the way in which they are arranged. Attending to these elements as part and parcel of I.E.D. is not only necessary to understand the context in which Levinthal presents his photography but also helpful to bring forth the book's unique potential as a mnemonic device. Entitled 'OSCAR MIKE (On the Move)', the book's introduction explains the background of the project in relation to Levinthal's previous work. He describes his intentions as follows: 'I was drawn to these figures in large part because I was both amazed at their existence and fascinated by what they represent. I wanted to make beautiful, compelling pictures of the horror of war. I wanted to create reality without hiding the unreality of what I was doing' (p. 5). His self-reflexive remarks are performative statements that give center stage to the photographs and construe all textual elements in the book as supporting material. The fact that he makes this comment in the introduction, the title of which comes from the same pool of military terminology, indicates that this textual performance is already part of the 'show', so to speak.

The book's material properties, featuring almost a hundred glossy pages bound in hardcover, invite the reader to glance at the photographs before reading any of the texts. Levinthal's reputation as a photographer also contributes to privileging image over text. Leafing through the pages, one instantly feels compelled to seek out patterns and connections among the photographs. Placed on successive pages, the pictures form a linear sequence, indicating that there is a narrative with a beginning and an end that holds them together. Printed in a larger font size than the other texts, the chapter titles seem to organize this unfolding sequence of images along different aspects of military deployment, suggesting that each of these chapters chronicles not so much different missions as different aspects of a typical mission, from clarifying the rules of engagement to facing the aftermath of exploding IEDs.

The placement of the short texts from The Sandbox instantly suggests that they function as captions, conventionally used to contextualize and 
explain the images closest to them on the page. A closer look, however, reveals otherwise. The first-person accounts of soldiers are in no way captions to Levinthal's photographs. Their relationship to the images is far more complex. Featuring soldiers' firsthand experience on battlegrounds, the blog from which they have been selected was launched by cartoonist Garry Trudeau, Levinthal's longtime friend and collaborator on Hitler Moves East (1972-1975), the project that earned Levinthal fame as an artist. The spatial arrangement of the texts vis-à-vis the images suggests that the texts are captions to the photographs. Their function, however, is not to explain the images. They constitute an outlet of memories and emotions related to military service in Afghanistan and Iraq, containing 'unclassified details of deployment-the everyday, the extraordinary, the wonderful, the messed-up, the absurd' (Trudeau, 2014). Making part of Trudeau's website Doonesbury.com, the blog was launched in 2006 and maintained by journalist and editor David Stanford as the site's duty officer until the withdrawal of American forces from Iraq in 2014, by which time the blog already encompassed a sizable archive exceeding The Lord of the Rings trilogy (Trudeau, 2014). Cooperating with Levinthal on the book edition of I.E.D., Stanford's selection of texts from the blog was guided by the intention to 'provide the boots-on-the-ground testimony that accompanies the images' (Levinthal, 2009, p. 5).

In terms of its content and structure 'ROE Rules of Engagement' stands out from the rest of the chapters. Forming a bridge between 'OSCAR MIKE (On the Move)' and 'Boots on the Ground', it provides glimpses of different aspects of a mission, foreshadowing the visual atmosphere of the chapters that follow. But it is also a bridge in another sense. The chapter opens with a computer-generated map of American military bases in Iraq (Levinthal, 2009, p. 8), with a close-up of a model soldier in the gun turret of a military vehicle on the facing page (p. 9). Underneath the map, the text reads:

The first time I got blown up, I had to remind myself to get up and look around for the trigger man, or possible gunman, set to take advantage of the confusion. I felt like I was floating through a world where time stood still. There's something about looking directly at an artillery shell, and seeing it vanish with a sharp crack and a rush of dust and debris, that changes you. My brain was yelling at me, 'This isn't normal! You shouldn't be alive and thinking right now!' and my body was yelling back, 'Well, I am definitely alive, so hoist your doubting ass up into the turret'. (p. 8)

The text's testimonial tone weaves together the map's abstract representation of territory and the model's miniature abstraction filtered through Levinthal's camera. The last word 'turret' materializes in the 
photograph, and so does the model soldier materialize as the text's author, infusing the abstract spatiality of the map with a twinge of lived space. Two pages later, the iconic photograph of pulling down Saddam Hussein's statue in Baghdad in 2003 appears with a text detailing an ambush similar to the previous one. ${ }^{4}$ The miniature soldier figure pointing his gun at the camera on the opposite page not only embodies the textually conveyed panic and confusion but also serves as a witty, if not ironically morbid, counterpoint to the monumental statue of the Iraqi dictator: a statue and a figurine, the former pulled down by force, the latter enlarged by imaging technologies.

The texts' narrative voice invests the images with a sense of intimacy and an uncanny aliveness, lending them a voice that appears to be coming either from the soldiers or from a disembodied witness whose gaze Levinthal's camera assumes. In one photograph in 'Embrace the Suck', a soldier wearing sunglasses is depicted with the object of his attention framed as his comrade on the facing page (Levinthal, 2009, p. 74). This other soldier is shown with his weapon in focus and his helmetless head slightly blurred, fading into the background (p. 75). While the combination of map, news photograph, blog text, and Levinthal's photographic rendering of the miniature intertwines historicity with simulation, the text underneath this latter photo forges an intimate narrative connection between the two images:

I catch his eyes, only for a moment, and I see everything that I need to see, fear and the look of being lost, as he babbles on about warlords and wiping them out with his AT-4 rocket launcher. I've seen the same look in many Joes, both here and in Iraq, a look of despair entwined with resolve and determination at the same time. 'What happens next?' with a slide of 'I will be going home'. (p. 75)

The text focalizes the soldier with a weapon through the eyes of the one on the opposite page wearing sunglasses (presumably the same figure featured from a different angle in the photograph facing that of Saddam's statue), whom the text positions as the agent of the gaze registering one of his comrades in a state of angst and confusion. The inclination to map the text onto the photograph thus supplements the work of the soft focus insofar as the first-person singular narration breathes life into the model figures in much the same way as the blur softens their details and enhances their realism.

Still, at the same time that the text personalizes the model, the haptic qualities of the miniature foreclose the possibility of full immersion in the reverse reality effect. The visual sensation of surface materiality foregrounds the model's materiality and underlines its difference from its referent. Plastic exceeds its function as imitation material in Barthes's sense. Instead of its form, its materiality is what comes to the 
fore. As such, it does not substitute the lived human body on grounds of formal similarity but asserts its difference on grounds of materiality. The voice emanating from the text is similarly excessive insofar as it refuses to be accommodated fully by the materiality of the model. For as much as it animates the model figures, it also reverberates as an echo between form and matter.

This echo is perhaps at its most eerie in the chapter 'IED'. As the title portends, the pictures in this chapter depict the devastating effects of explosive devices in the immediate aftermath of explosion. Severed limbs and burned body parts abound, matching up with the text's vague references to outfits that 'wouldn't melt to our skin if one of those impressive fireballs engulfed the truck' (p. 54), to sensing the impending prospect of being 'blown up' (p. 55), to the sound of the 'sharp hammerstrike of the exploding bomb' (p. 59), and to 'burnt, mangled bodies' (p. 62) mingling with wreckage in the wake of a car bomb attack. The images operate by a different dynamics than in the other chapters. The detailed depiction of the materiality of plastic in most of these images prevents the soft focus from achieving its full potential as a tool of realism. Even the blurred details appear to be too close to shed their materiality (Figure 11.2). To simulate bodily wounds and the wreckage of vehicles, Levinthal uses real fire to burn off parts of the models, only to expose burnt plastic in sharp focus. Rather than using paint to imitate wounds and damage, he applies the force of fire to reenact the destruction inflicted by the bomb. While in the other chapters the exposure of surface materiality mitigates the model's performative potential to stand in for other materials, the

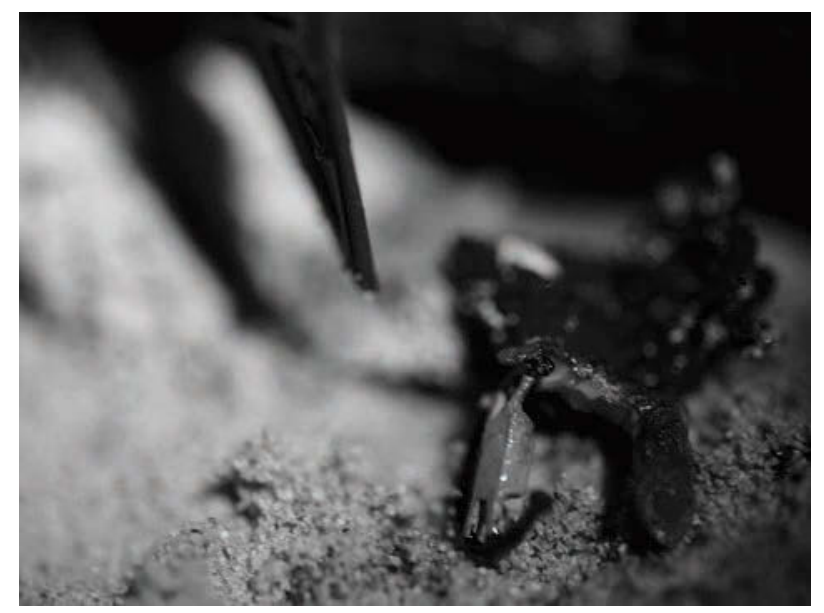

Figure 11.2 A photograph from I.E.D.: War in Afghanistan and Iraq. Courtesy of David Levinthal Studio. 
scattered chunks of burnt plastic reflect, both materially and formally, the vulnerability and plasticity of the human body. Here, Levinthal's interest is less with realism and more with material transformation. Violence by fire, in other words, reduces both the lived body and its plastic representation to distorted and blackened stuff, allowing form to fold back on matter and disclose the plasticity of the body and the corporeality of plastic.

\section{Conclusion: Modeling the Memories of Others}

In their respective readings of Levinthal's Mein Kampf, James Young (2000) and Ernst van Alphen (2005) describe the project as emblematic of second-generation Holocaust art. When Levinthal was asked by one of his teachers at Yale why he took photos of toys rather than reality, he answered, 'These toys are my reality!' (qtd. in Young, 2000, p. 44, emphasis in original). Mein Kampf is about the reality of toys and, metonymically, of the various media through which Levinthal and his generation experienced and learned about the Holocaust. His response to his teachers echoes in his later projects, and I.E.D. is no exception. But here, as I have argued throughout this chapter, the imagined reality of toys is translated into an obsession with realism that informs the practice of building model kits.

Levinthal's images, as we have seen, activate both optical and haptic engagements. They simultaneously highlight and obscure the abyss between the materiality of the model and the augmented materialities that assembling, painting, and photographing models bring forth. By doing so, his photographic representations of miniatures open loopholes for memory work to take place. This work is propelled, on the one hand, by his photographic mediations of the models and on the other, by the inclusion of texts from The Sandbox. By positioning them as 'enrichments' to the photographs, however, Levinthal discloses the function of these accounts as an affective supplement to the images. Edited, selected, and taken out of the context of the blog, the texts' rootedness in private memory-indeed, in the memory of othersis to serve a reality effect: their specificity of detail, much like Barthes's reality effect, adds a personal 'touch' to the photographs and recycles memories into an atmospheric quality central to the transfer of prosthetic memories.

Seven years after its publication, I.E.D., as we know in retrospect, is about a war that officially ended with the withdrawal of American troops in 2011, yet this campaign resulted in subsequent wars and the rise of ISIS in Iraq and Syria. Deaths resulting from the explosion of improvised explosive devices are a daily reality in the region (and elsewhere) that does not seem to end in the foreseeable future. While modelers did not 
waste their time to re-create scenes of the Syrian civil war with a variety of equipment deployed on all sides, I.E.D. gathers a strange patina. Its mnemonic potential exceeds the spatiotemporal realm of the war that its title indicates, and, by way of modeling the memories of others, it triggers associations of an unfolding present.

\section{Notes}

$1 \mathrm{http}: / / \mathrm{www}$. fieldsofglorymodels.co.uk.

2 For instance, FineScale Modeler is one of the most popular websites and a magazine dedicated to diorama building with a regularly updated list of clubs all around the world: http://www.finescale.com.

3 For an example of a photography guide for model builders, visit http:// photoguide.tiono.com.

4 For a reproduction of the photograph in The New York Times, see Semple (2007).

\section{References}

Bachelard, G. (1994) The Poetics of Space: The Classic Look at How We Experience Intimate Spaces (Trans. M. Jolas) (Boston: Beacon Press).

Barthes, R. (1986) The Rustle of Language (Trans. R. Howard) (New York: Hill and Wang).

Barthes, R. (1993) Mythologies (Trans. A. Lavers) (New York: Vintage).

Benjamin, W. (1999) 'Little History of Photography' in H. Eiland and G. Smith (eds) Selected Writings Vol. 2 (Trans. E. Jephott and K. Shorter) (Cambridge, MA: Harvard University Press). 507-530.

Booher, K. (2013) 'I.E.D.' in P. Roth and K. Booher (eds) War Games (Heidelberg: Kehrer). 106-121.

Brown, B. (2001) 'Thing Theory' Critical Inquiry 28.1 (Autumn): 1-22.

Bruno, G. (2014) Surface: Matters of Aesthetics, Materiality, and Media (Chicago: The University of Chicago Press).

Coleman, M. (2013) 'Levinthal's Images Humanize Conflict Through Action Figures', The Washington Diplomat (May 30) http://www.washdiplomat.com/ index.php?option=com_content $\&$ view=article \&id=9253:levinthals-images humanize-conflict-through-action-figures\&catid=1503:june-2013\&Itemid=530 (Accessed on 23 June 2016).

Feinstein, S. (2000) 'Zbigniew Libera's Lego Concentration Camp: Iconoclasm in Conceptual Art about the Shoah', Other Voices 2.1 http://www.othervoices.org/2.1/feinstein/auschwitz.php (Accessed on 23 June 2016).

Fleming, D. (1996) Powerplay: Toys as Popular Culture (Manchester, UK: Manchester University Press).

Freud, S. (2003) The Uncanny (Trans. D. McLintock) (London: Penguin). Genette, G. (1997) Paratexts: Thresholds of Interpretation (Trans. J. Lewin) (Cambridge: Cambridge University Press).

Hirsch, M. (2012) The Generation of Postmemory: Writing and Visual Culture after the Holocaust (New York: Columbia University Press). 
Hutcheon, L. (1986/1987) 'Postmodern Paratextuality and History', Texte 5.6: 301-312.

Knoblauch, L. (2010) 'David Levinthal, I.E.D.: War in Afghanistan and Iraq @ Stellan Holm', Collector Daily (January 13) https://collectordaily.com/davidlevinthal-i-e-d-war-in-afghanistan-and-iraq-stellan-holm (Accessed on 23 June 2016).

Kuznets, L. R. (1994) When Toys Come Alive: Narratives of Animation, Metamorphosis, and Development (New Haven, CT: Yale University Press).

Landsberg, A. (2004) Prosthetic Memory: The Transformation of American Remembrance in the Age of Mass Culture (New York: Columbia University Press).

Levinthal, D. (2009) I.E.D.: War in Afghanistan and Iraq (Brooklyn, NY: powerHouse Books).

Levinthal, D. (2016) David Levinthal http://www.davidlevinthal.com (Accessed on 23 June 2016).

Mamiya Leaf (2008) 'David Levinthal' YouTube video (December 12) https:// www.youtube.com/watch?v=NtjPhr2Isus (Accessed on 15 July 2016).

Marks, L. (2000) The Skin of the Film: Intercultural Cinema, Embodiment, and the Senses (Durham, NC: Duke University Press).

Merleau-Ponty, M. (2005) Phenomenology of Perception (Trans. C. Smith) (London and New York: Routledge).

Merlock Jackson, K. (2001) 'From Control to Adaptation: America's Toy Story', Journal of American and Comparative Cultures 24.1-2 (Spring/Summer): 139-145.

Mrosko, C. (2014) Building Dioramas (Waukesha, WI: Kalmbach Books).

O'Sullivan, M. (2013) 'Art Review: "David Levinthal: War Games” at the Corcoran Gallery of Art', The Washington Post (May 16) https:/www.washingtonpost.com/ entertainment/art-review-david-levinthal-war-games-at-the-corcoran-gallery-ofart/2013/05/16/995ef8f2-bbe5-11e2-89c9-3be8095fe767_story.html (Accessed on 23 June 2016).

Paine, S. (2000) How to Build Dioramas: Aircraft, Armor, Ship, and Figure Models (Waukesha,WI: Kalmbach Books).

Perry, G. (2013) Playing at Home: The House in Contemporary Art (London: Reaktion Books).

Plate, L., and A. Smelik (eds) (2013) Performing Memory in Art and Popular Culture (London and New York: Routledge).

Semple, K. (2007) 'Iraq Confronts Hussein Legacy Cast in Bronze', The New York Times (8 April) http://www.nytimes.com/2007/04/08/world/ middleeast/08monuments.html?_r=1 (Accessed on 23 June 2016).

Sicart, M. (2014) Play Matters (Cambridge, MA: The MIT Press).

Stewart, S. (1999) On Longing: Narratives of the Miniature, the Gigantic, the Souvenir, the Collection (Durham, NC: Duke University Press).

Sutton-Smith, B. (1986) Toys as Culture (New York: Gardner).

Trudeau, G. (2014) Doonesbury http://gocomics.typepad.com/the_sandbox (Accessed on 23 June 2016).

Ullrich, W. (2009) Die Geschichte der Unschärfe (Berlin: Wagenbach).

Valli, M., and M. Dessanay (2011) Microworlds (London: Laurence King). 


\section{László Munteán}

Van Alphen, E. (2005) Art in Mind: How Contemporary Images Shape Thought (Chicago: The University of Chicago Press).

Van Gelder, H. and H. Westgeest (2011) Photography Theory in Historical Perspective (Malden, MA: Blackwell).

Wells, R. (2013) Scale in Contemporary Sculpture: Enlargement, Miniaturisation and the Life-Size (Farnham, UK: Ashgate).

Young, J. (2000) At Memory's Edge: After-Images of the Holocaust in Contemporary Art and Architecture (New Haven, CT: Yale University Press).

Young, J. (2009) 'Regarding the Pain of Women: Questions of Gender and the Arts of Holocaust Memory', PMLA 124/5 (October): 1778-1786. 


\section{List of Contributors}

Aleid Fokkema is Senior Lecturer at the Media and Communication Department of Erasmus University, Rotterdam. Her publications over the past decades have consistently been oriented around representations of identity in contemporary fiction, especially in relation to a sense of place. Her current research interests are concerned with the mediating role of knowledge in espionage fiction and film and with images of self and other in war films.

Anna Forné is Associate Professor of Hispanic Literature and Cultures at the University of Gothenburg (Sweden). Her current research, financed by the Swedish Foundation for Humanities and Social Sciences, is on The Politics of Poetics: The Testimonial Genre and the Literary Prize of Casa de las Américas (1970-2011). Her previous research focused on the narrative configurations of memories of dictatorship in Argentina and Uruguay. She has published extensively in the field of memory studies and Latin American literature and culture.

Elisa Giaccardi is Professor of Interactive Media Design at the Department of Industrial Design Engineering of TU Delft and a recipient of its Technology Fellowship for top female scientists. Her background brings together the humanities, digital media, and interaction design. She regularly lectures and publishes in international journals and at leading conferences for interaction design and human-computer interaction. She is the editor of Heritage and Social Media (Routledge, 2012), in which she uses heritage as a lens to understand how emerging information and communication technology and services are changing the way in which people participate in the assessment and passing on of the 'things we value'.

Louis van den Hengel is Assistant Professor of Gender Studies and Literature and Art at Maastricht University. He is the author of the book Imago (2009) on ancient Roman sculpture and the embodiment of gender, and has published articles on contemporary art and cultural theory in journals such as Biography: An Interdisciplinary Quarterly, Criticism: A Quarterly for Literature and the Arts, and the Dutch Journal 
of Gender Studies. His current research examines the interrelations between affect, materiality, and time in contemporary performance art; his special focus in this research is the work of the Serbian and New York-based performance artist Marina Abramović. He has observed and participated in several of Abramović's recent works, including The Artist Is Present (New York, 2010), The Abramović Method (Milan, 2012), and the long-durational performance 512 Hours created at the Serpentine Galleries in London in 2014.

Willy Jansen is Professor Emeritus of Gender Studies at Radboud University, Nijmegen. She has done extensive anthropological fieldwork in the Middle East, North Africa, and Southern Europe and has published widely on gender, religion, education, and sexuality. Currently, she is involved in research projects on gender and ritual in Spain and on sexual rights in Bangladesh. Her publications include the monograph Women without Men: Gender and Marginality in an Algerian Town (Leiden, 1987) and several edited volumes, including Moved by Mary: The Power of Pilgrimage in the Modern World (2009, co-edited with A. K. Hermkens and C. Notermans) and Gender, Nation and Religion in European Pilgrimage (2012, co-edited with C. Notermans).

László Munteán is Assistant Professor of Cultural Studies and American Studies at Radboud University, Nijmegen, the Netherlands. His publications have focused on the memorialization of 9/11 in literature and the visual arts, American cities and architecture, as well as on the architectural heritage of Budapest. In a broader sense, his scholarly work revolves around the juncture of literature, visual culture, and cultural memory.

Celeste Olalquiaga is a cultural historian dedicated to the contradictions and leftovers of modernity, especially modern ruins and kitsch, and to the tension between nature and technology. Her books Megalopolis (1992) and The Artificial Kingdom (1998) have been translated into several languages. In 2013, she founded PROYECTO HELICOIDE, a nonprofit association dedicated to rescuing the cultural memory of El Helicoide de la Roca Tarpeya.

Liedeke Plate is Associate Professor of Gender Studies and Literary and Cultural Studies at Radboud University, Nijmegen, the Netherlands. Her research focuses on literature, gender, and cultural memory. She is the author of Transforming Memories in Contemporary Women's Rewriting (Palgrave, 2011) and co-editor of, among other works, Technologies of Memory in the Arts (Palgrave, 2009) and Performing Memory in Art and Popular Culture (Routledge, 2013). 
Maggie L. Popkin is Assistant Professor of Art History at Case Western Reserve University and a member of the American excavations at Samothrace, Greece. She is the author of The Architecture of the Roman Triumph: Monuments, Memory, and Identity (Cambridge University Press, 2016). Her research on Greco-Roman art has appeared in journals including American Journal of Archaeology, Hesperia, Journal of the Society of Architectural Historians, and Journal of Late Antiquity.

Anneke Smelik is Katrien van Munster Professor of Visual Culture at Radboud University, Nijmegen, where she is coordinator of the MA program Creative Industries. She (co-) edited many books, most recently Thinking Through Fashion: A Guide to Key Theorists (2016) and Delft Blue to Denim Blue: Contemporary Dutch Fashion (2017). She published widely on issues of identity, body, memory, and technology in cinema, videoclips, digital art, and fashion. Anneke Smelik is project leader of the research program Crafting Wearables: Fashionable Technology (2013-2018), funded by the Netherlands Organization for Scientific Research.

Susan Stewart is a poet, critic, and translator, the author of six books of poetry, including Columbarium, which won the National Book Critics Circle Award, and the forthcoming Cinder: New and Selected Poems, as well as On Longing: Narratives of the Miniature, the Gigantic, the Souvenir, the Collection (1983). A former MacArthur fellow, she is the Avalon Foundation University Professor in the Humanities at Princeton University.

Lianne Toussaint is a $\mathrm{PhD}$ candidate at the Department of Cultural Studies of Radboud University, Nijmegen, the Netherlands, who is writing a dissertation on the embodied, material, communicative, and ethical dimensions of wearable technology. In 2015, she received a Fulbright Grant for a visiting scholarship at Parsons The New School for Design in New York. Her research is part of 'Crafting Wearables: Fashionable Technology' (2013-2018), a collaborative research project funded by the Netherlands Organization for Scientific Research.

Inge van de Ven is Assistant Professor of Online Culture at Tilburg University. In 2015 she completed her PhD project entitled Monumental Novels in a Global and Digital Age at Utrecht University, after which she worked as a postdoctoral researcher at Education for Learning Societies (ELS, UU). She has published articles in journals such as the European Journal of English Studies, Between, and Image \& Narrative, and in several edited volumes. 
This page intentionally left blank 


\section{Index}

2666 (Bolaño) 6, 18, 107, 115-21

Aarhus Centre for Contemporary Art 68

abject 39-40

Abramović, Marina 19, 125-7, 139; and flesh memory 131-5

Acconci, Vito 131

Action Pants: Genital Panic (EXPORT) 131-4

The Act of Killing (film) 9-10, 20-21, 175-88; disruption and apophasis 184; as a documentary 183-7; past and present context $177-80$; reenactments in 181

actor-network theory 11

Adorno, Theodor W. 184, 187

aesthesis and cultural value 53

aesthetic theory 160

affect: of alienation 175-6; creating sensations of memory 129-31 agency: definition 13, 98; human 13; material 91, 98-99, 102; of objects 3-4, 12-16; performed by technology 100; and remembering between humans and non-humans 69-73; of things 72; of wearables in fashion 14, 70, 90, 102

À la recherche du temps perdu 1,111 Alfonsín, Raúl 161

alienation in participants 175-6

Alphen, Ernst van 111, 205

Amateur Press Association 68 anaphoric singulative mode of narration 113, 115, 120

Andalusia 19, 144, 147

Andermann, Jens 165

'angel of history,' 31

anthropocentrism 83-84

Appadurai, Arjun 6, 15, 51, 57, 76-77 archaeology 37-38

Archimboldi, Benno von 115

archive and performance of live art 130-31

archives of effect 135-40

archiving the ephemeral 135-8

Argentina 158, 162, 170

artifacts: attaching memories

to objects 73-76; changing

materiality and memory 76 ; human

interactions with 66-67

The Artist is Absent 125-6, 139

The Artist is Present 125-6

Assmann, Aleida 46, 106

Assmann, Jan 10, 79

Augustus (emperor) 47, 49

aura of things 31-33

Auslander, Philip 133, 134

Austin, J. L. 133

Aynsley, Jeremy 5

Bachelard, Gaston 191-3, 195, 200

Bantock House Museum 67

Barad, Karen 8, 13, 72, 83

Barrett, Estelle 3-4

barrios by El Helicoide 35-36

Barthes, Roland 38, 193, 194, 197

Bataille, Georges 16, 39

Benjamin, Walter 16, 30-41, 93, 199; notion of dialectical image 16 , $31-33,36$; theory of cultural ruins 37-38

Bennett, Jane 12, 13

Bennett, Tony 3

Berzowska, Joanna 96, 97

Beuys, Joseph 131

Bhopal gas leak 69

biography of objects $6-7,15$, 144-5, 148

Bishop, Claire 128 


\section{Index}

Blejmar, Jordana 169-70

blogs of war memories 6, 21, 192, 201, 205

blood painting 137

Blood Script (Coble) 137

body: and interaction with clothes 98-99; invaded by place and reliving memory 176 ; as a living archive 136-8; in the making of a memory 5, 125-40; materiality of 99; physical impact due to reenactments $181-3$

Body Pressure (Nauman) 131

body-to-body transmission of art knowledge 132-5

Boijmans Van Beuningen Museum 92, 100-1

Bolaño, Roberto 6, 18, 107, 115-19; and dissolution of singularity in his writing 118-19; inclusion of lists and enumerations in his writing 116-17; use of rhythm in his writing 119

Bolt, Barbara 3

Bonner, Frances 185

Booher, Kaitlin 197

'Book IV: The Part about the Crimes' (Bolaño) 107, 115-20

Boradkar, Prasad 92

Bouwsma, W. 149

Boybood Island (Knausgård) 113

Brecht, Bertolt 160

Breward, Christopher 5

Brown, Bill 7, 38, 54, 159-60, 163, 199

Bruno, Giuliana 3, 198

Bruzzi, Stella 167, 185

Bunratty Folk Park 67

Byrne, Denis 66

\section{Carolean Guitar 78-79}

Carri, Albertina 7, 20, 158-70

Catholics offering gifts 145

Cervantes, Miguel de 113

Chalayan, Hussein 18, 89-91, 94-102

Chin, Ava 95

Chiocciola 77-78

Clark, Andy 11

Clark, Judith 94

clothes: interaction between body and 98-99; and memories 5; as type of memory archive 92-95

Coble, Mary 19, 127, 131, 135-8 cofradías 145-6

collective memory 54, 164

comedy in The Act of Killing (film)

176, 183, 187

co-memorations 69

Comisión Nacional sobre la Desaparición de Personas (CONADEP) 161

commemoration and material magnitude 6

communitas feelings 154

The Conditioning (Pane) 131

Congo, Anwar 179-83, 186

Connected Everyday Lab (Delft University of Technology) 77, 79-80

Connerton, Paul 135

conscious memory 37

Constable, John 67

Coole, Diana 3

corporeality 19-21

costalero 149

Couceyro, Analía 159, 166-8

coup d'état in Indonesia 176, 178

Coyne, Richard 70

Cronberg, Anja Aronowsky 92

cross-dressing 186

cultural biography of things $6-7,15$, 144,148

cultural circuits 38

cultural memory 18, 65, 91-92, $96,98,100$; being created by performance 129-31

cultural residues 38-39

cultural ruins $37-38$

cultural value 30 ; and aesthesis 53

culture, participatory, 68

cult values 32

database: versus narrative 108-9, 120; transforming into a narrative 109, 120

A Death in the Family (Knausgård) 109-10

delegated performance 128

Deleuze, Gilles 127

Delft University of Technology 77, 79-80

Derrida, Jacques 109

De Wavrin, Leah 89

dialectical image 16, 31-33, 36

dictatorship and depicting its

memories 159, 162

digital heritage 65-66

digitalization 6,18 
Digital Natives (exhibition) 68

digital technology 16, 33, 56; aiding participatory culture $67-69$; to engage museum visitors $67-68$ dioramas 21, 193, 194

Dirty War (Argentina) 20, 158, 161

disappearances during the Dirty War 158,161

DNA of performances 162-63

documentary modes 183-7

documentary reenactments 165-70

Don Quixote (Cervantes) 113

Doyère, Valérie 72

Drexler, Arthur 34

Driessen, Henk 143-44

dualism of subjects and objects 11

The Earthquake Shelf 76

Eco, Umberto 111

Edensor, Tim 38

effective history 136

El Helicoide de la Roca Tarpeya 16, 29-41

'Embrace the Suck' (Levinthal) 201, 203

emergent sensibilities of cultural circuits 38

Entering the Other Side (Abramović) 131

Entwistle, Joanne 99

Ernst, Wolfgang 117

estrangement effect 160

Evans, Caroline 93, 96-7

excess producing the abject 39

exhibition values 32

EXPORT, VALIE 131, 132

Ezrahi, DeKoven 187

family remembering during Holy Week processions 153-4

fashion: ephemeral nature 93; history through fashion 89-91; integrated with technology 5, 14, 18, 89-102; performs memory to bridge past to the future 94-95

feminist activism 136

Ferris, Kieran 67

Fields of Glory Models 193-4

Fischer-Lichte, Erika 135

flesh memory 131-5

Fokkema, Aleid 9-10, 20, 21

folding of time $5,19,126$

forgetting 3; fear of 9

Forné, Anna 7, 20 forensic architecture 14-15

Fosh, Lesley 67

Foucault, Michel 136

Freud, Sigmund 37-38, 39

Frost, Samantha 3

Frow, John 50

funerary objects $50-51$

Gatibotto, Verónica 159

Geist 79-80

Gell, Alfred 12

Genette, Gérard 112

Giaccardi, Elisa 8, 17, 67-8

Gibson, Robyn 5

gifts to the divine 144-5

glass' sensorial qualities 53-54

Golan, Fyodor 91

Gómez, Antonio 159

Gosden, Chris 144

guerrilla street art project 69

Gutzman, Jeffrey 193, 201

Halbwachs, Maurice 14

Hallan, Elizabeth 5

haptic visuality 195-6, 198-9

Heidegger, Martin 7-8

Hejinian, Lyn 187

Hengel, Louis van den 5, 19

heritage as cultural work of engagement 67

hermandades 145

Herzog, Werner 179

HIJOS 162-3

Hirsch, Marianne 21, 164, 165, 192

Hitler Moves East (Levinthal) 202

Hockey, Jenny 5

Holly, Michael Ann 54

Holocaust art 191-2, 205

Holy Week processions in Andalusia 19-20, 143-55

Homer 119

How to Explain Pictures to a Dead Hare (Beuys) 131

human agency 13

Hunt, Carole 92, 100

Hunt Museum (Limerick) 67

Huyssen, Andreas 57

identity: and Holy Week processions $145,147-50$; religious objects building social identity 145 , 148-50; shaped by objects 7; souvenirs creating metropolitan identity $51-58$ 


\section{Index}

\section{I.E.D.: War in Afghanistan and Iraq} (Levinthal) 6, 21, 192-206

illumination of things 31

imagined memories 57

immanent significance 197-8, 200

'incorporating practice,' 135

individual memory 14

Indonesia and its coup d'-etat and anti communist purge 20,175-6, 178

Indonesian Communist Party 178

Ingold, Tim 12, 70, 99, 101

Internet 70

Internet of Things (IoT) 4, 8, 16, $17,70-73$; adding connections to materiality of the object 83-84; attaching memories to objects 73-76; remembering with an object 79-82; and social lives of things 77-79

intra-action of people and things 8 , $72,98-99$

iPhone dress 91

iterative materializations and memory, 72

Iversen, Ole Sejer 68

Jansen, Willy 7, 19

Jenkins, Henry 68

Jones, Andrew 11

Jones, Ann Rosalind 92

Joyce, Patrick 3

Juárez murders 115, 118

killing's reenactment of past acts 175

kinship and memories of 153-5

Knausgård, Karl Ove 6, 18, 107, 109-15; effect of the infinite in his writing 11; inclusion of lists and enumerations in his writing 111 ; open-ended memory writing 114-5, 120

Kondo, Marie 9

Kopytoff, Igor 6, 15, 51, 57, 76-7, 144

Kristeva, Julia 16, 39, 187

Kwint, Marius 5, 11, 13

Lacan, Jacques 16, 39-40

Lacanian reste 39-40

landmarks 55-56

Landsberg, Alison 57, 192, 198

La Roca Tarpeya 33-4

Latour, Bruno 11

La Vita è Bella (film) 187

Law, John 3
LeDoux, Joseph 72

Lefebvre, Henri 56

leftover of the psyche 39-40

Lego Concentration Camp Set 191

Lehmann, Ulrich 93

Lepecki, André 138

Levinthal, David 6, 21, 191-4, 195-206

LGBT histories being captured 135-6

Libera, Zbigniew 191

lieux de mémoire 1, 10, 106, 180, 188

Lin, Maya 119

live art 127-9

The Look of Silence (film) 188

Los rubios (film) 7, 20, 158-70;

Playmobil figures in 169-70; and relationship between reality and image 166-70; turning objects of memory into things 163-4

Lowenthal, David 66

Lynch, Kevin 55, 56

macellum in Puteoli 47

Macón, Cecilia 158-9

Málaga 144, 145-7

Manovich, Lev 108, 109, 112, 120

manque 39-40

marginalized people suffering violence 136

Margulies, Ivone 166

MARKER (performances) 137

Marks, Laura 195-6

Marschner, Felix 80

Marshall, Yvonne 144

Mary: her suffering symbolic of all women 152-3; statue of her in Holy Week processions 143-55

mass media and acquiring memories, 57

material agency 90-1, 98-99, 102

materiality 185 ; of the body 99 ; and embodied nature of memory 10 , 185; entangled memory 1-3, 17-19, 92, 99; of fiber 98; as meeting of matter and imagination 54; and memory 100, 160; of miniatures 195-200; and performance 4-12, 52, 66, 93-95; photographic 195-200; as relations between people and things 3, 160; and remembering 66-69

material turn 3

material witnesses 14-15 
Mauss, Marcel 144-5

'Medea' fashion collection 93

Mein Kampf (Levinthal) 191, 192-3, 197

me.mento printer $79,80-81$

memory: ability to manipulate through images 52; archived by clothes 92-95; attaching to objects 73-76; becoming part of the object 77-79, 162-3; being manipulated by souvenirs 45-58; brought into the present (reenactment) 175; and clothes 5, 92-95; collective 54, 164; conscious 37; cultural 96, 98, 100; effects 164-5; embodied 10, 99, 132-5; entangled with materiality 1-2, 17-19, 99; of histories of pain 135-8; imagined 57; individual 14 ; invoked by religious art objects 143-55; as iterative materializations 72 ; and materiality 100, 160; mediated by technology 96-98; mediated through performance 126-7; modeling of others', 191206; model kits as performances of 194-5; and modernity 40-41; of objects 100, 159-65; paratextual 200-5; participatory approach to 65 ; performances of 4-12, 52, 66, 94-95; prosthetic 57; reshaped by technology through fashion 89-102; sociality 14 ; soft technologies of 14, 96-98, 101; tracing 77-79; unconscious 37; and use of nonhumans to help humans remember 71-72

The Memory Cabinet of Mrs. K.

(Stewart) 2, xv

Mérida Vase 48-49

Merleau-Ponty, Maurice 94, 197 metalepsis 166, 168

metamorphosis by fashion 94 military blog 6, 21, 192, 200-1, 206

Miller, Daniel 9-10, 11, 12, 72, 98, $144,175,176,182$

miniature dioramas 21, 193, 194

miniature toys and their reality 191-206

Min Kamp (Knausgård) 6, 18, 107, 109-15

model kits as performances of memory 193-5

modernity and memory 40-41

monumentality 18-19 monumental novel 18-19, 106-21;

2666 (Bolaño) as example 115-20;

Min Kamp (Knausgård) as example 106-7, 114

monuments in Puteoli 47

Mothers and Grandmothers of Plaza de Mayo 158, 162, 163, 165

Mousavi, Mirsaeid 77

Moving People (art project), 69-70

Mower, Sarah 91

Mrosko, Chris 193, 194

Muñoz, José Esteban 138

Munteán, László 6, 21

Myerhoff, Barbara 153-4

My Struggle (Min Kamp) (Knausgård) $6,18,107,109-15$

narrative: anaphoric singulative mode $113,115,120$; as a cause-andeffect trajectory 109; and counting 117-18; versus database 108-9, 120 ; invention of 52 ; self-reflexive 166-8; syntagmatic 112 ; used by Knausgård 110-11

National Museum of Scotland 75

Nauman, Bruce 131

nazarenos 146

new materialism 3, 98

Nichols, Bill 166, 168-9

Nokia skirt 91

non-humans and remembering between humans 69-73

Nora, Pierre 1, 10, 106

Note to Self (Coble) 136

Nouzeilles, G. 162, 165

novel as a monument 106-21

Nunca más report 161-2

objects. See also things: agency of 3-4, 12-15; attaching memories to $73-79,100,159-65,185-6$; autonomous ability to remember 79-82; becoming things 7,70 , 159-60, 199-200; biography of religious art objects 144-5, 148; building social identity $145,148-50$; changed relationship with subjects 160, 163; creating new spaces of remembrance 66 ; dualism with subjects 11 ; embodying memories 162-3; mnemonic potential of 2; residual 38; that matter 9-10, 175-6; thingness of $7-8,38,160,199$ 


\section{Index}

objet petit a 39-40

O'Carolan, Turlough 78

occasions of contingency 160, 199

O’Connor, Kaori 98

Olalquiaga, Celeste 4, 16, 46, 52-3

Olsen, Bjørnar 5, 52

'One Hundred and Eleven' collection 18, 89-102

Oppenheimer, Joshua 175, 179, 182,188

optical unconscious 199

optical visuality 195-6

Pancasila Youth 179, 181

Pane, Gina 131

paratextual memories 200-6

Pargament, K. 145

participatory approach to memory 65

participatory culture 68

participatory practices of remembering 17

past into the present $4,5,17,21,31$, $38,52,65$, 91, 93-97, 106, 119-20, 126-8, 132, 135-9, 163-70, 182,194

Pemuda Pancasila (PP) 179

Pengkhianatan G30S/PKI (film) 179

people entangled with things 3, 8-9, 17-19, 99

Pérez, Mariana Eva 168

performance: as act of memory 165 ; archiving its ephemerality 135-8; delegated 128; DNA of 163; documenting 131-5; as embodied 175-7; materialist ontology of 128-9, 135-8; of memory 4-5, 52, $66,94-95,125-40$; model kits as performances of memory $194-5$; as mode of disappearance 128-9; and re-performance 5, 19; re-presenting memories in "Los rubios," 163-4

personal memory tracer $77-8$

Phelan, Peggy 128, 129, 132

Photobox printer 79, 81-82

photographs: collages creating new modes of perception 163-5; materialities by David Levinthal 195-200

Pickering, Andrew 98

Pilkington Vase 48-49

places: and meaning ascribed to them 176; that matter in cinema 180-1, 185
Plate, Liedeke 8, 17, 53-4, 56, 94, $96,108,154,175$

Plato 71

political identity and Holy Week processions 150

Popkin, Maggie 6-7, 16-17

Porter, James 53

postmemories 164, 192

Potter, Sally 198

Power of Art House 69

Pozzuoli 45

Prague Vase 48-49, 50

Pritchett, Patrick 184

prosthetic memories 57, 192, 198

Proust, Marcel 1-2, 111

psychic 'leftover,' 16

psychoanalysis 37-38

Puteoli 17, 45, 46; history and monumental appearance 47-48; relationship with Rome 48, 55; as tourist attraction 50

Puteolian vases 6-7, 17, 45-58; creating memory and metropolitan identity $51-58$

quasi-objects 11

quasi-subjects 11

queer histories being captured 135-8

reality effect 194,197

reality of affect 185

reality of toys 200

realness aura 33

reenactment 19-20, 128-9, 166; activating memory $125-40$; in The Act of Killing (film) 181-3, 185; affecting the body $175-7$; 'incorporating practice,' 135 ; of singular performance works 131-5; as social memory 135 ; of violence 20-21

Rehding, Alexander 107

reification 183-7

religious art objects 7; social and cultural memories of 143-55

religious identity and Holy Week processions 149-50

religious processions 143-55

remembering: autonomous ability for objects to remember 79-82; family during Holy Week processions 153-4; between humans and nonhumans 69-73; and materiality 


\section{6-69; participatory practices}

of, 17

renewed materialism 98

residual objects 38

residual sensibilities 16 ; of cultural circuits 38

Rhythm 0 (Abramovic) 139

Riegl, Aloïs 195

Rigney, Ann 106

ritual objects as bodily social memory 151-3

'Roads' (show) 34

robotic dresses 89-90

'ROE Rules of Engagement' (Levinthal) 201-202

Roman Empire and souvenirs for memory manipulation 45-58

Rome and its relationship with Puteoli 47-8, 55

routes of reference 163-4

Rudofsky, Bernard 34

Rufford Abbey 67

ruins: cultural $37-38$; as a memory 4; modern 16, 30-41

Ryan, Susan Elizabeth 93

sacred economy 145

Saltzman, Lisa 5

Samuel, Raphael 1

The Sandbox 21, 192, 201, 205

Santa Teresa murders 115-19

Santone, Jessica 132

Schlunke, Katrina 10-11, 164

Schneider, Rebecca 129-31

Seedbed (Acconci) 131

self-presentation by souvenirs 45-46

self-reflexive narrative 166-8

Semana Santa (Spain) 143, 145-7

sensation of material 2

Serapis 49

Serre, Michel 11

Seven Easy Pieces (Abramovic) 131-5

shape memory material 91, 99-100

Shirky, Clay 68

Sicart, Miguel 191

Silence of the Lands (online platform), 68

Silva, Alcino 72

Simmel, Georg 93

Smelik, Anneke 5, 14, 18, 53, 56, 94, $96,108,154,175$

Smith, Laurajane 67

Smith, R. C. 68 social identity constructed by religious objects $145,148-50$

sociality of memories $13-4$

social lives of things $6-7,15,57,76-79$

social media $17,65,83$; aiding interpretations of heritage 67-69; and iterative materializations of memory $72-73$

social memory expressed by religious ritual objects $151-3$

socioeconomic identity and Holy

Week processions 147-9

soft computation 97

soft technologies of memory 14 , 96-98, 101

Sontag, Susan 163-4

sorrows expressed during Holy Week processions 151-3

souvenirs 16-17, 45-58;

historicizing 45 ; materiality of 46 ; and narrative constructed around them 52-54

space as a locus 38

Speed, Chris 71

spiritual economy 145

Stallybrass, Peter 5, 92, 100, 101

Stanford, David 202

Sterne, Laurence 110

Stewart, Susan 2, 46, 52, 194, 195, xv

1001 Stories of Denmark (online platform) 68

Sturken, Marita 13

subject: changed relationship with object 160,163; dualism with object 11 ; as object of memory 165-70

Suharto, General 178

Symbolic order 39-40

syntagmatic narrative 112

Tahari, Elie 91

Tales of a Changing Nation (exhibition) 75-76

Tales of Things (online platform) 74-75, 77

Tate Britain 67

Taylor, Diana 130, 163

techno-fashion 5, 14, 18, 89-102

technologies of memory 13-14, 65, 95, 154, 169

technology: mediating memory 96-98; reshaping processes of memory through fashion 89-102 


\section{Index}

thingness of objects $8,38,160,199$

things. See also objects: aura of 31-33; cultural value of 30 ; as distinctive from an object 7-8; entangled with people 8-9, 17-19, 99; illumination of 31 ; shape human memory 13 ; social lives of $6-7,57,76-79$; surplus of 8 things that matter $10,175-6,185$ 'thing theory,' 7, 54, 158-60, 163 Thomas, Julian 66 Thomas Lips (Abramovic) 131 thrones in religious processions 146-7 time: as a continuum 38 ; folding of 5 , 19,126

tourist photography 50

Toussaint, Lianne 5, 14, 18

toys and their reality $192-5,200$

traumatic reenactment 20-21

Trentmann, Frank 8

Trigg, Dylan 180, 183

Trudeau, Garry 202

Turner, Edith 154

Turner, Victor 154

unconscious memory 37

Union Carbide Bhopal gas leak 69

Universidad Central de Venezuela, 37

University of Edinburgh 74

'Untitled 1' (Coble) 136

'Untitled 3' (Coble) 137

urban imaginary 16, 29

usable past 149
Valdes, Marcela 119

vases, Puteolian 6-7, 17, 45-58;

highlighting landmarks 55-56;

sensorial qualities of 53-54;

shaping memories of Puteoli 54-56

Venezuela 33-34

Ven, Inge van de 6,18

violence and reenactments of 20-21

Virgin of Experanza statue 147

Virgin of Servitas statue 147

virtual reality 33

Waldner, Jean-Baptiste 75

war memories experienced through blogs 6, 21, 192, 201, 205

wearables in fashion 14, 70, 89, 91, 97-98

wearable technology 89

Weizman, Eyal 14-15

Wells, Rachael 195

West, Susie 67

Williams, Raymond 16, 38, 40

Wilson, Elizabeth 92, 99

wish image 31,36

women suffering with Mary as mothers 152-3

Wood, Elizabeth 169

Woodward, Ian 3

Yes (film) 198

Young, James 197, 205 